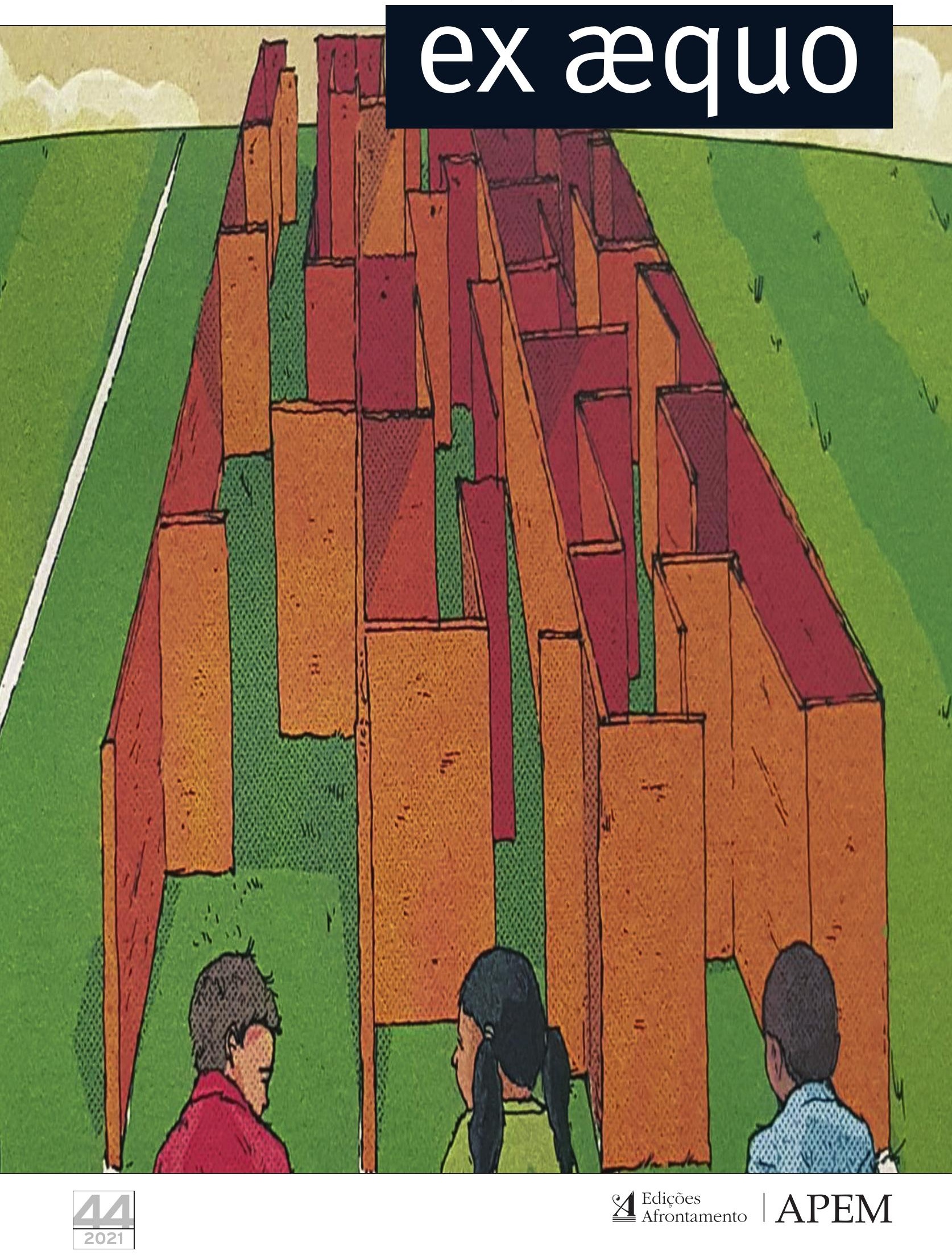




\section{ex æquo}

Revista semestral $\bullet \mathrm{N}^{\circ} 44,2021 \bullet$ preço: $15 €$

Revista da Associação Portuguesa de Estudos sobre as Mulheres - APEM 
ex æquo - Revista da Associação Portuguesa de Estudos sobre as Mulheres

Revista semestral • N. ${ }^{\circ} 44,2021$

\section{Diretora}

Virgínia Ferreira - Faculdade de Economia da Universidade de Coimbra

\section{Diretoras/es Associadas/os}

Cristina C. Vieira - Faculdade de Psicologia e Ciências da Educação, Universidade de Coimbra Maria João Silveirinha - Faculdade de Letras, Universidade de Coimbra

Lina Coelho - Faculdade de Economia, Universidade de Coimbra

Sara Isabel Magalhães - Centro de Psicologia, Universidade do Porto

Manuel Abrantes - SOCIUS/CSG - Investigação em Ciências Sociais e Gestão, ISEG, Universidade de Lisboa

Carla Cerqueira - Universidade Lusófona do Porto

\section{Diretoras de Secções}

Cristina C. Vieira - Recensões; Maria João Silveirinha - Estudos e Ensaios

\section{Diretoras Anteriores}

Virgínia Ferreira (1999-2003); Helena Costa Araújo (2003-2007); Teresa Pinto (2007-2014)

Revisão: Teresa Mourinho Tavares

Coordenação do Dossier: Carla Cerqueira - Universidade Lusófona do Porto; Maria Helena Santos - Instituto Universitário de Lisboa e Renísia Garcia Filice - Universidade de Brasília, Brasil

Propriedade do Título: Associação Portuguesa de Estudos sobre as Mulheres - APEM NIPC: 502914513

N. ${ }^{\circ}$ Registo no ex-ICS, atual ERC - Entidade Reguladora para a Comunicação Social: 123506

ISSN: 0874-5560; ISSN eletrónico: 2184-0385

\section{Depósito Legal: 136336/99}

Sede da Redação: Centro Maria Alzira Lemos - Casa das Associações, Parque Infantil do Alvito, Estrada do Alvito, 1300-054 Lisboa

Telefone: 962730527 E-mail: apem1991@gmail.com URL: http://exaequo.apem-estudos.org/ Edição/Impressão: Edições Afrontamento; Impressão e acabamento: Rainho \& Neves, Lda./Santa Maria da Feira/Portugal

Sede da Editora/Impressão/Encomendas: Edições Afrontamento, Rua de Costa Cabral, 859, 4200-225 Porto / geral@edicoesafrontamento.pt

N. ${ }^{\circ}$ de edição: 2056

Capa: Departamento Gráfico/Edições Afrontamento

Tiragem: 500 exemplares

Publicação apoiada por:

FCT Fundação para a Ciência e a Tecnologia MINISTÉRIO DA EDUCAÇÃO E CIÂNCIA

A ex æquo é uma revista com dupla arbitragem científica, sob anonimato.

DOI: https: / / doi.org/10.22355/ exaequo.2021.44.00

Indexação: SCOPUS - https://www.scopus.com/sources;

SciELO Citation Index da Thomson Reuters: SciELO Citation Index - http://wokinfo.com/ products_tools/multidisciplinary/scielo/;

SciELO/Portugal - Scientific Eletronic Library Online: http://www.scielo.mec.pt/scielo. php?script=sci_serial\&pid=0874-5560\&lng=pt;

DOAJ (Directory of Open Access Journals) - https://doaj.org/toc/2184-0385

SHERPA/RoMEO: http://www.sherpa.ac.uk/romeo/issn/0874-5560/pt/

Catálogo Latindex - Sistema Regional de Información en Línea para Revistas Científicas de América Latina, el Caribe, España y Portugal: http://www.latindex.unam.mx/latindex/ficha? folio=14734;

ERIH PLUS (European Reference Index for the Humanities): https://dbh.nsd.uib.no/publiseringskanaler/erihplus/periodical/info?id=482587;

Qualis CAPES (Brasil): https://qualis.capes.gov.br/

Nota: Ver Estatuto Editorial e composição do Conselho Científico no final da revista. 


\section{ÍNDICE}

Editorial

Virgínia Ferreira

Dossier: Desigualdades sociais e medidas de ação afirmativa.

Coordenação de Carla Cerqueira, Maria Helena Santos e Renísia Garcia Filice

Desigualdades sociais e medidas de ação afirmativa: entre avanços, resistências, incompreensões e novos desafios

Carla Cerqueira, Maria Helena Santos e Renísia Garcia Filice

A sub-representação política das mulheres no governo local é irrelevante? Revisão do que sabemos e do que falta saber em Portugal.

Ana Ribeiro

Quando o pouco não chega a muitas: análise inicial da distribuição dos recursos públicos de campanha para a Câmara dos Deputados em 2018 no Brasil

Maria Cecilia Eduardo e Juliana Inez Luiz de Souza

A favor, contra, ou assim-assim? Posições e discursos de membros dos órgãos de gestão sobre limiares de representação legalmente vinculativos, mérito e igualdade.

Sara Falcão Casaca, Maria João Guedes, Susana Ramalho Marques e Nuno Paço

Ações afirmativas no ensino superior brasileiro

Elisabete Corcetti e Susane Petinelli-Souza

Ladies in red: uma análise das medidas legais de combate à violência política de gênero no Brasil e em Portugal

Camila Lamartine, Camila Franco Henriques

The Parity Law in Practice: Implementation and direct outcomes

Ana Lúcia Teixeira, Ana Espírito-Santo e Maria Helena Santos

Para uma crítica pós-colonial/ descolonial das relações sociais em contexto académico: vozes de estudantes brasileiras

Rovênia Amorim Borges e Almerindo Janela Afonso

Zonas de liberdade LGBTI+? Práticas e gramáticas para uma intervenção profissional inclusiva com crianças e jovens LGBTI+ 


\section{Estudos e Ensaios}

What Can We Say About Gender Studies in Colombia? An analysis from a socio-bibliometric perspective

Jean Nikola Cudina, Julio César Ossa, Elsa María Castrillón-Correa, Andrea Precht, Josiane Suelí Bería e Fernando Andrés Polanco

Chronicles of Civil Society in Assam and Meghalaya: Converting girls and women from «bad to good»....

Barnali Das e Rekha Pande

Artivismo feminista y Flashmob: lenguaje corporal en el mundo oriental

Teresa Colomina-Molina

\section{Recensões}

Poesia e prosa, de Judith Teixeira, organização e estudos introdutórios de Cláudia Pazos Alonso e Fabio Mario da Silva. Alfragide: Dom Quixote, 2015, 370 pp.

Manuel Abrantes

Gênero, neoconservadorismo e democracia: disputas e retrocessos na América Latina, de Flávia Biroli, Maria das Dores Campos Machado e Juan Marco Vaggione. São Paulo: Boitempo Editorial, 2020, 224 pp. Monise Martinez

Feminist Media Studies, de Alison Harvey. Cambridge: Polity Press, 2020, 211 pp....... 230 Bibiana Garcez

Estatuto Editorial 235

Declaração de ética e de boas práticas da ex æquo........................................................ 236

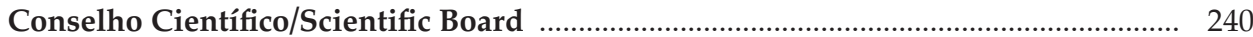

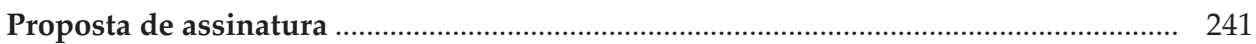

A ex æquo consta da lista de revistas diamante em acesso aberto (Open Access Diamond Journals), por ser de acesso livre para quem lê e para quem nela publica/ex æquo is an «Open Access Diamond journal» - free for readers and authors.

Os conteúdos dos textos publicados são da responsabilidade de quem os assina, não refletindo, necessariamente, a posição da APEM ou da Direção da ex æquo. 


\section{EDITORIAL}

\section{Virgínia Ferreira}

(1) https: / / orcid.org/ 0000-0003-3838-054X

Neste quadragésimo quarto número da ex æquo dedicamos o dossier temático às "Desigualdades sociais e medidas de ação afirmativa". A sua organização esteve a cargo de Carla Cerqueira (Universidade Lusófona - CICANT, Portugal), Maria Helena Santos, (Instituto Universitário de Lisboa - ISCTE-IUL e CIES, Portugal) e Renísia C. Garcia Filice - (Universidade de Brasília - UnB, Brasil).

As políticas de 'ação afirmativa' nasceram nos anos de 1960, nos EUA, para apoiar a luta por uma sociedade mais justa, sem opressão e discriminação raciais. Desde então, a sua filosofia e praxis têm-se estendido a outros eixos de desigualdade e discriminação, nomeadamente, o das relações sociais de género. Definidas como instrumentos de promoção da justiça racial, sexual, social em termos gerais, continuam envoltas em forte polémica em torno das profundas divergências sobre as vias a percorrer para alcançar a justiça almejada, sejam as suas justificações 'compensatórias', de uma herança profundamente discriminatória, 'redistributivas' de oportunidades ou 'úteis' na contenção da conflitualidade social. Abrangendo uma ampla gama de políticas, a ação afirmativa visa aumentar a inclusão de grupos sociais cuja sub-representação em profissões ou posições sociais de mais alto estatuto é entendida como sendo um resultado da discriminação, passada ou presente, de que são alvo. No caso das desigualdades entre mulheres e homens, traduzem-se em estratégias corretivas ou compensatórias das situações de desigualdade e discriminação com que se confrontam mulheres e homens.

Estas políticas passam necessariamente pelo reconhecimento de que há pessoas com menos oportunidade de alcançar os seus objetivos devido a impedimentos de natureza histórica, social e política, independentes da sua vontade. Trata-se, portanto, de ultrapassar a lógica limitada da igualdade perante a lei, paradigma da ideologia liberal, e intervir no sistema organizado socialmente sobre uma estrutura social baseada na desigualdade de oportunidades e de tratamento de cada pessoa em função das suas características raciais, sexuais, étnicas, etc., que podem até, em alguns casos, ter expressão biológica, mas que são social e culturalmente construídas, através de atitudes, comportamentos e modos de ordenação social.

Entendidas enquanto políticas temporárias, destinadas a um grupo específico, centradas nas suas desvantagens, procuram através de "medidas especiais" promover a aquisição, por parte dos membros do grupo, dos requisitos necessários à sua integração nos lugares sociais donde estão arredados, total ou parcialmente. Ou, em alternativa, são centradas na determinação da integração compulsória. Uma vez que envolvem tratamento desigual de um determinado grupo, seja qual for o critério que o define, recolhem a rejeição generalizada de um senso comum robustecido no caldo do individualismo e do liberalismo. A esta luz, uma vez instaurada a igualdade de todas as pessoas perante a lei, haveria apenas que aplicar leis gerais, abstratas e iguais para toda a gente, sem distinção de raça, de género, de etnia, etc.

Há que reconhecer que se trata de políticas que desafiam profundamente as filosofias políticas dominantes, como tal é extensa a agenda de investigação que em seu torno se tem desenvolvido e que tem atravessado várias fases. Enquanto parte importante, desde há décadas, das políticas de igualdade de género europeias, no quadro das quais adota a designação de 'ações positivas', as análises concentram-se atualmente na sua apli- 
cação e efetividade, desvelando-nos um mundo de clara confrontação, de resistência passiva ou de aceitação relutante, da parte dos grupos sociais privilegiados, e de visões ambivalentes e sensibilidades mistas, da parte dos grupos alvo. Em causa está a perceção de como a estrutura cristalizada vai reagir às medidas 'especiais' com normas diferentes das formal e informalmente implantadas, e quem diz a estrutura diz as pessoas - as instaladas e as intrusas. Com que eficácia são aplicadas estas políticas de ação positiva / ação afirmativa? A sua eficácia é a mesma ou difere consoante o campo de aplicação? A sua longevidade reforça a sua aceitação ou a sua rejeição? A sua naturalização está condenada pelo seu caráter temporário? Diga-se que se trata de questões infindáveis e que irão permanecer nas nossas agendas de investigação à medida que a aplicação deste tipo de políticas se dissemina em cada vez mais países, por reivindicação dos grupos sub-representados, e a polémica em seu torno se agudiza em resultado do crescimento das forças políticas crentes no neoliberalismo e no suprassumo do estatuto do indivíduo. No campo das políticas de igualdade de género europeias, em particular, a resistência é um resultado do forte crescimento dos movimentos anti-género.

A ex æquo promete continuar atenta a esta problemática, desde já, no próximo dossier que reunirá artigos em torno dos Desafios feministas ao Direito: resistências e possibilidades.

Além do conjunto de textos compilados no dossier temático deste número, disponibilizamos a leitura de outros textos que respondem a outras inquietações científicas. $\mathrm{O}$ primeiro artigo da secção de Estudos e Ensaios prolonga o diálogo relativamente às abordagens bibliométricas, no caso vertente relativamente aos Estudos de Género na Colômbia. Jean Nikola Cudina e colegas, interrogam-se sobre o "What Can We Say About Gender Studies in Colombia? An analysis from a socio-bibliometric perspective", sugerindo linhas de caracterização através do estudo sociobibliométrico de 1328 artigos sobre género registada na base de dados Scopus. Uma das principais conclusões é a de que, à semelhança do que tem acontecido em outras geografias, o ensino superior público é um pilar fundamental do desenvolvimento registado nesta área de estudos. Barnali Das e de Rekha Pande, por seu turno, providenciam-nos as "Chronicles of Civil Society in Assam and Meghalaya: Converting girls and women from 'bad to good'", evidenciando a complexidade paradoxal dos processos de "resgate" de mulheres vítimas de tráfico sexual, numa região da Índia, que acabam encarceradas em lugares altamente vigiados e sujeitas a uma lógica patriarcal de contraste entre modelos de mulheres 'boas' e 'más'. Por fim, Teresa Colomina-Molina mostra como o "Artivismo feminista y Flashmob: lenguaje corporal en el mundo oriental" favorece o empoderamento das mulheres na Índia e no Sudeste Asiático, ao poderem recorrer às redes sociais, nomeadamente o Instagram, para coletivamente se expressarem através da dança e do movimento do corpo.

As sugestões de leitura no capítulo das Recensões são as seguintes: Manuel Abrantes sugere-nos a obra Poesia e prosa, de Judith Teixeira, porque se trata de um contributo importante para desocultar o trabalho artístico de mulheres durante a Primeira República e a experiência de quem ousou desafiar os códigos de género impostos à sua criatividade e sexualidade. Monise Martinez dá-nos a conhecer uma obra que, certamente, vai suscitar o interesse de quem na América Latina acompanha a revista. Trata-se da obra sobre Gênero, neoconservadorismo e democracia: disputas e retrocessos na América Latina, de Flávia Biroli, Maria das Dores Campos Machado e Juan Marco Vaggione, na qual encontramos análises multidisciplinares dos movimentos anti-género cada vez mais visíveis naquela e noutras geografias. Bibiana Garcez chama a atenção para a importância da perspetiva feminista nos estudos mediáticos, tal como são analisados por Alison Harvey em Feminist Media Studies, para "futuras, mais profundas e emancipadoras explorações do campo". 


\section{Dossier \\ Desigualdades sociais e medidas de ação afirmativa}





\title{
DESIGUALDADES SOCIAIS E MEDIDAS DE AÇÃO AFIRMATIVA: ENTRE AVANÇOS, RESISTÊNCIAS, INCOMPREENSÕES E NOVOS DESAFIOS
}

\author{
Carla Cerqueira * \\ (D) https: / / orcid.org/0000-0001-6767-3793 \\ Maria Helena Santos \\ (D) http: / / orcid.org/0000-0001-7708-4634 \\ Renísia Garcia Filice \\ (D) https: / / orcid.org/0000-0003-4595-9744
}

What is the hardest for some does not even exist for others.

Sara Ahmed $(2017,142)$

A igualdade, diversidade e inclusão social tornaram-se objetivos das sociedades ocidentais, promovidos e reivindicados por várias organizações e coletivos da sociedade civil, corroborados por estudos académicos e formalizados por diversas convenções e legislações. No entanto, as desigualdades persistem e as ideologias dominantes têm permanecido relativamente bem instaladas, contribuindo para a manutenção de sistemas estruturais de opressão, como o sexismo, o racismo, o classismo, a homofobia, o capacitismo, entre outros. Nestes termos, em diferentes contextos e regiões geográficas, os grupos denominados como minorias sociais têm-se organizado e desenvolvido ações políticas importantes que são contempladas nos debates sobre políticas públicas, quaisquer que sejam elas, desde que comprometidas com as suas exigências e trajetórias singulares. Estas reivindicações colocam a tónica na dimensão redistributiva (Fraser 2006) e de reconhecimento identitário (Phillips 2009), a fim de consolidar uma noção de justiça social (Fraser 2013).

* Universidade Lusófona - CICANT, Porto, Portugal.

Endereço postal: Universidade Lusófona, Rua Augusto Rosa nº 24, 4000-098 Porto, Portugal.

Endereço eletrónico: carla.cerqueira@ulp.pt

** Instituto Universitário de Lisboa (ISCTE-IUL), CIS-IUL, Lisboa, Portugal.

Endereço postal: CIS-IUL, Av. das Forças Armadas, 1649-026 Lisboa, Portugal.

Endereço eletrónico: helena.santos@iscte-iul.pt

*** Universidade de Brasília/UnB. Brasília/DF, Brasil.

Endereço postal: Universidade de Brasília, SQN 412, bloco k, apto 205, Asa norte, Brasília/DF, Brasil.

Endereço eletrónico: renisiagarcia@gmail.com 
Phillips (2009) faz uma indagação instigante de como podemos alcançar a igualdade reconhecendo a diferença, ao invés de nos focarmos em como podemos eliminar a desigualdade. A autora contribui para a reflexão sobre a perspetiva hegemónica e as formas mais comuns de problematizar a naturalização das desigualdades. Neste sentido, contribui para pensar na relação das políticas de igualdade/ /oportunidade e equidade, considerando a diversidade em vez de uma uniformidade. Para Phillips, não se pode esperar o alcance da igualdade se as diferenças forem ignoradas. Nesses termos, a abordagem interseccional apresenta-se relevante quando consideramos a intersecção das desigualdades de género, raça, etnicidade, classe e outros marcadores identitários como elementos que formatam as desigualdades que atingem grupos tidos historicamente como minoritários, como é o caso das mulheres, negros, negras, LGBTQIA+, indígenas, ciganos/as, quilombolas e muitos outros, impactados que são de formas diferenciadas pela má distribuição económica, a qual acaba por contribuir para sedimentar as desigualdades sociais.

Em diálogo com Phillips, evocamos Nancy Fraser (2013) quando a mesma problematiza a ideia de justiça e nos apresenta uma noção de justiça anormal numa visão reconstrutiva e multidimensional de justiça (Richa 2019). A autora evidencia que um padrão normativo homogéneo (e hegemónico) não é capaz de dialogar com dinâmicas identitárias diferenciadas, que exigem uma justiça (a)normal do ponto de vista do reconhecimento das diferenças, posicionalidades (Urpia 2020) variadas que se dão no âmbito da desigualdade económica, e para além dela. Assim, com base na contribuição de Fraser (2006; 2013), a justiça e a distribuição dos recursos aparecem como ponto de conflitualidade, mas também de diálogo. É preciso analisar as reivindicações de justiça social, tanto na perspectiva da redistribuição, como do reconhecimento. O contributo de ambas, Phillips e Fraser, soma-se a uma perspetiva interseccional de análise e lança luz sobre outras possibilidades de tensionar a noção de reparação histórica que estrutura e orienta o debate sobre políticas de ação afirmativa, seja no Brasil, em Portugal ou noutro país, propondo a articulação, sem o deslocamento radical da desigualdade para a diferença, mas também sem ofuscar o peso da diferença no debate da desigualdade de classe.

A segregação de género, raça, etnia e classe no mundo do trabalho, mas não só, é exemplo disso, persistindo desigualdades no mundo educativo, político, associativo e empresarial que colocam determinados sujeitos sociais em condições de invisibilidade, em particular as mulheres, que são postas em desvantagem em comparação com os homens, nomeadamente no que diz respeito aos lugares de poder e tomada de decisão (Filice 2011; Santos 2011; Santos e Amâncio 2014), situação que se agrava quando são somadas outras pertenças identitárias como a raça/ /cor, sexualidade, entre outras.

Partindo de um olhar sobre a segregação de género existente, de facto, após a tentativa de implementação da democracia e da igualdade formal, rapidamente se começou a perceber que persistiam barreiras informais, invisíveis (discriminações estruturais, fenómenos como os «tetos de vidro», o «labirinto» ou os «muros de 
vidro») ligadas ao género que continuavam a dificultar o acesso das mulheres a certos cargos e a progressão da sua carreira, impedindo que elas lá permanecessem muito tempo (fenómeno conhecido por «penhascos de vidro»). Esta realidade é bem patente em diversas esferas e complexifica-se à medida que outros marcadores sociais, como a raça, a etnia, a classe, a idade, a orientação sexual, a diversidade funcional, etc., são vistos de forma interseccional (Crenshaw 1989; Cerqueira \& Magalhães 2017; Collins 2018; Akotirene 2019).

Neste cenário, fruto de reivindicações dos movimentos sociais, feministas e antirracistas (Krook e O'Brien 2010) e das instituições internacionais, como a Organização das Nações Unidas, a União Europeia e o Conselho Europeu (Procacci e Rossilli 1997; EIGE 2015), entre outras, houve, nas últimas décadas, o reconhecimento das desigualdades nos resultados, que incide de diferentes formas sobre mulheres, mulheres negras e outras minorias, e tem levado países de diversas partes do mundo a desenvolver ações e a implementar diversos tipos de medidas de ação afirmativa, em contextos por vezes contrários à sua aplicação (e.g., ver Long e Bateman 2020). Para alguns autores e autoras, mais do que seguir a tradicional e lenta «via incremental», percebe-se que medidas como as quotas se tornaram uma estratégia da «via rápida» (Dahlerup e Freidenvall 2005) com o objetivo de aumentar a representação das mulheres na política. Este tem sido um ponto controverso, tendo, com o passar dos anos, outros grupos sociais sido também objeto de legislação de quotas, incluindo os baseados na língua, religião, etnia, nacionalidade, raça, casta, idade, expatriação, profissão, domicílio e diversidade funcional (Krook e O'Brien 2010).

Em países como o Brasil, por exemplo, as quotas são o resultado de ações políticas articuladas na tensão do movimento negro e do movimento negro feminista com o Estado, imbricadas em relações sociais conflituosas. Embora este tipo de medidas constitua um mecanismo crucial para redinamizar o progresso no sentido da igualdade substancial, a sua implementação é diversa. Em alguns países, esta não é uma condição necessária, como se verifica pelos casos da Finlândia e da Dinamarca, mas também não é uma condição suficiente, como ilustra o caso da França e do Brasil (IPU 2020). Além disso, há outras estratégias paralelas e alternativas às quotas, que podem ser desenvolvidas, por exemplo, pela sociedade civil, pelos partidos políticos, pelos parlamentos e/ou pelos órgãos do Estado (Krook e Norris 2014).

No geral, apesar da rápida difusão das medidas de ação afirmativa em várias regiões do mundo e tipos de sistemas políticos, assim como do sucesso registado, as quotas são uma das medidas mais críticas das últimas duas décadas (Krook e Zetterberg 2014), gerando, como foi dito, fortes controvérsias sociais (Bacchi 1996; Maggie e Fry 2002; Dahlerup 2008; Santos e Amâncio 2012a; 2012b). Não obstante as resistências, tal fenómeno tem suscitado interesse, tanto por parte da população em geral como da academia, conduzindo a um amplo e crescente desenvolvimento da investigação sobre as quotas e os seus impactos na educação, na saúde, no 
mercado de trabalho, na esfera associativa e política a nível nacional e internacional (e.g., ver Filice 2011; Paixão et al. 2013; Telles e Paixão 2013; Beloshitzkaya 2020; Espírito-Santo e Santos 2020; Warikoo e Allen 2020). Nestes termos, compreender as variadas e complexas formas de acolhimento, rejeição e resultados em relação às políticas afirmativas, reconhecendo contextos de extrema desigualdade de classe, género, raça, etnia e outros marcadores sociais, motivou-nos a propor este dossiê e a contribuir para a problematização neste campo de investigação.

Além disso, em Portugal, apesar de haver alguns estudos, nomeadamente na área da psicologia social (e.g., Santos e Amâncio 2012a; 2012b), da sociologia e da ciência política (e.g., Baum e Espírito-Santo 2012; Espírito-Santo 2015) ou dos média (e.g., Cabrera, Flores e Mata 2012), a investigação sobre esta temática não tem, de todo, acompanhado o desenvolvimento internacional e não apresenta, na maior parte das vezes, um olhar interseccional. Este nasceu da experiência de mulheres negras estadunidenses, latino-americanas, brasileiras, indianas (Gonzalez 1988; Crenshaw 1989; Collins e Bilgue 2018; Filice e Carnaúba 2019; Akotirene 2019; Gonzalez 2020a; 2020b), e tem sido apropriado como uma ferramenta para pensar as engrenagens diversificadas e contextualizadas de múltiplas desigualdades e formatos de ações afirmativas em curso em diferentes partes do mundo, para tentar minimizar os seus impactos nefastos. Atualmente, já encontramos uma vasta literatura a nível internacional que problematiza as assimetrias de género partindo desta base interseccional, que funciona como uma ferramenta teórica, metodológica e política.

O Brasil torna-se exemplar no continente sul-americano devido às suas especificidades, uma vez que regista várias ações afirmativas que resultam de um múltiplo e diverso movimento negro mais politicamente articulado a partir de 1978 . Essas ações afirmativas desencadearam instrumentos de políticas públicas de alcance nacional e internacional, tendo em vista os seus impactos na educação e no mercado de trabalho nacional e, especialmente, na possibilidade da procura, por parte de estudantes negros/as, de formação académica internacional (Borges 2015). O caso do Brasil contribui para conhecermos alguns tipos de experiências de ações afirmativas, que ganham em potência explicativa com abordagens transversais e interseccionais, incorporando-se aos estudos sobre políticas e ações afirmativas (Brugué, Paya e Canal 2015; Filice e Carnaúba 2019). Neste país, há estudos que mostram a atuação do movimento negro educador (Gomes 2017) e mudanças ocorridas a partir da atuação de mulheres negras, que, embora ainda de maneira tímida, têm contribuído para mudar a face racista académica e têm feito a diferença em cargos de gestão (Botelho e nascimento 2016; Cruz 2018), num contexto de extremo retrocesso, em termos de políticas de Estado e de governo, com a eleição do atual Presidente, Jair Messias Bolsonaro. Assim, pensar em metodologias interativas no campo das políticas públicas é considerar abordagens interseccionais de género, raça, classe e outras pertenças identitárias, e como variados segmentos têm conseguido pautar as suas singularidades no que se refere à imple- 
mentação de políticas afirmativas (Filice e Carnaúba 2019), em cenários muitas vezes marcados por resistências ou discursos paradoxais.

A abordagem interseccional está cada vez mais presente no debate teórico recente e visa ampliar a compreensão sobre os modos como múltiplas categorias de pertença identitária se articulam e contribuem para colocar as pessoas numa situação de maior privilégio ou opressão. No entanto, faltam mais estudos que incluam esta abordagem de modo a compreendermos melhor a complexidade inerente às várias desigualdades sociais e de que forma é que as políticas públicas podem colmatá-las. As políticas de ação afirmativa têm trazido mudanças institucionais e sociais importantes no sentido de esbater as desigualdades historicamente existentes, garantindo o acesso a oportunidades que antes eram vedadas a determinados grupos e sujeitos sociais. Contudo, continuam a ser, muitas vezes, incompreendidas e a gerar polémica no espaço público.

Este dossiê temático, composto por 8 artigos, inicia-se com um artigo de Ana Ribeiro intitulado «A sub-representação política das mulheres no governo local é irrelevante? Revisão do que sabemos e do que falta saber em Portugal.» A autora apresenta uma análise que incorpora a revisão da literatura e entrevistas com especialistas da área para problematizar o caso concreto do governo local e como este apresenta especificidades, nomeadamente a existência de uma eficácia diferenciada da Lei da Paridade e de poucos estudos voltados para a realidade do poder local.

No texto «Quando o pouco não chega a muitas: análise da distribuição dos recursos públicos de campanha para a Câmara dos Deputados em 2018», as autoras Maria Cecília Eduardo e Juliana Inez Luiz de Souza analisam o caso concreto das mulheres que participam na esfera política partidária no Brasil, voltando a análise para o índice de Gini, que mostra que os partidos concentram os recursos em poucas mulheres, deixando de estimular uma maior participação feminina e visando apenas a maximização de lugares.

De seguida, Sara Falcão Casaca, Maria João Guedes, Susana Ramalho Marques e Nuno Paço analisam as posições e os discursos de membros dos órgãos de gestão das empresas legalmente vinculadas a limiares mínimos de representação equilibrada entre mulheres e homens. No artigo «A favor, contra, ou assim-assim? Posições e discursos de membros dos órgãos de gestão sobre limiares de representação legalmente vinculativos, mérito e igualdade», concluem que a lei não é consensual e que ainda são várias as resistências ou o não reconhecimento das situações de discriminação na área.

$\mathrm{O}$ artigo "Ações afirmativas no ensino superior brasileiro», da autoria de Elisabete Corcetti e Susane Petinelli-Souza, apresenta uma reflexão sobre as ações afirmativas no ensino superior brasileiro, levando em consideração a perspectiva de raça/etnia e género. Parte de um estudo qualitativo, baseado em pesquisa documental, o qual mostra que a implantação da Lei das Cotas no ensino superior brasileiro valoriza menos a dimensão de género do que outros aspetos considerados nos estudos interseccionais. 
Por sua vez, em «Ladies in red: Uma análise das medidas legais de combate à violência política de género no Brasil e em Portugal», Camila Lamartine e Camila Franco Henriques discutem de que forma é que Portugal e o Brasil têm criado mecanismos para enfrentar a violência política de género. As autoras baseiam-se numa análise de comentários de leitores no Facebook dos jornais Público e Folha de S. Paulo, dirigidos a Dilma Rousseff e a Marisa Matias, para concluir que o Brasil está mais avançado nesta discussão.

No artigo «The Parity Law in Practice: Implementation and direct outcomes», Ana Lúcia Teixeira, Ana Espírito-Santo e Maria Helena Santos apresentam um mapeamento da implementação da Lei da Paridade em Portugal, dos seus instrumentos e medidas, e avaliam os seus efeitos na esfera política, contribuindo para a discussão sobre o sucesso da implementação da lei das quotas no contexto português.

O texto «Para uma crítica pós/descolonial das relações sociais no contexto académico: vozes de estudantes brasileiras» centra-se num estudo empírico referente ao contexto português que revela que as relações sociais e académicas não são atravessadas unicamente por estereótipos de género. Rovênia Amorim Borges e Almerindo Janela Afonso concluem, a partir de uma metodologia interseccional e de conceitos pós-coloniais/descoloniais, que as condições de subalternidade se jogam na interação complexa das identidades étnico-raciais, de género e de nacionalidade.

O dossiê encerra com uma contribuição de Mafalda Esteves, Ana Cristina Santos e Alexandra Santos voltada, por um lado, para as boas práticas enquanto medidas de ação afirmativa no mainstreaming LGBT+e, por outro, para as resistências e vazios que existem neste domínio e que afetam crianças e jovens LGBT+. O artigo «Zonas de Liberdade LGBTI+? Práticas e gramáticas para uma intervenção profissional inclusiva com crianças e jovens LGBTI+» resulta de um projeto europeu que recorreu a metodologias quantitativas e qualitativas envolvendo crianças, jovens e profissionais das áreas da educação, saúde e intervenção familiar.

\section{Referências}

Ahmed, Sara. 2017. Living a Feminist Life. Durham \& London: Duke University Press.

Akotirene, Carla. 2019. O que é interseccionalidade? São Paulo: Sueli Carneiro; Pólen.

Beloshitzkaya, Vera. 2020. «Affirmative gender equality policies in Central and Eastern Europe: Moving beyond the EU requirements.» Party Politics 27(5): 953-964. DOI: https: / / doi.org/10.1177/1354068820906785

Bacchi, Carol Lee. 1996. The Politics of Affirmative Action: Women, Equality and Category Politics. London: SAGE.

Baum, Michael, e Ana Espírito-Santo. 2012. «Portugal's Quota-Parity Law: An Analysis of its Adoption.» West European Politics 35(2): 319-42. DOI: http: / / dx.doi.org/10.1080/0 1402382.2011.648009 
Borges, Rovênia Amorim. 2015. «Interseccionalidade de gênero, raça e classe no Programa Ciência sem Fronteiras: Um estudo sobre estudantes brasileiros com destino ao EUA.» Dissertação de Mestrado Profissional em Educação, Universidade de Brasília, Brasília.

Botelho, Denise, e wanderson flor do nascimento. 2016. «Celebração móvel: Políticas públicas, transversalidade e interseccionalidade de gênero e raça.» In A transversalidade de Gênero e Raça nas Políticas Públicas, organizado por Deborah Silva Santos, Renísia Cristina Garcia Filice, e Ruth Meyre Mota Rodrigues, 26-41. São Paulo: Comunicação Integrada.

Brugué, Quim, Ramón Canal, e Palmira Paya. 2015. «¿Inteligencia administrativa para abordar "problemas malditos"? El caso de las comisiones interdepartamentales.» Gestión y política pública, 24(1): 85-130. Disponível em http://www.scielo.org.mx/ scielo.php?script=sci_arttext\&pid=S1405-10792015000100003.

Cabrera, Ana, Flores, Teresa Mendes, e Maria José Mata. 2012. "O feminino como "intruso" na política: Uma análise do contexto histórico e da representação fotojornalística das deputadas portuguesas no Parlamento Paritário e nas discussões da Lei da Paridade.» Revista Media e Jornalismo: politica no feminino 11(21): 77-127.

Cerqueira, Carla, e Sara I. Magalhães. 2017. «Ensaio sobre cegueiras: cruzamentos intersecionais e (in)visibilidades nos media.» ex aequo 35: 9-20. DOI: https:/ / doi.org/ 10.223 55/ exaequo.2017.35.01

Collins, Patricia Hill, e Sirma Bilge. 2018. Intersectionality. Cambridge, UK: Polity Press.

Crenshaw, Kimberlé. 1989. «Demarginalizing the Intersection of Race and Sex: A Black Feminist Critique of Antidiscrimination Doctrine, Feminist Theory, and Antiracist Politics.» University of Chicago Legal Forum 1: 139-167.

Cruz, Fernanda Natacha Bravo, e Doriana Daroit. 2017. «Dos nexos efêmeros ao fazer Estado: ensaio sobre transversalidade em conferências nacionais de políticas públicas.» NAU Social 8(15): 103-124. DOI: https: / / doi.org/10.9771/ns.v8i15.31403

Dahlerup, Drude, e Lenita Freidenvall. 2005. "Quotas as a "fast track" to equal representation for women.» International Feminist Journal of Politics 7(1): 26-48. DOI: https: / / doi.org/ $10.1080 / 1461674042000324673$

Dahlerup, Drude. 2008. «Gender Quotas: Controversial but Trendy.» International Feminist Journal of Politics 10(3): 322-328. DOI: https: / / doi.org/10.1080/14616740802185643

EIGE. 2015. Gender equality in power and decision making. Review of the implementation of the Beijing Platform for Action in the EU Member States. Luxembourg: Publications Office of the European Union. Disponível em http://data.consilium.europa.eu/doc/document/ST-13532-2015-ADD-1/en/pdf

Espírito-Santo, Ana. 2015. «Citizens' attitudes towards descriptive representation: The case of women in Portugal.» European Journal of Women's Studies 23(1): 43-59. DOI: https: / / doi.org/10.1177/1350506814568036

Espírito-Santo, Ana, e Maria Helena Santos. 2020. «The share of women in decision-making positions across different levels of government.» Representation 57(4): 419-437. DOI: https: / / doi.org/10.1080/00344893.2020.1847180

Fraser, Nancy. 2006. «Da redistribuição ao reconhecimento? Dilemas da justiça na era "pós-socialista".» Cadernos De Campo 15(14-15): 231-239. DOI: https:/ / doi.org/10.11606/ issn.2316-9133.v15i14-15p231-239

Fraser, Nancy. 2013. «Justiça anormal.» Revista da Faculdade de Direito da USP 108: 739-768. Disponível em https: / / www.revistas.usp.br/rfdusp/article/view / 68001

Filice, Renísia Cristina Garcia. 2011. Raça e classe na gestão da educação básica brasileira: a cultura na implementação de políticas públicas. Campinas: Autores Associados. 
Filice, Renísia Cristina Garcia, e Rayssa Carnaúba. 2019. «Metodologia interativa na gestão de políticas públicas: métodos combinados numa abordagem antissexista e antirracista.» In Tecendo redes antirracistas: Africas, Brasis e Portugal, organizado por Anderson Ribeiro Oliva et al., 109-132. Belo Horizonte: Editora Autêntica.

Gomes, Nilma Lino. 2017. O movimento negro educador. Saberes construídos na luta por emancipação. Petrópolis, RJ: Vozes.

Gonzalez, Lélia. 1988. «A categoria político-cultural de amefricanidade.» Tempo Brasileiro 92/93: 69-82.

Gonzalez, Lélia. 2020a. «A mulher negra na sociedade brasileira: uma abordagem político econômica.» In Por um Feminismo Afro-latino-americano: ensaios, intervenções e diálogo, organizado por Marcia Lima e Flávia Rios, 49-64. Rio de Janeiro: Zahar.

Gonzalez, Lélia. 2020b. «Por um feminismo afro-latino-americano.» In Por um Feminismo Afro-latino-americano: ensaios, intervenções e diálogo, organizado por Marcia Lima e Flávia Rios, 139-150. Rio de Janeiro: Zahar.

IPU. 2020. Monthly ranking of women in national parliaments. Disponível em https:// data.ipu.org/women-ranking

Krook, Mona Lena, e Diana O’Brien. 2010. «The Politics of Group Representation: Quotas for Women and Minorities Worldwide.» Comparative Politics 42(3): 253-272.

Krook, Mona Lena, e Pär Zetterberg. 2014. «Electoral quotas and political representation: Comparative perspectives.» International Political Science Review 35(1): 3-11. DOI: https: / / doi.org/10.1177/0192512113508422

Krook, Mona Lena, e Pippa Norris. 2014. «Beyond Quotas: Strategies to Promote Gender Equality in Elected Office.» Political Studies 62(1): 2-20. DOI: https: / / doi.org / 10.1111 / 1467-9248.12116

Long, Mark C., e Nicole A. Bateman. 2020. «Long-run changes in underrepresentation after affirmative action bans in public universities.» Educational Evaluation and Policy Analysis 42(2): 188-207. DOI: https: / / doi.org/10.3102/ 0162373720904433

Maggie, Yvonne, e Fry, Peter. 2002. «O debate que não houve: a reserva de vagas para negros nas universidades brasileiras.» Revista Enfoques 1(1): 93-117.

Paixão, Marcelo, Irene Rossetto, Elisa Alonso Monçores, e Danielle Oliveira. 2013. «Legados da cor: mobilidade social segundo a condição de escolaridade de mães e filhos.»IBGE - Estudos \& Análises 2: 143-160.

Phillips, Anne. 2009. «Da desigualdade à diferença: um caso grave de deslocamento?» Revista Brasileira de Ciência Política 2: 223-240. Disponível em https: / / www.proquest.com/open view / 133200c75a6b709e9a373db52ad26597/1?pq-origsite=gscholar\&cbl=1626348

Procacci, Giovanna, e Maria Grazia Rossilli. 1997. «La construction de l'égalité dans l'action des organisations internationales.» In Encyclopédie politique et historique des femmes, organisée par Christine Fauré, 827-859. Paris: PUF.

Richa, Morgana de Almeida. 2018. «Políticas públicas judiciárias: uma abordagem multidimensional no estudo do acesso à justiça.» Tese de doutoramento em Direito, Pontifícia Universidade Católica de São Paulo, São Paulo.

Santos, Maria Helena. 2011. Do défice de cidadania à paridade política: Testemunhos de deputadas e deputados. Porto: Edições Afrontamento.

Santos, Maria Helena, e Lígia Amâncio. 2012a. «Resistências à igualdade de género na política.» ex æquo 25: 45-58.

Santos, Maria Helena, e Lígia Amâncio. 2012b. «Género e política. Análise sobre as resistências nos discursos e nas práticas sociais face à lei da paridade.» Sociologia, Problemas e Práticas 68: 79-101. 
Santos, Maria Helena, e Lígia Amâncio. 2014. «Sobreminorias em profissões marcadas pelo género: consequências e reações.» Análise Social 212: 700-726.

Telles, Edward, e Paixão, Marcelo. 2013. «Affirmative Action in Brazil.» LASA Forum XLIV(2): 10-11.

Urpia, Ana. 2020. «Por uma noção corporalizada e posicional de subjetividade de gênero.» Revista Psicologia Política 20(48): 385-401. Disponível em http:/ / pepsic.bvsalud.org/ scielo.php?script=sci_arttext\&pid=S1519-549X2020000200010\&lng=pt\&nrm=iso

Warikoo, Natasha, e Utaukwa, Allen. 2020. «A solution to multiple problems: the origins of affirmative action in higher education around the world.» Studies in Higher Education 45(12): 2398-2412.

Carla Cerqueira. Doutorada em Ciências da Comunicação pela Universidade do Minho (2012). É investigadora integrada do Centro de Investigação em Comunicação Aplicada, Cultura e Novas Tecnologias (CICANT) e Professora Auxiliar na Universidade Lusófona do Porto. Os seus interesses de investigação incluem género, feminismos, interseccionalidade, média e comunicação. Editou e publicou diversos livros, capítulos e artigos nessas áreas e mantém um envolvimento ativo com várias associações científicas (inter)nacionais e organizações não-governamentais.

Maria Helena Santos. É licenciada (2001), mestre (2004) e doutorada (2011) em Psicologia Social e das Organizações pelo Instituto Universitário de Lisboa (IscteIUL). Atualmente, é investigadora integrada no CIS-Iscte. Os seus principais interesses de investigação têm-se centrado nos estudos de género e nas medidas de ação afirmativa em contextos profissionais marcadamente femininos e masculinos, com especial foco no contexto da política. É autora e coautora de vários livros, capítulos e artigos em revistas científicas nacionais e internacionais.

Renísia Cristina Garcia Filice. Professora Associada da Universidade de Brasília (UnB). Pós-doutora em Sociologia pela Universidade do Minho. Integra a Comissão de Implementação de Políticas Afirmativas/UnB. Líder do Grupo de Estudos e Pesquisas em Políticas Públicas, História, Educação das Relações Raciais e Gênero/ Geppherg/UnB e do projeto Tecendo Redes Antirracistas: África(s), Brasis e Portugal. Pesquisa sobre História, Educação das Relações Raciais e Gênero; Gestão de Políticas Públicas em gênero, raça e classe; Políticas de Ações Afirmativas numa perspectiva intersetorial, transversal e interseccional. 



\title{
A SUB-REPRESENTAÇÃO POLÍTICA DAS MULHERES NO GOVERNO LOCAL É IRRELEVANTE? ${ }^{1}$ REVISÃO DO QUE SABEMOS E DO QUE FALTA SABER EM PORTUGAL
}

\section{Ana Ribeiro}

(D) http: / / orcid.org/0000-0003-4986-0493

\section{Resumo}

A introdução de quotas legislativas (33,3\%), em Portugal, em 2006, influenciou positivamente a proporção de mulheres eleitas, mas, ao contrário dos restantes patamares políticos, no governo local a imparidade subsiste acentuadamente em alguns órgãos e cargos, situação que representa terreno fértil de pesquisa. Contudo, verifica-se uma escassez de estudos sobre o tema. $\mathrm{O}$ artigo equaciona a relação entre a falta de conhecimento sobre as especificidades locais e o desacerto da solução legislativa. $\mathrm{O}$ levantamento exaustivo de literatura, que identificou 43 títulos, e o contacto com investigadoras/es significativas/os permitiram clarificar causas da eficácia diferenciada da Lei da Paridade, explicar a escassez de estudos e anotar tópicos para investigação futura.

Palavras-chave: Governo local, género, democracia, lei, Portugal.

\begin{abstract}
Does Women's Underrepresentation in Local Government Matter? Review of what we know and should know in Portugal

This essay is based on a systematic literature review that identified 43 academic studies on local government in Portugal, where women's underrepresentation subsists, despite the gender quotas (33,3\%) introduced in 2006. The analysis, and the contact with the significant researchers on the subject, made it possible to understand why the Parity Law has a different impact on local government and on the national and European parliaments. It also explains the gaps in the existing studies, and identifies topics for future research.
\end{abstract}

Keywords: Local government, gender, democracy, law, Portugal.

* «Does Women's Underrepresentation Matter?» é a questão que surge num artigo que me inspirou a realizar o exercício presente neste texto (Holman 2017). Agradeço à Professora Mirya Holman a disponibilidade com que acolheu as minhas perguntas e partilhou o seu trabalho.

** CICS.NOVA - Centro Interdisciplinar de Ciências Sociais da Faculdade de Ciências Sociais e Humanas da Universidade Nova de Lisboa, Lisboa, Portugal.

Endereço postal: Colégio Almada Negreiros, Campus Campolide, 1070-312 Lisboa, Portugal. Endereço eletrónico: anaribeiro@campus.fcsh.unl.pt 


\begin{abstract}
Résumé
La sous-représentation des femmes au gouvernement locale n'est pas un problème? Revue de ce que nous savons et savons pas encore au Portugal

L'article est basé sur une revue systématique de la littérature qui a identifié 43 études sur genre et gouvernement local au Portugal, où la sous-représentation politique des femmes persiste, malgré les quotas de genre $(33,3 \%)$ introduits en 2006. Cette évaluation critique a rendu possible répondre pourquoi la «Loi sur la parité» a un impact différent sur les niveaux de gouvernement local et le national et européen, mais aussi expliquer le manque d'études sur genre et politique local et identifier sujets pour recherche future.
\end{abstract}

Mots-clés: Gouvernement local, genre, démocratie, loi, Portugal.

\title{
Apresentação do tema e objetivos do artigo
}

As mulheres formam, na maioria dos países, pelo menos metade do eleitorado, mas encontram-se em minoria em lugares de decisão política, mesmo em países que adotaram legislação tendente a assegurar a paridade (Freidenvall e Dahlerup 2013). Os estudos que abordam este fenómeno centram-se maioritariamente nos parlamentos nacionais, descurando o conhecimento sobre os patamares locais de governação; no entanto, é no governo local que a sub-representação política permanece globalmente mais acentuada (ONU 2019), fator que o qualifica como terreno fértil de pesquisa.

Em Portugal, espelhando a situação internacional, verifica-se uma insuficiência de estudos sobre o «poder local» ${ }^{1}$. Este artigo problematiza a relação entre ambos os fenómenos, a imparidade política entre mulheres e homens no plano local e a escassez de estudos sobre o tema.

Após o 25 de abril de 1974, Portugal assumiu o compromisso com a igualdade na representação política, percurso que teve por expoente a aprovação da Lei

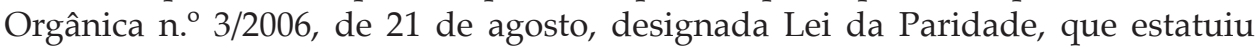
quotas, fixadas em 33,3\% (DR 2006). Embora os estudos internacionais demonstrem que a introdução de quotas não é condição necessária ou suficiente para assegurar o aumento da representação política das mulheres (Freidenvall e Dahlerup 2013), em Portugal, esta medida influenciou positivamente a proporção de mulheres eleitas. Contudo, esse movimento não tem sido igual nos três patamares políticos abrangidos pela Lei da Paridade (Santos, Teixeira e Espírito-Santo 2018), destacando-se negativamente os órgãos do governo local relativamente à Assembleia da República (AR) e Parlamento Europeu (PE).

A Constituição Portuguesa de 1976 inaugurou a expressão «poder local» para vincar a diferença entre a instituição existente na ditadura e a nova noção de autarquia democrática. No texto opta-se por «governo local», formulação mais próxima do termo presente nos documentos e estudos internacionais. 
Com efeito, considerando os últimos atos eleitorais realizados em cada patamar político ${ }^{2}$, na AR a eleição de mulheres ascendeu, em 2019 ( 6 de outubro), a 40\% (92M/230HM) (IPU 2019); no Parlamento Europeu, nesse mesmo ano (26 de maio), o valor foi superior com 43\% de mulheres eleitas (9M/21HM) (PE 2019), ou seja, o limiar de paridade em vigor no momento da eleição foi ultrapassado. Nos órgãos locais - a saber, dois deliberativos, a Assembleia Municipal (AM) e a Assembleia de Freguesia (AF); dois executivos, a Câmara Municipal (CM) e a Junta de Freguesia -, verificou-se situação diversa. Em 2017, a percentagem de mulheres eleitas foi a seguinte: $\operatorname{AM}(34,6 \%), \operatorname{AF}(33,2 \%), C M(29,2 \%)$, não estando disponível o valor percentual de mulheres eleitas para a JF (Santos, Teixeira e Espírito-Santo 2018, 28). No ato eleitoral precedente, em 2013 , existem dados relativos à percentagem de mulheres eleitas nos quatro órgãos locais que totalizaram 31,1\% (Tavares et al. 2016, 283) $)^{3}$.

Os dados disponíveis sobre o patamar local permitem verificar que a representação nos órgãos deliberativos é superior relativamente aos executivos. Nas presidências dos órgãos é muito baixa, como ilustra a $\mathrm{CM}$, onde a barreira dos $10 \%$ de representação só foi ultrapassada em 2017, ano em que foram eleitas 32 presidentes (no universo de 308 municípios). Assim, apesar de a proporção de mulheres ter aumentado na política local, não acompanha a subida verificada nos demais patamares de governo, nem atingiu o objetivo mínimo fixado na Lei da Paridade, exceto na AM, permanecendo acentuadamente baixa em alguns órgãos e cargos.

Uma possível explicação para o impacto diferenciado da Lei da Paridade relaciona o desacerto desta solução legislativa perante as idiossincrasias locais. A Lei previu (art. ${ }^{\circ} .^{\circ}$ ) uma reapreciação do impacto sobre a promoção efetiva da paridade, decorridos cinco anos da entrada em vigor, a realizar pela AR; no entanto, as duas alterações verificadas aconteceram já em 2017 e $2019^{4}$. Neste âmbito, sublinha-se a possibilidade de avaliação em sede académica, quer de anteprojetos de leis a apresentar ao parlamento, ex ante (Pequito Teixeira 2009), quer do impacto de medidas legislativas através de investigação empírica, ex post (Espada 2002), o que tem ocorrido, embora as sugestões, críticas e pareceres apresentados nem sempre sejam adotados.

No que se refere especificamente às medidas de política aplicadas às desigualdades de género, sublinha-se que, apesar da curta existência dos estudos de género em Portugal, estes têm contribuído para avaliar e corrigir as políticas e seus

2 O presente artigo foi redigido antes das eleições autárquicas de 26 de setembro de 2021.

3 Em consulta realizada a 22 de setembro de 2021 ao portal da DGAI/SGMAI, o estudo eleitoral de 2013 é o último com dados das autárquicas sistematizados por sexo. Informação consultada em https: / / www.sg.mai.gov.pt / Noticias / Paginas / Divulgação\%20de\%20estudos\%20Eleitorais. aspx [Consultado em 22 de setembro de 2021].

4 A alteração da Lei da Paridade de 2019 (Lei Orgânica n. ${ }^{\circ}$ 1/2019, de 29 de março) só vai ter efeito prático pela primeira vez nas eleições autárquicas de 2021 (26 de setembro), ou seja, não influenciou os atos eleitorais de 2019 da AR e PE. 
efeitos (Torres 2016). No entanto, as investigações que abordam a política sob uma lente de género incidem maioritariamente sobre o patamar político nacional (Teixeira 2016). Significa isto que a democracia local é irrelevante para a temática da igualdade?

Esta questão espoletou a reflexão que está na base deste artigo, que explora a hipótese de as insuficiências no desenho da Lei da Paridade refletirem a falta de conhecimento sobre as especificidades locais. Para aceitar ou rejeitar a validade deste raciocínio, procurou apurar-se o que se sabe e o que deveria saber-se sobre o tema.

A procura de respostas foi realizada através do levantamento dos estudos existentes, complementado com a identificação e contacto com os/as investigadores/as significativos/as, procedimento detalhadamente descrito na secção do artigo dedicada à metodologia. Segue-se a cronologia do processo de implementação de quotas legislativas e análise do quadro legal mais amplo que influencia a representação política das mulheres localmente. Este enquadramento legislativo precede e contextualiza a revisão de literatura sobre representação política local na perspetiva de género. Procurou-se, deste modo, explicar a insuficiência dos estudos e evidenciar a necessidade de acrescentar conhecimento ao tema para aperfeiçoar a democracia local.

Ainda que apresentados resumida e parcelarmente, estes resultados constituem uma ferramenta útil para um questionamento informado sobre a sub-representação política no governo local, porque só a informação «promove a consciencialização de todos e, em particular, daqueles que beneficiam com as mudanças» (Beleza 1998, 66). A pertinência desta análise é acentuada perante a realização de eleições locais no último quadrimestre de 2021, sujeitas a um conjunto de alterações legislativas, já que se mantém atual a observação da primeira autora nacional a abordar a representação política no governo local sob a perspetiva de género: a reflexão sobre este problema está «sujeita ao ciclo das eleições» (Jordão 2003,19)!

\section{Metodologia e dados}

Foi efetuado um levantamento exaustivo da literatura sobre a representação política das mulheres no governo local, tendo a análise consistido em fazer o recorte de contributos que de forma substantiva esclareçam porque é menos equilibrada relativamente à $\mathrm{AR}$ e $\mathrm{PE}$, patamares políticos igualmente abrangidos pela Lei da Paridade. Foi estabelecido como critério de seleção dos estudos a existência de um escrutínio prévio, que decorre da revisão anónima por pares, no caso dos artigos, e do exame científico a que estão sujeitos os trabalhos académicos (dissertações e teses). Pretendeu-se, assim, garantir a qualidade da amostra, já que o reconhecimento prévio pelos pares atesta a «credibilidade e aprovação» das fontes (Silvestre e Silvestre 2012, 47). 
Como critério de pesquisa foi estabelecido que os estudos seriam recolhidos prioritariamente on-line, já que o trabalho se iniciou durante o primeiro confinamento da crise pandémica que impossibilitou o acesso a centros de documentação e bibliotecas, situação que veio acrescentar valor às características positivas já conhecidas deste meio, como a rapidez e acessibilidade.

A pesquisa bibliográfica realizou-se: (i) no Google Scholar, que reúne publicações de conteúdo científico, artigos académicos publicados em revistas científicas, contendo também as dissertações e teses dos Repositórios Científicos de Acesso Aberto de Portugal (RCAAP); (ii) na Biblioteca do Conhecimento Online (b-on), que acrescenta aos conteúdos anteriores publicações e $e$-books sem acesso livre, que disponibiliza aos seus membros. A consulta das duas bases de dados fez-se através da utilização de um conjunto de palavras-chave: Portugal, «representação política», género, mulheres, democracia, lei, paridade, «poder local», «Governo local», municípios ${ }^{5}$.

Para a constituição da amostra final foram observadas várias etapas. Foram escrutinadas as primeiras 100 entradas de cada base de dados através da leitura dos resumos, de que resultaram 23 artigos/estudos. Efetuou-se a revisão das referências bibliográficas com o intuito de identificar novos títulos adequados ao tema, o que fez sobressair o conjunto de autoras e autores significativas/os para o campo em estudo, ou seja, quem é invariavelmente citada/o. Foram consultadas as respetivas páginas na Internet para apurar quais os que permanecem «investigadores activos» (Silvestre e Silvestre 2012, 48), seguindo-se o contacto via email com: Albertina Jordão, Ana Espírito-Santo, Ana Lúcia Teixeira, Diana Maciel, Lígia Amâncio, Manuel Lisboa, Maria Antónia Pires de Almeida e Maria Helena Santos. Porque verificado que, salvo exceção (Jordão 2000, 2003), os/as investigadores/as recorrem a dados secundários (resultados eleitorais oficiais), foi também contactada Sónia Tavares, na qualidade de Chefe de Divisão Jurídica e de Estudos Eleitorais da Secretaria Geral do Ministério da Administração Interna (DGAI/SGMAI).

O contacto direto teve por intuito confirmar se a lista de estudos sobre o tema que se apresentou a cada autor/a se encontrava completa; se estavam a desenvolver nova pesquisa; ou consideravam fazê-lo ${ }^{6}$. No caso da DGAI/SGMAI, pretendeu-se apurar se o estudo periódico «Perfil do autarca - caracterização dos eleitos locais» conheceria edição quanto aos resultados de 2017; verificar a existência de uma lista de presidentes de CM eleitos/as entre 1976 e 2017. Este procedimento revelou-se muito vantajoso porque permitiu completar a seleção de estudos, já que foram recebidos conference papers, apresentações em workshops/aulas, relatórios, que representam informação útil para identificar pistas de análise e observar a relevância do tema na academia, bem como conhecer os contornos alargados do

Consulta realizada a 18 de junho de 2020.

Foram contabilizadas 100\% de (amáveis) respostas. 
tema. Foi também recebida a lista sistematizada pela DGAI/SGMAI de presidentes de CM, o que permitiu ultrapassar discrepâncias encontradas nos estudos quanto ao número de mulheres eleitas e sistematizar os dados que se apresentam na Tabela 1 (em anexo), com o número e percentagem de mulheres eleitas presidentes de Câmara por distrito (1976-2017) . Estes contactos revelaram, também, que há trabalhos em processo de publicação e outros em perspetiva, principalmente pela curiosidade científica que desperta um novo ato eleitoral ${ }^{8}$.

Porque constituem uma via de resposta complementar às questões orientadoras (causas para a escassez de estudos; o que se sabe e o que deveria saber-se sobre o tema que explique o impacto diferenciado das medidas legislativas), os trabalhos recebidos foram adicionados à amostra inicial, que no final integrava 43 títulos.

Uma das limitações desta metodologia relaciona-se com a possibilidade de não terem sido contempladas algumas publicações pertinentes que não se enquadraram nas palavras-chave definidas, embora as etapas que se sucederam possam ter reduzido essa falha.

\section{A sub-representação política das mulheres no governo local é irrelevante?}

Quadro legal: implementação de quotas e medidas promotoras da paridade local

Os direitos políticos das mulheres portuguesas antes do 25 de abril eram muito limitados (Melo 2017). A partir de 1974, o Estado português assume o compromisso político com a igualdade, e a Constituição da República Portuguesa (CRP), aprovada em 1976 (DR 1976), vem proporcionar garantias legais para o exercício dos direitos políticos das mulheres. Com a revisão constitucional de 1997 (DR 1997) fica consagrado o princípio da igualdade material, que admite a aprovação de iniciativas legislativas que favoreçam o acesso das mulheres aos cargos políticos.

Esta alteração foi influenciada por uma corrente de pensamento desenvolvida no Conselho da Europa (CE) a partir do questionamento sobre a relação da igualdade de género e o conceito de democracia (Sineau 2003). A génese concetual da «democracia paritária» dá-se num Seminário realizado pelo CE, em 1988, e ganha definição na Declaração de Atenas, em 1992, adotada na primeira Conferência Europeia sobre as Mulheres no Poder, afirmando-se como a «full integration of women, on an equal footing with men, at all levels and in all areas of the workings of a democratic society, by means of multidisciplinary strategies» (Sineau 2003, 28).

\footnotetext{
Os dados da tabela 1 permitem ainda apurar que, dos 3674 mandatos camarários da democracia, apenas $4 \%$ são mandatos femininos.

8 Neste sentido, informaram ter artigos em vias de publicação ou redação, em termos individuais, Maria Antónia Pires de Almeida, e coletivamente, Ana Espírito-Santo, Ana Lúcia Teixeira e Maria Helena Santos.
} 
Este renovado entendimento da democracia foi acolhido em Portugal pelas Organizações não Governamentais de Defesa dos Direitos das Mulheres e pela Comissão para a Igualdade e para os Direitos das Mulheres - CIDM, que pressionaram o Estado a tomar iniciativas legislativas que promovessem a igualdade material (Monteiro 2011). O novo preceito constitucional tem origem nas propostas apresentadas à AR pela Associação Portuguesa das Mulheres Juristas, que preconizava a plena igualdade entre mulheres e homens no exercício dos direitos cívicos e políticos. Contudo, como sublinha Vital Moreira, o texto finalmente aprovado não adota a formulação exercício de direitos, mas antes, promover a igualdade no exercício de direitos cívicos e políticos, «o que não é a mesma coisa» $(1998,51)$. Ainda assim, subsiste a interpretação de que o legislador nacional ficou «obrigado a uma espécie de obrigação de resultado, consistente em melhorar a proporção entre homens e mulheres no exercício de direitos cívicos e políticos» (Miranda et al., s.d., 30) ${ }^{9}$, a alcançar, nomeadamente, pela introdução de medidas especiais temporárias (também designadas de discriminação positiva) que a norma constitucional de 1997 veio permitir.

Neste contexto surge, em 1998, a iniciativa legislativa conhecida em termos mediáticos como Lei das Quotas (para mulheres) (Viegas e Faria 2001), que pretendia garantir «a igualização no acesso de ambos os sexos aos órgãos políticos» (DP 1999, 1111). Contudo, restringia-se às listas de candidaturas apresentadas nas eleições para a AR e para o PE, excluindo as Assembleias Legislativas das Regiões Autónomas dos Açores e da Madeira, e os órgãos (eletivos) do governo local. Exceções apresentadas como provisórias e justificadas pelo facto de o problema da sub-representação ter «mais visibilidade e premência» nos patamares nacional e europeu (DP 1999, 1112).

Esta tentativa de promover a igualdade falhou, no sentido em que a Proposta de Lei de 1998 foi rejeitada, mas introduziu na agenda política nacional e no debate público o tema da desigualdade de facto da representação política das mulheres. Apenas em 2006 veio a ser promulgada a denominada «Lei da Paridade» (DR 2006), que estabelece uma representação mínima de 33,3\% de cada um dos sexos nas listas eleitorais, ao contrário da situação de paridade, próxima ou equivalente a 50/50, que o seu título anuncia. Requer a ordenação das listas dos/as candidatos/ /as segundo o sistema fecho éclair (não podendo ser colocadas consecutivamente mais de duas pessoas do mesmo sexo), e a previsão de penalizações para as listas não cumpridoras.

Trata-se de uma solução limitada face ao cenário de paridade traçado em Atenas e às possibilidades oferecidas pela alteração constitucional, mas, ao contrário da Proposta de Lei de 1998, a Lei aprovada abrange os órgãos eletivos locais (exceto os órgãos das freguesias com 750 ou menos eleitores/as e dos municípios com 7500 ou menos eleitores/as), continuando, porém, a não vigorar nas Assembleias Legislativas Regionais.

Como resulta das disposições conjugadas do art. ${ }^{\circ} 9 .^{\circ}$ e do art. $^{\circ} 109^{\circ}$ da CRP. 
Como referido, a Lei da Paridade previu a avaliação periódica do seu impacto pela AR e eventual revisão dos seus termos, após 5 anos, o que veio a ocorrer em 2019, passando a intitular-se Lei da Paridade nos Órgãos Colegiais Representativos do Poder Político (DR 2019). O seu âmbito de aplicação foi alargado: (i) aumentou para $40 \%$ a representação mínima de cada um dos sexos nas listas de candidaturas; (ii) alterou-se o processamento das listas não conformes, deixando de haver penalizações financeiras e passando, ao invés, a ser rejeitada toda a lista nos casos em que a correção não se realize no prazo previsto na lei eleitoral; (iii) passou a abranger a lista de candidatos/as a vogal das $\mathrm{JF}^{10}$ e as listas de candidatos/as às mesas dos órgãos deliberativos da AM e AF.

Este conjunto de alterações influencia, pela primeira vez, o ato eleitoral de 2021, a que se junta a anulação da exceção de formar listas paritárias para os órgãos das freguesias com 750 ou menos eleitores/as e dos municípios com 7500 ou menos eleitores/as, já que a Lei Orgânica n. ${ }^{\circ} 1 / 2017$, de 2 de maio (art. ${ }^{\circ} 3^{\circ} .^{\circ}$ (DR 2017), que veio revogar esta exceção, entrou em vigor em 2018, ou seja, não conheceu aplicação antes das autárquicas de 2021. Esta exceção fundou-se na alegada escassez de mulheres referida por decisores políticos locais no momento de preencher as listas de candidaturas (Espírito-Santo e Santos 2017). Argumento contrariado por Maria Manuel Leitão Marques (Ministra da Presidência), que justificou não haver esse problema quando «Em mais de $90 \%$ das freguesias do país, há mais mulheres do que homens» ${ }^{11}$.

Outras medidas legislativas podem, tendencialmente, influenciar o aumento da proporção de mulheres na política local, ainda que não fosse esse o objetivo a determinar a sua criação. É o caso da referida Lei Orgânica n. ${ }^{\circ} 1 / 2017$, de 2 de maio, que permite que as candidaturas para a eleição dos titulares dos órgãos políticos locais sejam apresentadas por grupos de cidadãos eleitores em alternativa a partidos políticos ou coligações partidárias, já que a formação de listas independentes (quando encabeçadas por mulheres) possibilita ultrapassar os «constrangimentos que as mulheres encontram nos partidos, no que diz respeito à sua colocação nos primeiros lugares nas listas» (Almeida 2019, 216), ou seja, lugares elegíveis. Há a referir que a maioria das listas locais independentes têm sido constituídas por pessoas dissidentes de partidos (mulheres e homens), ou seja, não emanam da sociedade civil, o que não só desvirtua a independência que deveria caracterizar essas

10 A composição dos executivos das JF apresenta particularidades. É nomeado/a presidente o/a candidato/a que encabeçar a lista mais votada na eleição para a AF; os vogais são eleitos pela AF na primeira sessão de trabalhos, de entre os seus membros, mediante proposta do/a presidente da JF, agora sujeita a composição paritária nos termos da Lei da paridade. Cf. Lei que regula a eleição dos titulares dos órgãos das autarquias locais (DR 2001).

11 «Nova lei da paridade só entra em vigor após ciclo eleitoral de 2019, diz ministra.» JN - Jornal de Negócios, 22 de janeiro de 2019. Disponível em https:/ / www.jn.pt/nacional/nova-lei-da-paridadeso-entra-em-vigor-apos-ciclo-eleitoral-de-2019-diz-ministra-10473101.html [Consultado em 18 de outubro de 2020$\}$. 
candidaturas (Pequito Teixeira 2009), como não há razões para acreditar que os critérios que norteiam a composição dessas listas se distingam dos adotados pelos partidos e, deste modo, beneficiem candidaturas femininas.

É também o caso da Lei n..$^{\circ}$ 46/2005, de 29 de agosto (DR 2005), que veio estabelecer limites à renovação sucessiva de mandatos de presidentes dos órgãos executivos locais, que teve em vista a renovação das elites locais pelo afastamento dos designados «dinossauros», homens presentes nos executivos locais desde a primeira eleição, em 1976. Esta Lei - aprovada em 2005, mas com efeitos práticos, pela primeira vez, no ato eleitoral de 2013 - suscitou dúvidas, que foram esclarecidas, três semanas antes do dia das eleições, pelo Acórdão Constitucional n. ${ }^{\circ}$ 480/2013 (DR 2013), o qual determinou que a limitação de mandatos é apenas e meramente territorial e não respeita à função. Assim, o limite apenas impede a eleição do/a mesmo/a candidato/a para um quarto mandato consecutivo na mesma autarquia, interpretação que beneficiou, desde logo, alguns «dinossauros» que se candidataram a municípios diferentes, tendo sido inclusivamente premiados porque as «transições geográficas constituíram mobilidade ascendente» (Almeida 2014, 13), ao serem eleitos em sedes de distrito. Ainda assim, esta Lei, ao impedir a perpetuação dos incumbentes nas autarquias (maioritariamente homens), pode beneficiar a entrada de mulheres (Teixeira 2016).

\section{Sub-representação politica local: análise das insuficiências de conhecimento}

A insuficiência de estudos sobre a participação política das mulheres no plano local é caracterizada não só pela escassez numérica, como também pelas limitações dos estudos existentes, que são, em geral, institucional, geográfica e temporalmente parcelares (Teixeira 2016).

Quanto ao primeiro fator, há poucos estudos devido a vários constrangimentos à atividade de pesquisa sobre as mulheres. A ideologia ditatorial presente nos sucessivos regimes da Ditadura Militar (1926-1928), Ditadura Nacional (1928-1933) e Estado Novo (1933-1974) não só negou direitos políticos às mulheres como impediu o desenvolvimento científico (Torres 2016), pelo que as ciências sociais surgem nas universidades portuguesas e se institucionalizam apenas com a democracia (Amâncio e Oliveira 2014). Já o género como categoria de análise pontua os trabalhos académicos apenas a partir da década de 1990 (idem). Na área género e política surgem, já no século XXI, as primeiras dissertações de mestrado (Jordão 2003) e teses de doutoramento (Santos 2010), num panorama vazio «de produção e reflexão teórica (...) da filosofia e da ciência política sobre a representação política das mulheres, a cidadania feminina ou os desafios que o feminismo pode trazer à democracia» (Jordão 2003, 91).

Além do surgimento tardio, a falta de estudos sobre as mulheres adensa-se quando estes abordam o campo político, o que está relacionado com a «inexistência de dados sistematizados, de informação estatística desagregada por sexo 
(apesar das recomendações, por parte de instâncias internacionais)» (Jordão 2003, 93). Há falta de dados oficiais sobre resultados eleitorais (Martins 2011), inacessíveis quanto aos primeiros anos da democracia (Saraiva 2017), ou não divulgados atempadamente quanto a eleições mais recentes (Santos 2010), o que implica que para conhecer o número de mulheres eleitas seja necessário «fazer o exercício de contagem manual, através dos nomes inscritos nos cadernos eleitorais» (Jordão 2003, 92). Nos sufrágios locais acresce a estes fatores a complexidade que aporta o número elevado de candidatos/as e eleitos/as (Saraiva 2014), tendo em conta que o conjunto dos quatro órgãos se traduz (atualmente) em mais de 35 mil mandatos a cada quatro anos; por comparação, a AR apresenta 230 assentos parlamentares, sendo 21 no PE.

Apesar das dificuldades assinaladas de acesso a dados oficiais, no âmbito do Ministério da Administração Interna foram publicados periodicamente, até 2013, estudos com a caracterização sociológica dos/as eleitos/as locais ${ }^{12}$ que incluíram um capítulo dedicado à caracterização das mulheres eleitas (exceto em 1989). Quanto aos resultados eleitorais de 2017, de acordo com o esclarecimento da Chefe de Divisão Jurídica e de Estudos Eleitorais da DGAI/SGMAI, não existe data prevista para a conclusão do estudo em curso.

Por oposição à falta de fontes surge, em 2013, uma base de dados (atualizada em 2014) com mais de 6000 entradas de dados biográficos dos/as eleitos/as locais para os cargos de presidente e vice-presidente de CM, entre outros cargos locais (Almeida 2013; 2014). Entre as muitas centenas de biografias masculinas surgem as poucas mulheres nomeadas e eleitas naqueles cargos (antes do 25 de Abril até 2013). É apresentada a sua caracterização sociodemográfica e percurso político, um recurso valioso perante a invisibilidade a que as mulheres são votadas, ainda que protagonizando papéis de relevo no espaço público.

As dificuldades e limitações que podem influenciar investigadores/as a não optar por esta temática surgem a par dos argumentos que justificam a incidência de pesquisas nos parlamentos nacionais. Entre esses argumentos está o facto de se tratar de um espaço que favorece a avaliação da participação política das mulheres e das iniciativas relacionadas com a igualdade (Cabrera, Flores e Mata 2012), além de que apurar a proporção de mulheres e homens nessa instância governativa se tornou uma medida padrão para aferir o índice democrático dos países (IPU 2020).

Apesar das razões que explicam a concentração de estudos no patamar político nacional, este não é o único relevante numa perspetiva de género. Não só os/ /as representantes locais se encontram numa posição privilegiada para identificar e afastar a persistência e a reprodução das desigualdades e promover sociedades igualitárias (Perista e Silva 2008), sendo de assinalar o papel crucial que podem

12 Realizados no âmbito da Secretaria-Geral do Ministério da Administração Interna, anteriormente Secretariado Técnico dos Assuntos para o Processo Eleitoral, nos anos de 1982, 1989, 1993, 1997, 2001, 2005, 2009 e 2013. 
desenvolver na implementação da Agenda 2030 (ONU 2019), como este nível de governo é reconhecido por ser uma escola de participação política para as mulheres (Jordão 2000; OMC 2003), sobretudo a atividade desenvolvida nas JF (Jordão 2000; Saraiva 2017).

Quanto ao segundo fator que qualifica a insuficiência de estudos, o facto de serem genericamente parcelares invalida a sua atualidade e limita a sua capacidade de produzir generalizações de pendor estatístico.

Com efeito, em termos geográficos, não existe um conhecimento uniforme sobre a representação política das mulheres no plano local. A realidade mais estudada no país corresponde ao conjunto dos municípios que integram o distrito (divisão administrativa supramunicipal) de Lisboa, o que se explica tanto pela concentração de universidades e «proximidade geográfica» ao objeto de estudo (Maciel 2008, 59), como por apresentar uma elevada proporção de mulheres a liderar municípios nesta área, o que promove e facilita a realização de entrevistas (Saraiva 2017).

Vários estudos abrangem o território nacional (Continente e Ilhas) (e.g. Espada 2002; OMC 2003; Nunes 2008; Santos 2010; Teixeira 2016; Almeida 2018), focando, na maioria, as presidentes de câmara. Os estudos geograficamente parcelares abrangem: os 16 municípios de Lisboa; alguns dos municípios do distrito do Porto (Gondomar, São João da Madeira, Santa Maria da Feira); os 24 municípios de Viseu; alguns municípios dos distritos de Setúbal (Setúbal, Palmela, Almada, Montijo) e de Portalegre (Portalegre, Nisa, Arronches); ainda mais dispersamente, os municípios de Mirandela/Bragança, Moura/Beja, Rio Maior/Santarém, havendo muitos municípios, distritos e até zonas do país, como o Algarve e as Regiões Autónomas dos Açores e da Madeira, não contemplados por qualquer estudo particular.

Os resultados dos estudos circunscritos geograficamente não podem ser extrapolados para o universo de autarquias (municípios e freguesias) do país atendendo à oposição, amplamente sublinhada pelos/as investigadores/as, entre contextos urbanos e rurais, mais e menos populosos, do interior e do litoral, do Norte, do Centro, do Sul e das Ilhas, que ditam diferenças que caracterizam o grupo de representantes e o grupo de representados. Mas mesmo estas dicotomias não são estanques, pelo que se impõe o teste empírico. Por exemplo, os/as presidentes de $\mathrm{CM}$ dos municípios de Lisboa surgem num contexto geográfico marcadamente urbano e a Sul, pelo que tendencialmente representam "posições, opiniões e comportamentos mais modernos e igualitários» (Maciel 2008, 115) que outros autarcas do país, o que impede generalizações ao todo territorial. Mas esta situação da capital do país apresenta-se ainda excecional entre outros contextos urbanos e a Sul «dada a proximidade dos centros de decisão política» (Jordão 2019, 185).

Já no grupo dos representados, é destacada a situação dos eleitores residentes em meios mais ruralizados, pouco populosos, em particular no interior, que os estudos identificam com opiniões mais conservadoras, menos igualitárias (Espada 2002; Teixeira 2016), resultado que contende com o facto de vários municípios com essas características terem eleito, entre 1976 e 2017, mulheres para liderar os seus executi- 
vos (Saraiva 2017). Entre estes encontram-se, inclusivamente, vários municípios com menos de 7500 eleitores/as abrangidos pela exceção de não cumprimento de listas «paritárias»: Góis/Coimbra, Sardoal/Santarém, Constância/Santarém, Portel/ /Évora, Alandroal/Évora, Arraiolos/Évora, Mourão/Évora, Santa Cruz da Graciosa/ /RAA, Lajes do Pico/RAA, Vila de Rei/Castelo Branco, Vila Velha de Rodão/Castelo Branco, Alvaiázere/Leiria, Castanheira de Pera/Leiria, Nisa/Portalegre, Arronches/ /Portalegre e Freixo de Espada à Cinta/Bragança.

Outra dificuldade assinalada nos estudos em termos de generalização de resultados prende-se não com a amostra observada, mas com a dimensão do próprio universo, sendo este o caso das presidentes de CM. Com efeito, entre 1976 e 2021, houve 154 mandatos femininos por eleição e 19 por nomeação, exercidos por 77 mulheres $^{13}$ : «perante um universo tão reduzido, a caracterização do grupo das mulheres presidentes de câmara torna-se necessariamente limitada e quase personalizada» (Almeida 2013, 106).

\section{Sub-representação política local: o papel dos partidos políticos}

Os estudos demonstram a grande discricionariedade permitida aos decisores políticos, nomeadamente, no momento de constituir as listas de candidaturas e, depois, na atribuição de pelouros. As mulheres são associadas a atividades de apoio, havendo resistência a colocá-las em posições de maior visibilidade e poder (Lisboa et al. 2006), impedidas, por vezes, de fazer uso das suas qualificações (Jordão 2000). Os limites em que se movimenta esta arbitrariedade são o foco de várias pesquisas que analisam a legislação que intenta materializar a igualdade de género na política, principalmente a Lei da Paridade (e.g. Martins 2011; Santos e Amâncio 2012; Espírito-Santo e Santos 2017). Os resultados dos estudos são consensuais ao atribuir aos partidos políticos a maior fatia de responsabilidade pela sub-representação local.

Os partidos políticos (secções locais) são caracterizados como «os canais quase exclusivos da mediação política» (Mendes 1993, 178-179) aos quais cabe garantir a «mobilização e participação de novos grupos sociais que, no período anterior a 1974, não se encontravam representados, quer nos partidos, quer nos órgãos locais de poder» (ibidem), como é o caso das mulheres (Almeida 2018). Os partidos têm poucas mulheres (Costa 2010) «e parece não haver interesse em motivá-las para aderirem ou filiarem-se» (Jordão 2000, 120); já quando lá estão, «não têm acesso ao poder (...) sendo-lhes vedado embora não oficialmente» (Mendes 1993, 181). Permanecem «clubes de homens» (Jordão 2000, 120), ainda que existam secções femininas no interior da maioria dos partidos (Costa 2010; Almeida 2018) e normas nos estatutos partidários relativas à seleção de candidatos/as (Costa

13 Mandatos por eleição: 154 (fonte: DGAI/SGMAI). Mandatos por nomeação (verificados até 22 de setembro de 2021): 19 (fontes: Almeida 2013; 2014; sites dos municípios portugueses). 
2010; Viegas 2016), e são os homens a sair beneficiados pelos processos de recrutamento pautados por critérios pouco transparentes (Lopes 2009), porque a regra que prevalece é privilegiar quem reúna as características dos três M: «Male, Middle Aged e Middle Class» (Almeida 2019, 218).

Este modus operandi das secções locais dos partidos reflete a sua «excessiva descentralização, e consequente desresponsabilização» (Santos, Teixeira e EspíritoSanto 2018, 19), sendo esta uma das razões que justifica que o incumprimento da Lei da Paridade seja comum no plano local. De acordo com informação consultada na Comissão Nacional de Eleições (CNE s.d.), desde que esta Lei foi implementada, em 2009, são apresentadas listas incumpridoras, mesmo pelos principais partidos (com assento Parlamentar). Tal não ocorre nas eleições para a AR, onde esta prática é esporádica (nos pequenos partidos), e PE, sem registo de incumprimento. Contudo, o grau de visibilidade mediática e impacto na opinião pública destas eleições também é diferenciado, e explica, em parte, a postura dos decisores políticos (Santos, Teixeira e Espírito-Santo 2018).

Vários estudos destacam que a interiorização dos princípios que norteiam a democracia paritária não foi feita por larga maioria dos políticos locais (e.g. Almeida 2014; Jordão 2019), o que ajuda a explicar a ineficácia da Lei da Paridade, mas também é sublinhado que o desenho da Lei faz com que, «ainda que integralmente cumprida, a proporção de mulheres seja reduzida» (Santos, Teixeira e EspíritoSanto, 2018, 20), principalmente, na presidência dos órgãos. Este aspeto ausente na Lei, já que esta se restringe ao aumento da sua presença numérica (Viegas 2016), revela pouca ambição quanto ao objetivo da liderança das mulheres.

Finalmente, os estudos apresentam propostas de alteração à Lei da Paridade que não foram contempladas na atualização de 2019. Também sugerem medidas e descrevem boas práticas que evidenciam que a lógica da paridade política não se reduz à implementação de quotas ou de outras medidas especiais temporárias estabelecidas transitoriamente com vista a compensar uma situação de desequilíbrio (Almeida 2020). Funda-se, antes, no reconhecimento do igual valor social de mulheres e homens e envolve medidas definitivas inscritas no direito, destinadas a repensar a distribuição de poder político em termos de igualdade de género para aprofundar a democracia (Santos 2010).

\section{Discussão de resultados e conclusões}

A imparidade política entre mulheres e homens no governo local, em Portugal, subsiste após a promulgação da Lei que introduziu quotas (33,3\%), em 2006. Este artigo explorou a hipótese que relaciona a insuficiência legislativa com a lacuna de conhecimento sobre as especificidades locais, e procurou determinar a relevância do tema para a academia. A revisão de literatura, aqui apresentada de forma parcelar e resumida, consistiu no recorte de contributos dos 43 estudos aca- 
démicos identificados pelo método de seleção exposto, que de forma substantiva permitiram esclarecer estas interrogações; a análise foi complementada pelo contacto via email com investigadoras/es significativas/os, para determinar a sua produção académica e conhecer trabalhos em perspetiva sobre o tema.

Os estudos atribuem às seções locais dos partidos políticos a responsabilidade pela deficitária participação e representação das mulheres na política local. A falta de adesão aos valores da democracia paritária e uma interpretação enviesada da legislação que a promove por parte dos decisores políticos locais manifesta-se, principalmente, nos momentos eleitorais na composição das listas de candidaturas em que as mulheres surgem invariavelmente na 3. ${ }^{a}, 6{ }^{a}{ }^{a}$ e $9 .{ }^{a}$ posições, atuação consentida pela falta de escrutínio mediático e da opinião pública.

Por outro lado, estão por explicar contradições evidenciadas pelo confronto de resultados entre estudos. É exemplo flagrante o facto de vários municípios com populações conotadas com valores conservadores e isentos da obrigação de apresentar listas paritárias (por terem menos de 7500 eleitores/as) elegerem mulheres presidentes de câmara, resultado paradoxal num cenário que prima pela resistência à Lei da Paridade.

Fica evidenciada a reduzida ambição do legislador nacional em contestar o paradigma atual de representação política. A revisão da Lei da Paridade (2019) ainda não acolhe a verdadeira paridade entendida como representação 50/50. Embora inclua alterações dirigidas ao patamar local de governação, continua ausente qualquer medida tendente a promover as presidências nos órgãos locais (paridade horizontal), onde se registam os índices mais elevados de sub-representação, apesar dos compromissos internacionais assumidos, que incluem o objetivo da liderança das mulheres, nomeadamente, a Agenda $2030^{14}$.

A insuficiência dos estudos não pode confundir-se com a irrelevância do tema para a academia, assunção que é de rejeitar: i) foi identificado um conjunto de investigadores/as ativos/as, que de forma continuada têm renovado a realização de pesquisas sobre o tema a partir dos seus trabalhos iniciais, persistindo apesar das dificuldades, com destaque para a falta de dados desagregados por sexo; ii) há trabalhos em vias de publicação e outros que se perspetivam após o ato eleitoral local de 2021, acrescido de relevo científico por coincidir com alterações legislativas tendentes a influenciar a representação descritiva das mulheres.

Conclui-se, que embora o panorama de conhecimento sobre o governo local seja muito incompleto, os estudos identificados nesta revisão não só explicam a (ODS) da Agenda 2030, é recomendado que os países façam uma avaliação separada no que se refere às posições executivas e ao cargo de presidente de câmara, uma vez que o indicador $5.5 .1 \mathrm{~b}$ ) Proportion of seats held by women in local governments (ONU 2017) apenas abrange os órgãos deliberativos, no caso de Portugal a AR e a AF. Cf. neste sentido https: / / unstats.un.org/sdgs / metadata/ files / Metadata-05-05-01b.pdf [Consultado em 08 de julho de 2021]. 
ineficácia diferenciada da legislação que promove a paridade, relativamente à AR e PE, como apresentam várias recomendações, sustentadas pela pesquisa, com vista a contrariar a sub-representação local, por meio de medidas legais e de outra natureza. É, assim, de rejeitar a hipótese que relaciona o desacerto da solução legislativa com a lacuna de conhecimento para explicar o problema da persistente sub-representação das mulheres na política local. Em termos de trabalhos futuros apresenta-se premente desenvolver estudos que abranjam a totalidade do território nacional.

\section{Referências bibliográficas}

Almeida, Maria Antónia Pires. 2013. O Poder Local do Estado Novo à Democracia: Presidentes de câmara e governadores civis, 1936-2012. Lisboa: Ed. Autor (ebook).

Almeida, Maria Antónia Pires. 2014. Dicionário biográfico do poder local em Portugal, 1936-2013. Lisboa: Ed. Autor (ebook).

Almeida, Maria Antónia Pires. 2018. «Women Mayors in Portugal: A Case Study in Political Representation and Citizenship.» Revista de Sociologia e Politica 26(68): 27-42. DOI: https:/ / doi.org/10.1590/1678987318266804

Almeida, Maria Antónia Pires. 2019. «As Mulheres no Poder Local em Portugal.» In Mulheres e Eleições, organizado por Ana Pires, Fátima Mariano e Ivo Veiga, 195-235. Coimbra: Almedina.

Almeida, Maria Antónia Pires. 2020. «Representação das mulheres nas câmaras municipais portuguesas: práticas e programas políticos.» Comunicação apresentada no Workshop Relocal Plotina: A Mulher como Agente de Transformação Local. Lisboa: ISEG (22 de janeiro).

Amâncio, Lígia, e João Manuel de Oliveira. 2014. «Ambivalências e desenvolvimentos dos estudos de género em Portugal.» Faces de Eva. Estudos sobre a Mulher 32: 23-42.

Beleza, Leonor. 1998. «Medidas para a promoção da igualdade na vida política.» In Democracia com mais cidadania: a questão da igualdade de participação política, organizado por Vitalino Canas et al., 65-81. Lisboa: Presidência Conselho Ministros - INCM.

Cabrera, Ana, Teresa Mendes Flores, e Maria José Mata. 2012. «O feminino como "intruso" na política: uma análise do contexto histórico e da representação fotojornalística das deputadas portuguesas no "parlamento paritário" e nas discussões da lei da paridade.» Media \& Jornalismo 11(21): 77-127.

CNE - Comissão Nacional de Eleiç̃es. s.d. «Violação da Lei da Paridade.» Disponível em http:/ / www.cne.pt/ content/violacao-da-lei-da-paridade [Consultado em 16 de outubro de 2020].

Costa, Edna Sofia. 2010. «Os Caminhos do Poder no Feminino.» Dissertação de Mestrado. Lisboa: Universidade Nova de Lisboa.

DP - Debates Parlamentares. 1999. «Proposta de Lei n. ${ }^{\circ}$ 194/VII.» Disponível em https:// debates.parlamento.pt/catalogo/r3/ dar/s2a / 07 / 04/042/1999-03-06/1111?pgs=11111112\&org=PLC [Consultado em 20 de outubro de 2020].

DR - Diário da República n. ${ }^{\circ}$ 86/1976, Série I de 10 de abril. «Decreto da aprovação da Constituição de 10 de Abril.» Disponível em https: / / files.dre.pt/1s/1976/04/08600/ 073807 75.pdf [Consultado em 04 de novembro de 2021]. 
DR - Diário da República n. ${ }^{\circ}$ 218/1997, Série I-A de 20 de setembro. «Lei Constitucional n. ${ }^{\circ}$ 1/97.» Disponível em https: / / dre.pt/dre/detalhe/lei-constitucional/1-1997-653 562 [Consultado em 04 de novembro de 2021].

DR - Diário da República n. ${ }^{\circ}$ 188/2001, Série I-A de 14 de agosto. «Lei Orgânica n. ${ }^{\circ}$ 1/2001.» Disponível em https: / / dre.pt/dre/detalhe/lei-organica/1-2001-524039 [Consultado em 04 de novembro de 2021].

DR - Diário da República n. ${ }^{\circ}$ 165/2005, Série I-A de 29 de agosto. «Lei n. ${ }^{\circ}$ 46/2005.» Disponível em https: / / dre.pt/ dre/ detalhe/lei/46-2005-245301 [Consultado em 04 de novembro de 2021].

DR - Diário da República n. ${ }^{\circ}$ 160/2006, Série I de 21 de agosto. «Lei Orgânica n. ${ }^{\circ}$ 3/2006.» Disponível em https: / / dre.pt/dre/detalhe/lei-organica/3-2006-540469 [Consultado em 04 de novembro de 2021].

DR - Diário da República n. ${ }^{\circ}$ 180/2013, Série II de 18 de setembro. «Acórdão n. ${ }^{\circ}$ 480/2013.» Disponível em https: / / dre.pt/dre/detalhe/acordao/480-2013-1340146 [Consultado em 04 de novembro de 2021].

DR - Diário da República n. ㅇ 84/2017, Série I de 02 de maio. «Lei Orgânica n. ${ }^{\circ}$ 1/2017.» Disponível em https:/ / dre.pt/dre/detalhe/lei-organica/1-2017-106955047 [Consultado em 04 de novembro de 2021].

DR - Diário da República n. ${ }^{\circ}$ 63/2019, Série I de 29 de março. «Lei Orgânica n. ${ }^{\circ}$ 1/2019.» Disponível em https:/ / dre.pt/dre/detalhe/lei-organica/1-2019-121712770 [Consultado em 04 de novembro de 2021].

Espada, Isabel. 2002. Género e comportamento eleitoral - o eleitorado português e a actividade política das mulheres. Lisboa: Instituto de Estudos para o Desenvolvimento.

Espírito-Santo, Ana, e Maria Helena Santos. 2017. «The implementation of gender quotas across different levels of government: The case of Portugal.» Comunicação apresentada no 5th European Conference on Politics and Gender, Lausanne, 8-10 de junho.

Freidenvall, Lenita, e Drude Dahlerup. 2013. Electoral Gender Quota Systems and their Implementation in Europe. Update 2013. Bruxelles: European Parliament. Disponível em https: / / www.europarl.europa.eu / RegData / etudes / note / join/ 2013 / 493011 / IPOLFEMM_NT(2013)493011_EN.pdf [Consultado em 18 de outubro de 2020].

Holman, Mirya, R. 2017. «Women in Local Government: What We Know and Where We Go from Here.» State and Local Government Review:1-12.DOI: https: / / doi.org / 10.1177 / 0160 $323 \times 17732608$

IPU - Inter-Parliamentary Union. 2019. «Parliaments. Portugal.» Disponível em https:/ / www.ipu.org/parliament/PT [Consultado em 20 de outubro de 2021].

IPU - Inter-Parliamentary Union. 2020. «Women in Politics: 2020.» Disponível em https: / / www.ipu.org/ resources / publications / infographics / 2020-03/women-in-politics2020 [Consultado em 19 de julho de 2020].

Jordão, Albertina. 2000. «Protagonistas do poder local: obstáculos e oportunidades.» ex aequo, 2/3:117-123.

Jordão, Albertina. 2003. «Elites discriminadas da democracia local. Representação política das mulheres nas autarquias da Grande Lisboa - uma evolução inexpressiva.» Dissertação de Mestrado. Lisboa: Universidade Aberta.

Jordão, Albertina. 2019. «Eleições Autárquicas - 40 Anos de Poder Local. Tantos Lugares e Tão Poucas Mulheres.» In Mulheres e Eleições, organizado por Ana Pires, Fátima Mariano e Ivo Veiga, 169-193. Coimbra: Almedina.

Lisboa, Manuel, Maria Graça Frias, Ana Dantas, e Dalila Cerejo. 2006. «Participação das mulheres nas elites politicas e económicas no Portugal democrático (25 de Abril de 1974 a 2004).» Revista da Faculdade de Ciências Sociais e Humanas 18: 163-187. 
Lopes, Ana Maria. 2009. «Desigualdades de género no poder local: duas autarquias em estudo.» Dissertação de Mestrado. Coimbra: Universidade de Coimbra.

Maciel, Diana. 2008. «Género e poder local.» Dissertação de Mestrado. Lisboa: ISCTE-Instituto Universitário de Lisboa.

Martins, Isabel Maria. 2011. «Participação Política das Mulheres nos Órgãos Executivos Camarários do Distrito de Viseu - 2005/2010. Contributos da Lei da Paridade.» Dissertação de Mestrado. Coimbra: Instituto Superior Miguel Torga.

Melo, Helena Pereira. 2017. Os Direitos das Mulheres no Estado Novo. A Segunda Guerra Mundial. Coimbra: Almedina.

Mendes, Maria Manuela. 1993. «As elites políticas num concelho da Área Metropolitana do Porto.» Sociologia, Problemas e Práticas 14: 177-198.

Miranda, Jorge, Maria Leonor Beleza, Maria Lúcia Amaral, Maria Luísa Duarte, e Vital Moreira. s.d. Trabalho Efectuado Sobre O Art. ${ }^{\circ} 109$ da CRP. Lisboa: FDUNL.

Monteiro, Rosa. 2011. «A Política de Quotas em Portugal: O papel dos partidos políticos e do feminismo de Estado.» Revista Crítica de Ciências Sociais 92: 31-50. DOI: https: / / doi. org $/ 10.4000 /$ rccs.3953

Moreira, Vital. 1998. «O artigo 109. ${ }^{\circ}$ da CRP e a igualdade de homens e mulheres no exercício de direitos cívicos e políticos.» In Democracia com mais Cidadania: a Questão da Igualdade de Participação Política, organizado por Vitalino Canas et al., 47-64. Lisboa: Presidência Conselho Ministros - INCM.

Nunes, Pedro. 2008. «Participação das mulheres na política autárquica em Portugal nos últimos 25 anos (1982 a 2005): especial relevo para as mulheres eleitas apuradas para a presidência dos órgãos.» Revista Enfoques: Ciencia Política y Administración Pública VI(9): 11-34.

OMC - Organização das Mulheres Comunistas. 2003. As Mulheres e o Poder Local. Lisboa: Edições Avante.

ONU - Organização das Nações Unidas. 2017. Work of the Statistical Commission pertaining to the Agenda for Sustainable Development. Disponível em https:// documents-dds-ny. un.org/doc/UNDOC/GEN/N17/207/63/PDF / N1720763.pdf?OpenElement [Consultado em 20 de outubro de 2020].

ONU - Organização das Nações Unidas. 2019. The Sustainable Development Goals Report 2019. Disponível em https: / / unstats.un.org/sdgs/report/2019/The-Sustainable-Development-Goals-Report-2019.pdf

PE - Parlamento Europeu. 2019. «Deputados.» Disponível em http: / /www.europarl.europa. $\mathrm{eu} / \mathrm{meps} / \mathrm{pt} / \mathrm{search} /$ advanced [Consultado em 20 de outubro de 2021].

Pequito Teixeira, Maria da Conceição. 2009. O Povo Semi-Soberano. Partidos Políticos e Recrutamento Parlamentar em Portugal (1990-2003). Coimbra: Almedina.

Perista, Heloísa, e Alexandra Silva. 2008. Igualdade de género na vida local: o papel dos municípios na sua promoção. Lisboa: CIG.

Santos, Maria Helena. 2010. "Género e Política: Factores Explicativos das Resistências à Igualdade.» Tese de Doutoramento. Lisboa: ISCTE-Instituto Universitário de Lisboa.

Santos, Maria Helena, e Lígia Amâncio. 2012. «Género e Política. Análise sobre as resistências nos discursos e nas práticas sociais face à Lei da Paridade.» Sociologia, Problemas e Práticas (68): 79-101.

Santos, Maria Helena, Ana Lúcia Teixeira, e Ana Espírito-Santo. 2018. «Balanço da implementação da Lei da Paridade em diferentes níveis de governo - Análise longitudinal.» Lisboa: CIG e Secretaria de Estado para a Cidadania e a Igualdade.

Saraiva, Ana Paula. 2014. «Liderança Feminina no Poder Político Local em Portugal: Representações, Media e Visibilidade.» Dissertação de Mestrado. Lisboa: Universidade Nova de Lisboa. 
Saraiva, Ana Paula. 2017. «Liderança política no feminino: As presidentes de câmara no poder local em Portugal.» Faces de Eva. Estudos sobre a Mulher 37: 41-61.

Silvestre, Hugo Consciência, e Maria João Cunha Silvestre. 2012. «A área, o tema e o problema de pesquisa como factores determinantes do processo de investigação.» In Metodologia para a Investigação Social, organizado por Hugo Consciência Silvestre e Joaquim Filipe Araújo, 35-62. Lisboa: Escolar Editora.

Sineau, Mariette. 2003. Genderware - the Council of Europe and the participation of women in political life. Strasbourg: Council of Europe.

Tavares, Sónia, Maria João Rodrigues, e João Feijó da Silva. 2016. «Perfil do Autarca - Caracterização dos Eleitos Locais.» Lisboa: MAI/SGMAI Secretaria Geral.

Teixeira, Ana Lúcia. 2016. «Desigualdades de género nos cargos políticos em Portugal: do poder central ao poder local.» Tese de Doutoramento. Lisboa: Universidade Nova de Lisboa.

Torres, Anália. 2016. «Por que precisamos de Estudos de Género, Feministas e Estudos sobre as Mulheres?» Disponível em http:/ / www.analiatorres.com/images/untitled $\%$ 20folder / Anália \%20Torres \%20-\%20Por\%20que\%20precisamos $\% 20$ de $\%$ 20estudos $\% 20$ de\% 20género.pdf [Consultado em 18 de julho de 2021].

Viegas, Beatriz Isabel. 2016. «Estudo sobre o Processo de Implementação da Lei da Paridade em Portugal. O Partido Socialista e as Eleições Autárquicas de 2013.» Dissertação de Mestrado. Lisboa: ISCTE - Instituto Universitário de Lisboa.

Viegas, José, e Sérgio Faria. 2001. As Mulheres na Política. Oeiras: Celta Editora. 


\section{ANEXO}

Tabela 1

Número e percentagem de mulheres eleitas presidentes de Câmara por distrito de norte para sul (1976-2017)

\begin{tabular}{|c|c|c|c|c|c|c|c|c|c|c|c|c|c|}
\hline $\begin{array}{l}\text { Distritos/ } \\
\text { Regiões } \\
\text { Autónomas }\end{array}$ & ڤొ & ๙ิ & 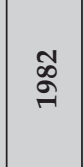 & $\begin{array}{l}\mathscr{L} \\
\stackrel{2}{=}\end{array}$ & $\begin{array}{l}\stackrel{2}{\circ} \\
\text { }\end{array}$ & รั & बे & ర్తి & 옹 & ठ્సે & 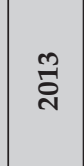 & 홍 & 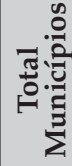 \\
\hline Viana do Castelo & & & & & & & & 1 & 1 & 1 & & & 3 \\
\hline Braga & & & & & & & & & & & & & 0 \\
\hline Vila Real & & & & & & & & & & & & & 0 \\
\hline Bragança & & & & & & & & & & 1 & 2 & 3 & 6 \\
\hline Porto & & & & & & 1 & 2 & 2 & 1 & 1 & 1 & 3 & 11 \\
\hline Aveiro & 3 & 2 & 2 & 1 & 1 & & & & & & 1 & 2 & 12 \\
\hline Viseu & & & & & & & & & 2 & 1 & & & 3 \\
\hline Guarda & & & & & & & 1 & 1 & & & & & 2 \\
\hline Coimbra & 1 & & & & & & & 1 & 1 & 2 & 1 & 2 & 8 \\
\hline Castelo Branco & & & & & 1 & 1 & 1 & 2 & 2 & 2 & & & 9 \\
\hline Leiria & & & & & & & 1 & 1 & 1 & & & 3 & 6 \\
\hline Santarém & 1 & 1 & 1 & 1 & 1 & & 1 & 1 & 1 & 4 & 5 & 4 & 21 \\
\hline Portalegre & & & & & & & & 1 & 1 & 2 & 3 & 3 & 10 \\
\hline Lisboa & & & 1 & & & 1 & 2 & 1 & 2 & 2 & 2 & 1 & 12 \\
\hline Setúbal & & & & 1 & 2 & 2 & 2 & 3 & 3 & 4 & 1 & 2 & 20 \\
\hline Évora & & 1 & 1 & & & & & & & & 4 & 3 & 10 \\
\hline Beja & & & & & & & & & & & & & 0 \\
\hline Faro & & & & & & & 1 & 1 & 1 & 1 & 3 & 4 & 11 \\
\hline Madeira & & & & & & & & & & & & 1 & 1 \\
\hline Açores & & & 1 & 1 & & & & 1 & 3 & 2 & & 1 & 9 \\
\hline Total Portugal & 5 & 4 & 6 & 4 & 5 & 5 & 12 & 16 & 19 & 23 & 23 & 32 & 154 \\
\hline Mandatos & 304 & 305 & 305 & 305 & 305 & 305 & 305 & 308 & 308 & 308 & 308 & 308 & \\
\hline$\%$ Mulheres & $1,6 \%$ & $1,3 \%$ & $2,0 \%$ & $1,3 \%$ & $1,6 \%$ & $1,6 \%$ & $3,9 \%$ & $5,2 \%$ & $6,2 \%$ & $7,5 \%$ & $7,5 \%$ & $10,4 \%$ & \\
\hline
\end{tabular}

Fonte: Elaboração própria, a partir de dados enviados pela DGAI/SGMAI 
Ana Ribeiro. Doutoranda na primeira edição (2018/2019) do Doutoramento em Estudos de Género (UNL e UL), desenvolve tese sobre liderança política das mulheres no Governo local para aprofundar pesquisa iniciada no mestrado em Comunicação, Media e Justiça (UNL), altura em que assinava Ana Paula Saraiva. Desde 2017, é investigadora no CICS.NOVA (Centro Interdisciplinar de Ciências Sociais da Faculdade de Ciências Sociais e Humanas da Universidade Nova de Lisboa).

Artigo recebido a 23 de novembro de 2020 e aceite para publicação em 3 de junho de 2021. 


\title{
QUANDO O POUCO NÃO CHEGA A MUITAS: ANÁLISE INICIAL DA DISTRIBUIÇÃO DOS RECURSOS PÚBLICOS DE CAMPANHA PARA A CÂMARA DOS DEPUTADOS EM 2018 NO BRASIL
}

\author{
Maria Cecília Eduardo* \\ (1) https: / / orcid.org/ 0000-0001-8115-9993 \\ Juliana Inez Luiz de Souza* \\ (D) https: / / orcid.org/ 0000-0003-1361-3159
}

\section{Resumo}

A baixa presença feminina nos cargos eletivos é um problema persistente das democracias representativas. Nesse processo complexo que envolve uma série de fatores, o acesso aos recursos financeiros aparece como uma das principais barreiras enfrentadas pelas mulheres. Com o intuito de amenizar essa dificuldade, recursos públicos de campanha são por lei direcionados às candidatas; porém, a distribuição dos montantes fica a cargo das lideranças partidárias. A análise distributiva apresentada neste artigo, com base no índice de Gini, mostra que os partidos concentram os recursos em poucas mulheres, deixando de estimular uma maior participação feminina e visando apenas a maximização de ganhos de cadeiras.

Palavras-chave: Participação política feminina, partidos políticos, financiamento de campanha, índice de Gini, Câmara dos Deputados.

\begin{abstract}
When Little Doesn't Come to Many: Analysis of the distribution of public campaign resources for the Brazilian Chamber of Deputies in 2018

The low female presence in elected positions remains a persistent problem for representative democracies. In this complex process that involves a series of factors, access to financial resources appears as one of the main barriers faced by women. In order to alleviate this difficulty, public campaign resources are, by law, directed to female candidates, but the distribution of the amounts is in the hands of the party leaders. The distributive analysis presented in this article, based on the Gini index, shows that parties concentrate resources on a few women, failing to encourage greater female participation and aiming only at maximizing seat gains.
\end{abstract}

Keywords: Female political participation, political parties, campaign financing, Gini index, Chamber of Deputies.

\footnotetext{
* $\quad$ Universidade Federal do Paraná (UFPR), Curitiba, Brasil.

Endereço postal: Universidade Federal do Paraná, 80060-150, Curitiba, PR, Brasil.

Endereço eletrónico: mariaceciliaedu@ufpr.br

** Universidade Federal do Paraná (UFPR), Curitiba, Brasil.

Endereço postal: Universidade Federal do Paraná, 80060-150, Curitiba, PR, Brasil.

Endereço eletrónico: jils@ufpr.br
} 


\begin{abstract}
Resumen
Cuando poco no llega a muchas: Análisis de la distribución de recursos de campañas públicas para la Cámara de Diputados en 2018 en Brasil

La escasa presencia femenina en cargos electos sigue siendo un problema persistente para las democracias representativas. En este complejo proceso que involucra una serie de factores, el acceso a los recursos financieros aparece como una de las principales barreras que enfrentan las mujeres. Para paliar esta dificultad, los recursos de las campañas públicas están, por ley, dirigidos a las candidatas, pero la distribución de los montos está a cargo del liderazgo de los partidos. El análisis distributivo presentado en este artículo, basado en el índice de Gini, muestra que los partidos concentran recursos en unas pocas mujeres, sin fomentar una mayor participación femenina y apuntando solo a maximizar la ganancia de escaños.
\end{abstract}

Palabras clave: Participación política femenina, partidos políticos, financiamiento de campañas, índice de Gini, Cámara de Diputados.

\title{
1. Introdução
}

A IV Conferência Mundial sobre a Mulher, em Pequim, colocou em pauta a discussão sobre a escassa presença (ou quase ausência) das mulheres nos espaços de tomada de decisão. Nessa conferência, realizada em setembro de 1995, foi firmada a Declaração de Pequim, assinada por 184 governos participantes, que se comprometeram a adotar medidas efetivas para o combate às discriminações e desigualdades relativas às mulheres. Esse evento alertou as lideranças globais para a importância da participação feminina em condições de igualdade nos processos decisórios como uma exigência básica de justiça e democracia, e também como uma condição necessária para que os interesses desse grupo sejam levados em consideração (Frossard 2006, 151-258).

É possível perceber que, durante esses 26 anos, tivemos um avanço no acesso das mulheres aos cargos eletivos. $O$ percentual de cadeiras parlamentares ocupadas por elas passou de 11,7\%, em 1996 (IPU 1997), para 25,5\%, em 2021 (IPU 2021). Porém, esse avanço não tem se dado de maneira uniforme entre os países. Se pensarmos na América Latina, por exemplo, 26,2\% da composição dos parlamentos é feminina. Mas, se fizermos o recorte para o Brasil, apenas 15,2\% do Congresso é composto por mulheres, fato que faz o país ocupar a posição número 140 no ranking referente à maior representatividade de mulheres em cargos eletivos. Os cinco países que encabeçam a lista são: Ruanda, Cuba, Emirados Árabes, Nova Zelândia e México (IPU 2021).

Sabemos com certeza que a desigualdade de gênero na política é um fenômeno complexo que envolve uma série de fatores culturais, socioeconômicos e institucionais que agem de maneira combinada, resultando em diferentes cenários. Muitas pesquisas apontam que, entre as barreiras estruturais, a falta de financiamento é o maior impedimento da entrada feminina nas elites políticas 
(Burrel 1985; Sacchet e Speck 2012a; Speck e Mancuso 2014; Fraga e Hassell 2020; Janusz, Barreiro e Cintron 2021). Tal percepção é compartilhada pelas candidatas que colocam a falta de investimento em suas campanhas como um fator que diminui significativamente suas chances eleitorais (Sacchet e Speck 2012a; Carroll e Sanbonmatsu 2013).

Procurando amenizar essa dificuldade enfrentada pela grande maioria das mulheres, o Supremo Tribunal Federal (STF) determinou que os partidos políticos devem conceder no mínimo 30\% do total recebido do Fundo Especial de Financiamento de Campanha (FEFC) às candidaturas femininas. Isto foi incluído no artigo 17 da Resolução do Tribunal Superior Eleitoral (TSE) no 23.607, que «[d]ispõe sobre a arrecadação e os gastos de recursos por partidos políticos e candidatos e sobre a prestação de contas nas eleições» (TSE 2019). A mesma Resolução, em seu artigo 19, estende a regra para os recursos do Fundo Partidário, quando destinados a campanhas.

Apesar de a destinação desse dinheiro público ter como intuito a promoção de mais mulheres nos cargos eletivos, a distribuição desses recursos fica a cargo das direções nacionais dos partidos, não havendo nenhuma diretriz que indique como esse montante deve ser dividido. Nesse sentido, este artigo busca entender em que medida os partidos políticos utilizam a distribuição de recursos financeiros como um meio de seleção informal de candidaturas que acaba por minar o fomento da participação política feminina.

Para isso, utilizamos dados da distribuição dos recursos públicos de campanha nas candidaturas para a Câmara dos Deputados, coletados no Repositório de Dados do TSE (TSE 2021). Por meio de técnicas de estatística descritiva e do índice de Gini, observamos que as campanhas analisadas apresentam um perfil concentrado, sem diferença entre os grupos, tanto de homens quanto de mulheres, de todos os partidos. Mas ao focarmos nos partidos que mais elegeram mulheres, vemos o peso dos fundos públicos nas campanhas femininas e como esse recurso ficou concentrado em poucas candidaturas, especialmente em quatro dos seis partidos que mais elegeram mulheres (PT, PSDB, PR e PP).

Colocadas essas informações, na próxima seção, apresentamos uma breve discussão da importância da participação política das mulheres. Na sequência, abordamos a relação entre os recursos financeiros e o desempenho eleitoral. Na terceira seção, propomos a utilização do índice de Gini como forma de mensurar a distribuição de recursos feita pelos partidos políticos, mencionando também a centralidade que esses atores ocupam na dinâmica eleitoral feminina. Passamos então para a apresentação e discussão dos resultados obtidos e finalizamos com nossas considerações. 


\section{Importância da participação política feminina}

A participação das mulheres nos processos políticos, especialmente como candidatas, é uma indicação-chave do progresso em direção a formação de governos mais inclusivos e democráticos, sendo considerada um indicador da força de um determinado sistema democrático ou organização política (Cigane e Ohman 2014). Sendo assim, é necessária a inclusão de membros de diversos grupos sociais nas arenas de decisão política, para que as Casas Legislativas sejam compostas por perfis e preferências representativas da diversidade dos países.

Teóricos como Robert Dahl (1989) e Arend Lijphart (1999) consideram a inclusão política feminina como um dos indicadores da qualidade democrática de uma nação, e a ausência desse grupo nas esferas de tomada de decisão como o maior ponto falho das democracias representativas. Isso porque, na maioria esmagadora dos países, as mulheres representam mais de 50\% do eleitorado, como é o caso do Brasil (Vieira 2020) e dos Estados Unidos da América (G1 2020). Logo, não seria estranho esperarmos que a participação desse grupo nos cargos eletivos girasse em torno desse percentual, o que não acontece. E é justamente essa discrepância entre a composição do eleitorado e do perfil do grupo que ocupa grande parte dos assentos nos parlamentos (Kist e Tanji 2015) que denuncia um limite claro das democracias ditas representativas.

A representação política pode ser basicamente entendida como descritiva, relacionada à identidade de quem ocupa o cargo, ou como substantiva, ligada ao conteúdo dos temas que são apresentados nos espaços decisórios (Pitkin 1967; Phillips 1995; Santos, Cerqueira e Cruz 2017). Trabalhando com a representação no seu sentido descritivo, entendemos que os espaços representativos deveriam funcionar como microcosmo da sociedade, sendo uma amostra da população. E que a proposta de adoção de mecanismos institucionais que possam criar mais espaços representativos para certos grupos historicamente excluídos, além de válida, é essencial (Mansbridge 1999).

Não ignoramos que a representação descritiva não garante uma lógica entre as vontades dos/as representantes e as dos/as representados/as, como bem coloca Pitkin (1967). Porém, podemos considerá-la um passo importante do processo, lembrando que ambos os tipos de representação, descritiva e substantiva, não são excludentes, mas sim complementares na busca de um sistema mais justo, que incorpore a presença e as ideias de diferentes grupos sociais (Phillips 1995).

Em suma, a severa sub-representação política feminina não só limita a diversidade dos parlamentos, como também contradiz um dos princípios da democracia representativa (Caul 1997). Robert Dahl (2009) afirma que, além da igualdade de voto, a democracia pressupõe igualdade de influência do processo decisório. E nesse sentido, o acesso aos recursos financeiros é um fator para maiores chances de sucesso eleitoral (Arraes, Amorim Neto e Simonassi 2017) e, consequentemente, de ingresso nas instâncias de tomada de decisão. 


\section{Acesso a recursos financeiros e desempenho eleitoral}

Assim como a participação política feminina, a relação entre dinheiro e política é um tema delicado que ganha destaque nas pautas editoriais dos mais diversos meios de comunicação, debates legislativos e também nas agendas de pesquisas acadêmicas. Segundo Zovatto (2005), o financiamento político se tornou uma questão estratégica de toda a democracia e, devido à sua complexidade, também se transformou em uma «verdadeira dor de cabeça».

A busca pelo voto em eleitorados cada vez maiores exige uma mobilização de dinheiro que permita aos partidos políticos se estruturarem, manterem-se ativos permanentemente, relacionarem-se com a sociedade civil e promoverem suas campanhas eleitorais. Sendo assim, os recursos financeiros são essenciais para as dinâmicas democráticas atuais, como é o caso das eleições (Nassmacher 2009).

Em relação a esse último ponto, a literatura da Ciência Política tem mostrado o financiamento como um dos principais fatores para explicar o sucesso eleitoral das candidaturas (Lemos, Marcelino e Pederiva 2010; Speck e Mancuso 2013; Mancuso e Figueiredo Filho 2014; Mancuso 2015; Horochovski et al. 2016). Analisando essas investigações, vemos que as campanhas políticas ficam cada vez mais caras, exigindo um maior aporte de dinheiro para maiores chances eleitorais. Todavia, precisamos frisar que a relação entre dinheiro e voto também é complexa e sofre a atuação de outros fatores como, por exemplo, dos capitais político, social e familiar.

Quando analisamos o peso do financiamento de campanha na participação política feminina, notamos a existência de um desequilíbrio no acesso aos recursos financeiros entre candidatos e candidatas, o qual precisa ser amenizado para que as mulheres tenham mais chances eleitorais (Sacchet e Speck 2012b; Araújo 2013; Eduardo 2018; Sacchet 2018; Barbieri et al. 2019). Isto porque, apesar da falta de recursos afetar tanto homens quanto mulheres, estas comandam uma proporção menor dos recursos financeiros mundiais (Doss, Grown e Deere 2008) e possuem um acesso limitado às redes e grupos de financiadores (Ballington e Kahane 2015; Sacchet 2009).

Nesse sentido, os fundos eleitorais, principalmente aqueles provenientes do dinheiro público, podem ser um elemento central para uma política de igualdade, tanto da perspectiva do direito do eleitorado, de poder tomar uma decisão informada sobre em quem irá votar, quanto dos representantes, de terem a possibilidade de fazer contato com o público e assim poderem explicar suas plataformas e propostas (Sacchet 2018). Uma vez que a distribuição equilibrada de recursos entre os partidos é um ponto-chave para a qualidade das competições democráticas (Sartori 1992), o mesmo se aplica à paridade entre os gastos de campanha de homens e mulheres que competem por um cargo eletivo (Sacchet e Speck 2012b).

Dentro dessa dinâmica distributiva, os partidos políticos assumem um papel central, ficando a cargo das lideranças partidárias a decisão de como e para quais candidaturas os recursos serão direcionados. Sendo assim, para um melhor enten- 
dimento da participação política das mulheres, precisamos observar como os partidos se comportam em relação a esse grupo.

\section{Ação partidária na dinâmica eleitoral feminina, recrutamento, cotas e a distribuição desigual dos recursos financeiros}

Atores centrais nas dinâmicas políticas, os partidos políticos atuam como gatekeepers dos cargos eleitorais, uma vez que recrutam e selecionam as candidaturas, moldando a composição do grupo de eleitos (Janusz, Barreiro e Cintron 2021; Norris e Lovenduski 1995). Eles comandam as campanhas, podendo facilitar o acesso aos recursos financeiros, seja de doadores ou do próprio partido. Podem também disponibilizar apoio profissional nas disputas, informações sobre o processo eleitoral e sobre os adversários, além de conceder tempo de exposição midiática (Sacchet e Speck 2012b; Janusz, Barreiro e Cintron 2021).

Em relação ao recrutamento, existe uma vasta literatura que aponta uma clara preferência pela nomeação de homens, que aconteceria devido à tendência das elites partidárias, majoritariamente masculinas, de recrutarem perfis semelhantes aos seus (Lawless e Fox 2010; Sanbonmatsu 2006; Hinojosa 2012; Sacchet e Speck 2012a; Crowder-Meyer 2013; Butler e Preece 2016).

Com o intuito de alterar esse cenário buscando um aumento direto da participação feminina, surge a política de cotas que obriga os partidos a nomearem um percentual mínimo de mulheres em suas listas de candidaturas. Esse mecanismo, atualmente adotado em alguma medida por 128 países em suas eleições legislativas (IDEA 2020), levou a um aumento no número de candidatas, como esperado. Porém, seu efeito sobre o número de eleitas, além de variar significativamente entre os Estados, ainda não atingiu o resultado almejado em grande parte das democracias representativas, como é o caso brasileiro (Bjarnegård e Zetterberg 2019; Hinojosa e Vazquez 2018; Sacchet 2018).

A eficácia das cotas está relacionada a arranjos institucionais que podem promover ou retardar o aumento no número de mulheres legisladoras, como o tipo de sistema eleitoral e o tipo de lista na qual as cotas são aplicadas, o tamanho das cotas, ou seja, o percentual mínimo reservado a um dos sexos, e a existência e a força de mecanismos de enforcement, ou sanções para os partidos que não cumpram a lei (Schwindt-Bayer 2009; Eduardo, Souza e Angeli 2019).

Nesse sentido, muitas pesquisas têm mostrado a debilidade dos partidos no cumprimento das cotas, devido, principalmente, a brechas nas leis que possibilitam essa atitude sem grandes (ou até mesmo nenhuns) danos (Hinojosa e Piscopo 2013; Wylie e dos Santos 2016; Bjarnegård e Zetterberg 2019; Gatto e Wylie 2021). Além da dificuldade do preenchimento da lista com um percentual mínimo obrigatório de mulheres, quando esse requisito é cumprido, ainda pode acontecer uma outra manobra partidária que seria a nomeação de candidatas somente para o 
preenchimento das cotas, as chamadas «candidaturas laranjas». Lembramos que os homens também podem ser enquadrados nesse tipo de manobra, porém o percentual de casos é muito menor nesse grupo (Wylie, dos Santos e Marcelino 2019).

Outra medida que tem o objetivo de aumentar a participação feminina na política é a alteração da Lei dos Partidos Políticos feita em 2009 (Art. 44, inciso 5). Ela define que no mínimo 5\% do total do Fundo Partidário deve ser destinado para a «criação e manutenção de programas de promoção e difusão da participação política das mulheres» (Brasil 1995). O intuito é não apenas promover a participação feminina nos processos eleitorais, mas também nas estruturas e instâncias dos partidos mudando seu carácter predominantemente masculino. Mas esta medida perdeu sua força 10 anos após sua aprovação, com a lei que anistiou os partidos que não cumpriram o valor mínimo determinado, deixando em torno de $\mathrm{R} \$ 70$ milhões sem serem investidos na formação de mulheres (Nexo 2019).

Além dessas atitudes, que indicam uma ausência de compromisso dos partidos com o fomento da participação política feminina, outra ação partidária danosa às mulheres é a distribuição desigual dos recursos financeiros entre os gêneros dentro dos partidos (Sacchet e Speck 2012a; Sacchet 2018; Janusz, Barreiro e Cintron 2021). A alocação desses recursos fica a cargo das lideranças partidárias (Janusz, Barreiro e Cintron 2021), ou seja, são elas que escolhem para quais campanhas o dinheiro será direcionado.

Esse fato ganha mais peso no cenário das eleições de 2018 no Brasil, em que grande parte do montante utilizado nos pleitos foi proveniente de fontes públicas, ficando as elites partidárias livres para administrarem o dinheiro da maneira mais conveniente, com uma exceção - o direcionamento de um percentual mínimo de $30 \%$ dos fundos públicos para as candidaturas femininas. A Resolução do Tribunal Superior Eleitoral n. ${ }^{\circ} 23.607$ (TSE 2019) não possui uma diretriz que indique como esse valor deve ser dividido, ficando a distribuição desses recursos a cargo das direções nacionais dos partidos.

Para observarmos como os partidos realizaram a divisão dos fundos públicos de campanha, ou seja, do Fundo Especial de Financiamento de Campanha (FEFC) e do Fundo Partidário, construímos um banco com os dados disponíveis no Repositório de Dados do TSE (TSE 2021). Nele, foram coletadas informações referentes às declarações individuais de 8.588 candidaturas aptas, para a Câmara dos Deputados, no ano de 2018. Esse grupo foi composto de 2.767 mulheres (32\%) e 5.821 homens (68\%), distribuídos em 35 partidos. Nesses dados, estabelecemos um recorte dos partidos que mais e menos elegeram parlamentares mulheres para averiguar como distribuíram os recursos públicos de campanha dentro de suas listas partidárias. Usamos como ferramenta de mensuração o índice de Gini, que mede o grau de concentração de renda em determinado grupo (Wolffenbüttel 2004). Seu valor varia de zero a um, sendo que quanto mais próximo de zero, mais igualitário é o cenário. Ao contrário, quanto mais próximo de um, maior a desigualdade de distribuição, ou seja, maior é a concentração. 
Na próxima seção, apresentamos um breve panorama dos montantes públicos mobilizados nas eleições de 2018 para a Câmara dos Deputados, juntamente com o desempenho partidário na distribuição desses recursos, com a utilização do índice de Gini.

\section{Resultados}

Nas eleições de 2018, a quantia de dinheiro público destinado para o financiamento de campanhas foi de $\mathrm{R} \$ 2,5$ bilhões. Este valor foi dividido, ficando a maior parte com o FEFC, pouco mais de R \$ 1,7 bilhão, e o valor remanescente, de aproximadamente R\$ 800 milhões, para o Fundo Partidário. É importante destacar que nesse pleito a maior fonte de dinheiro foram os recursos públicos, visto que a Lei $n^{\circ} 13.165$ (Brasil 2015) já estava em vigor, não permitindo doações de pessoas jurídicas. Os dados obtidos nas declarações de receita das candidaturas em disputa para os cargos da Câmara do Deputados mostram que, do valor total declarado, a parte oriunda dos fundos públicos corresponde a $76 \%$.

\section{Gráfico 1}

Tipos de recursos das declarações de receita das candidaturas para a Câmara do Deputados (2018)

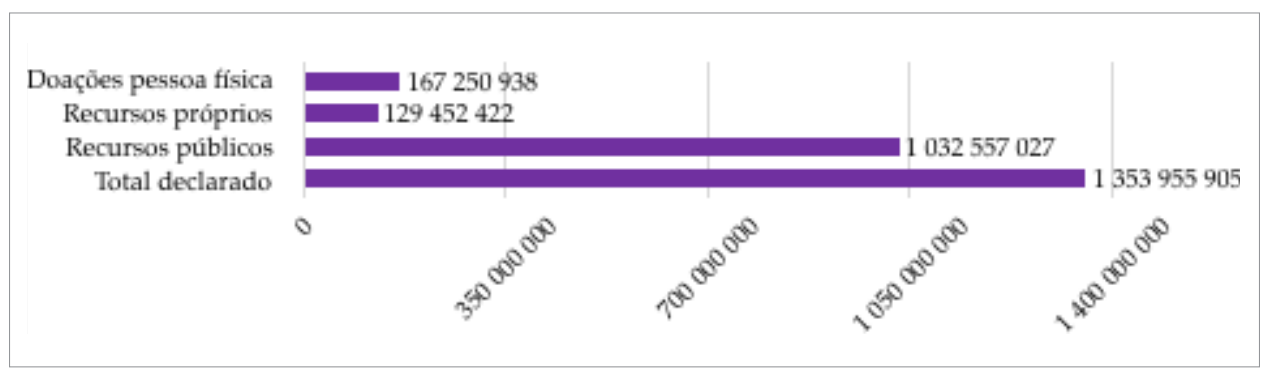

Fonte: Elaboração das autoras com base no Repositório de dados do TSE (2021).

Ainda antes de passarmos para a análise por partidos, achamos importante frisar que, por meio do uso de técnicas de estatística descritiva, podemos notar diferenças entre as candidaturas femininas e masculinas em relação às fontes da receita declarada. A principal é que mesmo os recursos públicos tendo sido os centrais em ambos os gêneros das candidaturas, no caso das mulheres eles representam aproximadamente $90 \%$ do total arrecadado, enquanto nas declarações dos homens são em torno de $73 \%$. 


\section{Gráfico 2}

Tipos de recursos por sexo das declarações de receita das candidaturas para a Câmara do Deputados (2018)

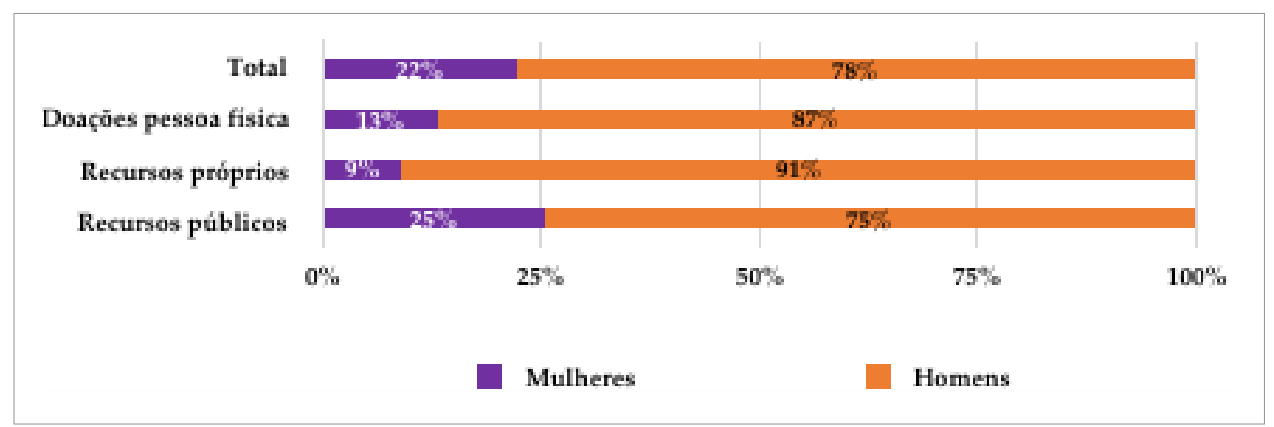

Fonte: Elaboração das autoras com base no Repositório de dados do TSE (2021).

A observação dos dados deixa clara também a diferença de investimento de recursos próprios nas campanhas. No grupo das mulheres, esse tipo de fonte equivale a apenas $4 \%$ do valor total; já no dos homens representa $11 \%$. Este dado é relevante para mostrar a importância e maior centralidade dos recursos públicos para as candidaturas femininas. Isto porque, na quase totalidade dos casos, as mulheres têm menos bens do que os homens (Doss, Grown e Deere 2008). Sacchet e Speck (2012b) também destacam que, no uso da renda, elas tem inclinação para uma visão «familiar» ou mais coletiva, com menos uso dos recursos para fins pessoais. Outro ponto apresentado por Lawless (2015) relacionado ao autofinanciamento é o da auto-seletividade, pois de acordo com a autora elas ainda têm maior tendência para duvidar de suas chances de serem eleitas do que seus pares masculinos.

Optamos por trabalhar com os seis partidos que mais elegeram parlamentares mulheres - PT, PSL, PSDB, PR, PP e PSOL - e os cinco que elegeram ao menos um parlamentar homem e nenhuma mulher - DC, PATRI, PHS, PMN, PPL e PSC ${ }^{1}$. Devido ao grande número de partidos (35), buscamos facilitar a visualização dos dados com essa redução, que se justifica pelo fato de o nosso interesse de análise ser justamente as agremiações que se mostraram mais (in)capazes de promover o acesso feminino aos cargos eletivos.

Partido dos Trabalhadores (PT), Partido Social Liberal (PSL), Partido da Social Democracia Brasileira (PSDB), Partido da República (PR), Progressistas (PP), Partido Socialismo e Liberdade (PSOL), Democracia Cristã (DC), Patriota (PATRI), Partido Humanista da Solidariedade (PHS), Partido da Mobilização Nacional (PMN), Partido Pátria Livre (PPL) e Partido Social Cristão (PSC). 
Elencados os partidos de análise, passamos para a averiguação de como foi feita a distribuição dos recursos públicos de campanha dentro das listas partidárias na competição para a Câmara dos Deputados por meio do índice de Gini. Achamos importante frisar que, no geral, as campanhas analisadas apresentam um perfil concentrado, sem diferença entre os grupos femininos e masculinos, já que o valor do índice de Gini tanto para o grupo de todos os homens de todos os partidos é 0,86 assim como para o grupo das mulheres de todos os partidos. Porém, a análise feita por partidos mostra peculiaridades escondidas pelos números totais.

Quatro dos seis partidos que mais elegeram mulheres apresentam uma concentração na distribuição de recursos dentro desse grupo. No caso do PT, vemos que a diferença é baixa; porém, nos partidos PSDB, PR e PP, podemos notar uma centralização de recursos maior entre as candidatas do que entre os candidatos, indicando que menos mulheres tiveram mais acesso aos recursos públicos. Isto pode nos mostrar que nesses partidos houve menos candidaturas femininas consideradas viáveis, em comparação às masculinas, e também que os partidos pulverizaram menos os seus recursos entre as mulheres do que entre os homens. Lembrando que, como nesse primeiro momento, não estamos analisando o perfil das candidaturas, mas somente fazemos uma leitura da distribuição quantitativa dos fundos públicos, fica fora do nosso debate a estratégia partidária que pode ter sido adotada nessa distribuição.

Já quando analisamos os índices dos partidos que não elegeram mulheres, é interessante notar que nos três casos em que o valor de concentração feminina foi maior que a masculina (DC, PMN e PSC), a diferença entre os gêneros é muito baixa. Ou seja, nesses partidos houve preferência por poucas candidaturas femininas; porém, o mesmo pode ser observado nos casos masculinos, havendo um acesso semelhante aos recursos entre homens e mulheres. Salientamos que o partido Democracia Cristã apresentou uma menor concentração de distribuição geral de fundos públicos que os outros dois citados.

Nessa lógica de análise, apenas o PSOL fica fora ao ter maior concentração de recursos nos homens, porém com o mesmo resultado de candidatas eleitas. Isso pode ser explicado pelos demais capitais eleitorais que têm peso na disputa, para além dos recursos monetários, como é o caso da influência que figuras políticas partidárias podem agregar nos votos do partido.

Salientamos que o índice utilizado, como todo mensurador quantitativo, possui suas limitações e, apesar de contribuir no debate do subfinanciamento feminino nas campanhas, mostra-se insuficiente para uma explicação mais ampla dos resultados eleitorais atingidos pelos partidos analisados, como é o caso das siglas PATRI, PHS e PPL. Apesar de a concentração de recursos ter sido menor no grupo feminino, ou seja, mais mulheres tiveram acesso ao dinheiro público, nenhuma deputada foi eleita. Nesse sentido, seriam necessárias mais informações, como o total do montante destinado para cada grupo e a receita média de cada candidatura, para um melhor entendimento. 
Tabela 1

Índice de Gini dos partidos que mais e menos elegeram parlamentares mulheres em 2018

\begin{tabular}{ccccc}
\hline \multirow{2}{*}{ Partido } & \multicolumn{2}{c}{ Número de eleitas/os } & \multicolumn{2}{c}{ Índice de Gini } \\
\cline { 2 - 5 } & Mulheres & Homens & Mulheres & Homens \\
\hline PT & 10 & 44 & 0,68 & 0,67 \\
\hline PSL & 9 & 43 & 0,86 & 0,94 \\
\hline PSDB & 8 & 21 & 0,75 & 0,64 \\
\hline PR & 6 & 27 & 0,75 & 0,56 \\
\hline PP & 5 & 33 & 0,68 & 0,47 \\
\hline PSOL & 5 & 5 & 0,71 & 0,79 \\
\hline DC & 0 & 1 & 0,67 & 0,64 \\
\hline PATRI & 0 & 5 & 0,82 & 0,93 \\
\hline PHS & 0 & 6 & 0,7 & 0,84 \\
\hline PMN & 0 & 3 & 0,84 & 0,82 \\
\hline PPL & 0 & 1 & 0,6 & 0,79 \\
\hline PSC & 0 & 8 & 0,86 & 0,84 \\
\hline
\end{tabular}

Fonte: Elaboração das autoras com base no Repositório de dados do TSE (2021).

No caso do PSL a situação foi um tanto quanto atípica. O partido teve um salto em sua bancada na Câmara, devido a forte influência do então candidato à Presidência, Jair Bolsonaro. A legenda, que antes possuía um único deputado federal, passou a compor a segunda maior bancada da Casa, com 52 cadeiras (Câmara dos Deputados 2021). Esse impulso dado pela figura de Bolsonaro às competições proporcionais diminuiu o efeito do dinheiro nas mesmas. Isso explicaria o alto número de vagas conquistadas mesmo com um baixo montante de recursos públicos mobilizados na disputa em análise ( $\mathrm{R}$ \$ 5.977.862), em comparação com os demais partidos. O PT e o PSDB, por exemplo, tiveram acesso a R\$ 87.651.338 e R\$ 81.850.296 dessa fonte, respectivamente.

Como já mencionado, esta investigação inicial propõe uma análise da atuação partidária na distribuição de recursos públicos de campanha, porém não aborda os perfis das candidaturas «privilegiadas». No entanto, achamos pertinente ressaltar que, em se tratando da tomada de decisão das lideranças partidárias na alocação de recursos, a preferência por certas candidaturas é muitas vezes explicada pela existência ou não de experiência política prévia (Janusz, Barreiro e Cintron 2021), o que mostra a perpetuação de um ciclo vicioso no qual a maioria esmagadora das mulheres permanece marginalizada. Isto porque a exclusão política feminina, que remonta à história da humanidade, persistindo até mesmo no 
início dos processos democráticos modernos, impossibilitou que esse grupo acumulasse esse capital durante muito tempo ${ }^{2}$.

Isso é mais agravado quando pensamos na utilização de dinheiro público que é investido justamente com o intuito de garantir mais equidade entre aqueles que competem e possuem recursos limitados, como é o caso de grande parte das mulheres. Epstein (1981) já pontuou que as aspirantes a candidatas têm mais dificuldade na obtenção de suporte financeiro e acabam não acessando grandes somas de recursos, ficando marginalizadas nessa rede de distribuição.

Apoiar uma mulher para a eleição, mesmo que seja para um cargo de moderada importância, é geralmente considerado um mau investimento. Os líderes do partido conseguem levantar fundos e adquirir poder, apoiando candidatos vencedores e, em seguida, negociando suas obrigações por meio de patronagem. Uma vez que as mulheres não são vistas como vencedoras, capazes de produzir um retorno àqueles que fizeram algum tipo de investimento, poucos chefes políticos estão dispostos a patrociná-las, exceto quando eles sabem que o investimento não será custoso. (Epstein 1981, 139)

Notamos que passados 40 anos dessa afirmação, a postura partidária em relação às mulheres candidatas se mantém a mesma. Tudo indica que os líderes dos partidos não utilizam os recursos públicos para estimular uma maior participação feminina, mas sim concentram esses valores em poucas candidaturas, sejam de homens ou de mulheres, visando apenas a maximização de ganhos de cadeiras, $\mathrm{o}$ que exemplifica a lógica e influência do jogo político-partidário.

Por fim, é necessário destacar que não se ignora a necessidade de um debate interseccional da participação política feminina, que aprofunde a discussão abordando fatores como a raça, a classe social, a identidade sexual, as diferenças regionais, entre outros. Isso, porém, extrapola os limites propostos por esta investigação inicial, uma vez que os achados prévios relacionados à raça, por exemplo, mostram que homens negros com candidaturas consideradas não competitivas apresentaram uma arrecadação geral menor do que as mulheres negras na mesma condição (Barbieri et al. 2019). O que evidencia como a complexidade desse processo não pode ser explicada apenas com dados quantitativos.

\section{Considerações finais}

A pesquisa buscou agregar dados empíricos para debater a diferença de distribuição de recursos públicos entre as campanhas de homens e mulheres. Partindo do fato de que no Brasil só é possível candidatar-se via partidos políticos, estes,

Mais uma vez salientamos que os dados aqui apresentados não nos permitem afirmar que esse foi o caso nas eleições para a Câmara dos Deputados de 2018. Porém, fica colocada a informação para que num próximo trabalho essa questão possa ser aprofundada. 
além de determinarem os tipos de candidaturas, por meio do recrutamento e da nomeação, agem diretamente na seleção dos perfis que serão eleitos, por meio da distribuição de recursos, vista a forte relação mencionada entre dinheiro e voto. Mesmo com a existência de medidas afirmativas como as cotas, que fazem com que as listas partidárias tenham mais nomeações de mulheres, os partidos continuam sabotando sistematicamente as chances de vitória feminina por não destinarem recursos a essas campanhas.

Sabemos que existem estratégias partidárias de alocação de recursos e que estes não serão distribuídos igualmente entre todas as candidaturas, pois caso o fossem, ficaria praticamente inviável para o partido o acesso aos cargos eletivos. Porém, esta análise inicial mostra que as lideranças partidárias dão mais acesso a diferentes candidaturas masculinas do que às femininas, reforçando o status quo através da exclusão das mulheres desses espaços, tal como apontado pelos estudos de gênero.

O problema é intensificado quando há indícios de que o recurso público que deveria ser investido na garantia de equidade de gênero na política, promovendo a participação de mais mulheres - é usado pelos partidos de forma concentrada apenas em poucas candidaturas que avaliam ter chance de sucesso eleitoral. Isso comprova o que a literatura já aponta, nomeadamente que, no grupo das candidaturas eleitas, não há diferença de arrecadação entre os gêneros: mulheres angariam tanto (ou até mais) recursos financeiros quanto os homens e ocupam uma posição de centralidade na rede de financiamento de campanhas (Junckes et al. 2015; Horochovski et al. 2016). Ou seja, as poucas mulheres que conseguem transpor todos os obstáculos estabelecidos em uma sociedade machista e adentram no campo político, têm uma performance eleitoral muito parecida com a de seus pares masculinos.

A falta de promoção da participação feminina na política é vista não só no período eleitoral, mas também no modus operandi dos partidos pela ausência de campanhas e programas que estimulem e preparem as mulheres para as disputas políticas. Legalmente, as siglas deveriam destinar um mínimo de $5 \%$ dos recursos do Fundo Partidário para essa finalidade (Brasil 1995). Porém, em maio de 2019, entrou em vigor uma lei que anistiou os partidos que não cumpriram com a determinação. $\mathrm{O}$ valor que deixou de ser investido na formação de mulheres foi de aproximadamente $R \$ 80$ milhões (Nexo 2019).

Por fim, destacamos a ainda permanente necessidade de mais pesquisas que desvelem esses padrões que perpetuam a sub-representação de mulheres na política, levantando as diferenças não só entre países, mas também entre partidos. Igualmente importante é a necessidade de as análises agregarem um olhar interseccional em que variáveis como raça, classe, orientação sexual, entre outras, também sejam mobilizadas. Assim como investigações que abordem a atuação partidária no fomento da participação política das mulheres no período anterior às eleições. Entender as dinâmicas internas dessas instituições pode nos ajudar e pensar em 
meios que estimulem uma prática mais inclusiva dentro dos partidos, e também pode funcionar como uma maneira de conscientização das lideranças partidárias para a importância da real integração desse grupo nas esferas de decisão.

\section{Referências bibliográficas}

Araújo, Clara. 2013. «Cotas Femininas e Financiamento de Campanha.» Cadernos ADENAUER 1: 11-30.

Arraes, Ronaldo, Octavio Amorim Neto e Andrei Simonassi. 2017. «Despesas de Campanha e Sucesso Eleitoral nos Pleitos Legislativos Brasileiros.»DADOS - Revista de Ciências Sociais 60(4): 1059-1093. DOI: https: / / doi.org/10.1590/001152582017142

Ballington, Julie e Muriel Kahane. 2015. «Mulheres na política: financiamento para a igualdade de gênero.» In Financiamento de partidos politicos e campanhas eleitorais, um manual sobre financiamento politico, organizado por Elin Falguera, Magnus Ohman e Samuel Jones, 399-451. Rio de Janeiro: FGV Editora.

Barbieri, Catarina Helena Cortada, Luciana de Oliveira Ramos, Fernanda Moraes, Hannah Maruci Aflalo, Ivan Osmo Mardegan, Juliana Fabbron Marin, Laís Menegon Youssef, Ciro Biderman, e George Avelino Filho. 2019. Democracia e Representação nas eleições de 2018: campanhas eleitorais, financiamento e diversidade de gênero. São Paulo: FGV Direito SP.

Bjarnegård, Elin e Pär Zetterberg. 2019. «Political Parties, Formal Selection Criteria, and Gendered Parliamentary Representation.» Party Politics 25(3): 325-335. DOI: https: / / doi.org/10.1177/1354068817715552

Brasil, Presidência da República. 1995. Lei no 9.096, de 19 de setembro de 1995. Disponível no endereço https: / / bit.ly /3j4aOeU [Consultado em 29 de maio de 2021].

Brasil, Presidência da República. 2015. Lei nº 13.165, de 29 de setembro de 2015. Disponível no endereço https: / / bit.ly / 36iuvtP [Consultado em 29 de maio de 2021].

Burrel, Barbara C. 1985. «Women's and Men's Campaigns for The U.S. House of Representatives, 1972-1982. A Finance Gap?» American Politics Quarterly 13(3): 251-272. DOI: https: / / doi.org/10.1177/1532673X8501300301

Butler, Daniel M., e Jessica Robinson Preece. 2016. «Recruitment and Perceptions of Gender Bias in Party Leader Support.» Political Research Quarterly 69(4): 842-851. DOI: https: / / doi.org/10.1177/1065912916668412

Câmara dos Deputados. 2021. Bancada na eleição. Disponível no endereço https://bit. ly/3x9zAQR [Consultado em 20 de junho de 2021].

Carroll, Susan. J., e Kira Sanbonmatsu. 2013. More Women Can Run: Gender and Pathways to the State Legislatures. New York: Oxford University Press.

Caul, Miki. 1997. «Women's Representation in National Legislatures: Explaining Differences Across Advanced Industrial Democracies.» Paper presented at the Western Political Science Association Meeting, 13-15 March, Tucson, Arizona.

Cigane, Lolita, e Magnuns Ohman. 2014. Political Finance and Gender Equality. Washington, D.C.: International Foundation for Electoral Systems.

Crowder-Meyer, Melody. 2013. «Gendered Recruitment without Trying: How Local Party Recruiters Affect Women's Representation.» Politics \& Gender 9(4): 390-413. DOI: https: / / doi.org/10.1017/S1743923X13000391

Dahl, Robert A. 1989. Democracy and Its Critics. New Haven \& London: Yale University Press. 
Dahl, Robert A. 2009. Sobre a democracia. Brasília: Editora UnB.

Doss, Cheryl, Caren Grown, e Carmen Diana Deere. 2008. Gender and Asset Ownership: A Guide to Collecting Individual Level Data. Washington, D.C.: World Bank. DOI: https: / / doi.org/10.1596/1813-9450-4704

Eduardo, Maria C. 2018. «Mulheres em campanha: uma análise da distribuição de recursos financeiros nos estados brasileiros e o desempenho eleitoral das mulheres nas eleições de 2014.» Guaju-Revista Brasileira de Desenvolvimento Territorial Sustentável 4(2): 187-208 .

Eduardo, Maria C., Juliana I. L. de Souza, e Alzira E. Angeli. 2019. «Cotas eleitorais para mulheres: análise bibliográfica da pesquisa científica nas Ciências Sociais.» BIB 90: 1-22. Disponível no endereço http:/ / anpocs.com/images/BIB/n90/Maria_juliana_ alzira_BIB_0009006_RP.pdf [Consultado em 05 de maio de 2020].

Epstein, Cynthia. 1981. «Women and Power: The Roles of Women in Politics in the United States.» In Access to Power: Cross-National Studies of Women and Elites, editado por Cynthia F. Epstein e Rose L. Coser, 124-146. London: George Allen \& Unwin.

Fraga, Bernard L., e Hans J. G. Hassell. 2020. «Are Minority and Women Candidates Penalized by Party Politics? Race, Gender, and Access to Party Support.» Political Research Quarterly 74(3): 540-555. DOI: https:/ / doi.org/10.1177/1065912920913326

Frossard, Heloisa (org.). 2006. «Declaração e Plataforma de Ação da IV Conferência Mundial sobre a Mulher de 1995.» In Instrumentos internacionais de direitos das mulheres, organizado por Heloisa Frossard, 151-258. Brasília: Secretaria Especial de Políticas para Mulheres.

G1. 2020. «Mulheres americanas, maioria entre eleitores, devem decidir eleição presidencial dos EUA.» G1, Jornal Nacional, 30 de outubro de 2020. Disponível no endereço https: / / glo.bo/2SGsgNC [Consultado em 29 de maio de 2021].

Gatto, Malu A. C., e Kristin N. Wylie. 2021. «Informal Institutions and Gendered Candidate Selection in Brazilian Parties.» Party Politics. DOI: https: / / doi.org/ 10.1177 / 135406882 11008842

Hinojosa, Magda. 2012. Selecting Women, Electing Women: Political Representation and Candidate Selection in Latin America. Philadelphia: Temple University Press.

Hinojosa, Magda, e Jennifer M. Piscopo. 2013. «Promoting women's right to be elected: twenty-five years of quotas in Latin America.» Disponível no endereço https: / / jenni ferpiscopo.files.wordpress.com/2013/09/hinojosa-piscopo-final-english.pdf [Cosultado em 29 de maio de 2021].

Hinojosa, Magda, e Lorena Vázquez Correa. 2018. «Selección de Candidaturas, Partidos y Mujeres en América Latina.» In Mujeres en la Política. Experiencias nacionales y subnacionales en América Latina, organizado por Flavia Freidenberg, Mariana Caminotti, Betilde Muñoz-Pogossian, e Tomas Dosek, 35-68. México: IECM - UNAM - IIJ.

Horochovski, Rodrigo R., Ivan J. Junckes, Edson A. Silva, e Neilor F. Camargo. 2016. «Estruturas de poder nas redes de financiamento político nas eleições de 2010 no Brasil.» Opinião Pública 22(1): 28-55. DOI: https:/ / doi.org/10.1590 / 1807-0191201622128

IDEA, International Institute for Democracy and Electoral Assistance. 2020. Disponível no endereço https: / / bit.ly/3h4vxzI [Consultado em 04 de novembro de 2020].

IPU - Inter Parliamentary Union. 1997. Women in national parliaments - World Average 1 January 1997. Disponível no endereço https:/ / bit.ly/3qEDE92 [Consultado em 29 de maio de 2021].

IPU - Inter Parliamentary Union. 2021. Disponível no endereço https://data.ipu.org/ [Consultado em 29 de maio de 2021]. 
Janusz, Andrew, Sofi-Nicole Barreiro, e Erika Cintron. 2021. «Political Parties and Campaign Resource Allocation: Gender Gaps in Brazilian Elections.» Party Politics: 1-11. DOI: https: / / doi.org/10.1177/13540688211018424

Junckes, Ivan J., Rodrigo R. Horochovski, Neilor F. Camargo, Joseli M. Silva, Edson A. Silva, e Leandro B. de Almeida. 2015. «Posicionamento das mulheres na rede de financiamento eleitoral e seu desempenho nas eleições de 2010 no Brasil: A dinâmica estrutural da exclusão e marginalização feminina no poder político.» Revista Latino-Americana de Geografia e Gênero 6(1): 25-47.

Kist, Cristine, e Thiago Tanji. 2015. «Eles não nos representam: por que os políticos são tão diferentes de seus eleitores?» Galileu, 28 de julho. Disponível no endereço https:/ / revistagalileu.globo.com/Multimidia/Infograficos/noticia/2015/07/ por-que-os-poli ticos-sao-tao-diferentes-de-seus-eleitores2.html [Consultado em 29 de maio de 2021].

Lawless, Jennifer L. 2015. «Female candidates and legislators.» Annual Review of Political Science 18: 349-366. DOI: https: / / doi.org/10.1146/ annurev-polisci-020614-094613

Lawless, Jennifer L., e Richard L. Fox. 2010. It Still Takes a Candidate: Why Women Don't Run for Office (Revised Edition). Cambridge: Cambridge University Press.

Lemos, Leany B., Daniel Marcelino, e João H. Pederiva. 2010. «Porque dinheiro importa: a dinâmica das contribuições eleitorais para o Congresso Nacional em 2002 e 2006.» Opinião Pública 16(2): 366-393. DOI: https: / / dx.doi.org/10.1590/S0104-62762010000 200004

Lijphart, Arend. 1999. Patterns of Democracy: Government Forms and Performance in 36 Countries. New Haven: Yale University Press.

Mancuso, Wagner P. 2015. «Investimento eleitoral no Brasil: balanço da literatura (2001-2012) e agenda de pesquisa.» Revista de Sociologia e Política 23(54): 155-183. DOI: https: / / dx.doi.org/10.1590/1678-987315235409

Mancuso, Wagner P., e Dalson B. Figueiedo Filho. 2014. «Financiamento empresarial nas campanhas para deputado federal no Brasil (2002-2010): determinantes e consequências.» $38^{\circ}$ Encontro Anual da ANPOCS. Disponível no endereço https: / / bit.ly/2Tmsf $\mathrm{Pb}$ [Consultado em 05 de maio de 2020].

Mansbridge, Jane. 1999. «Should blacks represent blacks and women represent women? A contingent "yes".» Journal of Politics 61(3): 628-657. DOI: https:// doi.org/10.2307/ 2647821

Nassmacher, Karl-Heinz. 2009. The Funding of Party Competition: Political Finance in 25 Democracies. Baden-Baden: Nomos.

Nexo, Jornal. 2019. «A sanção de Bolsonaro à anistia aos partidos. E o que representa.» Jornal Nexo, 21 de maio. Disponível no endereço https: / / bit.ly/361I6oT [Consultado em 20 de maio de 2020].

Norris, Pippa, e Joni Lovenduski. 1995. Political Recruitment. Cambridge: Cambridge University Press.

Phillips, Anne. 1995. The Politics of Presence. Oxford: Clarendon Press.

Pitkin, Hanna F. 1967. The Concept of Representation. Berkeley/Los Angeles/London: University of California Press.

Sacchet, Teresa. 2009. «Capital Social, Gênero e Representação Política no Brasil.» Opinião Pública 15(2): 306-332. Disponível no endereço https:/ / periodicos.sbu.unicamp.br/ ojs/index.php/op/article/view/ 8641333 [Consultado em 29 de maio de 2021].

Sacchet, Teresa. 2018. «Why gender quotas don't work in Brazil? The role of the electoral system and political finance.» Colombia Internacional (95): 25-54. DOI: https://doi. org / 10.7440/ colombiaint95.2018.02 
Sacchet, Teresa, e Bruno W. Speck. 2012a. «Financiamento Eleitoral, Representação Política e Gênero: uma análise das eleições de 2006.» Opinião Pública 18(1): 177-197. DOI: https: / / doi.org/10.1590/S0104-62762012000100009

Sacchet, Teresa, e Bruno W. Speck. 2012b. «Dinheiro e sexo na política brasileira: financiamento de campanha e desempenho eleitoral em cargos legislativos.» In Mulheres nas eleições 2010, organizado por José E. D. Alves, Céli R. J. Pinto e Fátima Jordão, 417-452. São Paulo: ABCP/SPM.

Sanbonmatsu, Kira. 2006. Where Women Run: Gender and Party in the American States. Ann Arbor: University of Michigan Press.

Santos, Maria Helena, Carla Cerqueira, e Rui Vieira Cruz. 2017. «Abrindo a caixa de Pandora: a participação política das mulheres, as desigualdades de género e a ação positiva.» Journal of Studies in Citizenship and Sustainability 3: 18-40. Disponível no endereço http: / / hdl.handle.net/10071/15487 [Consultado em 29 de maio de 2021].

Sartori, Giovanni. 1992. Elementos de teoria política. Madrid: Alianza.

Schwindt-Bayer, Leslie A. 2009. «Making Quotas Work: The Effect of Gender Quota Laws on the Election of Women.» Legislative Studies Quarterly 34(1): 5-28. Disponível no endereço http: / / www.jstor.org/ stable/20680225 [Consultado em 29 de maio de 2021].

Speck, Bruno W., e Wagner P. Mancuso. 2014. «A study on the impact of campaign finance, political capital and gender on electoral performance.» Brazilian Political Science Review 8(1): 34-57. DOI: http:/ / doi.org/10.1590/1981-38212014000100002

Speck, Bruno W., e Wagner P. Mancuso. 2013. «O que faz a diferença? Gastos de campanha, capital político, sexo e contexto municipal nas eleições para prefeito em 2012.» Cadernos Adenauer XIV(2): 109-126. Disponível no endereço https: / / bit.ly/2UhBAYt [Consultado em 29 de maio de 2021].

TSE-Tribunal Superior Eleitoral. 2019. Resolução n ${ }^{\circ}$ 23.607, de 17 de dezembro de 2019. Disponível no endereço https: / / bit.ly / 3AifCFB [Consultado em 29 de maio de 2021].

TSE-Tribunal Superior Eleitoral. 2021. Repositório de dados eleitorais. Disponível no endereço https: / / bit.ly / 2SJsKmc [Consultado em 05 de março de 2021].

Vieira, Sergio. 2020. «Maioria do eleitorado feminino ainda enfrenta desafios na política.» Agência Senado, 26 de outubro de 2020. Disponível no endereço https:/ / bit.ly/367 QOlL [Consultado em 29 de maio de 2021].

Wolffenbüttel, Andréa. 2004. O que é? - Índice de Gini. IPEA, Instituto de Pesquisa Econômica Aplicada, 01 de novembro de 2004. Disponível no endereço https://bit.ly/ 3xaxcZZ [Consultado em 20 de junho de 2021].

Wylie, Kristin, e Pedro dos Santos. 2016. «A Law on Paper Only: Electoral Rules, Parties, and the Persistent Underrepresentation of Women in Brazilian Legislatures.» Politics E Gender 12(3): 415-442. DOI: http:/ / doi.org/10.1017/S1743923X16000179

Wylie, Kristin, Pedro dos Santos, e Daniel Marcelino. 2019. «Extreme non-viable candidates and quota maneuvering in Brazilian legislative elections.» Opinião Pública 25(1): 1-28. DOI: https: / / doi.org / 10.1590/1807-019120192511

Zovatto, Daniel. 2005. «Financiamento dos partidos e campanhas eleitorais na América Latina: uma análise comparada.» Opinião Pública 11(2): 287-336. DOI: http:/ / dx.doi. org/10.1590/S0104-62762005000200002 
Maria Cecília Eduardo. Cientista política. Mestra e Doutoranda em Ciência Política pela Universidade Federal do Paraná, Brazil. É pesquisadora do Laboratório de Análise dos Partidos Políticos e Sistemas Partidários (LAPeS) e estuda os temas: participação política feminina e financiamento de campanhas.

Juliana Inez Luiz de Souza. Cientista política. Mestra e Doutoranda em Ciência Política pela Universidade Federal do Paraná, Brazil. Bacharela em Artes Cênicas pela Faculdade de Artes do Paraná, Brazil. Integrante do grupo de pesquisa «Midiaculturas, poder e sociedade» da UFPR. Estuda temas de gênero, diversidade sexual e política, com foco nas disputas discursivas presentes na mídia e no parlamento.

Artigo recebido a 30 de junho e aceite para publicação em 26 de outubro de 2021. 


\title{
A FAVOR, CONTRA, OU ASSIM-ASSIM? POSIÇÕES E DISCURSOS DE MEMBROS DOS ÓRGÃOS DE GESTÃO SOBRE LIMIARES DE REPRESENTAÇÃO LEGALMENTE VINCULATIVOS, MÉRITO E IGUALDADE
}

\author{
Sara Falcão Casaca \\ (D) https: / / orcid.org/0000-0002-7944-5007 \\ Maria João Guedes** \\ (D) https: / / orcid.org/ 0000-0002-4342-2620 \\ Susana Ramalho Marques \\ (1) https: / / orcid.org/0000-0001-7116-7252 \\ Nuno Paço \\ (D) https: / / orcid.org/0000-0001-9930-460X
}

\section{Resumo}

Este artigo procura analisar as posições e os discursos de membros dos órgãos de gestão das empresas legalmente vinculadas a limiares mínimos de representação equilibrada entre mulheres e homens. Os resultados mostram que, apesar de não ser expressiva a oposição a medidas vinculativas de ação positiva, a Lei em vigor está longe de ser consensual. As posições de resistência estão mais presentes entre os homens, enquanto são as mulheres que mais contrariam a narrativa de que as medidas vinculativas comprometem a meritocracia. Os discursos das mulheres tendem a negar experiências de discriminação, embora, contraditoriamente, algumas admitam a necessidade de prestar mais provas de competência que os seus colegas. Esta narrativa sugere que as condições em

* Instituto Superior de Economia e Gestão, Universidade de Lisboa; SOCIUS - Centro de Investigação em Sociologia Económica e das Organizações/CSG - Investigação em Ciências Sociais e Gestão - Lisboa, Portugal.

Endereço postal: Instituto Superior de Economia e Gestão, Universidade de Lisboa, Rua do Quelhas, n. ${ }^{\circ}$ 6, 1200-781 Lisboa, Portugal.

Endereço eletrónico: sarafc@iseg.ulisboa.pt

** Instituto Superior de Economia e Gestão, Universidade de Lisboa; SOCIUS - Centro de Investigação em Sociologia Económica e das Organizações/CSG - Investigação em Ciências Sociais e Gestão - Lisboa, Portugal.

Endereço postal: Instituto Superior de Economia e Gestão, Universidade de Lisboa, Rua do Quelhas, n. ${ }^{\circ}$ 6, 1200-781 Lisboa, Portugal.

Endereço eletrónico: mjguedes@iseg.ulisboa.pt

*** SOCIUS - Centro de Investigação em Sociologia Económica e das Organizações/CSG Investigação em Ciências Sociais e Gestão, Lisboa, Portugal.

Endereço postal: SOCIUS / CSG, Rua Miguel Lupi 20, 1249-078 Lisboa, Portugal.

Endereço eletrónico: smarques@iseg.ulisboa.pt

**** SOCIUS - Centro de Investigação em Sociologia Económica e das Organizações/CSG Investigação em Ciências Sociais e Gestão, Lisboa, Portugal.

Endereço postal: SOCIUS / CSG, Rua Miguel Lupi 20, 1249-078 Lisboa, Portugal.

Endereço eletrónico: npaco@iseg.ulisboa.pt 
que exercem cargos de gestão são ainda pautadas pela desigualdade em relação aos pares do sexo masculino.

Palavras-chave: Empresas, ação positiva, mérito, igualdade de género, órgãos de gestão.

\begin{abstract}
For, Against, or Somewhere in the Middle? Positions and discourses of board members about legally binding thresholds of representation, merit and equality

This paper seeks to analyse the positions and discourses of board members serving in companies that are legally bound by a minimum balanced threshold of representation between men and women. The results show that, despite the lack of a marked opposition to legally binding affirmative action measures, the current Law is far from consensual. The greater opposition and resistance is voiced by male board members, while female board members make up the majority of those who contradict the narrative that binding measures may compromise meritocracy. Women tend to deny any experience of discrimination throughout their professional careers, but, contradictorily, they also admit having to provide more proof of competence than their male colleagues. Such a narrative suggests that the conditions in which they serve on boards is still pervaded by inequality in relation to their male peers.
\end{abstract}

Keywords: Companies, affirmative action, merit, gender equality, board members.

\title{
Resumen
}

¿A favor, en contra, o indiferencia? Posiciones y discursos de los miembros de órganos de dirección de las empresas sobre los umbrales de representación jurídicamente vinculantes, merito y igualdad

Este artículo busca analizar las posiciones y discursos de miembros de órganos de dirección de empresas legalmente vinculadas a umbrales de representación equilibrada entre mujeres y hombres. Los resultados muestran que, aunque no existe una expresiva oposición a medidas vinculantes de acción positiva, la legislación vigente está lejos de estar consensuada. Se verifica una mayor resistencia por parte de los hombres, al paso que son fundamentalmente las mujeres que contradicen la narrativa de que las medidas vinculantes amenazan la meritocracia. Los discursos de las mujeres tienden a descartar cualquier experiencia de discriminación en su carrera profesional, pero admitiendo, contradictoriamente, la necesidad de demostrar más competencia que sus homólogos. Esta narrativa sugiere que las condiciones en que las mujeres ejercen los cargos de dirección son marcadas por desigualdades en relación a sus homólogos do sexo masculino.

Palabras clave: Compañías, acción positiva, merito, igualdad de género, órganos de dirección.

\section{Introdução}

A sub-representação de mulheres em cargos de gestão de topo no universo empresarial subsiste de forma transversal em todo o mundo (ILO 2019). A adoção de medidas de ação positiva, por via da definição de limiares mínimos de representação de mulheres e homens nos órgãos de gestão das empresas, tem vindo a ser seguida em vários países europeus (e.g. Mensi-Klarbach e Seierstad 2020). No con- 
texto português, na sequência de infrutíferos incentivos à autorregulação e à adoção voluntária de metas para aumentar a representação de mulheres nos órgãos de administração das empresas cotadas em bolsa (Casaca 2017a; 2017b), entrou em vigor, a 1 de janeiro de 2018, a Lei n. ${ }^{\circ}$ 62/2017, de 1 de agosto, que estabelece o regime da representação equilibrada entre mulheres e homens nos órgãos de administração e de fiscalização das entidades do setor público empresarial (setor empresarial do Estado e setor empresarial local) e das empresas cotadas em bolsa.

Este artigo tem como ponto de partida este recente quadro legislativo. A alusão a "posições e discursos» inspira-se no trabalho prévio de Nogueira (2009), embora este se tenha centrado na análise dos discursos de mulheres em cargos de liderança de vários domínios. Já Santos (2010) analisou as posições de deputadas, deputados e estudantes universitárias/os quanto à Lei da Paridade (aplicável à área política). O presente texto contribui para o enriquecimento da literatura existente, uma vez que não são ainda conhecidos estudos que, em Portugal, tenham aplicado uma abordagem metodológica quantitativa e qualitativa à análise das posições e dos discursos de mulheres e de homens a exercer cargos de gestão nas empresas abrangidas pela referida Lei.

Tendo como referência estudos realizados noutros contextos, esperávamos apreender posicionamentos diversos quanto à adoção de medidas vinculativas de ação positiva, com maior oposição por parte dos homens. Neste caso, a perceção de que essas medidas podem ameaçar e comprometer o status quo dominante tenderia a sustentar uma narrativa assente nos riscos de anulação do mérito e da justiça social. No que se refere às mulheres, além da presença dessa tónica crítica, esperava-se uma maior polarização de posições, incluindo uma narrativa declaradamente apoiante e uma narrativa evolutiva (transição de uma posição de relutância para uma posição favorável), ambas sustentadas no reconhecimento de que a abordagem vinculativa cria oportunidades para a revelação do mérito (e.g. Seierstad 2016). Se o cumprimento estrito dos limiares definidos pela Lei cabe a quem nomeia ou designa os membros dos órgãos de gestão, as posições das mulheres e dos homens que integram esses órgãos afigura-se fundamental para uma melhor compreensão do potencial de efetividade do quadro legal (Benschop e Verloo 2006; Lombardo e Mergaert 2013; Verge e Lombardo 2021).

Os resultados obtidos através da aplicação de um inquérito por questionário e da realização de entrevistas semiestruturadas permitem concluir que, apesar de a maioria dos membros dos órgãos de gestão não se manifestar abertamente contra a adoção de medidas vinculativas de ação positiva, a opção legislativa em curso está longe de ser consensual. É entre os homens que as posições e os discursos se apresentam mais críticos, ao passo que são essencialmente as mulheres quem tende a contrariar a narrativa segundo a qual as medidas vinculativas comprometem a meritocracia, legitimando a ocupação de cargos de gestão de topo com base nas respetivas competências. Não obstante as mulheres entrevistadas ocuparem cargos de poder, as suas narrativas sugerem que as condições em que os exercem 
são ainda pautadas pela desigualdade em relação aos seus pares. Se, por um lado - e à semelhança do estudo prévio de Nogueira (2009) -, os seus discursos tendem a afastar qualquer experiência de discriminação, por outro lado, contraditoriamente, admitem a necessidade de prestar mais provas de trabalho e de competência do que os seus pares do sexo masculino.

\section{Medidas de ação positiva: conceptualização e contextualização}

As medidas de ação positiva (ou ação afirmativa) podem ser descritas como «medidas destinadas a um grupo específico, com as quais se pretende eliminar e prevenir a discriminação ou compensar as desvantagens decorrentes de atitudes, comportamentos e estruturas existentes» (Comissão Europeia 1998, 11). As abordagens subjacentes têm vindo a ser distintas, ora favorecendo incentivos à autorregulação das empresas quanto ao estabelecimento de metas de representação de mulheres e homens nos lugares de gestão e ao respetivo horizonte temporal (opção «ligeira» ou soft), ora determinando a obrigatoriedade legal de cumprimento de limiares mínimos de representação equilibrada (abordagem regulatória vinculativa). Esta última opção tem variado quanto ao grau de «robustez» (hardness) do quadro sancionatório aplicável a situações de incumprimento (Mensi-Klarbach e Seierstad 2020).

A designação de «quotas» na literatura de referência é relativamente comum, sobretudo no quadro dos estudos de origem anglo-saxónica. Esta opção, porém, está longe de ser consensual, sendo mesmo criticada por alguma literatura feminista e por organizações defensoras dos direitos das mulheres. O principal argumento é o de que, enquanto as quotas se aplicam a grupos específicos e minoritários de uma determinada população, as medidas de ação positiva servem o propósito da «paridade» e da efetivação da igualdade substantiva. Estas visam, portanto, a igual representação de ambas as metades da humanidade, mulheres e homens, nos processos de decisão e nas instâncias de poder (Murray, Krook e Opello 2012; Coucello et al. 2016; Lépinard e Rubio-Marín 2018).

A adoção de medidas vinculativas de ação positiva abrangeu, em vários países, primeiramente os cargos de representação política (Holli 2011). Em Portugal, a Lei da Paridade aplicável a esse universo entrou em vigor em 2006, antecipando-se em mais de uma década relativamente à Lei que, desde janeiro de 2018, se aplica aos órgãos de administração e de fiscalização das empresas cotadas em bolsa e do setor público empresarial. Como mais à frente se verá, a centralidade do tema na agenda política foi relativamente tardia e não isenta de resistências por parte da elite empresarial (Espírito-Santo 2018) e de atores políticos com representação parlamentar (Casaca 2017b).

Em 2003, sob a forma de Recomendação, o Comité de Ministros do Conselho da Europa definiu o valor de referência para o limiar mínimo de paridade, esclare- 
cendo que «participação equilibrada de mulheres e homens significa que a representação de cada um dos sexos em qualquer órgão de decisão da vida política ou pública não deve ser inferior a 40\%» (Conselho da Europa 2003, 3). No âmbito da União Europeia (UE), é a partir desse ano que passam a ser disponibilizados indicadores que permitem o acompanhamento, embora superficial, da representação de mulheres e homens na tomada de decisão na esfera empresarial. É na segunda década do seculo XXI que o tema passa a ser explicitamente integrado nas agendas para a igualdade do espaço da UE (Casaca 2017a). Neste contexto, assume relevância a Estratégia para a Igualdade 2010-2015, na qual a «igualdade na tomada de decisão na esfera económica» é inscrita como uma das seis áreas estratégicas. Em 2011, por iniciativa da Vice-Presidente da Comissão Europeia e Comissária para a área da Justiça, Direitos Fundamentais e Cidadania, Viviane Reding, foi lançado um apelo às empresas cotadas em bolsa (Call for self-regulation: Women on the Board, Pledge for Europe) para que voluntariamente estabelecessem metas conducentes a um maior equilíbrio entre mulheres e homens nos conselhos de administração. A esta iniciativa seguiu-se, um ano depois, a apresentação da proposta de Diretiva Europeia, cuja aprovação está ainda suspensa por falta de consenso político.

Não obstante este impasse, estão em vigor medidas vinculativas de ação positiva em sete países: Bélgica, Itália e França (desde 2011), Alemanha (2016), Áustria (2017), Portugal (2018) e Grécia (2020). Este último país, a Espanha e os Países-Baixos já tinham em vigor enquadramentos legislativos ligeiros, desde 2000, 2007 e 2009, respetivamente (EIGE 2020). Os quadros normativos em vigor são, todavia, muito distintos, seja quanto aos limiares de representação, aos segmentos de empresas vinculadas e respetiva expressão no universo empresarial, aos órgãos de gestão e tipos de cargos abrangidos, seja ainda no que se refere aos horizontes temporais de implementação e ao estabelecimento (ou não) de sanções. Também os argumentos adotados têm sido diversos, desde aqueles centrados nos propósitos de aprofundamento da justiça social (minoritários) até aos fundamentos utilitaristas (maioritários) (Humbert, Kelan e Clayton-Hathway 2019; MensiKlarbach e Seierstad 2020).

É de notar que somente a França introduziu a obrigatoriedade de cumprimento do limiar mínimo de paridade (40\%), embora apenas aplicável a cargos não executivos, sendo que a Espanha incorporou essa referência para cargos executivos e não executivos, embora, como já referido, seguindo uma abordagem ligeira e não vinculativa (EIGE 2020). No caso dos demais países, o limiar mínimo tem sido fixado em torno de 33,3\%. Em Portugal, a Lei n. ${ }^{\circ}$ 62/2017, de 1 de agosto, determina a obrigatoriedade de uma representação mínima de 33,3\% do sexo sub-representado nos órgãos de administração e de fiscalização das entidades do setor público empresarial (setor empresarial do Estado e setor empresarial local), a partir de 1 de janeiro de 2018, a cumprir-se para cargos executivos e não executivos. Estabelece, ainda, a obrigatoriedade de uma representação mínima de $20 \%$ do sexo sub-representado nos órgãos de administração e de fiscalização das empresas 
cotadas em bolsa, a partir de 1 de janeiro de 2018, e de 33,3\% após 1 de janeiro de 2020 (requisitos aplicáveis à primeira assembleia geral eletiva e a renovações de mandatos, para o conjunto de cargos executivos e não executivos). Em caso de incumprimento, o quadro sancionatório prevê a aplicação de repreensões com registo público, sanções pecuniárias ou a nulidade do ato de designação. À semelhança do que se verifica noutros países onde está em vigor um quadro normativo vinculativo, também em Portugal a Lei impulsionou o aumento da representação de mulheres nos órgãos de gestão de empresas legalmente vinculadas (Casaca et al. 2021a; 2021b; Casaca, coord., et al. 2021).

\section{Posições e discursos relativamente a medidas de ação positiva: revisão da literatura}

O debate em torno de medidas de ação positiva tem sido perpassado por uma assinalável controvérsia (e.g. Teigen 2000; Dahlerup 2008; Santos e Amâncio 2012a; 2012b; Espírito-Santo 2018). A tónica de oposição tende a ser fundamentalmente exposta pela elite dominante, dada a perceção de potencial ameaça às posições e relações de poder vigentes (Verge e Lombardo 2021). Não surpreende, portanto, que as posições de resistência sejam mais comuns entre os homens que ocupam cargos de poder (Meier 2008; Santos e Amâncio 2010a; 2010b; Murray, Krook e Opello 2012), podendo condicionar ou mesmo minar a legitimidade das medidas vinculativas e o respetivo potencial de efetividade (Verge e Lombardo 2021). Lombardo e Mergaert (2013) conceptualizam a resistência como um fenómeno que emerge durante um processo de mudança, designadamente na fase de implementação de uma determinada política de igualdade de género, em que a oposição dos atores expressa a tentativa de preservação do status quo. À luz desta definição, a resistência exprime-se por via de um discurso adverso relativamente à política em questão, podendo assumir a forma de distanciamento explícito quanto aos objetivos da mesma ou traduzir-se em ações que desafiam a sua efetividade. Seierstad (2016) dá conta de como a resistência de vários homens, no contexto empresarial da Noruega, condicionou o potencial de transformação das relações de poder nos órgãos de gestão, limitando o reconhecimento da legitimidade das mulheres e um igual estatuto relativamente aos seus pares. Essa posição, conclui a autora, «causou dificuldades às mulheres "pioneiras", que precisaram de provar o seu valor num ambiente crítico e muitas vezes hostil» (Seierstad 2016, 396).

Ainda que haja evidência de um maior apoio a este tipo de medidas por parte das mulheres, tradicionalmente excluídas dos círculos de poder, é possível encontrar discursos de rejeição, de aceitação e de ambivalência, sendo que estes podem mudar ao longo do tempo (Teigen 2000; Meier 2008; Sealy 2010; Seierstad 2016; Seierstad et al. 2017). Além disso, vários estudos têm demonstrado que a posição de rejeição, no caso das mulheres, é frequentemente indissociável do receio de 
questionamento das suas competências e da legitimidade para o exercício de cargos de poder, bem como da antecipação do risco de sub-representação e isolamento (Sealy 2010; Simpson, Ross-Smith e Lewis 2010; Kelan e Wratil 2014). A este propósito, a literatura tem também indagado se a mudança descritiva, gerada pela obrigatoriedade de cumprimento de limiares mínimos de representação de cada sexo, potencia a mudança substantiva (Krook e Zetterberg 2014), permite um mínimo de «massa crítica» capaz de superar as desvantagens experienciadas pelas sobreminorias (Santos e Amâncio 2014) - ou tokens (Kanter 1977) -, e se são observadas transformações nas relações de poder intraboard (situação em que mulheres e homens se reconhecem e relacionam em condições de igualdade) (Elstad e Ladegard 2012; Engeli e Mazur 2018).

Alguns estudos têm procurado compreender se, no caso das mulheres, a perceção de barreiras e de desvantagens estruturais em função do sexo favorece uma posição de apoio a medidas vinculativas de ação positiva, ou se, num registo oposto, a ausência dessa perceção sustenta uma posição mais distanciada e crítica em relação às mesmas. A partir de uma análise efetuada aos discursos de mulheres em posições de liderança em diversos contextos, Nogueira (2009) identificou: i) um «discurso essencialista», em que as mulheres negam a vivência de qualquer discriminação, justificando o sucesso alcançado a partir de caraterísticas pessoais muito específicas - competências femininas que as tornam especiais -, embora admitam amiúde que em certos momentos tiveram de trabalhar mais do que os homens para atingir os mesmos objetivos (discurso dominante); e ii) um «discurso de resistência», veiculado por mulheres que assumem ter sido vítimas de discriminação por parte de colegas homens, sublinhando que essa experiência lhes permitiu desenvolver competências para enfrentar outros comportamentos discriminatórios (discurso minoritário).

De entre os argumentos desfavoráveis à implementação de medidas vinculativas de ação positiva sobressai a retórica da meritocracia, que expõe o receio de que tal opção possa comprometer a seleção/nomeação com base no mérito. Santos e Amâncio (2010a; 2010b; 2012a; 2012b), a propósito do estudo sobre os discursos em torno da Lei da Paridade, sublinharam o quanto o mérito é genderizado. De acordo com as autoras, as avaliações tendem a ser enviesadas e «constroem-se em torno das expectativas de menor mérito por parte das mulheres e de legitimidade reconhecida aos homens para ocuparem os cargos de deputados» (Santos e Amâncio 2010a, 49). Além disso, como constatado por Sealy (2010), a partir de entrevistas a administradoras do sector bancário, a noção de meritocracia havia diminuído após terem verificado que o acesso a capital social era mais determinante do que as suas competências profissionais e de gestão. Mais recentemente, Seierstad (2016) identificou a existência de uma «narrativa evolutiva» em entrevistas realizadas a administradoras não executivas. Estas assumiram ter transitado de uma posição de ceticismo em relação a medidas vinculativas de ação positiva, a par de uma forte adesão à retórica da meritocracia, para uma posição firme de 
apoio às mesmas, reconhecendo que permitem a criação de oportunidades de carreira para outras mulheres competentes. Vários estudos têm apoiado esta linha de argumentação, demonstrando que a opção vinculativa não compromete a meritocracia, considerando a elevada qualificação das pessoas eleitas/nomeadas e o seu contributo para a qualidade dos processos de tomada de decisão (e.g. Baltrunaite et al. 2014; Besley et al. 2017).

Além dos argumentos que associam as medidas de ação positiva à desconstrução da dimensão genderizada do mérito, tem sido também enfatizado o contributo das mesmas para uma maior justiça individual e social. As narrativas a favor enfatizam a igualdade de resultados, numa perspetiva mais individual, e/ou apoiam uma visão mais ampla e societal que coloca a tónica na reparação das desvantagens estruturais baseadas no sexo (e.g. Dahlerup 2008; Lépinard e RubioMarín 2018). No entanto, a retórica da (in)justiça é também utilizada por narrativas oponentes, segundo as quais a escolha deve recair sobre a pessoa mais qualificada, independentemente do sexo, sob pena de se incorrer numa discriminação inversa e/ou de se violar o princípio do mérito (Dahlerup 2008; Kelan e Wratil 2014). Uma outra narrativa, seguindo uma argumentação utilitarista (business case), coloca a tónica nos benefícios da diversidade, sustentando que a complementaridade entre características femininas e masculinas conduz a melhores resultados financeiros e económicos, tanto a nível organizacional como para as economias e as sociedades em geral (Simpson, Ross-Smith e Lewis 2010; Terjesen e Sealy 2016; Huse 2018).

\section{Análise e discussão dos resultados}

\section{Opções metodológicas e descrição dos/as participantes}

O estudo apoiou-se numa abordagem metodológica mista, que combinou o método quantitativo com o qualitativo em diferentes momentos da investigação. Esta opção decorreu, numa primeira fase, do propósito de desenvolver uma análise descritiva e abrangente que permitisse comparar as posições de mulheres e de homens - membros dos órgãos de gestão das empresas legalmente vinculadas quanto a medidas de ação positiva e ao quadro legal vigente em particular. Num momento seguinte, e num plano complementar, empreendeu-se uma análise interpretativa dessas posições e das narrativas que as sustentam, assim como das eventuais ambivalências e contradições discursivas. Procurou-se ainda compreender se, segundo as perceções das pessoas inquiridas e entrevistadas, o facto de serem mulheres ou de serem homens influiu nos respetivos percursos profissionais.

No primeiro trimestre de 2019, foram contactadas todas as empresas cotadas em bolsa e do setor público empresarial para recolha do endereço de email do secretariado da administração. Terminado o respetivo processo de recolha, foi dis- 
tribuído pela lista de endereços um documento com informação sobre o Projeto ${ }^{1}$, o convite para que membros dos órgãos de administração e de fiscalização preenchessem um inquérito por questionário (online) e participassem numa entrevista futura. Na sequência deste contacto, foi distribuído um inquérito por questionário a 230 membros $(\mathrm{M}=87$ e $\mathrm{H}=143)$. Obteve-se um total de 161 respostas válidas ( $\mathrm{M}=84$ e $\mathrm{H}=77)$, tendo-se salvaguardado o anonimato das pessoas participantes. Considerando os universos totais de membros efetivos nos anos em que o questionário foi aplicado, as respostas representam, aproximadamente, 9\% de membros do universo das empresas cotadas em bolsa e $10 \%$ no caso das entidades do setor público empresarial. No que diz respeito à idade das pessoas inquiridas, esta situava-se entre os 30 e os 81 anos (média=52 anos), sendo, em média, os homens mais velhos do que as mulheres ( 54 anos e 50 anos, respetivamente).

Foram ainda realizadas 43 entrevistas semiestruturadas $(M=22$ e $H=21)$, entre novembro de 2019 e novembro de 2020. A idade das pessoas entrevistadas situava-se entre os 33 e os 69 anos (média=52 anos), sendo a idade média das mulheres de 50 anos (intervalo etário 38-61 anos) e a dos homens de 54 anos (intervalo etário 33-69 anos).

As entrevistas foram integralmente transcritas e anonimizadas com recurso à atribuição de um código a cada pessoa entrevistada ${ }^{2}$. O conteúdo foi sujeito a análise de conteúdo, com recurso ao software MAXQDA 2020, da qual resultou a identificação de um conjunto de dimensões temáticas transversais ao discurso das pessoas entrevistadas, cada uma das quais desagregada por subtemas. A apresentação dos resultados está organizada em torno de três domínios: (i) limiares vinculativos de representação equilibrada entre mulheres e homens nos cargos de gestão, (ii) medidas de ação positiva e a questão do mérito, e (iii) igualdade de oportunidades ou experiência de discriminação no percurso profissional.

1 «Women on Boards: An Integrative Approach / Mulheres nos Órgãos de Gestão das Empresas: Uma Abordagem Integrada» (PTDC/SOC-ASO/29895/2017), financiado pela Fundação para a Ciência e Tecnologia e pelo Ministério da Ciência, Tecnologia e Ensino Superior (MCTES), através de fundos nacionais (PIDDAC), e desenvolvido no âmbito do Centro de Investigação em Sociologia Económica e das Organizações (SOCIUS)/Consórcio em Ciências Sociais e Gestão (CSG), do ISEG-ULisboa.

2 A anonimização das entrevistas foi efetuada de acordo com o seguinte racional: a primeira letra corresponde ao sexo da pessoa entrevistada $(\mathrm{M}=$ Mulher $/ \mathrm{H}=$ Homem), seguida de um conjunto de três letras que correspondem ao universo da empresa de referência (Cot = Empresa cotada em bolsa $/$ See = Empresa do setor empresarial do Estado/Sel = Empresa do setor empresarial local), e terminando com um ou dois algarismos, que representam o número da entrevista (por ordem cronológica de realização). 
Limiares vinculativos de representação equilibrada entre mulheres e homens nos cargos de gestão: a favor, contra, ou assim-assim?

Cerca de metade das pessoas inquiridas - mais as mulheres (50\%) do que os homens (40,8\%) - manifestou-se a favor de medidas voluntárias de autorregulação que permitam uma representação equilibrada entre mulheres e homens nos órgãos de gestão. É manifestamente inferior a proporção de respostas a favor de medidas vinculativas de ação positiva (33,3\% das mulheres e 27,6\% dos homens) (Anexos, Quadro 1). A proporção de homens que se exprimiu contra quaisquer medidas de representação equilibrada duplica a de mulheres (30,3\% e 14,3\%, respetivamente), embora a diferença não seja estatisticamente significativa $(p>0,05)$. Na mesma linha, quando inquiridos/as especificamente sobre a Lei em vigor, as mulheres manifestaram uma maior concordância com a mesma, sendo as diferenças estatisticamente significativas $(p<0,05)$. Este sentido de respostas é confirmado pelas entrevistas; neste caso, as perspetivas relativamente ao novo quadro legal repartiram-se entre um posicionamento favorável (sem reservas ou com mudança ao longo do tempo [narrativa evolutiva]) e a ambivalência (com argumentos tanto a favor como contra), com uma minoria de pessoas a manifestarem discordância. Os exemplos seguintes são ilustrativos destas posições:

Eu sou a favor na medida em que a Lei pode acelerar, digamos assim, este processo de integração das mulheres. E se as mulheres ... colocarem a jogo todas as suas competências e, entre aspas, brilharem, depois, nesses sítios, não tenho a menor dúvida que a Lei, aí, ajudou a que esta evolução e esta paridade fosse mais cedo. (H_Sel33)

Hoje em dia sou uma adepta das quotas, [...], mas aqui há uns tempos atrás achava que não, que as pessoas tinham que chegar lá só pelo mérito. A verdade é que, à medida que a minha carreira foi evoluindo, eu também comecei a chegar à conclusão que há tantos homens que chegam aos lugares sem nenhum mérito, que nós também merecemos chegar lá por outras razões. (M_See7)

No que se refere à posição ambivalente, com argumentos tanto a favor como contra a Lei, esta assentou sobretudo numa narrativa que descreve as medidas vinculativas de ação positiva como um mal necessário. Os exemplos seguintes são ilustrativos desta perspetiva:

Acho que foi um mal necessário. Por um lado, pode abrir aqui um bocadinho aquela desculpa do «só está porque há as quotas», mas não, mas claramente foi uma porta que teve de se obrigar a abrir, e depois cabe a cada mulher, assim como cabe a cada homem, entrar e fazer o seu caminho. Mas veio acelerar a diversidade, e acelerar este processo, acho que faz todo o sentido. (M_See13)

Se me perguntar diretamente se eu acho que tem que existir legislação a impor, eu acho que infelizmente tem. Eu não sou muito fã, diria, de haver uma legislação que 
obrigue, porque eu acho que isso devia ser consensual e natural, em função das aspirações das pessoas aos cargos, e em função da capacidade que as pessoas têm para os exercer, e não porque é homem, ou porque é mulher. (M_See18)

\section{Medidas de ação positiva e a questão do mérito...}

Verificou-se entre as pessoas inquiridas uma manifesta concordância ( 1 =Discordo Totalmente a $5=$ Concordo Totalmente) com a declaração «As mulheres que estão a ser nomeadas para os cargos nos órgãos de administração têm as competências necessárias para assumir esses cargos» $(\mathrm{M}=4,16 ; \mathrm{H}=3,92)$. Houve, no entanto, uma menor concordância relativamente à afirmação «Deve ser o Estado, sob a forma de leis ou similares, e não os/as acionistas, a decidir quem devem ser os membros do órgão de administração» $(\mathrm{M}=2,29 ; \mathrm{H}=2,05)$ (Anexos, Quadro 2).

Da análise a um conjunto de afirmações relacionadas com a competência das mulheres, as que obtiveram mais concordância foram «Existem mulheres competentes em número suficiente para assumir os cargos executivos» $(\mathrm{M}=4,63 ; \mathrm{H}=4,26)$ e «Existem mulheres competentes em número suficiente para assumir os cargos nos órgãos de administração» $(\mathrm{M}=4,61$ e 4,28). As diferenças entre as respostas das mulheres e dos homens são estatisticamente significativas $(p<0,01$ e $p<0,02$, respetivamente) (Anexos, Quadro 2).

Apenas uma minoria de pessoas entrevistadas, cerca de cinco, exprimiu abertamente uma posição desfavorável em relação à Lei, com uma argumentação sobretudo assente na retórica da meritocracia - tal como exemplificado pelos seguintes depoimentos:

Eu sou contra a Lei das quotas, tudo quanto seja obrigatório, a mim arrepia-me um bocadinho, até porque nós, mulheres, na minha opinião, nunca nos devemos afirmar pelo sexo, ou pelo género, como quisermos, mas sim por aquilo que temos capacidade para fazer. (M_Sel22)

Em conversa com uma amiga minha sobre estas questões, a opinião dela é contrária à minha, ela é favor da Lei da Paridade e eu sou do mérito. (H_See27)

São essencialmente as mulheres quem considera que as medidas vinculativas de ação positiva não põem em causa o mérito, enquanto os homens são quem mais refere que a Lei pode violar esse princípio:

Acho que há muitos homens com pouco mérito nos Conselhos de Administração. (M_Cot_15)

Não é por terem que escolher uma mulher que vão escolher uma incompetente porque têm muitas mulheres competentes, até diria que têm mais mulheres competentes do que homens competentes. (M_See28) 
Custa-me um bocadinho nós subvertermos o princípio da competência por via do princípio da quota, ou seja, eu sinto-me violentado se eu tiver que deixar uma pessoa competente de fora para colocar uma pessoa incompetente para cumprir uma quota, sinto-me violentado. Mas também sinto, e este é um sentimento contraditório, eu sei que se não forçarmos, a transformação depois também não se faz. (H_Sel21)

É de salientar a existência de discursos contraditórios por parte de algumas pessoas entrevistadas, que, apesar de se manifestaram contra limiares vinculativos de representação equilibrada entre mulheres e homens para os órgãos de gestão, rejeitam que essa obrigação possa comprometer a meritocracia. O contrário também pôde ser observado: discursos aparentemente favoráveis à existência de limiares vinculativos e que, simultaneamente, exprimiram o receio de que o mérito possa ser posto em causa. Os seguintes excertos ilustram esses casos:

Não acho [...] que é por força de uma Lei que as mulheres têm de estar lá, as mulheres têm de estar lá pela competência, por aquilo que valem e por aquilo que sabem fazer. [...] Como eu tenho muita confiança no mérito das mulheres em geral, nunca seria posto em causa o mérito [com a introdução da Lei], porque se trata de fazer ascender uma mulher que se calhar por outra via não chegaria lá. (M_Sel9)

Por mim [a Lei] parece-me bem. [...] Eu penso que a questão da paridade é, obviamente, muito importante, mas eu acho que a paridade não pode deixar de ser acompanhada com competência, ou seja, porque senão corremos o risco de ter efeitos perversos relativamente a isso, ou seja, começarmos a ter empresas, pessoas, só porque são de um sexo ou de outro, têm de estar lá de qualquer maneira, e que depois não acrescentam nada. (H_See19)

Igualdade de oportunidades e ausência de discriminação, mas...

Parece haver uma perceção generalizada, entre as pessoas inquiridas, de que o percurso profissional foi pontuado pela igualdade de oportunidades; assim, a ampla maioria considera que teria tido as mesmas oportunidades de progressão na carreira caso fosse do sexo oposto, sendo a tendência de resposta semelhante para homens e mulheres (77,9\% e 80,7\%, respetivamente) (Anexos, Quadro 1). Também a maioria das pessoas entrevistadas referiu que o facto de serem mulheres ou de serem homens não condicionou nem facilitou os respetivos percursos profissionais. Dada a sub-representação de mulheres em órgãos de gestão, procurou-se aprofundar o sentido dos discursos das entrevistadas, nem sempre isentos de contradições. Se no decurso da entrevista algumas afirmaram nunca se terem sentido limitadas/discriminadas nas suas aspirações e percursos profissionais, houve momentos em que admitiram a necessidade de dar mais provas de trabalho e de competência que os seus pares do sexo masculino (realidade igualmente reco- 
nhecida pelos homens quanto às colegas administradoras). Os seguintes excertos constituem exemplos destes registos contraditórios:

O facto de ser mulher não me impede de seguir os meus sonhos, ou as oportunidades que me surgem na vida [...]. Eu tenho que me esforçar muito mais para mostrar aquilo que eu penso, e as ideias que eu tenho, e que gostava de implementar, ou a minha opinião sobre determinados aspetos [...]. Eu tenho que me esforçar muito mais para fazer levar a minha opinião, para a levarem a sério, e até perceberem, para a considerarem. (M_Sel10)

Eu sempre pensei, e continuo a pensar, que pelo facto de ser mulher tenho os mesmos direitos, as mesmas aspirações [...] que [outra pessoa] qualquer, seja homem ou mulher [...]. Eu acho também que nós mulheres temos sempre que provar mais [...], temos que apresentar mais trabalho, para convencer as pessoas, porque infelizmente ainda há muita gente que acha que as mulheres não têm as mesmas capacidades de chefia que os homens, ainda está muito enraizado também na sociedade. (M_See_24)

As mulheres têm que mostrar muito mais que são merecedoras de determinados cargos. Não devia ser assim, não é? [...] Continuo a achar e falando com outras mulheres dirigentes, sinto que elas fazem um esforço muito maior no sentido de estar permanentemente a mostrar que merecem aquele lugar. (M_Sel29)

\section{Conclusões e considerações finais}

Este artigo teve como ponto de partida o recente quadro legislativo que determina limiares mínimos de representação equilibrada entre mulheres e homens nos órgãos de gestão das empresas cotadas em bolsa e do setor público empresarial, analisando as posições e os discursos de membros daqueles órgãos quanto aos seguintes domínios: limiares vinculativos de representação equilibrada, medidas de ação positiva e a questão do mérito, e a experiência de igualdade ou de discriminação no percurso profissional.

Quanto aos primeiro e segundo domínios em análise, constatou-se que apenas um terço das mulheres e um pouco mais de um quarto dos homens inquiridos se manifestaram a favor de medidas vinculativas de ação positiva. À semelhança do verificado noutros estudos, são os homens quem mais se exprime contra uma opção vinculativa (Meier 2008; Santos e Amâncio 2010a; 2010b; Murray, Krook e Opello 2012). No caso das entrevistas em profundidade, o mesmo sentido de respostas pôde ser confirmado. As perspetivas relativamente ao novo quadro legal repartiram-se entre uma posição favorável (sem reservas ou com mudança de posição [narrativa evolutiva]) e ambivalente (com argumentos tanto a favor como contra), com uma minoria a manifestar a sua discordância relativamente ao mesmo. Neste último caso, os argumentos veiculados associaram-no a um «mal 
necessário» ou, como identificado noutro estudo, a uma «estratégia imperfeita num mundo imperfeito» (Seierstad 2016, 397).

Entre as pessoas que consideraram que as medidas vinculativas de ação positiva não põem em causa a meritocracia, as mulheres estavam em maioria, justificando a sua posição com base na competência das próprias e das administradoras suas conhecidas. Como esperado, foram essencialmente os homens a expor uma narrativa crítica e uma linha de argumentação contrária. Tanto no caso das mulheres como no dos homens, as reservas relativamente a esta questão assentaram em argumentos de (in)justiça/violação do princípio do mérito (Dahlerup 2008; Santos e Amâncio 2010a; Baltrunaite et al. 2014; Kelan e Wratil 2014; Seierstad 2016; Besley et al. 2017).

Relativamente ao terceiro tema (experiência de igualdade ou de discriminação no percurso profissional), os resultados dão conta de uma perceção generalizada - tanto no caso dos homens como no das mulheres - de terem beneficiado de igualdade de oportunidades. Os discursos das mulheres, a este respeito, consolidam uma narrativa de ausência de discriminação ou de limitações impostas às suas aspirações e percursos profissionais. À imagem do concluído por Nogueira (2009), registámos discursos contraditórios por parte de algumas mulheres, que tanto afirmaram nunca se terem sentido limitadas/discriminadas, como admitiram a necessidade de prestar mais provas de trabalho e de competência que os seus colegas. Esta constatação sugere que, não obstante ocuparem cargos de poder, as condições em que os exercem são ainda pautadas pela desigualdade em relação aos pares do sexo masculino.

Importa notar que cerca de um quinto das pessoas inquiridas $(30,3 \%$ no caso dos homens) manifestou-se contra quaisquer medidas tendentes a promover uma representação equilibrada entre mulheres e homens nos órgãos de gestão. Embora o cumprimento estrito dos limiares definidos pela Lei seja responsabilidade de quem nomeia ou designa os membros dos órgãos de gestão - acionistas ou membros do governo -, as pessoas inquiridas fazem parte de um grupo de atores-chave na transformação do status quo dominante e na efetivação da igualdade substantiva (objetivo subjacente à adoção de medidas de ação positiva). Enquanto posições críticas e de oposição dificilmente podem sustentar dinâmicas de interação favoráveis à igualdade entre mulheres e homens nos órgãos de gestão, já o reconhecimento do quadro legal enquanto oportunidade de superação de desvantagens estruturais em função do sexo pode indiciar a predisposição para a partilha efetiva do poder empresarial e económico. Nesse sentido, os resultados obtidos alertam para a necessidade de uma estratégia política integrada que potencie o respetivo alinhamento de todos os atores relevantes. Esta estratégia deve contemplar programas de sensibilização e de capacitação em torno das causas das assimetrias entre mulheres e homens em cargos de poder, visando a eliminação de estereótipos de género e a igualdade efetiva entre mulheres e homens nas organizações. Neste âmbito, afigura-se igualmente importante a ampla disseminação de infor- 
mação sobre os perfis de mulheres e homens em cargos de poder, favorecendo a desconstrução da retórica da meritocracia (Lombardo e Mergaert 2013; Verge e Lombardo 2021).

São várias as linhas de investigação que ficam por prosseguir. Uma delas prende-se com a análise dos efeitos da mudança descritiva suscitada pela Lei - refletida numa aceleração na representação de mulheres nos órgãos de gestão das empresas legalmente vinculadas - na representação substantiva (Krook e Zetterberg 2014). A este respeito, os resultados alcançados suscitam várias questões: em que medida um maior equilíbrio nos órgãos de gestão conduzirá a uma maior integração de temas relativos à promoção da igualdade entre mulheres e homens nas respetivas empresas? Que repercussões terá a determinação de limiares mínimos de representação de cada sexo no perfil de membros que integram os órgãos de gestão e nos circuitos de poder? Este artigo oferece um dos olhares analíticos possíveis, num terreno que se afigura fértil e aberto a várias outras investigações futuras.

\section{Referências bibliográficas}

Baltrunaite, Audinga, Piera Bello, Alessandra Casarico, e Paola Profeta. 2014. «Gender quotas and the quality of politicians.» Journal of Public Economics 118: 62-74. DOI: https:/ / doi. org/10.1016/j.jpubeco.2014.06.008

Benschop, Yvonne, e Mieke Verloo. 2006. «Sisyphus' Sisters: Can Gender Mainstreaming Escape the Genderedness of Organizations?» Journal of Gender Studies 15(1): 19-33. DOI: https:/ / doi.org/10.1080/09589230500486884

Besley, Timothy, Olle Folke, Torsten Persson, e Johanna Rickne. 2017. «Gender Quotas and the Crisis of the Mediocre Man: Theory and Evidence from Sweden.» American Economic Review 107(8): 2204-2242. DOI: https:/ / doi.org/10.1257/ aer.20160080

Casaca, Sara Falcão. 2017a. «A igualdade entre mulheres e homens e a tomada de decisão na esfera económica: o longo percurso dos instrumentos normativos.» Revista do Centro de Estudos Judiciais 1: 173-199.

Casaca, Sara Falcão. 2017b. «Portugal: The Slow Progress of the Regulatory Framework.» In Gender Diversity in the Boardroom. Volume 2: Multiple Approaches Beyond Quotas, editado por Cathrine Seierstad, Patricia Gabaldon, e Heike Mensi-Klarbach, 45-75. Londres: Palgrave Macmillan.

Casaca, Sara Falcão, Maria João Guedes, Susana Ramalho Marques, e Nuno Paço. 2021a. «WoBómetro.» Disponível no endereço https://womenonboards.pt/wobometro/ [Consultado em 2 de maio de 2021].

Casaca, Sara Falcão, Maria João Guedes, Susana Ramalho Marques, e Nuno Paço. 2021b. «Is a progressive law accelerating the longstanding snail's pace? Women on corporate boards in Portugal.» Revista de Administração de Empresas 61(2): 1-7. DOI: https: / / doi. org/10.1590/S0034-759020210206

Casaca, Sara Falcão (coord.), Maria João Guedes, Susana Ramalho Marques, Nuno Paço, e Heloísa Perista. 2021. Equilibrio entre Mulheres e Homens nos Órgãos de Gestão das Empresas - Livro Branco. Lisboa: SOCIUS [no prelo]. 
Comissão Europeia - Direcção-Geral do Emprego, Relações Laborais e Assuntos Sociais. 1998. A igualdade em 100 palavras - Glossário de termos sobre igualdade entre homens e mulheres. Luxemburgo: Serviço das Publicações Oficiais das Comunidades Europeias. Disponível no endereço https: / / op.europa.eu/pt/publication-detail / / publication/ 7342d801-86cc-4f59-a71a-2ff7c0e04123 [Consultado em 28 de junho de 2021].

Conselho da Europa. 2003. «Recomendação Rec (2003) 3 do Comité de Ministros aos Estados Membros sobre participação equilibrada de mulheres e homens na tomada de decisão política e pública (adoptada pelo Comité de Ministros a 12 de Março de 2003).» Disponível no endereço https:/ / rm.coe.int/CoERMPublicCommonSearchServices / DisplayDCTMContent?documentId=0900001680591601 [consultado em 20 de maio de 2021].

Coucello, Ana, Maria do Céu Cunha Rêgo, Maria Alzira Lemos, Margarida Marcelino Marques, Maria Reynolds de Sousa, Maria Regina Tavares da Silva, e José Gabriel Trindade Santos. 2016. «Afinal, o que é a Democracia Paritária? A participação de mulheres e homens na organização social.» Lisboa: Plataforma Portuguesa para os Direitos das Mulheres (Projecto Capacita). Disponível no endereço http:/ / plataformamulhe res.org.pt/ site/wp-content/ ficheiros / 2016/ 04 / PpDM-Argumentario-afinal-o-quee-a-democracia-paritaria.pdf [Consultado em 28 de junho de 2021].

Dahlerup, Drude. 2008. «Gender Quotas: Controversial but Trendy.» International Feminist Journal of Politics 10(3): 322-328. DOI: https: / / doi.org/10.1080/14616740802185643

EIGE-European Institute for Gender Equality. 2020. Beijing + 25: The Fifth Review of the Implementation of the Beijing Platform for Action in the EU Member States. Luxemburgo: Publications Office of the European Union. Disponível no endereço https://eige. europa.eu / publications / beijing-25-fifth-review-implementation-beijing-platform-action-eu-member-states [Consultado em 14 de junho de 2021].

Elstad, Beate, e Gro Ladegard. 2012. «Women on corporate boards: key influencers or tokens?», Journal of Management and Governance 16: 595-615. DOI: https:/ / doi.org/ 10.1007/ s10997-010-9165-y

Engeli, Isabelle, e Amy Mazur. 2018. «Taking implementation seriously in assessing success: The politics of gender equality policy.» European Journal of Politics and Gender 1(1-2): 111-129. DOI: https:/ / doi.org/10.1332/251510818X15282097548558

Espírito-Santo, Ana. 2018. «From Electoral to Corporate Board Quotas: The Case of Portugal.» In Transforming Gender Citizenship, editado por Éléonore Lépinard, e Ruth Rubio-Marín, 216-244. Cambridge, U.K.: Cambridge University Press. DOI: https://doi. org/10.1017/9781108636797.008

Holli, Anne Maria. 2011. «Transforming Local Politics? The Impact of Gender Quotas in Finland.» In Women and Representation in Local Government, editado por Barbara Pini, e Paula McDonald, 142-158. London \& New York: Routledge.

Humbert, Anne Laure, Elisabeth K. Kelan, e Kate Clayton-Hathway. 2019. «A rights-based approach to board quotas and how hard sanctions work for gender equality.» European Journal of Women's Studies 26(4): 447-68. DOI: https://doi.org/10.1177/135050681 9857125

Huse, Morten. 2018. «The Business Utility Case for Women on Boards: Going Beyond the Surface.» In More Women on Boards: An International Perspective, editado por Lynne E. Devnew, Marlene Janzen Le Ber, Mariateresa Torchia, e Ronald J. Burke, 17-34. Charlotte, NC: Information Age Publishing.

ILO - International Labour Organization. 2019. A Quantum Leap for Gender Equality: For a Better Future of Work for All. Geneva: ILO. Disponível no endereço https: / / www.ilo. 
org/wcmsp5 / groups / public/ ---dgreports /---dcomm/---publ/ documents / publica tion/wcms_674831.pdf [Consultado em 3 de maio de 2021].

Kanter, Rosabeth Moss. 1977. «Some Effects of Proportions on Group Life: Skewed Sex Ratios and Responses to Token Women.» American Journal of Sociology 82(5): 965-990. DOI: https:/ / doi.org/10.1086/226425

Kelan, Elizabeth, e Patricia Wratil. 2014. «In Defence of Merit - Have CEOs Become Corporate Feminists?» Comunicação apresentada na $8^{\text {th }}$ Biennial International Interdisciplinary Conference, Universidade de Keele, 24-26 de junho.

Krook, Mona Lena, e Pär Zetterberg. 2014. «Electoral quotas and political representation: Comparative perspectives.» International Political Science Review 35(1): 3-11. DOI: https: / / doi.org/10.1177/0192512113508422

Lei n. ${ }^{\circ}$ 62/2017, de 1 de Agosto - Regime da representação equilibrada entre mulheres e homens nos órgãos de administração. Disponível no endereço https:/ / www.pgd lisboa.pt / leis / lei_mostra_articulado.php?artigo_id=2730A0013\&nid=2730\&tabela $=$ leis \&pagina $=1 \&$ ficha $=1 \&$ so_miolo $=\&$ nversao $=$ [Consultado em 11 de maio de 2021].

Lépinard, Eléonore, e Ruth Rubio-Marín. 2018. «The French parity reform.» In Transforming Gender Citizenship: The Irresistible Rise of Gender Quotas in Europe, editado por Eléonore Lépinard, e Ruth Rubio-Marín, 62-93. Cambridge, U.K.: Cambridge University Press.

Lombardo, Emanuela, e Lut Mergaert. 2013. «Gender Mainstreaming and Resistance to Gender Training: A Framework for Studying Implementation.» NORA - Nordic Journal of Feminist and Gender Research 21(4): 296-311. DOI: https: / / doi.org/10.1080 / 0803 8740.2013.851115

Meier, Petra. 2008. «A Gender Gap not Closed by Quotas: The Renegotiation of the Public Sphere.» International Feminist Journal of Politics 10(3): 329-47. DOI: https:/ / doi.org/ $10.1080 / 14616740802185650$

Mensi-Klarbach, Heike, e Cathrine Seierstad. 2020. «Gender Quotas on Corporate Boards: Similarities and Differences in Quota Scenarios.» European Management Review 17(3): 615-631. DOI: https:/ / doi.org/10.1111/emre.12374

Murray, Rainbow, Mona Lena Krook, and Katherine A. R. Opello. 2012. «Why Are Gender Quotas Adopted? Parity and Party Pragmatism in France.» Political Research Quarterly 65(3): 529-543. DOI: https: / / doi.org/10.1177\%2F1065912911414590

Nogueira, M. Conceição. 2009. «Women in Positions of Power in Portugal: Contradictory Positions and Discourses.» Journal of Women, Politics and Policy 30(1): 70-88. DOI: https: / / doi.org/10.1080/15544770802367804

Santos, Maria Helena. 2010. «Género e Política: Factores explicativos das resistências à igualdade.» Tese de Doutoramento em Psicologia Social e das Organizações. Lisboa: ISCTE-IUL.

Santos, Maria Helena, e Lígia Amâncio. 2010a. «A (in)justiça relativa da acção positiva - A influência do género na controvérsia sobre as quotas baseadas no sexo.» Análise Psicológica 28(1): 43-57. DOI: https: / / doi.org/10.14417/ ap.251

Santos, Maria Helena, e Lígia Amâncio. 2010b. "A competência política, a desigualdade de género e as medidas de acção positiva: Uma questão "natural" ou de "competência"?» Psicologia 24(1): 117-140. DOI: https:/ / doi.org/10.17575/rpsicol.v24i1.299

Santos, Maria Helena, e Lígia Amâncio. 2012a. «Género e política: análise sobre as resistências nos discursos e nas práticas sociais face à Lei da Paridade.» Sociologia, Problemas e Práticas 68: 79-101. Disponível no endereço https://journals.openedition.org/spp/ 696 [Consultado em 14 de junho de 2021]. 
Santos, Maria Helena, e Lígia Amâncio. 2012b. «Resistências à Igualdade de Género na Política.» ex æquo 25: 45-58. Disponível no endereço https:/ / scielo.pt/pdf/aeq/n25/n25a 05.pdf [Consultado em 15 de junho de 2021].

Santos, Maria Helena, e Lígia Amâncio. 2014. «Sobreminorias em profissões marcadas pelo género: consequências e reações.» Análise Social 212: 700-726. Disponível no endereço http:/ / analisesocial.ics.ul.pt/documentos/AS_212_d04.pdf [Consultado em 18 de junho de 2021].

Sealy, Ruth. 2010. «Changing perceptions of meritocracy in senior women's careers.» Gender in Management 25(3): 184-197. DOI: https:/ / doi.org/10.1108/17542411011036392

Seierstad, Cathrine. 2016. «Beyond the Business Case: The Need for Both Utility and Justice Rationales for Increasing the Share of Women on Boards.» Corporate Governance: An International Review 24(4): 390-405. DOI: https: / / doi.org/10.1111/ corg.12117

Seierstad, Cathrine, Gillian Warner-Søderholm, Mariateresa Torchia, e Morten Huse. 2017. «Increasing the Number of Women on Boards: The Role of Actors and Processes.» Journal of Business Ethics 141: 289-315. DOI: https://doi.org/10.1007/s10551-0152715-0

Simpson, Ruth, Anne Ross-Smith, e Patricia Lewis. 2010. «Merit, special contribution and choice: How women negotiate between sameness and difference in their organizational lives.» Gender in Management 25(3): 198-207. DOI: https: / / doi.org/ 10.1108 / 1754 2411011036400

Teigen, Mari. 2000. «The affirmative action controversy.» NORA - Nordic Journal of Women's Studies 8(2): 63-77. DOI: https: / / doi.org/10.1080/08038740050167515

Terjesen, Siri, e Ruth Sealy. 2016. «Board Gender Quotas: Exploring Ethical Tensions from a Multi-Theoretical Perspective.» Business Ethics Quarterly 26(1): 23-65. DOI: https:/ / doi.org/10.1017/ beq.2016.7

Verge, Tània, e Enamuela Lombardo. 2021. «The contentious politics of policy failure: The case of corporate board gender quotas in Spain.» Public Policy and Administration 36(2): 232-251. DOI: https: / / doi.org/10.1177/0952076719852407 


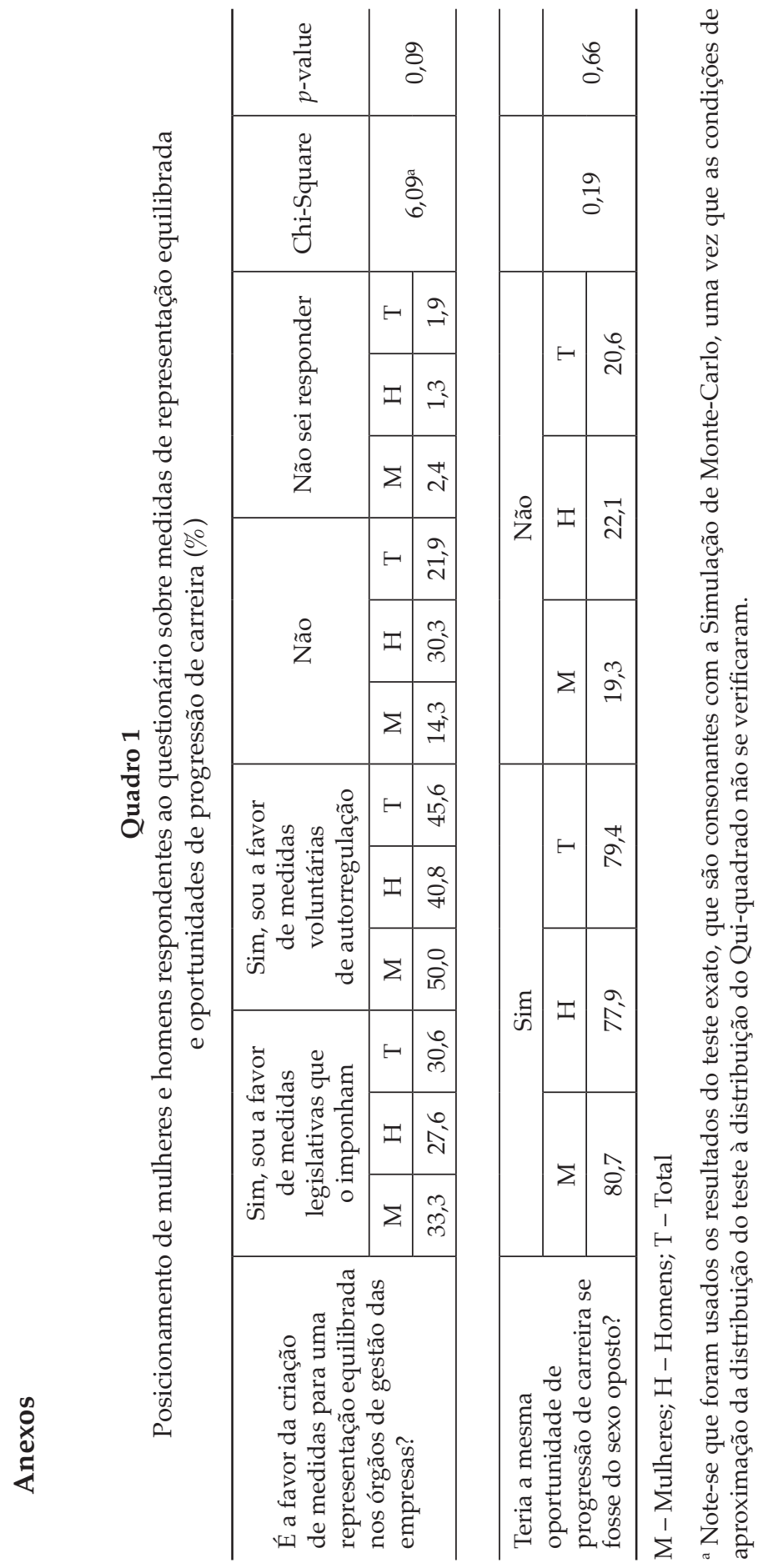


Sara Falcão Casaca, Maria João Guedes,

Susana Ramalho Marques, Nuno Paço

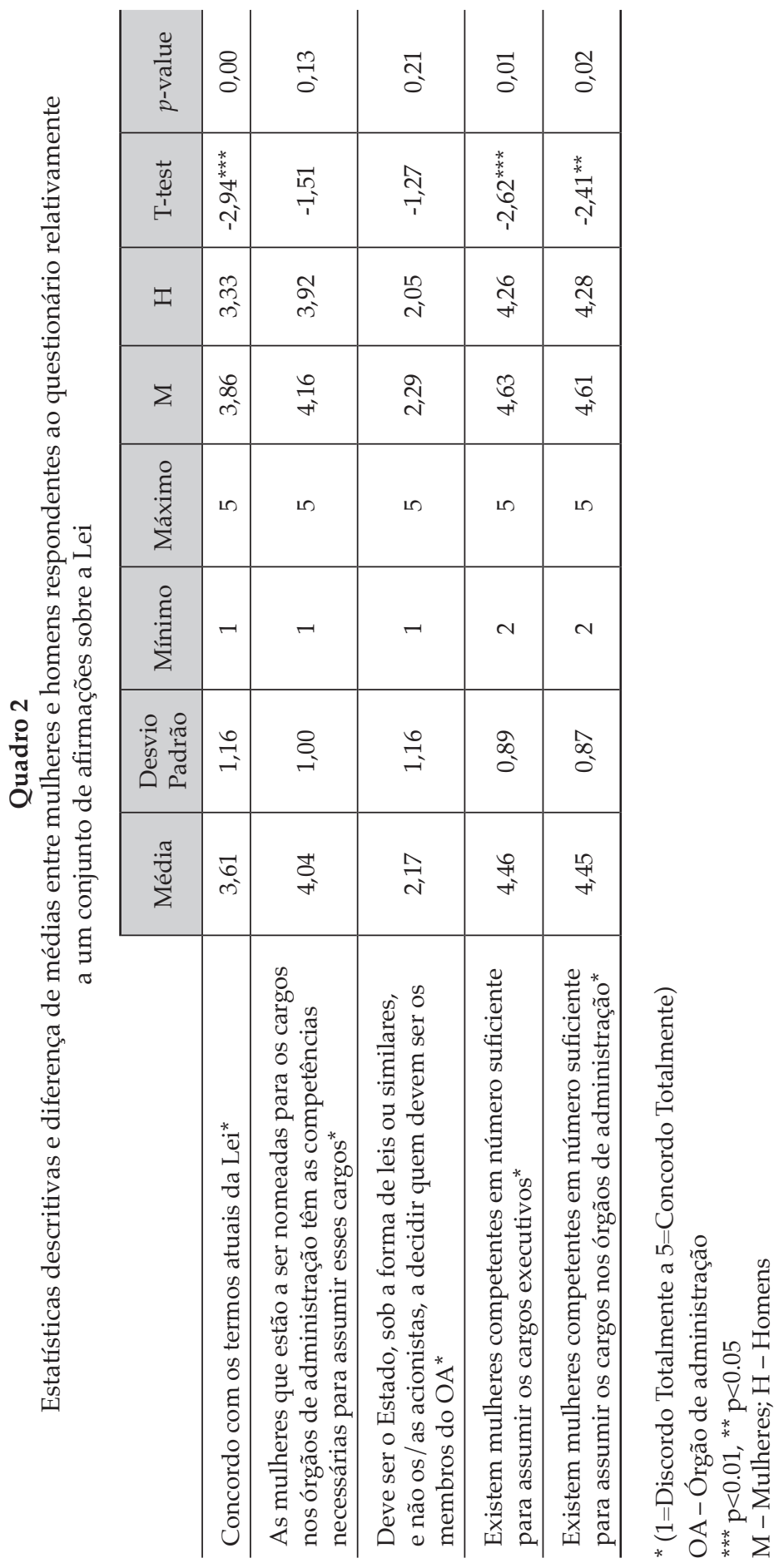

ex æquo, n. ${ }^{\circ} 44$, pp. 57-77. DOI: https:/ / 10.22355/ exaequo.2021.44.05 
Sara Falcão Casaca. Professora Associada com Agregação do Instituto Superior de Economia e Gestão, Universidade de Lisboa, investigadora integrada do Centro de Investigação em Sociologia Económica e das Organizações (SOCIUS)/Consórcio em Ciências Sociais e Gestão (CSG), onde coordena a linha de investigação Trabalho, Emprego, Organizações e Género. É coordenadora do Programa de Doutoramento em Sociologia Económica e das Organizações.

Maria João Guedes. Professora Auxiliar com Agregação do Instituto Superior de Economia e Gestão, Universidade de Lisboa (ISEG-ULisboa) e investigadora do ADVANCE - Centro de Investigação Avançada em Gestão do ISEG, Universidade de Lisboa. Os seus interesses de investigação recaem na área da corporate governance, tendo desenvolvido trabalhos nas áreas de performance e sobrevivência das empresas através de uma perspectiva multidisciplinar, como liderança, género e elementos psicológicos.

Susana Ramalho Marques. Investigadora pós-doc no SOCIUS / CSG (ISEG-ULisboa), no Projeto «Mulheres nos Órgãos de Gestão das Empresas: uma abordagem integrada». A sua atividade de investigação tem-se centrado no multiculturalismo, minorias e a igualdade de género. Licenciada em Psicologia e mestre em Psicologia Social e das Organizações pelo ISCTE-IUL. Concluiu o doutoramento em Sociologia Económica e das Organizações no ISEG-ULisboa, com uma análise diacrónica das políticas de articulação trabalho-família em Portugal.

Nuno Paço. Bolseiro do Projeto «Mulheres nos Órgãos de Gestão das Empresas: uma abordagem integrada» (FCT e SOCIUS / CSG). É licenciado em Administração Pública pelo Instituto Superior de Ciências Sociais e Políticas, Universidade de Lisboa (ISCSPULisboa), e Mestre em Gestão de Recursos Humanos pelo Instituto Superior de Economia e Gestão, Universidade de Lisboa (ISEG-ULisboa). Desenvolveu a investigação de mestrado no âmbito do equilíbrio entre mulheres e homens nos órgãos de governo das empresas.

Artigo recebido em 03 de julho de 2021 e aceite para publicação em 29 de outubro de 2021. 



\section{AÇÕES AFIRMATIVAS NO ENSINO SUPERIOR BRASILEIRO}

\section{Elisabete Corcetti*}

(D) https: / / orcid.org/ 0000-0002-4484-2758

Susane Petinelli-Souza**

(D) https: / / orcid.org/0000-0003-2570-8323

\section{Resumo}

O presente artigo tem o objetivo de desenvolver reflexões sobre as ações afirmativas no ensino superior brasileiro, levando em consideração a perspectiva de raça/etnia e gênero. $\mathrm{O}$ estudo qualitativo ocorreu a partir de pesquisa documental. A implantação da Lei de Cotas vem contribuindo para a inclusão racial nas instituições de ensino brasileiras, tornando-se um relevante instrumento para reverter a exclusão de indivíduos na educação superior. Entretanto, ainda existem ações a serem desenvolvidas com vistas ao seu aprimoramento. A partir do estudo realizado, é perceptível que, na concepção de políticas públicas no ensino superior, o gênero vem sendo preterido em relação a outros aspectos considerados nos estudos interseccionais.

Palavras-chave: Ações afirmativas, ensino superior, raça, gênero.

\section{Abstract}

\section{Affirmative Action in Brazilian Higher Education}

The aim of this paper is to examine affirmative action measures in Brazilian higher education, taking into account the perspective of race/ethnicity and gender. The qualitative study was based on documentary research. The implementation of the Quota Law has contributed to racial inclusion in Brazilian educational institutions, becoming a relevant means to reverse the exclusion of individuals from higher education. However, some actions still need to be undertaken in order to improve it. The study carried out shows that, in the design of public policies in higher education, gender has been neglected in relation to other aspects considered in intersectional studies.

Keywords: Affirmative action, higher education, race, gender.

\footnotetext{
* Instituto Federal de Educação, Ciência e Tecnologia do Espírito Santo (IFES), Guarapari, Brasil. Endereço postal: IFES, CEP 29216-795 Guarapari, Brasil.

Endereço eletrónico: elisabetecor@ifes.edu.br

** Universidade Federal do Espírito Santo (UFES), CEP 29075-910 Vitória, Brasil.

Endereço postal: UFES, CEP 29075-910 Vitória, Brasil.

Endereço eletrónico: susane.souza@ufes.br
} 


\section{Resumen}

\section{Medidas de acción afirmativa en la educación superior brasileña}

Este artículo tiene como objetivo desarrollar reflexiones sobre las medidas de acción afirmativa en la educación superior brasileña, teniendo en cuenta la perspectiva de raza/etnia y género. El estudio cualitativo se basó en una investigación documental. La implementación de la Ley de Cuotas ha contribuido a la inclusión racial en las instituciones educativas brasileñas, convirtiéndose en un instrumento relevante para revertir la exclusión de las personas en la educación superior. Sin embargo, aún quedan medidas por desarrollar con miras a su mejora. Del estudio realizado se desprende que, en el diseño de políticas públicas en la educación superior, se ha descuidado el género en relación con otros aspectos considerados en los estudios interseccionales.

Palabras clave: Acción afirmativa, educación superior, raza, género.

\section{Introdução}

No Brasil, segundo dados da PNAD Contínua (Pesquisa Nacional por Amostra de Domicílios Contínua), o número de mulheres é superior ao de homens, ou seja, mais da metade da população brasileira é composta por mulheres. Ao mesmo tempo, mais da metade da população brasileira é composta por pessoas negras, considerando o somatório de pessoas pretas e pardas (Instituto Brasileiro de Geografia e Estatística 2020).

Assim, o Brasil vem promovendo algumas ações afirmativas que contemplam aspectos tais como raça/etnia e gênero, dentre outros. Para Mendonça e Aranha $(2020,186)$, «a política de cotas raciais é uma ação afirmativa, pois tem por objetivo criar, através da discriminação positiva, a igualdade material entre brancos e negros para o acesso ao ensino superior público». Dessa forma, estudantes pretos/as ou pardos/as passaram a compor a maioria nas instituições de ensino superior da rede pública do país $(50,3 \%)$ em 2018. No entanto, permanecem sub-representados/as, já que constituem $55,8 \%$ da população, reforçando a existência das medidas que ampliam e democratizam o acesso à rede pública de ensino superior (Instituto Brasileiro de Geografia e Estatística 2019).

No que se refere à participação por sexo, dos 20 cursos de graduação mais numerosos em 2017, que reuniram 5.432.301 matrículas de graduação, verificou-se que as mulheres continuam sendo maioria em cursos tradicionalmente femininos, como Serviço Social, Enfermagem, Nutrição, Psicologia, Letras, Pedagogia e demais licenciaturas, enquanto carreiras científicas de prestígio na Física, na Matemática, na Computação e nas Engenharias permanecem como campos de conhecimento e de cultura masculinos (Instituto Nacional de Estudos e Pesquisas Educacionais Anísio Teixeira 2019).

Levando em consideração esse cenário, o presente artigo tem o objetivo de desenvolver reflexões sobre as ações afirmativas no ensino superior brasileiro, considerando a perspectiva de raça/etnia e gênero. 
Para tal, realizou-se uma busca no catálogo de teses da CAPES como as palavras-chave «ações afirmativas» e «ensino superior», sendo encontrados 256 trabalhos entre os anos de 2013 e 2021. Os resumos desses trabalhos foram lidos a fim de selecionar as pesquisas que tinham como análise as ações afirmativas no ensino superior brasileiro, as resistências e a inclusão de mulheres. Porém, no presente artigo foram considerados apenas os trabalhos mais atualizados, ou seja, publicados entre 2017 e 2021. O critério utilizado para definir o recorte temporal dos últimos cinco anos foi a fluidez do fluxo de novas publicações associadas ao tema de pesquisa. Também foi realizada pesquisa em sites governamentais brasileiros para coleta de dados sobre ações afirmativas no ensino superior. Trata-se de um estudo qualitativo e pesquisa documental, lidando-se com documentos que ainda não tinham sido sistematizados.

Além disso, para tecer reflexões sobre as ações afirmativas no ensino superior brasileiro também se tornou necessária a utilização dos estudos interseccionais, visto que a crença na superioridade inata de uma raça sobre as outras e o seu direito à predominância (racismo), a crença na superioridade inata de um sexo sobre o outro e o seu direito à predominância (sexismo), além da discriminação etária, do heterossexismo, do elitismo e do classicismo, constituem aspectos que precisam ser considerados. Afinal, «recusar-se a reconhecer a diferença torna impossível enxergar os diferentes problemas e armadilhas que nós, mulheres, enfrentamos» (Lorde 2019, 143).

\section{As ações afirmativas no ensino superior brasileiro}

Além dos tratados internacionais sobre direitos humanos, as ações afirmativas também foram se tornando cada vez mais relevantes, pois são medidas temporárias que, buscando remediar um passado discriminatório, objetivam acelerar o processo de igualdade para as mulheres e os grupos étnicos e raciais. Portanto, podem ser consideradas políticas compensatórias que buscam promover uma igualdade formal até uma igualdade material e substantiva (Organização das Nações Unidas para a Educação, a Ciência e a Cultura 2007).

Segundo Moehlecke (2002), a expressão «ação afirmativa» tem origem nos anos 1960, nos Estados Unidos, quando o país vivia um momento de reivindicações democráticas, expressas no movimento pelos direitos civis e na busca pela igualdade de oportunidades.

Barbara Bergman (1996), inicialmente, apresenta uma concepção mais fluida de ação afirmativa, indo de um programa formal com um planejamento e uma equipe para executá-lo até atividades de um gestor que, conforme sua consciência, decide agir de modo diferente.

A definição de ação afirmativa engloba políticas e parâmetros diversos, dependentes de contextos institucionais e culturais de cada país. Com isso, as jus- 
tificações públicas para a necessidade de sua implementação variam, algumas sendo multiculturalistas, enquanto outras buscam por justiça social (Feres Junior e Campos 2016).

Uma ação afirmativa pode ocorrer por meio de programas para melhorar a capacidade de grupos sub-representados em determinados contextos, a fim de terem acesso a oportunidades e a medidas que lhes dão tratamento preferencial (Foley e Williamson 2019).

Em uma perspectiva mais complexa, Bergmann $(1996,7)$ define ação afirmativa como «planejar e agir para acabar com a ausência de certos tipos de pessoas - aquelas que pertencem a grupos que foram subordinados ou deixados de fora de certos empregos e escolas.» Ela exemplifica: pode ser uma seguradora tentando modificar sua tradição de promover apenas homens brancos para cargos executivos, pode ser o escritório de admissões de uma universidade que busca aumentar o número de pessoas negras que ingressam no $1 .^{\circ}$ ano, procurando aqueles/as que podem não ter aprendido a se sair bem em testes de múltipla escolha, mas que são muito inteligentes.

No Brasil, os indicadores educacionais da população preta ou parda apresentaram melhorias entre 2016 e 2018, tanto como resultado da escolaridade acumulada ao longo das gerações quanto em decorrência de políticas públicas de acesso à educação (Instituto Brasileiro de Geografia e Estatística 2019). Contudo, é possível constatar uma desigualdade entre mulheres por meio do recorte racial. O percentual de mulheres brancas com ensino superior completo é mais do que o dobro do calculado para as mulheres pretas ou pardas.

No campo da educação superior federal, diversas medidas foram adotadas na década de 2000 visando a ampliação e a democratização no acesso ao ensino superior, como o aumento de recursos públicos para as instituições, a contratação de docentes e técnicos/as, a ampliação expressiva da quantidade de campi, e com isso, o alargamento da oferta de vagas para estudantes. Além disso, recuperou-se o investimento na universidade pública e foram adotadas políticas de expansão de acesso e permanência (Ésther 2015; Instituto Brasileiro de Geografia e Estatística 2019).

Outra ação foi o Programa Universidade para todos (PROUNI), desde 2005, por meio do qual estudantes candidatam-se a uma bolsa. Para isso, devem atender a alguns critérios: participação no Exame Nacional do Ensino Médio, obtenção de nota mínima estabelecida pelo Ministério da Educação, usufruto de renda familiar, por pessoa, de até três salários-mínimos. Outras condições também são exigidas, como ter cursado o ensino médio completo em escola pública (ou em escola privada com bolsa integral da instituição) ou ainda ser pessoa com deficiência, professor/a da rede pública de ensino básico (em efetivo exercício), integrando o quadro permanente da instituição e concorrendo a vagas em cursos de Licenciatura, Normal Superior ou Pedagogia. No entanto, os/as estudantes podem continuar excluídos/as de cursos tradicionais e elitizados, acessando, muitas vezes, o ensino superior em instituições de qualidade duvidosa (Costa e Ferreira 2017). 
A Lei de Cotas, Lei ${ }^{\circ}$ 12.711, de 29 de agosto de 2012, normatizou as cotas em todas as universidades federais brasileiras, incluindo a reserva de vagas para pessoas pretas, pardas e indígenas e para estudantes oriundos/as de escolas públicas e economicamente carentes. $\mathrm{O}$ artigo $1 .^{\circ}$ da referida Lei diz que as instituições federais de educação superior deverão reservar, no mínimo, 50\% de suas vagas para os/as estudantes que cursaram todo o ensino médio em escolas públicas. Destas, 50\% devem ser destinadas a estudantes advindos/as de famílias com renda igual ou inferior a um salário-mínimo e meio per capita.

Pessoas negras, indígenas e com deficiência terão reserva de vagas no âmbito dos primeiros 50\%, em proporção igual à existente desses grupos na população do estado onde está localizada a instituição de ensino. Importante lembrar que a reserva de vagas não garante a permanência de alunos/as, sendo necessárias outras políticas de assistência estudantil (Mendonça e Aranha 2020, 186), visto que muitos/as estudantes procedem de famílias pobres e não possuem condições econômicas para manterem seus estudos e atividades acadêmicas na universidade: gastos com transporte, alimentação e livros podem impedir que estudantes cotistas prossigam até a conclusão do curso.

No Ministério da Educação, há referência a ações afirmativas no âmbito da Educação para as Relações Étnico-Raciais, como o Programa Institucional de Iniciação Científica, que é um convênio com o CNPq para a concessão de bolsas anuais de iniciação científica para estudantes de graduação que pertençam ao público-alvo de ações afirmativas de ingresso na universidade, prioritariamente da população negra. Há também o Programa de Bolsa Permanência, uma ação do governo federal de concessão de auxílio financeiro a estudantes matriculados/as em instituições federais de ensino superior em situação de vulnerabilidade socioeconômica e para estudantes indígenas e quilombolas (Ministério da Educação 2021).

Recktenvald, Mattei e Pereira (2018), ao analisarem o Programa Nacional de Assistência Estudantil (PNAES), que tem como objetivo ampliar as condições de permanência dos/as estudantes no ensino superior público federal, verificaram que no artigo $3 .^{\circ}$ do Decreto n. ${ }^{\circ} 7.234$, que o estabelece, há uma articulação das atividades de ensino, pesquisa e extensão, dentre outras, e cita áreas de atuação das ações da assistência estudantil, como alimentação, moradia estudantil, transporte, esporte, atenção à saúde, cultura, inclusão digital, apoio pedagógico, creche e acesso, participação e aprendizagem de estudantes com deficiência, transtornos globais do desenvolvimento, altas habilidades e superdotação.

O percentual de vagas destinadas às políticas de ações afirmativas para o ano letivo de 2014 nas universidades federais da região sudeste foi de $41 \%$. Assim, os dados mostram que a implantação da Lei de Cotas vem contribuindo para a inclusão racial nessas instituições de ensino, tornando-se um relevante instrumento para reverter a atual exclusão dos indivíduos na educação superior (Silva 2019).

Oliveira (2017) observou que estudantes cotistas em cursos de alto prestígio social tendem a colaborar para a transformação das condições institucionais e inte- 
lectuais da universidade, uma vez que as formas de organização dessas instituições de ensino e as especificidades dos cursos são questionadas e confrontadas com as condições sociais dos/as alunos/as. A partir disso, são verificadas questões como mudanças curriculares, relações interpessoais na comunidade acadêmica, horário de funcionamento da universidade, etc.

Nesse mesmo sentido, Macedo (2017) realizou uma avaliação sobre a eficácia do PNAES para a permanência de cotistas nos cursos de graduação da Universidade Federal da Paraíba, entre 2012 e 2016, e concluiu que o programa abrangeu estudantes cotistas de todos os cursos da instituição, contribuindo para a permanência desses alunos e alunas. Todavia, o programa envolveu poucos/as estudantes, na medida que apenas $66 \%$ das solicitações foram atendidas, sendo necessários estudos sobre o porquê dos indeferimentos das solicitações de benefícios, o que a princípio aponta para uma elevada seletividade das solicitações.

Apesar de todas dificuldades enfrentadas por estudantes, alguns estudos apontam para a reduzida taxa de evasão de estudantes cotistas em relação à taxa de evasão de estudantes não cotistas (Souza 2019; Silva, Xavier e Costa 2020). Logo, o PNAES trouxe contribuições para a efetivação dos direitos dos/as estudantes e pode ser uma importante estratégia para ampliar o capital cultural e oportunizar a conclusão do curso (Alvarenga 2020). No entanto, percebe-se que esse programa ainda é insuficiente para atender ao quantitativo maior de estudantes que têm ingressado nas universidades públicas estaduais e federais no Brasil (Souza 2017).

Outro aspecto para além das dificuldades financeiras é o enfrentamento de situações de racismo e dificuldades de relacionamento com estudantes não cotistas (Oliveira 2017). Logo, as ações afirmativas, por meio do sistema de cotas, permitiram a emergência da diversidade racial nesses ambientes, provocando tensões até então amortizadas (Medeiros 2017).

Santos (2020) analisou as interações de caráter conflitante relacionadas aos/às estudantes negros/as cotistas na Universidade Federal Fluminense (UFF) e constatou que os conflitos raciais são frequentes e estruturados, principalmente relacionados ao campo simbólico, após a implementação da Lei de Cotas. Porém, a partir dos coletivos de estudantes negros/as na universidade, houve avanços no tratamento dos conflitos.

Assim, em movimentos de resistência contra a discriminação racial, alunos / /as cotistas desenvolvem e valorizam a convivência com os seus pares, o reconhecimento entre si, o envolvimento político (por meio do diretório acadêmico de estudantes) e a constituição de espaços de afeto, acolhimento e luta contra o racismo institucional e estrutural (Oliveira 2019; López 2020). Desse modo, a constituição de relações com professores/as e com outros/as estudantes favorece o engajamento na vida acadêmica e contribui para que estudantes cotistas se vejam e sejam reconhecidos e reconhecidas como partes da comunidade acadêmica (Assis 2019). 


\section{E as ações afirmativas com foco no gênero no ensino superior brasileiro?}

Apesar de o Brasil ter figurado entre os cinco países latino-americanos com melhores condições de resposta às transformações de famílias e mercados de trabalho no período de 2004 a 2014, e de, no mesmo período, a América Latina ter conseguido reverter ligeiramente as desigualdades socioeconômicas, a diferença entre a participação das mulheres pobres e das não pobres na força de trabalho era semelhante à existente no início daquela década. Ainda que as desigualdades socioeconômicas e de gênero estejam relacionadas, não é qualquer tipo de política que consegue promover simultaneamente a equidade socioeconômica e a equidade de gênero (Blofield e Martínez 2014).

A fim de compreender como diferentes visões do Estado sobre as mulheres permeiam o conteúdo dos objetivos, das metas e das iniciativas propostas no âmbito do Plano Plurianual (PPA) 2016-2019, Mello, Ribeiro e Marques (2020) apontam que, entre os programas temáticos desse PPA que apresentavam termos associados à dimensão de gênero, as menções às mulheres aparecem atreladas a áreas temáticas de igualdade de gênero e políticas de desenvolvimento social e sempre em conjunto com outros públicos específicos. Os esforços pela promoção de igualdade de gênero estavam concentrados em algumas partes do aparato administrativo do Executivo Federal, ocorrendo uma alta suscetibilidade dessa agenda conforme as oscilações da relevância política atribuída pelo governo. A concentração de esforços ocorreu em 11 dos ministérios vigentes na época, prevalecendo a Presidência da República e o Ministério dos Direitos Humanos. Portanto, as mudanças na Presidência da República, a partir de 2016, ainda no primeiro ano do PPA, podem ter acarretado a desarticulação na promoção da igualdade de gênero no âmbito do atual governo federal.

Cabe salientar que políticas públicas voltadas para as mulheres são menos abrangentes e estão apoiadas em uma visão tradicional do feminino que vincula a responsabilidade feminina a atividades de educação e cuidado de filhos, pessoas idosas e doentes, enquanto as políticas públicas de gênero consideram os processos de socialização entre homens e mulheres e os conflitos nessas relações, buscando promover a autonomia das mulheres (Bandeira 2005). Outro aspecto a ser mencionado é o uso simultâneo (nas políticas governamentais brasileiras) dos termos igualdade e equidade. Para Espinoza (2007), igualdade envolve uma avaliação que procura tratar todos do mesmo modo, ao passo que equidade procura tratar as pessoas de diferentes maneiras, levando em consideração as históricas injustiças vividas. De acordo com Fraser (2011) e McDonald (2013), para além de uma justiça distributiva na busca pela paridade de participação, as pessoas (em nosso estudo, as mulheres) podem ser impedidas de interagir em termos de paridade por hierarquias institucionalizadas culturalmente, que lhes negam ou dificultam certas posições, devido a uma histórica desigualdade de status e de reconhecimento, o que torna necessário políticas que promovam essa inserção. 
A partir de um olhar interseccional, Kimberlé Crenshaw, Audre Lorde, Sueli Carneiro, dentre outras, consideram que não existe hierarquia de opressões entre gênero, classe e raça, por exemplo. O que existe é um olhar a partir de uma perspectiva interseccional, procurando identificar como elas se inter-relacionam e como se somam e potencializam os efeitos sobre um determinado grupo (Berth 2019). Outrossim, Kyrillos (2020) destaca que os estudos interseccionais estão relacionados com as lutas sociais e as elaborações teóricas iniciadas por mulheres negras, e que o seu uso em estudos de gênero amplia a compreensão das diversas relações entre as desigualdades.

Nesse sentido, dentre as ações afirmativas no país está o Programa PróEquidade de Gênero e Raça, criado em 2005, que trabalha na construção de ações afirmativas que contribuam para modificar a estrutura que opera na divisão sexual do mercado de trabalho brasileiro por meio da adesão de empresas públicas e privadas que promovam a igualdade entre mulheres e homens no trabalho e reduzam a desigualdade racial (Secretaria Especial de Políticas para as Mulheres 2016; Instituto Ethos 2016).

Mesmo com esse Programa, em 2015, apenas 28,2\% dentre as 500 maiores empresas no Brasil utilizavam políticas de promoção de igualdade, como programa para contratação de mulheres, metas para a participação delas em cargos de comando, redução da desigualdade salarial, dentre outras políticas. Os motivos apontados pelas empresas para a reduzida presença feminina em cargos de comando são a insuficiente qualificação profissional para os cargos $(28,9 \%)$, a falta de interesse das próprias mulheres por cargos de maior responsabilidade $(34,2 \%)$ e a falta de experiência para lidar com o assunto (36,9\%). A contratação de mulheres em funções operacionais e administrativas causa um afunilamento hierárquico que evidencia a menor inclusão de mulheres nos níveis organizacionais elevados (Instituto Ethos 2016; Proni e Proni 2018).

Algumas das ações desenvolvidas pelas empresas participantes são: a) adoção de ações afirmativas no recrutamento e seleção de estagiários/as e jovens aprendizes com a ampliação do percentual de contratação de mulheres jovens e da população negra; b) estímulo para a adoção de ações afirmativas na cadeia de relacionamentos a fim de garantir a diversidade de gênero, raça e etnia em peças publicitárias e comunicação visual; c) adoção de cotas para contratação de mulheres em funções tradicionalmente desempenhadas por homens e adoção de cotas raciais em contratos externos. O Programa acaba promovendo uma cultura de igualdade de gênero e raça que ultrapassa o ambiente organizacional, estimulando mudanças mais amplas na sociedade (Instituto Ethos 2016; Proni e Proni 2018).

Um estudo realizado em empresas de capital aberto e que possuíam políticas específicas para gênero na área de gestão de pessoas (Coca-Cola, Nestlé, Unilever, Volkswagen, Magazine Luiza, Natura, Banco do Brasil e Petrobras) aponta uma dificuldade para a inserção de mulheres, mesmo em empresas que adotam programas e ações para a promoção da equidade de gênero: mesmo em empresas onde a 
participação feminina é crescente nos cargos de liderança, há um estreitamento de oportunidades à medida que aumenta o nível hierárquico e a defasagem salarial entre homens e mulheres é mantida (Proni e Proni 2018). Ainda que ocorram os esforços mencionados, que a educação tenha tido melhorias no país e que as mulheres venham superando os homens nos indicadores educacionais, elas ainda não alcançaram resultados compatíveis com sua qualificação no mercado de trabalho (Instituto Brasileiro de Geografia e Estatística 2018; Carvalhaes e Ribeiro 2019).

A educação foi uma das principais bandeiras do movimento feminista, visto que o processo de formação se apresentava como uma possiblidade de emancipação e de acesso ao mercado de trabalho (Carvalho e Mendes 2015). Ainda assim, Vianna e Unbehaum (2004) apontam que, no Brasil, poucas investigações consideram a discriminação de gênero nas políticas públicas educacionais.

Ocorreram muitas mudanças na força de trabalho e na educação durante as últimas décadas, pois as mulheres ampliaram sua representação, melhoraram sua remuneração e obtiveram mais reconhecimento do seu trabalho, seja por meio de subsídios e publicações, seja por meio de premiações. No entanto, persistem diferenças nos campos da ciência, tecnologia, engenharia e matemática (STEM) (Charlesworth e Banaji 2019).

Também não existe paridade entre raça e gênero em relação à desigualdade no campo do ensino superior, pois apesar de o número de mulheres estudantes ser maior do que o de estudantes homens, a distribuição entre eles está em desiquilíbrio nos diversos cursos e carreiras, o que tem reflexos na distribuição de docentes universitários/as e pesquisadores/as, assim como na distribuição de profissionais no mercado de trabalho. Além disso, os estudos sobre ciência e gênero apresentam evidências de que, apesar da melhora dos indicadores educacionais no ensino superior, as mulheres permanecem em desvantagem na carreira acadêmica e no campo científico (Barros e Mourão 2018; Carvalhaes e Ribeiro 2019).

Em estudo realizado na Universidade Federal do Espírito Santo, os dados demonstram que mais homens do que mulheres ingressam em cursos das áreas de ciências exatas e engenharias e que, entre as mulheres, as pardas e pretas estão representadas em menor número, indicando que, apesar dos avanços nos sistemas de ingresso e das políticas públicas de cotas, permanece uma sub-representação de determinados grupos raciais nos cursos considerados de maior prestígio. Outro aspecto apontado pelo estudo é que são poucas as mulheres professoras, reforçando a rarefeita presença feminina nessa área (Petinelli-Souza, Corcetti e Sartori 2021).

Mesmo as mulheres sendo maioria no ensino superior brasileiro, a escolha de cursos permanece estruturada pelo viés de gênero, com mulheres sub-representadas em cursos de maior prestígio e sobrerrepresentadas nos de menor prestígio (Carvalhaes e Ribeiro 2019).

A sub-representação das mulheres ocorre em áreas como a ciência e a tecnologia, engenharias, na indústria criativa, em cargos políticos e altos cargos em 
empresas. Por outro lado, o fenômeno da sobrerrepresentação feminina ocorre em atividades ligadas às áreas de educação infantil, cuidados com crianças, idosos e doentes, higiene e limpeza e prestação de serviços.

De qualquer modo, o governo federal não vem promovendo políticas no ensino superior que considerem o gênero, o que pode vir a prejudicar, neste caso, ainda mais as mulheres negras e mulheres pobres. Também não há política ou ação no ensino superior para aquelas mulheres que precisam de renda para permanecer estudando, tampouco para aquelas que se defrontam com a maternidade.

No âmbito educacional, existem algumas dimensões em relação à igualdade de gênero a considerar: a) haveria igualdade de gênero se existisse igualdade de acesso entre homens e mulheres, ou seja, oportunidade para ambos acessarem o mesmo tipo de educação no sistema escolar, de qualquer nível, inclusive no nível superior; b) haveria igualdade de permanência se ambos tivessem as mesmas condições de permanência no sistema de ensino durante o seu processo de formação; c) haveria igualdade de produção se ambos tivessem a probabilidade de adquirir conhecimentos semelhantes; e d) haveria igualdade de resultado se homens e mulheres tivessem as mesmas oportunidades de usufruírem de vidas com rendimentos iguais e obtivessem trabalhos do mesmo status social (Farrell 1999; Espinoza 2007). Atingir a igualdade de gênero pressupõe que os/as estudantes não sejam excluídos/as ou não sejam desencorajados/as das trajetórias que levam a melhores empregos somente porque são meninas ou mulheres.

Embora, ao longo da história, as mulheres tenham se tornado cada vez mais críticas e atentas às desigualdades que sofrem em relação aos homens, a consciência de gênero, muitas vezes, permaneceu abaixo de outras consciências coletivas, como a racial e a de classe (Aronson e Boisson 2015). Portanto, ao se constatar na atualidade a existência de mulheres que foram subalternizadas por meio da combinação de diversos processos, como o de racialização, de colonização, de exploração capitalista, dentre outros (Lugones 2019), torna-se imprescindível desenvolver ações afirmativas no formato de políticas públicas em prol da igualdade e equidade de gênero no ensino superior.

No ensino superior, as mulheres podem ter dúvidas com relação à legitimidade de sua inserção em certas áreas profissionais, originadas em estereótipos de gênero que demarcam que alguns campos do conhecimento são destinados aos homens. Isso pode levar ao abandono da área escolhida (Dasgupta e Stout 2014). Os estereótipos de gênero também produzem uma desvalorização do trabalho feminino e uma valorização do trabalho masculino, ao mesmo tempo que o gênero é atravessado por categorias sociais, como raça e etnia, classe social e idade (Valentine, Trautner e Spade 2019).

Os diplomas não conferem os mesmos ganhos para os/as profissionais formados/as, pois existem diferenças de acesso e conclusão entre estudantes em termos de gênero, etnia/raça e classe, o que pode gerar desigualdades no mercado de trabalho (Carvalhaes e Ribeiro 2019). 


\section{Conclusões}

Não há dúvidas de que as ações afirmativas no ensino superior brasileiro proporcionaram, a partir de 2000, um maior acesso de grupos que estiveram excluídos desse nível de ensino durante muitos anos. Elas também introduziram uma nova forma de organização no movimento estudantil, a partir do recorte racial, em benefício de suas próprias demandas.

Logo, as ações afirmativas no ensino superior vêm caminhando para alcançar o seu objetivo de minimizar as desigualdades sociais e raciais no Brasil. Entretanto, elas ainda não abrangem as desigualdades de gênero. Embora as mulheres sejam maioria nas universidades brasileiras, a baixa participação nos cursos de ciências exatas, matemática e engenharias (formadores de mão de obra para as profissões consideradas do futuro), faz com que elas fiquem mais vulneráveis às mudanças que a tecnologia impõe ao mercado de trabalho.

A partir do estudo realizado, torna-se perceptível que, na concepção de políticas públicas no ensino superior, o gênero vem sendo preterido em relação a outros aspectos considerados nos estudos interseccionais. No momento da pesquisa, a Secretaria Nacional de Políticas para as Mulheres, que é vinculada ao Ministério da Mulher, da Família e dos Direitos Humanos, não apresentou política nem ação específica para o ensino superior. Do mesmo modo, o Ministério da Educação não apresentou política nem ação que considerasse o gênero ou, ao menos, que fosse voltada para as mulheres.

\section{Referências bibliográficas}

Alvarenga, Paula Pereira de. 2020. «Ações afirmativas no Ensino Superior Público e as (im) possibilidades de enfrentamento da reprodução das desigualdades raciais e de classe.» Dissertação de mestrado. Universidade Federal de Lavras, Lavras, Brasil.

Aronson, Pamela, e Hélène Boisson. 2015. «Féministes ou postféministes: Les jeunes femmes, le féminisme et les rapports de genre.» Politix 1(1): 135-158. DOI: https:/ / doi. org / 10.3917 / pox.109.0135

Assis, Roney Marques Pereira de. 2019. «Afiliação social do estudante cotista da UFRGS: uma análise da permanência a partir das dinâmicas relacionais.» Dissertação de mestrado. Universidade Federal do Rio Grande do Sul, Porto Alegre, Brasil.

Bandeira, Lourdes. 2005. Brasil: fortalecimento da Secretaria Especial de politicas para as mulheres: avançar na transversalidade da perspectiva de gênero nas políticas públicas. Brasília: SPM. [Consultado em 20 de abril de 2021].

Barros, Suzane Carvalho da Vitória, e Luciana Mourão. 2018. «Panorama da participação feminina na educação superior, no mercado de trabalho e na sociedade.» Psicologia $\mathcal{E}$ Sociedade 30: 1-11. DOI: https:/ / doi.org/10.1590/1807-0310/2018v30174090

Bergmann, Barbara R. 1996. In Defense of Affirmative Action. New York: Basic Books.

Berth, Joice. 2019. Empoderamento. S. Paulo: Pólen Produção Editorial LTDA.

Blofield, Merike, e Juliana Martínez. 2014. «Trabajo, familia y cambios en la política pública en América Latina: equidad, maternalismo y corresponsabilidade.» Revista Cepal 114: 107-125. [Consultado em 20 de abril de 2021]. 
Carvalhaes, Flavio, e Carlos Antônio Costa Ribeiro. 2019.«Estratificação horizontal da educação superior no Brasil: desigualdades de classe, gênero e raça em um contexto de expansão educacional.» Tempo Social 31(1): 195-233. DOI: http:/ / dx.doi.org/10.11606/ 0103-2070.ts.2019.135035

Carvalho, Guilherme Paiva de, e Marcília Gomes Mendes. 2015. «Gênero e políticas educacionais no Brasil.» Caderno Espaço Feminino 28(1): 7-23. [Consultado em 13 de fevereiro de 2021].

Charlesworth, Tessa E.S., e Mahzarin R. Banaji, M. R. 2019. «Gender in Science, Technology, Engineering, and Mathematics: Issues, Causes, Solutions.» Journal of Neuroscience 39(37): 7228-7243. DOI: https: / / doi.org/10.1523/JNEUROSCI.0475-18.2019

Costa, Danielle Dias da, e Norma-Iracema de Barros Ferreira. 2017. «O PROUNI na educação superior brasileira: indicadores de acesso e permanência.» Avaliação: Revista da Avaliação da Educação Superior (Campinas) 22(1): 141-163. DOI: http:/ / dx.doi.org/ $10.1590 /$ s1414-40772017000100008

Dasgupta, Nilanjana, e Jane G. Stout. 2014. «Girls and Women in Science, Technology, Engineering, and Mathematics: STEMing the Tide and Broadening Participation in STEM Careers.» Policy Insights from the Behavioral and Brain Sciences 1(1): 21-29. DOI: https: / / doi.org/10.1177/ 2372732214549471

Espinoza, Oscar. 2007. «Solving the equity-equality conceptual dilemma: a new model for analysis of the educational process.» Educational Research 49(4): 343-363. DOI: https: / / doi.org/10.1080/00131880701717198

Ésther, Angelo Brigato. 2015. «Que universidade? Reflexões sobre a trajetória, identidade e perspectivas da universidade pública brasileira.» Espacio, Tiempo y Educación 2(2): 197-221. Disponível em https://www.espaciotiempoyeducacion.com/ojs/index.php/ ete/article/view/ 57 [Consultado em 20 de abril de 2021].

Farrell, Joseph P. 1999. «Changing conceptions of equality of education: forty years of comparative evidence.» In Comparative education: The dialectic of the global and the local, organizado por Robert Arnove \& Carlos Alberto Torres, 150-177. Lanham: Rowman \& Littlefield.

Feres Júnior, e João Luiz Augusto Campos. 2016. «Ação afirmativa no Brasil: multiculturalismo ou justiça social?» Lua Nova: Revista de Cultura e Política 99: 257-293. DOI: https: / / doi.org/10.1590/0102-6445257-293/99

Foley, Meraiah, e Sue Williamson. 2019. «Managerial Perspectives on Implicit Bias, Affirmative Action, and Merit.» Public Administration Review 79(1): 35-45. DOI: https:/ / doi. org/10.1111/ puar.12955

Fraser, Nancy. 2011. «Féminisme, Capitalisme et Ruses de l'Histoire.» Cahiers du Genre 50: 165-192. DOI https: / / doi.org/10.3917/ cdge.050.0165

Instituto Brasileiro de Geografia e Estatística. 2018. Desigualdades Sociais por Cor ou Raça no Brasil. Estudos e Pesquisas, Informação Demográfica e Socioeconômica. Rio de Janeiro: IBGE.

Instituto Brasileiro de Geografia e Estatística. 2019. Desigualdades Sociais por cor ou raça no Brasil. Estudos e Pesquisas, Informação Demográfica e Socioeconômica. Rio de Janeiro: IBGE.

Instituto Brasileiro de Geografia e Estatística. 2020. Pesquisa Nacional por Amostra de Domicílios Contínua. Características gerais dos domicílios e dos moradores 2019. Rio de Janeiro: IBGE.

Instituto Ethos. 2016. Perfil social, racial e de gênero das 500 maiores empresas do Brasil e suas ações afirmativas. São Paulo: BID.

Instituto Nacional de Estudos e Pesquisas Educacionais Anísio Teixeira (INEP). 2019. Resumo técnico do Censo da educação superior 2017. Brasília: Instituto Nacional de Estudos e Pesquisas Educacionais Anísio Teixeira. 
Kyrillos, Gabriela de Moraes. 2020. «Uma análise crítica sobre os antecedentes da interseccionalidade.» Revista Estudos Feministas 28(1): 1-12. DOI: https://doi.org/10.1590/ 1806-9584-2020v28n156509

López, Esteban Cipriano Costa. 2020. «O Coletivo Nuvem Negra desafiando o racismo institucional no ensino superior.» Dissertação de mestrado. Pontifícia Universidade Católica do Rio de Janeiro, Rio de Janeiro, Brasil.

Lorde, Audre. 2019. «Idade, raça, classe e gênero: mulheres redefinindo a diferença.» In Pensamento feminista: conceitos fundamentais, organizado por Eloísa Buarque de Hollanda, 239-249. Rio de Janeiro: Bazar do Tempo.

Lugones, María. 2019. «Rumo a um feminismo decolonial.» In Pensamento feminista: conceitos fundamentais, organizado por Eloísa Buarque de Hollanda, 357-377. Rio de Janeiro: Bazar do Tempo.

Macedo, Geórgia Dantas. 2017. «A eficácia do Programa Nacional de Assistência Estudantil (PNAES) para permanência dos ingressantes do sistema de cotas na UFPB.» Dissertação de mestrado. Universidade Federal da Paraíba, João Pessoa, Brasil.

McDonald, Peter. 2013. «Societal foundations for explaining low fertility: Gender equity.» Demographic Research 28: 981-994. DOI: https: / / doi.org/10.4054/DemRes.2013.28.34

Medeiros, Richelly Barbosa de. 2017. «Educação superior e sistema de cotas: a trajetória acadêmica de estudantes negros/as da Universidade Federal do Ceará - UFC.» Dissertação de mestrado. Universidade Estadual do Ceará, Fortaleza, Brasil.

Mello, Janine, Ana Camila Ribeiro, e Danusa Marques. 2020. Policy texts e o papel das ideias nas políticas públicas: visões estatais sobre as mulheres no PPA 2016-2019. Brasília/Rio de Janeiro: Ipea. [Consultado em 13 de fevereiro de 2021].

Mendonça, Erica da Silva, e Maria Lúcia Machado Aranha. 2020. «Política de cotas raciais: instrumento de promoção de equidade e justiça social.» Revista Em Pauta: teoria social e realidade contemporânea 18(45): 180-195. Disponível em https: / www.e-publicacoes. uerj.br/index.php/revistaempauta/article/view/47226 [Consultado em 20 de abril de 2021].

Ministério da Educação. 2021. Disponível no endereço http:/ / portal.mec.gov.br/programa-bolsa-permanencia [Consultado em 20 de abril de 2021].

Moehlecke, Sabrina. 2002. «Ação afirmativa: história e debates no Brasil.» Cadernos de Pesquisa 117: 197-217. DOI: https:/ / doi.org/10.1590/S0100-15742002000300011

Oliveira, Soraia Santos de. 2017. «Afiliação universitária: trajetórias de estudantes cotistas e não cotistas em cursos de alto prestígio social na Universidade Federal da Bahia.» Dissertação de mestrado. Universidade Federal da Bahia, Salvador, Brasil.

Oliveira, Guilherme dos Santos. 2019. «Coletivos de estudantes negros no ensino superior brasileiro: políticas da diversidade e organização política estudantil.» Dissertação de mestrado. Universidade do Estado do Rio de Janeiro, Duque de Caxias, Brasil.

Organização das Nações Unidas para a Educação, a Ciência e a Cultura. 2007. Ações Afirmativas e Combate ao Racismo nas Américas. Brasília, DF: Ministério da Educação, Organização das Nações Unidas.

Petinelli-Souza, Susane, Elisabete Corcetti, e Maurício Sartori. 2021. «Female under-representation in STE: The case of the Federal University of Espírito Santo.» Cuestiones de género: de la igualdad y la diferencia 16: 662-678. DOI: http:/ / dx.doi.org/10.18002/cg. v0i16.6626

Proni, Thaíssa Tamarindo da Rocha Weishaupt, e Marcelo Weishaupt Proni. 2018.«Discriminação de gênero em grandes empresas no Brasil.» Revista Estudos Feministas 26(1): 1-21. DOI: https: / / doi.org/10.1590/1806-9584.2018v26n141780 
Recktenvald, Marcelo, Lauro Mattei, e Vilmar Alves Pereira. 2018. «Avaliando o Programa Nacional de Assistência Estudantil (PNAES) sob a ótica das epistemologias.» Avaliação: Revista da Avaliação da Educação Superior (Campinas) 23(2): 405-423. DOI: https: / / doi.org/10.1590/s1414-40772018000200008

Santos, Marcelo Barbosa. 2020. «Conflitos na Universidade Federal Fluminense. Uma reflexão sobre as interações entre estudantes cotistas negros e comunidade universitária no contexto das ações afirmativas.» Tese de doutorado. Universidade Federal Fluminense, Niterói, Brasil.

Secretaria Especial de Políticas para as Mulheres. 2016. Programa Pró-Equidade de Gênero e Raça. Rompendo fronteiras no mundo do trabalho. Brasília: SPM. [Consultado em 13 de fevereiro de 2021].

Silva, Guilherme Henrique Gomes da. 2019. «Um panorama das ações afirmativas em universidades federais do sudeste brasileiro.» Cadernos de Pesquisa 49(173): 184-206. DOI: https: / / doi.org/10.1590/198053145665

Silva, Bruna Caroline Moreira; Wescley Silva Xavier, e Thiago de Melo da Costa. 2020. «Sistema de cotas e desempenho: uma comparação entre estudantes cotistas e não cotistas.» Administração Pública e Gestão Social 12(3): 1-21. DOI: https: / / doi.org/10.21118/ apgs.v12i3.6125

Souza, Jussier do Nascimento. 2017. «Avaliação da implementação da política de assistência estudantil do IFPB: estudo de caso no campus Picuí.» Dissertação de mestrado. Universidade Federal do Rio Grande do Norte, Natal, Brasil.

Souza, Eloiso Moulin de. 2019. «Affirmative action and social stereotypes: deconstructing the myth of minority inferiority.» Education Policy Analysis Archives 27(75): 1-27. DOI: https: / / doi.org/10.14507/ epaa.27.3615

Valentine, Catherine G., Mary Nell Trautner, e Joan Z. Spade (ed.). 2019. The Kaleidoscope of Gender: Prisms, Patterns, and Possibilities. London: Sage Publications.

Vianna, Cláudia Pereira, e Sandra Unbehaum. 2004. «O gênero nas políticas públicas de educação no Brasil: 1988-2002.» Cadernos de Pesquisa 34(121): 77-104. DOI: https: / / doi. org/10.1590/S0100-15742004000100005

Elisabete Corcetti. Possui graduação em Administração pela Faculdade de Ciências Econômicas, Contábeis e de Administração de Varginha (1992), mestrado em Administração pela Universidade Federal do Espírito Santo (2009), doutorado em Economia Doméstica pela Universidade Federal de Viçosa (2019) e doutorado-sanduíche em Educação pela Universidade de Lisboa (2017). Atualmente é professora do Instituto Federal de Educação, Ciência e Tecnologia do Espírito Santo.

Susane Petinelli Souza. Professora da Universidade Federal do Espírito Santo (UFES) desde 2009. Leciona no ensino superior desde 2003. Possui graduação em Administração de Empresas pela Universidade Federal do Rio Grande do Sul (2002), mestrado em Administração pela UFES (2006) e Doutorado em Educação pela UFES (2011). Sócia fundadora da SBEO - Sociedade Brasileira de Estudos Organizacionais. Atualmente é coordenadora do grupo de pesquisa MOR - Mulheres e Organizações.

Received on 5 July and accepted for publication on 14 October 2021. 


\title{
LADIES IN RED: UMA ANÁLISE DAS MEDIDAS LEGAIS DE COMBATE À VIOLÊNCIA POLÍTICA DE GÊNERO NO BRASIL E EM PORTUGAL
}

\author{
Camila Lamartine* \\ (D) https: / / orcid.org/0000-0002-0011-7773 \\ Camila Franco Henriques \\ (D) https: / / orcid.org/0000-0003-2149-8541
}

\section{Resumo}

A violência política de gênero é uma realidade que demonstra a insuficiência das ações afirmativas existentes para garantir o exercício pleno dos direitos políticos das mulheres. Assim, este artigo busca investigar de que forma Brasil e Portugal têm atuado legalmente na criação de mecanismos de enfrentamento da violência política de gênero. Foram analisados comentários de leitores nas páginas do Facebook dos jornais Público e Folha de S. Paulo, dirigidos a Dilma Rousseff e a Marisa Matias, enquadrando-os nas seguintes categorias de discriminação de gênero: Cultura Machista, Desqualificante e Ódio. Conclui-se que, apesar dos dados alarmantes de violência política contra mulheres, apenas o Brasil está em processo de discussão de medidas legais para seu enfrentamento.

Palavras-chave: Violência política de gênero, mulheres, Brasil, Portugal, ações afirmativas.

\footnotetext{
Abstract

Ladies in Red: An analysis of legal measures to combat political gender violence in Brazil and Portugal

Political gender violence is a reality that demonstrates the insufficiency of existing affirmative action measures to guarantee the full exercise of women's political rights. Thus, this article seeks to investigate how Brazil and Portugal have acted legally in the creation of mechanisms to face political gender violence. Readers' comments addressed to Dilma Rousseff and Marisa Matias and posted on the Facebook pages of the newspapers Público and Folha de S. Paulo were analysed and sorted into the following categories of gender discrimination: Sexist Culture, Disqualification and Hate. It is concluded that, despite the
}

* $\quad$ Faculdade de Ciências Sociais e Humanas (FCSH)/ Instituto de Comunicação da Nova (ICNOVA), Lisboa, Portugal.

Endereço postal: FCSH/ICNOVA, Avenida de Berna, 26-C, 1069-061 Lisboa, Portugal.

Correio eletrónico: camilalamartinemb@gmail.com

** Faculdade de Direito da Universidade de Lisboa (FDUL), Lisboa, Portugal.

Endereço postal: FDUL, Alameda da Universidade, Cidade Universitária, 1649-014 Lisboa, Portugal.

Correio eletrónico: camilafrancoh@gmail.com 
alarming data on political violence against women, only Brazil is in the process of discussing legal measures to combat it.

Keywords: Political gender violence, women, Brazil, Portugal, affirmative action.

\begin{abstract}
Résumé
Ladies in Red: Une analyse des mesures légales de lutte contre la violence politique de genre au Brésil et au Portugal

La violence politique de genre est une réalité qui démontre l'insuffisance des actions positives existantes pour garantir le plein exercice des droits politiques des femmes. Ainsi, cet article cherche à étudier comment le Brésil et le Portugal ont agi légalement dans la création de mécanismes pour faire face à la violence politique de genre. Les commentaires des lecteurs sur Facebook des journaux Público et Folha de S. Paulo ont été analysés, adressés à Dilma Rousseff et Marisa Matias, en les classant dans les catégories suivantes de discrimination de genre : Culture Machiste, Disqualification et Haine. Il est conclu que, malgré les données alarmantes sur la violence politique à l'égard des femmes, seul le Brésil est en train de discuter des mesures juridiques pour la combattre.
\end{abstract}

Mots-clés: Violence politique de genre, femmes, Brésil, Portugal, actions positives.

\title{
1. Introdução
}

A política é predominantemente masculina desde que foi criada na Grécia, sendo desigual e excludente por origem. Apenas a partir do século XX, passou-se a ter uma progressiva inserção das mulheres na vida política, com a criação de ações afirmativas, como a lei de quotas no Brasil e a lei da paridade em Portugal.

Mas a tomada de espaço político pelas mulheres, muitas vezes, parece uma intromissão. E desta aparente intromissão decorre um ambiente hostil permeado de violência, materializando-se a denominada violência política de gênero, que pode ser vista como mais uma expressão da própria violência de gênero, cujo intuito é apagar e restringir os direitos políticos das mulheres, sendo o gênero o único princípio dessa violência (Albaine 2017).

A violência política de gênero surge de diversas formas. Mulheres são silenciadas, censuradas pelas suas decisões e aparência física, chegando a ser assediadas, violentadas, e até mortas (Instituto Update 2020). Conforme informação apresentada no site do Senado brasileiro (2020), dados levantados pela ONU Mulheres em colaboração com a União Parlamentar Internacional (Inter-Parliamentary Union - IPU) mostram números alarmantes sobre violências sofridas pelas parlamentares: $82 \%$ viveram violência psicológica; $44 \%$ receberam ameaças de morte, estupro, espancamento ou sequestro; $26 \%$ sofreram violência física no parlamento. Dessas, 39\% afirmaram que as condutas impactaram negativamente em seus mandatos e liberdade de expressão. Isto demonstra que as ações afirmativas existentes, em específico as cotas, não são suficientes para assegurar o exercício dos direitos políticos das mulheres. 
Diante deste cenário, e pela necessidade de se pensar em formas de as mulheres exercerem plenamente seus direitos políticos, este estudo parte do questionamento: De que forma Brasil e Portugal têm atuado legalmente na criação de mecanismos para o enfrentamento da violência política de gênero? O seu objetivo geral é analisar a violência política de gênero, retratada pelos casos de Dilma Rousseff e Marisa Matias nas campanhas digitais \#foraDilma e \#vermelhoemBelém, e averiguar como o parlamento dos Estados brasileiro e português têm atuado no seu enfrentamento.

O presente trabalho será, assim, qualitativo e utilizará o método indutivo quanto à abordagem e o comparativo quanto ao procedimento. A pesquisa será feita por meio do levantamento bibliográfico e documental, e a análise será feita através da revisão de literatura.

O artigo se dividirá em três partes. Primeiro discorrerá sobre a evolução da inserção de mulheres na política, dando especial ênfase às leis de cotas e de paridade. Seguidamente, demonstrará a violência política de gênero, a partir dos casos de Dilma Rousseff e Marisa Matias, pela análise dos comentários no Facebook das notícias «Cunha manda e governo Temer terá que se ajoelhar, diz Dilma» do jornal Folha de S. Paulo, no Brasil, e «Insulto não diz nada sobre as mulheres, mas tudo sobre Ventura, defende Marisa Matias» do jornal Público, em Portugal. Por fim, investigará quais as medidas que Brasil e Portugal têm tomado para o enfrentamento da violência política de gênero.

\section{A participação das mulheres na política}

A política é uma forma de atuação social excludente por origem. Criada na Grécia, ela surge da criação da polis, constituinte do espaço público, frequentado apenas por homens. Enquanto isso, as mulheres eram limitadas às tarefas domésticas, no âmbito do oikos (Tiburi 2019). A polis era considerada um fim em si mesma, enquanto o oikos tinha a função de dar condições para que a vida pública se concretizasse (Azevedo 2019). Essa situação se manteve por milênios.

Foi o movimento feminista que possibilitou a entrada das mulheres no contexto político, em princípio com o sufragismo eclodido no Reino Unido (Saffioti 2013). Esses movimentos garantiram uma série de avanços na luta feminina por reconhecimento a nível de direitos humanos (Pinto 2010).

Nesta senda, discorrer-se-á, brevemente, sobre a evolução da relação entre as mulheres e a política no Brasil e em Portugal, em dois momentos: primeiro, com uma resenha histórica da inserção política das mulheres portuguesas e brasileiras e, depois, com a análise da Lei de Cotas no Brasil e da Lei da Paridade em Portugal. 


\subsection{A inserção das mulheres na politica portuguesa e brasileira}

Inserida no momento de eclosão do movimento sufragista, Carolina Beatriz Ângelo foi a primeira mulher a votar em Portugal (Lousada [2011], 4). Conforme a regulamentação eleitoral existente até a eleição da Assembleia Constituinte em maio de 1911, podiam votar todos os portugueses, maiores de 21 anos, residentes no território nacional, que soubessem ler e escrever e fossem chefes de família, dando sustento à mesma (Portugal 1911). Diante desta disposição, Carolina Beatriz Ângelo, com 33 anos, viúva, mãe de uma menina de 8 anos, médica praticante e com rendimento próprio, entrou com um pedido judicial de autorização para exercer o direito de sufrágio (Lousada [2011], 2) e consagrou-se na história portuguesa ao votar para a Assembleia Constituinte de 1911.

Para que o movimento das sufragistas não ganhasse força e se beneficiasse da abertura na legislação eleitoral, em julho de 1913 o Código Eleitoral foi alterado ${ }^{1}$, permitindo o voto a todo o cidadão português do sexo masculino, maior de 21 anos e que soubesse ler e escrever (Portugal 2013), vedando expressamente a participação feminina. Verifica-se, assim, a insistência na exclusão de mulheres do espaço político.

As mulheres só adquiriram direito a votar e serem votadas durante o Estado Novo. Maria Baptista Guardiola, Maria Domitília de Carvalho e Maria Cândida Parreira foram as primeiras mulheres eleitas deputadas. No entanto, estas mulheres não representavam a mulher portuguesa comum - analfabeta quando não era da elite, e quando era, educada até ao primeiro grau. Apesar de eleitas, não atuaram em presidências ou secretarias na Assembleia Nacional e reforçaram, por meio de seus discursos, a ideologia governamental baseada na tríade Deus-PátriaFamília, defendendo o papel das mulheres como serventes, submissas e mães (Adão e Remédios 2005, 85), sugerindo que o espaço a elas ofertado fortalecia o sistema de dominação e exclusão imposto.

No Brasil, Isabel de Mattos Dillon, em 1885, invocou a Lei Saraiva, por possuir o título de dentista, e pediu o alistamento eleitoral. O juiz de primeira instância indeferiu, alegando que a provisão eleitoral não incluía a qualificação de mulheres (A Federação 1886). Isabel recorreu e ganhou em segunda instância, mas não teve sua inscrição reconhecida no alistamento eleitoral pela mesma justificativa do juiz de primeira instância (Ministério do Interior 1889): era mulher. Décadas depois, em 1928, Celina Guimarães Viana, professora, se torna a primeira mulher a votar no Brasil diante da Lei estadual 600/1927, que estabelecia a extinção da distinção por sexo no Estado do Rio Grande do Norte.

Carlota Pereira de Queiroz foi a primeira mulher eleita deputada federal, em 1933, enquanto no Senado as primeiras representantes mulheres, Júnia Marise e

Disponível em https://purl.pt/5854/1/documentos/Legislacao\%20Eleitoral\%20-\%20REPU BLICA.pdf [Consultado a 23 de junho de 2021]. 
Marluce Pinto, só foram eleitas em 1990. Em 2011, mulheres ocuparam a mesa da presidência do Congresso Nacional, sendo Rose de Freitas vice-presidente da Câmara dos Deputados e Marta Suplicy vice-presidente do Senado.

O cargo mais alto do executivo foi exercido somente por uma mulher, Dilma Rousseff, a única presidente mulher do Brasil até o momento. Dilma sofreu impeachment na metade do seu segundo mandato, tendo exercido a presidência por 6 anos.

Mesmo com a possibilidade legal de participação de mulheres na vida política, independentemente de posicionamentos ideológicos, entre 1935 e 1974 em Portugal, não havia mulheres em cargos governamentais e seu percentual na Assembleia Nacional foi, em média, 2\% (Adão e Remédios 2005, 87). A participação de mulheres no governo «[...] entre 1976 e 1995 limitou-se a seis Ministras, 33 Secretárias de Estado e quatro Subsecretárias de Estado, o que representa 5,8\% do total dos membros dos governos deste período» (Almeida 2015, 167). Já o mais alto cargo de governação em Portugal foi desempenhado por uma mulher somente em 1979. Maria de Lurdes Pintasilgo foi nomeada Primeira-Ministra, exercendo um mandato curto de apenas cinco meses (Almeida 2015). Atualmente, as mulheres representam 39\% do parlamento (Lusa 2021).

No Brasil atual, as mulheres representam 9,94\% do total de deputados federais e $16 \%$ dos senadores, mesmo sendo mais da metade da população, sendo um dos países com menor representatividade feminina no Congresso Nacional (Toledo e Jardim 2019).

Percebe-se, assim, que há uma progressiva inserção das mulheres na vida política, tanto em Portugal, quanto no Brasil, e isso decorreu, também, diante da adoção de ações afirmativas para impulsionar a participação política feminina.

\subsection{Espaço para elas: a Lei de Cotas no Brasil e a Lei da Paridade em Portugal}

Acompanhando uma mudança global fomentada por movimentos sociais e feministas, Portugal e Brasil adotaram o sistema de paridade e de cotas, respetivamente, como uma via mais célere para o enfrentamento da desigualdade de gênero na política (Santos e Espírito-Santo 2017).

Em Portugal, as mulheres conseguiram um maior avanço legislativo a partir da implementação da Lei da Paridade no ano de 2009. Atualmente, a lei estipula que haja um mínimo de $40 \%$ de mulheres nas listas eleitorais para a Assembleia da República, autarquias e Parlamento Europeu, e impõe aos partidos a alternância de sexos nas listas, ou seja, não se pode registar duas pessoas do mesmo sexo de forma consecutiva.

Com a Lei da Paridade houve uma maior inserção política de mulheres, ainda que elas se enquadrem como minoria na maior parte dos cargos de poder e gestão (Almeida 2015, 172). Neste quesito, importa destacar que, apesar do uso do termo «paridade», houve, na realidade, a instituição de um limiar mínimo de paridade 
com o número de mulheres suficiente para compor uma massa crítica política, ou seja, um número suficiente para possibilitar mudanças (Santos e Espírito-Santo 2017, 19).

No Brasil, ações afirmativas para inclusão de mulheres na política começaram com a Lei 9.100/1995, que estipulava o mínimo de 20\% das candidaturas de cada partido ou coligação para mulheres. Dois anos depois, com a Lei 9.504/1997, foi regulado o mínimo de $30 \%$ e máximo de $70 \%$ das candidaturas para cada sexo. A alteração na lei das eleições pela lei 12.034/2009 substituiu o termo «reservar» por «preencher» no parágrafo $3 .^{\circ}$ do artigo 10 , no que diz respeito ao percentual mínimo e máximo para cada sexo.

Apesar da adoção da Lei da Paridade e da Lei de Cotas, ainda falta muito para a conquista da igualdade no sistema político, considerando que somente duas mulheres, em ambos os países aqui analisados, conseguiram ser eleitas para o cargo mais alto de comando, com a ressalva de que, em Portugal, nenhuma mulher ainda foi eleita Presidente da República. Além disso, verificou-se, no tópico anterior, que a representação das mulheres em cargos políticos e governamentais ainda está muito aquém da real representação da população (Senado Federal 2020).

A violência contra as mulheres na política é uma das formas de afastá-las desses espaços (Lunz 2021), além de outros aspectos que não serão aqui analisados, mas que devem ser, ao menos, citados, como a incipiente socialização das mulheres na política, a discriminação dentro dos próprios partidos e a falta de tempo e energia pela desigual divisão sexual do trabalho (Ferreira 1999; Almeida 2015; Santos e Espírito-Santo 2017; Lunz 2021).

A sub-representação feminina na política é um reflexo da construção social baseada no patriarcado, onde o silenciamento é o grande precursor da violência, que atinge domínios psicológicos e físicos (Biroli 2010). Práticas visíveis e invisíveis precisam ser denunciadas, mas para que isso ocorra, é necessário que se conheça e reconheça como a violência política de gênero se materializa, o que será feito a seguir.

\section{Violência política de gênero}

Antes de adentrar no componente gênero, é importante entendermos de que trata a violência política, especificamente, considerando que a violência, por si só, funciona como uma ferramenta elementar da política constituindo-se como fenômeno instrumental, uma vez que exercer política se relaciona ao exercício do poder, da centralização das relações de poder e do uso da força, ainda que de forma organizada e legítima (Lauris e Hashizume 2020, 8).

Lauris e Hashizume $(2020,11)$ sugerem quatro formas distintas de atividade pela qual a violência política se concretiza. Inicialmente, manifesta-se a partir de atos físicos, simbólicos ou de intencional desestabilização psicológica. Em segundo 
lugar, realiza-se por ações coletivas ou individuais, mas de maneira isolada, difusa ou organizada. Depois, há a inserção de uma maior demonstração de força física e de intimidação emocional ou psicológica. Por fim, apresenta os danos causados pelos adversários diretos, sejam pessoas físicas ou jurídicas.

Uma das ramificações dessa violência é a de gênero, exercida diretamente contra as mulheres, cujo mote é unicamente o componente de gênero. Ou seja, se dirige às mulheres somente porque elas são mulheres (Albaine 2017). Parece fácil identificar esse tipo de violência; no entanto, como elucida o Instituto Update $(2020,53)$, quando o gênero é fator basilar, ela está tão enraizada e entranhada na sociedade que acaba sendo naturalizada.

Impedir mulheres de exercerem o seu direito político de votar e serem votadas por meio de agressões psicológicas, sexuais ou físicas tem nome: violência política de gênero. E deve desfazer-se uma confusão comum: violência de gênero não é apenas um ataque a alguém de um gênero específico, mas sim um ataque motivado pelas expectativas sobre o papel que a vítima deveria desempenhar na sociedade. Em geral, no caso da violência contra as mulheres, seus algozes acreditam que ela não deveria ocupar outro lugar que não o da submissão (Instituto Update 2020, 52).

Como elucida Pinho (2020, 3), a América Latina tem sido ferrenha crítica neste assunto, tendo a Bolívia sido pioneira ao tipificar a violência política contra as mulheres em 2012. No México, houve a implementação da Lei sobre o Acesso das Mulheres a uma Vida Livre de Violência e do Código Federal Eleitoral em 2013.

Dessa forma, o Instituto Update define a violência política de gênero como todas as ações ou omissões, de forma direta ou indireta, que objetivam menosprezar ou anular o reconhecimento dessas mulheres, o exercício e o usufruto dos direitos e prerrogativas de um cargo público. Além disso, também é enquadrada a prática de desestímulo e limitação de mandatos femininos (Instituto Update 2020, 52).

O relatório Violência Política e Eleitoral no Brasil (Lauris e Hashizume 2020) demonstra que a experiência dos homens e mulheres em relação aos casos de violência política são drasticamente divergentes. Todavia, a constante vitimização da mulher deve ser sobreposta ao fato da ocupação de cargos políticos por elas ser menor.

Também se percebe que os maiores ataques ao sexo feminino na política dizem respeito aos abusos psicológicos, assédios e intimidações: «Trata-se de situações sistemáticas de assédio ao trabalho de determinadas/os políticas/os de grupos partidários minoritários via procedimentos, obstruções, denegação de pedidos, omissões propositais e outros tipos de estratégias de bloqueio» (Lauris e Hashizume 2020, 70).

Isto é ainda mais agravado e intensificado devido à Internet, que atua como um grande espaço fomentador da disseminação de campanhas de desinformação e fake news, pois permite que a não identificação do propagador (pelo menos não fisicamente) seja gatilho de liberdade condicional (Recuero 2014). Como corrobora 
Jenkins $(2009,7)$, a Internet desenvolve-se como um espaço público idealmente democrático, que permite a participação popular e formas inovadoras de envolvimento cívico e meios de (re)construção da opinião pública.

Essa violência direcionada às mulheres na política tem o poder sexista de ir mais além do ato em si. Serve, em certa parte, como uma ferramenta de desencorajamento, através do exemplo para os outros milhares de mulheres que tencionam adentrar no sistema político, como se o poder da tomada de decisão e governação da sociedade não fosse campo ou espaço para mulheres, voltando a premissa dicotômica do público e do privado. «Para além da forma e do objetivo, a violência política de gênero se diferencia dos ataques violentos cometidos por oponentes em meio ao embate político, em função de sua origem mais difusa» (Pinho 2020, 5).

A violência política de gênero permanece naturalizada, não vindo a ser nem ao menos reconhecida e tipificada na legislação vigente em Portugal e no Brasil. E, para demonstrar casos emblemáticos dessas questões, parte-se para a análise dos casos de Dilma Rousseff e Marisa Matias.

\section{Ladies in red: violência nos casos de Dilma Rousseff e Marisa Matias}

O vermelho é a cor mais antiga de denominação cromática do mundo e, portanto, é simbólica de todas as atitudes positivas em relação à vida. É a cor que traduz força, vida, coragem, mas também a cor da agressividade e excitação (Heller 2014, 55). Não é à toa que foi a cor escolhida por Marisa Matias e Dilma Rousseff para suas campanhas. Além de ser a cor utilizada pelos seus partidos, Bloco de Esquerda e Partido dos Trabalhadores respetivamente, é através do vermelho que intencionou-se transmitir a energia vibrante dessas políticas.

Apesar de estarem em contextos sociopolíticos diferentes, inclusive em termos de temporalidade, os casos demonstram e representam a violência política de gênero exercida sobre as mulheres políticas, pois, como visto, a violência política de gênero pode se revelar em diversos formatos, não sendo as agressões físicas as únicas a serem contempladas (Albuquerque e Alves 2018). Essa violência pode ser exercida por inúmeros agentes a começar pelo Estado, e incluindo também os partidos políticos, a mídia e até mesmo os usuários das redes sociais digitais (Albaine 2017).

Pandora Penaforte (2017), que faz um minucioso estudo acerca da contribuição dos comentários anónimos na construção da opinião pública, explicita que, particularmente, os comentários dos jornais online apresentam um teor linguístico mais ofensivo, onde os usuários verbalizam conteúdos que são prejudiciais. Para a autora, esses comentários traduzem uma total inexistência de literacia que seja capaz de pensar e fomentar um espaço público que seja de fato democrático, o que identifica, ainda, a ausência de uma democracia deliberativa. 
Esses comentários conseguem traduzir a opinião dos usuários principais do jornal e a sua participação, como no caso de um dos jornais aqui analisados, o Público que, através das caixas abertas para comentários, pretende perceber e conhecer instantaneamente a opinião dos leitores em relação a assuntos específicos (Ribeiro 2013), incluindo os que são mais complexos e delicados.

Assim, optou-se por analisar os comentários efetuados pelos leitores em duas postagens dos perfis no Facebook de grandes jornais em cada país, sendo no Brasil a Folha de São Paulo, com 5.503.455 seguidores, e o jornal Público em Portugal, com 1.184.768 seguidores. A escolha da plataforma se deu devido ao seu alcance mundial, sendo líder absoluto em número de usuários de acordo com dados do portal Statista ${ }^{2}$, sendo a primeira a superar a marca de 1 bilhão de utilizadores, somando na atualidade 2,701 bilhões de usuários ativos, além de ser bastante utilizada pela mídia como catalisador de opinião dos seus utilizadores.

Para definir as postagens analisadas, utilizou-se a ferramenta pesquisar em ambos os perfis, introduzindo o nome das mulheres políticas Dilma Rousseff (BR) e Marisa Matias (PT). Dentre as postagens filtradas, optou-se por selecionar as que vieram após ações diretas de violência política de gênero.

No caso de Dilma Rousseff, a análise se debruçou na publicação do dia 28 de maio de 2016 - três meses antes de ser destituída do cargo de presidenta - na página do Facebook da Folha de São Paulo. Intitulada "Cunha manda e governo Temer terá que se ajoelhar, diz Dilma» ${ }^{3}$, contabiliza 3,8 mil curtidas/gostos e 837 comentários.

No caso de Marisa Matias, a postagem é referente ao discurso de Matias após o ocorrido durante comício em Portalegre, que originou a campanha online \#vermelhoemBelem. A publicação do dia 15 de janeiro de 2021 no perfil do Facebook do Público «Insulto não diz nada sobre as mulheres, mas tudo sobre Ventura, defende Marisa Matias» ${ }^{4}$ computa 3,4 mil curtidas/gostos e 305 comentários.

Dos comentários contidos nas postagens, foram esmiuçados 50 no de Dilma Rousseff e 31 no de Marisa Matias, que continham algum tipo de insulto e/ ou ofensa direcionados a elas e não se repetiam, apresentando uma linguagem imprópria, falta de respeito pela diversidade e um intuito de minorar e rebaixar descaracterizando o que seria democracia deliberativa (Penaforte 2017, 10). Destes, importa relevar que sua maioria foi proferida por pessoas do sexo masculino. $\mathrm{Na}$ matéria da Folha de São Paulo registou-se 62\% de comentários masculinos para 38\% de femininos, enquanto a do Público apresentou $88,5 \%$ para $11,5 \%$.

2

https: / / www.statista.com/ statistics / 272014/ global-social-networks-ranked-by-numberof-users / [Consultado a 20 de maio de 2021].

3 https://www.facebook.com/folhadesp/posts/1364452010263465 [Consultado a 15 de maio de 2021].

4 https:// www.facebook.com/Publico/posts/10159211612026983 [Consultado a 15 de maio de 2021]. 
A fim de melhor perceber as tipologias da natureza ofensiva dos comentários, os dados foram divididos em três grandes categorias. A primeira, intitulada "Cultura Machista», inclui insultos relacionados à questão do papel social da mulher, bem como seus aspetos físicos e estéticos no tocante a um padrão de beleza utópico e subjetivamente definido. O outro núcleo de análise é o «Desqualificante», onde são alocados os comentários que fazem referência ao mansplaining, coação psicológica e desmerecimento da função ou papel desenvolvido referente ao cargo. Por fim, a terceira categoria intitula-se «Ódio», agregando todos os discursos de ódio, com caráter de violência e ainda de misoginia.

Vale ressaltar que os comentários transcritos permaneceram fiéis ao original, não sendo corrigidas pelas autoras gralhas ou faltas de pontuação.

\subsection{Cultura machista}

A cultura machista está enraizada na sociedade, pois, como refere Akotirene (2019), existem discursos proferidos pelo sexo masculino que são produzidos diretamente pela ordem patriarcal e são, por fim, os grandes responsáveis no que tange à criação de modelos subjetivos do ser feminino. Dessa forma, as mulheres são estigmatizadas como uma categoria pertencente ao outro, ao pai, ao irmão, ao marido, e acabam obrigadas a obedecer, transformando-se, também, em cúmplices da própria violência com que são deparadas cotidianamente.

Neste tópico os comentários revelam uma atenção particular em relação à imagem, até à própria alocução proferida por André Ventura, durante o comício onde questionou o uso do batom vermelho de Matias, considerando-o inadequado: «Não está muito bem em termos de imagem e performance, assim com os lábios muito vermelhos como se fosse uma coisa de brincar». Esta fala compreende um discurso machista, sexista quando enquadra a mulher como «coisa de brincar», sendo uma clara e direta violência política de gênero, pois como referem Lauris e Hashizume (2020), a intimidação psicológica e discriminatória com o agravante de conteúdo de teor ofensivo visa desestabilizar a participação política. Assim, Ventura profere este comentário dirigido a sua adversária a fim de estremecer sua candidatura e desestruturá-la.

ComM.1: Eu acho que uma sombra nos olhos e um rímel lhe ficavam melhor que o batom! COMM.2: CÁ PARA MIM A MARISA E A ANA GOMES TEM UM FRAQUINHO PELO VENTURA!

ComD.1: Ajoelhar? Será ela quando as investigações terminarem pena que vai ser prisão domiciliar, cheia de regalias podia ser em um presídio feminino normal. Ela poderia liberar os instintos sexuais a vontade]

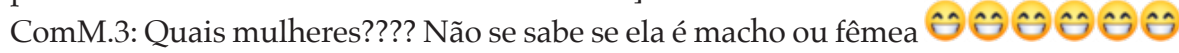
ComM.5: Anda a comer muito! Será chocolate?? 
ComD.2: Eu não entendo porque esta mulher não vai cuidar dos netos, em vez de continuar falando besteira

ComD.4: A mulher Sapiens !

Estes comentários fazem alusão ao papel social imputado às mulheres, o que, como explicam Dantas e Rubim (2018, 21), comprova a inexpressiva presença feminina nos editoriais políticos, cujo enquadramento se baseia em estereótipos de gênero com expressivo destaque às questões familiares e estéticas quando se fala de uma mulher num posto político.

\subsection{Desqualificante}

O grupo Desqualificante apresentou-se como o mais expressivo, enquadrando-se nele todos os comentários que duvidassem da capacidade das políticas, as descredibilizassem e colocassem num papel de vitimização constante, tão bem utilizado e retratado pela mídia.

Percebe-se uma necessidade masculina em demonstrar conhecimento superior, desqualificando o discurso das mulheres, em especial seu intelecto, e explicando o óbvio. Isso pode-se denominar de mansplaining ${ }^{5}$, um termo cunhado pela escritora Rebecca Solnit no livro Os homens explicam tudo para mim (2017), onde ela tece uma ferrenha crítica acerca da ideia de que, por serem mulheres, elas não saberiam de assuntos além daqueles relativos ao desempenho dos seus papéis sociais tradicionais, não sendo capazes de exercer o cargo. Isto acontece na medida em que um homem minora o conhecimento de uma mulher e tenta explicar em seu lugar a premissa de que ela, por ser mulher, não seria capaz de perceber a temática (Liguori 2015).

ComM.15: Mulher mal consigo própria e com a vida, é um problema que dispara para todas as direções. Calhou te a ti André, que não lhe deste colinho.

ComM.21: Esta Marisa é muito fraca, coitada!

ComM.24: É sempre bom haver um palhaço, para animar as hostes

ComM.25: Está na moda a teoria do coitadinho e das vítimas com telhados de vidro.

ComD.07: e uma mentirosa patológica!

ComD.16: Hahahahaha, Dilma sempre falou asneiras enquanto estava no poder, será que o afastamento a fez deixar de praticar as asneiras?

ComD.24: É tão incompetentA, que sequer soube escolher seus pares.

ComD.25: Louca, apenas isso

Como explicam Dantas e Rubim $(2018,8)$, os estereótipos mais comuns tornam-se espontaneamente identificados e acessíveis em todos os lados, sobretudo na mídia,

O termo mansplaining é resultado da fusão entre man (homem em inglês) e explain (verbo explicar em inglês), que seria em tradução «homens a explicar». 
enfatizando que esta narrativa ultrapassa a questão estética, que serve como avaliação de desempenho onde as características femininas tornam-se basilares. Portanto, é notória a associação entre desempenho e gênero neste tipo de função.

Nesta categoria, especificamente no caso de Dilma Rousseff, é importante ressaltar a prática do bropriating, muito comum em diversos comentários analisados. O bropriating também parte da união de duas palavras, a abreviação bro (de irmão em inglês) e appropiating (apropriação em inglês), que resultaria em «homens que se apropriam». Esta ação acontece quando um homem toma a ideia de uma mulher recebendo o bônus em seu lugar, a invisibilizando a partir da apropriação (Liguori 2015).

ComD.20: Pois é...a língua é o chicote...no desgoverno dela o Lula mandava, pintava, bordava, e deitava e rolava

ComD.21: Que moral essa mulher tem? Tem quem por tras ne?!

Na análise dos comentários a Dilma Rousseff, é notório o apagamento da sua desenvoltura enquanto presidente na perspetiva de que todos os seus atos de governo foram manipulados por um homem que seria seu mentor, uma vez que esta não teria capacidade para fazer tal trabalho sozinha. Para Liguori (2015) isto pode ser considerado como uma surdez seletiva que se relaciona diretamente ao gênero, onde se nega que as mulheres sejam protagonistas das suas próprias histórias.

\section{3. Ódio}

A categoria Ódio apresentou uma certa discrepância em relação às publicações analisadas, sendo a brasileira bem maior em número de comentários. No entanto, os comentários tiveram aqui um teor de violência física aprofundado com misoginia. É claramente perceptível nas entrelinhas a repulsa contida através de verdadeiros discursos de ódio e conteúdo demasiadamente ofensivo.

ComM.27: Cabra filha dum gatuno que te formatou para seres mais uma

ComM.29: Eu gostava muito de insultar esta senhora e chamar-lhe vários nomes

ComM.30: Não vales nada. Nem como mulher, nem como política.

ComD.40: Essa barra de gelo ainda ta falando?? Alguém enfia uma mandioca bem grande na boca dela pelo amor de Deus??

ComD.41: A Rainha do NADA está cada dia mais louca... a entrevada acabará no manicômio judiciário até o fim de suas penas federais

ComD.48: VAI ATÉ PRO INFERNO.

ComD.49: Continua exumando a defunta

ComD.50: VAI pro inferno que é seu lugar cão 
Isto é explicado por Recuero (2014) na medida em que o ciberespaço permite que a máscara do ecrã deixe de lado a interação presencial, tornando livre o usuário para expor seus pensamentos devido ao distanciamento físico.

É esta liberdade implícita da cibercultura que serve como espaço para a emergência de discursos de caráter agressivo, ofensivo, hostilizado e propagador de violência devido a uma errónea postura dos leitores (e cidadãos) no que diz respeito à construção verbal e opiniões desestimulantes embasadas, na maioria das vezes, em motivações partidárias (Ribeiro 2013,437).

\section{Medidas governamentais para o enfrentamento da violência política de gênero em Portugal e Brasil}

Como demonstrado, a socialização feminina somada à violência política de gênero limita e afasta esse grupo da vida política. Dessa forma, para que haja uma maior participação das mulheres na vida política é necessária a implementação de políticas públicas que atuem no favorecimento da igualdade de gênero garantindo meios emancipatórios a elas. Essas medidas dão oportunidade para que exista um desenvolvimento prático das garantias políticas e civis já conquistadas no papel, ainda que se viva numa sociedade que as discrimina e hostiliza, uma vez que tem por base o patriarcado (Pinto 2010).

Neste sentido, percebeu-se pelos dados apresentados que a participação das mulheres na vida política ainda está aquém do que representaria a quantidade das mulheres nas respetivas populações, mesmo que já tenham passados mais de 10 anos da implementação das ações afirmativas pensadas para incluí-las. Verificou-se, também, que a violência política de gênero é um dos fatos que afasta mulheres da vida política, mas que permanece sem legislação para sua repressão. Assim, importa que sejam pensadas novas medidas para o exercício pleno dos direitos políticos das mulheres.

Na América Latina, após a implementação na Bolívia, em 2012, este tema entrou na pauta legislativa no Equador, Costa Rica, México e Peru, mas não foi, ainda, aprovado. Contudo, países como Equador e Peru têm regulamentações sobre assédio político (Pinho 2020, 3), que têm como foco o combate à violência política de gênero, mesmo sem usar o termo.

No Brasil, em 2020, a Câmara dos Deputados aprovou um Projeto de Lei para o combate da violência política contra as mulheres. O Projeto de Lei 349/15 foi proposto pela deputada Rosângela Gomes e aprovado. Conceitua violência política contra as mulheres, no Art. $3^{\circ}$, como «[...] toda ação, conduta ou omissão com a finalidade de impedir, obstaculizar ou restringir os direitos políticos da mulher».

Na função de relatora, a deputada Ângela Amin reforça a importância da regulamentação e explica que, antes da Lei Maria da Penha, a violência doméstica era naturalizada, bem como a violência política de gênero ainda é. Relembrou que, 
nas últimas eleições, muitas mulheres sofreram ataques misóginos e que a Internet tem sido um meio de intensa veiculação desse tipo de violência. Pertinente se faz o cuidado de tratar, além de questões de gênero, questões de cor, raça ou etnia para proteção de candidatas e mandatárias (Amin 2020). O projeto ainda aguarda análise no Senado.

Enquanto o Brasil mostra ao menos um princípio de discussão legislativa sobre o tema, em Portugal não foram encontrados debates para proposições de ações afirmativas para o enfrentamento da violência política de gênero no âmbito legislativo.

\section{Considerações finais}

Como exposto, as mulheres, progressivamente, inserem-se na vida política, havendo um aumento percentual relevante nas últimas décadas, em especial com as ações afirmativas já existentes (Lei da Paridade e Lei de Cotas). Todavia, sua participação ainda está aquém do que se espera numa representação real e igualitária da sociedade.

É curioso observar que, em quase 80 anos de vida política das mulheres, tanto no Brasil quanto em Portugal, apenas uma mulher ocupou o cargo mais alto na chefia do Estado, ainda que em terras lusitanas nenhuma mulher tenha sido Presidente. Isto reforça a hipótese da insuficiência de ações afirmativas que fomentem a participação política das mulheres.

Relacionada à inserção política feminina, a violência política de gênero acaba por afastar as mulheres da vida política, sendo que a grande maioria dos casos se realiza através de ameaças, intimidações, ofensas e humilhações. É crucial identificar essas violências para desnaturalizá-las.

Nos casos de Dilma Rousseff e Marisa Matias, a violência política de gênero foi demonstrada, não só através dos comentários dos leitores no ciberespaço, como também nos discursos que precederam tais campanhas digitais. São ataques de ódio que devem ser melhor analisados em relação à mídia, aos jornalistas e demais formadores de opinião.

Em resposta à questão de investigação deste artigo, revela-se que apenas o Brasil possui uma discussão em andamento no Parlamento sobre a criação de mecanismos legais para o enfrentamento desta violência. Apesar disso, Portugal se mostra à frente quanto à percentagem de participação feminina no Parlamento, com 39\%, enquanto no Brasil é de 9,94\% na Câmara dos Deputados e $16 \%$ no Senado. Talvez, por isso, sinta-se mais necessidade desse debate no Brasil neste momento, reforçando a hipótese de que a violência política de gênero, dentre outros fatores, afasta as mulheres da vida política.

Contudo, provou-se que a violência política de gênero é realidade em ambos os países e a crescente participação das mulheres nesse espaço público não implica a extinção deste tipo de conduta. Pelo que se reforça a necessidade de uma maior 
investigação e um olhar mais atento em relação aos casos desse tipo de violência e à desnaturalização do papel social das mulheres. Especialmente porque é imperiosa a maior participação de mulheres nos espaços políticos, tendo em vista que elas são os melhores indivíduos para representar as demandas femininas. Tanto assim é que a proposição do Projeto de Lei, quanto à escolha das relatoras, foi feita por deputadas federais.

Neste período pandémico, em que o isolamento social deixa clara a centralidade do papel da mulher no seio familiar e no que tange à própria organização da sociedade (Instituto Update 2020), percebe-se a necessidade de avançar numa democracia mais igualitária com livre participação feminina no exercício de seus direitos políticos e nas tomadas de decisões, não só no âmbito privado, como sempre lhes foi atribuído, mas, especialmente, no âmbito público, para que haja uma efetiva possibilidade de representação e de transformação social.

\section{Referências bibliográficas}

Adão, Áurea, Maria José Remédios. 2005. «A narratividade educativa na $1^{\mathrm{a}}$ fase da governação de Oliveira Salazar. A voz das mulheres na Assembleia Nacional portuguesa (1935-1945).» Revista Lusófona de Educação 5(5): 85-109.

Akotirene, Carla. 2019. O que é interseccionalidade? São Paulo: Pólen.

Albaine, Laura. 2017. «Contra la violencia política de género en América Latina: Las oportunidades de acción.» Comunicação apresentada ao $9^{\circ}$ Congresso Latino Americano de Ciência Política, 26-28 de julho, Montevideu, Uruguai.

Albuquerque, Juliene, Elba Alves. 2018. «Apontamentos sobre a violência contra a mulher na política institucional brasileira.» Revista Debates Insubmissos 1(2): 143-163. DOI: https: / / doi.org/10.32359/ debin2018.v1.n2.p143-163

Almeida, Maria Antónia Pires. 2015. «Mulheres na política portuguesa.» In Percursos feministas: desafiar os tempos, editado por Eduarda Ferreira, Isabel Ventura, Luísa Rego, Manuela Tavares, Maria Antónia Pires de Almeida, 164-174. Lisboa: UMAR/Universidade Feminista.

Amin, Ângela. 2020. Parecer proferido em Plenário ao PL nº. 349, de 2015. Disponível no endereço https:/ / www.camara.leg.br/proposicoesWeb/prop_mostrarintegra;jsessionid=node0fh3p2ca55vqf1wkgvy5ivv66626172081. node0?codteor=1949662\&filename=Tramitacao-PL+349/2015 [Consultado em 27 de junho de 2021].

Azevedo, Camyla Galeão de. 2019. «Mulheres na política e a divisão sexual do trabalho: retratos da sub-representação feminina na política do Estado do Pará.» Dissertação de Mestrado, Programa de Pós-Graduação em Direito, Políticas Públicas e Desenvolvimento Regional, Centro Universitário do Estado do Pará. Disponível no endereço https: / / www.cesupa.br/MestradoDireito/dissertacoes / 2019/Dissertacao_Camyla_ Galeao.pdf [Consultado em 21 de maio de 2021].

Biroli, Flávia. 2010. «Gênero e família em uma sociedade justa: adesão e crítica à imparcialidade no debate contemporâneo sobre justiça.» Revista de Sociologia e Política 18(36): 51-65. DOI: https: / / doi.org/10.1590/S0104-44782010000200005

Dantas, Fernanda Argolo, Linda Oliveira Rubim. 2018. “"TCHAU QUERIDA!”: Questões de gênero na cobertura da mídia sobre o governo Dilma.» Revista Observatório 4(1): 466-491. DOI: https:/ / doi.org/10.20873/uft.2447-4266.2018v4n1p466 
A Federação. 1886. «Notícia sobre alistamento de Izabel Dillon.» A Federação (289). Partido Republicano. Disponível no endereço http://memoria.bn.br/DocReader/DocReader.aspx?bib=388653\&pesq=\%22Izabel $\% 20 \% 20$ Dillon $\% 22 \&$ pasta $=$ ano $\%$ 20188\&pagfis $=3386$ [Consultado em 23 de junho de 2021].

Ferreira, Virgínia. 1999. «Os paradoxos da situação das mulheres em Portugal.» Revista Crítica de Ciências Sociais 52/53: 199-227. Disponível no endereço http:/ / hdl.handle. net / 10316/11571 [Consultado em 25 de maio de 2021].

Heller, Eva. 2014. A psicologia das cores. Como as cores afetam a emoção e a razão. Barcelona: Editora Gustavo Gili.

Instituto Update. 2020. Eleitas: mulheres na política. Disponível no endereço https:/ / www. institutoupdate.org.br/eleitas/ [Consultado em 12 de junho de 2021].

Jenkins, Henry. 2009. «Confronting the Challenges of Participatory Culture. Media Education for the 21st Century.» The John D. and Catherine T. MacArthur Foundation. Disponível no endereço https://www.macfound.org/media/article_pdfs/jenkins_white_ paper.pdf [Consultado em 22 de novembro de 2021].

Lauris, Élida, Maurício Hashizume. 2020. Violência Política e Eleitoral no Brasil: panorama das violações de direitos humanos de 2016 a 2020. Coordenado por Élida Lauris, Sandra Carvalho, Gláucia Marinho e Darci Frigo. Curitiba: Terra de Direitos e Justiça Global. Disponível no endereço http:/ / www.global.org.br/wp-content/uploads / 2020/09/ Relat\%C3\%B3rio_Violencia-Politica_FN.pdf [Consultado em 12 de junho de 2021].

Liguori, Maíra. 2015. «O machismo também mora nos detalhes.» Disponível no https: / / www.geledes.org.br/o-machismo-tambem-mora-nos-detalhes/ [Consultado em 22 de novembro de 2021].

Lousada, Isabel. [2011]. «Escrevendo e bordando, a nação e a bandeira, as palavras e os actos: símbolos e poder pela pena de Adelaide Cabete e Carolina Beatriz Ângelo.» In Anais do XIV Seminário Nacional Mulher e Literatura / V Seminário Internacional Mulher e Literatura. Disponível no endereço https: / / run.unl.pt/ bitstream/10362 / 6936/1 / isabel_lousada.pdf [Consultado em 20 de março de 2021].

Lunz, Leandro da Silva (2021). «Mulheres na política: Myrthes Bevilácqua Carradi e Luzia Alves Toledo no poder legislativo - 1980 a 2018.» Revista do Arquivo Público do Estado do Espírito Santo 4(7): 83-96.

Lusa. 2021. «Portugal tem mais mulheres no Governo e Parlamento que média da UE». Público, Igualdade de Gênero. Disponível em https:/ / www.publico.pt/2021 / 03/07 / politica/noticia/portugal-mulheres-governo-parlamento-media-ue-1953412 [Consultado em 27 de junho de 2021].

Ministério do Interior. 1890. «Sobre o alistamento.» A Ephoca, 18 de abril, p. 2. Disponível no endereço http:// memoria.bn.br/DocReader/DocReader.aspx?bib=373370\&pesq=\% 22isabel $\% 20$ souza $\% 20 \mathrm{de} \% 20$ mattos $\% 22 \&$ pasta $=$ ano $\% 20189 \&$ pagfis $=672$ [Consultado em 23 de junho de 2021].

Penaforte, Pandora Gonçalves de Porto Guimarães. 2017. «Opiniões "sem rosto": o comentário anónimo e construção da opinião pública.» Dissertação de mestrado, ISCTE-IUL. Disponível em http:/ / hdl.handle.net/10071/14848 [consultado em 20 de setembro de 2021].

Pinho, Tássia Rabelo de. 2020. «Debaixo do Tapete: A Violência Política de Gênero e o Silêncio do Conselho de Ética da Câmara dos Deputados.» Revista Estudos Feministas 28(2). DOI: https: / / doi.org/10.1590/1806-9584-2020v28n267271

Pinto, Céli Regina Jardim. 2010. «Feminismo, História e Poder.» Revista de Sociologia e Politica 18(36): 15-23. Disponível em https:/ / www.scielo.br/j/rsocp/a/GW9TMRsY gQNzxNjZNcSBf5r / ?lang=pt\&format=pdf [Consultado em 15 de junho de 2021 
Portugal. 1911. «Código Eleitoral» Disponível no endereço http://app.parlamento.pt/ upload/Comunicar / Anexos / 2015 / N10 / codigoeleltoralabr1911.pdf [Consultado em 23 de junho de 2021].

Portugal. 1913. «Código Eleitoral.» Disponível no endereço http:/ /app.parlamento.pt/ upload/Comunicar/Anexos/2015/N10/ codigoeleitoral1913.pdf [Consultado em 23 de junho de 2021].

Recuero, Raquel. 2014. «A questão do ódio nos sites de rede social.» Disponível no http: / / www.raquelrecuero.com/arquivos / 2014/10/a-questao-do-odio-nos-sites-de-redesocial.html [Consultado em 21 de março de 2021]

Ribeiro, Fábio Fonseca. 2013. «A participação dos cidadãos nos média portugueses: estímulos e constrangimentos.» Tese de Doutoramento em Ciências da Comunicação, Especialidade de Sociologia da Comunicação, Universidade do Minho. Disponível em http://repositorium.sdum.uminho.pt/handle/1822/27212 [Consultado em $20 \mathrm{de}$ setembro de 2021].

Saffioti, Heleieth. 2013. A mulher na sociedade de classes. São Paulo: Expressão Popular.

Santos, Maria Helena, Ana Espírito-Santo. 2017. «Para além dos Números: Transformações de Género associadas à Lei da Paridade.» Journal of Studies on Citizenship and Sustainability 2: 18-34.

Senado Federal. 2020. Violência afasta mulheres da política, dizem debatedoras. Disponível no endereço https: / / www12.senado.leg.br/noticias/materias/2020/03/05/violencia-afastamulheres-da-politica-dizem-debatedoras [Consultado em 23 de novembro de 2021].

Solnit, Rebecca. 2017. Os homens explicam tudo para mim. Trad. de Isa Mara Lando. São Paulo: Cultrix.

Tiburi, Márcia. 2019. Feminismo em comum: para todas, todes e todos. Rio de Janeiro: Rosa dos Tempos.

Toledo, Cláudia Masani Queda de, e Neymilson Carlos Jardim. 2019. «A baixa representatividade feminina na política: obstáculo a ser vencido na democracia brasileira.» Revista da Faculdade de Direito da Universidade Federal de Uberlândia, 47(2):318-333. Disponível em https: / / www.researchgate.net/publication/338613921_A_baixa_representatividade _feminina_na_politica [Consultado em 22 de novembro de 2021].

Camila Lamartine. Investigadora do Instituto de Comunicação da Nova (ICNOVA). Doutoranda em Ciências da Comunicação com especialização em Ciências Sociais pela Universidade Nova de Lisboa (UNL). Membro da Associação Portuguesa de Ciências da Comunicação (SOPCOM). Jornalista e Mestre em Branding and Design pela Universidade Europeia (IADE) e Universidade da Beira Interior (UBI). Tem publicado acerca dos feminismos, ciberespaço e novos ativismos sociais.

Camila Franco Henriques. Doutoranda na Faculdade de Direito da Universidade de Lisboa. Pesquisadora de Direitos Humanos, inclusão social e desigualdade de gênero. Advogada. Integrante da Comissão da Mulher Advogada - OAB/PA. Coordenadora do Grupo de Pesquisa Gênero e Justiça - perspectivas interdisciplinares. Integrante do Núcleo de História do Direito (FDUL). Mestre em Direitos Humanos e Inclusão Social pela UFPA, com período de estudos na PUC/PR e visiting scholar na American University Washington College of Law.

Artigo recebido a 1 de julho e aceite para publicação a 10 de outubro de 2021. 



\title{
THE PARITY LAW IN PRACTICE: IMPLEMENTATION AND DIRECT OUTCOMES
}

\author{
Ana Lúcia Teixeira \\ (1) https: / / orcid.org/ 0000-0002-8086-2254 \\ Ana Espírito-Santo * \\ (D) http:/ / orcid.org/0000-0002-4059-8129 \\ Maria Helena Santos \\ (D) http:/ / orcid.org/ 0000-0001-7708-4634
}

\begin{abstract}
Portugal adopted legislative quotas in 2006, passing the so-called Parity Law which specifies that candidate lists must include a minimum representation for each sex, and neither sex can occupy more than two consecutive positions in the candidate lists. This paper follows the Gender Equality Policy in Practice (GEPP) approach and aims to deepen our understanding of the adoption and implementation process of the Parity Law in Portugal. After mapping how the law was implemented in Portugal - including a description of the tools and instruments that were set up and how the process unfolded in practice - an assessment of the policy's direct effects is carried out, contributing to the open debate on the indicators of success related to legislative quota laws.
\end{abstract}

Keywords: Parity, law, women, equality, politics.

\section{Resumo}

A Lei da Paridade na prática: implementação e impacto direto

Portugal adotou em 2006 a Lei da Paridade, que assegura uma representação mínima de cada sexo, não podendo nenhum dos sexos ocupar mais de duas posições consecutivas

* Centro Interdisciplinar de Ciências Sociais (CICS.NOVA), Faculdade de Ciências Sociais e Humanas (NOVA FCSH), Lisboa, Portugal.

Postal address: CICS.NOVA, Colégio Almada Negreiros, Campus de Campolide, 1070-312 Lisboa, Portugal.

Electronic address: analuciateixeira@fcsh.unl.pt

** ISCTE - Instituto Universitário de Lisboa (ISCTE-IUL), Centro de Investigação e Estudos de Sociologia (CIES), Lisboa, Portugal.

Postal address: CIES-IUL, Av. das Forças Armadas, 1649-026 Lisboa, Portugal.

Electronic address: ana.espirito.santo@iscte-iul.pt

*** ISCTE - Instituto Universitário de Lisboa (ISCTE-IUL), Centro de Investigação e de Intervenção Social (CIS - IUL), Lisboa, Portugal.

Postal address: CIS - IUL, Av. das Forças Armadas, 1649-026 Lisboa, Portugal.

Electronic address: helena.santos@iscte-iul.pt

NB. The work of this author is funded by national funds through FCT - Fundação para a Ciência e a Tecnologia, I.P., under the Transitory Norm - DL 57 / 2016/CP 1359/CT0023. 
nas listas eleitorais. O artigo segue a abordagem Gender Equality Policy in Practice (GEPP) e visa aprofundar a compreensão do processo de adoção e implementação da Lei da Paridade em Portugal. Depois de mapear a forma como a lei foi implementada - incluindo uma descrição das ferramentas e instrumentos que foram criados e como se desenrolou na prática - é feita uma avaliação dos efeitos diretos da política, contribuindo para o debate sobre os indicadores de sucesso relacionados com as leis de quotas.

Palavras-chave: Paridade, lei, mulheres, igualdade, política.

\section{Résumé}

La Loi sur la parité en pratique: mise en œuvre et impact direct

En 2006, le Portugal a adopté la Loi sur la parité, qui garantit une représentation minimum de chaque sexe, ne pouvant aucun des sexes occuper plus de deux positions consécutives dans les listes électorales. Cet article suit l'approche de la Politique de L'égalité de Genre en Pratique (GEPP) et vise à approfondir la compréhension du processus d'adoption et de mise en œuvre de la Loi sur la parité au Portugal. Après avoir décrit la manière dont la loi a été mise en œuvre - y compris une description des outils et instruments crées et de la manière dont elle a été appliquée dans la pratique - une évaluation des effets directs de la politique est réalisée, contribuant pour le débat sur les indicateurs de succès liés aux lois sur les quotas.

Mots-clés: Parité, loi, femmes, égalité, politique.

\section{Introduction}

This paper presents an analysis of the implementation of the Parity Law, which was adopted in Portugal in 2006 (Organic Law 3/2006, 21 August). Up until 2019, according to this law, all candidate lists presented for legislative, European, and local elections were to include at least a 33\% minimum representation for each sex, and neither sex could occupy more than two consecutive positions. Parties that did not respect this threshold were fined. In 2019, this law was revised, and now $40 \%$ is the minimum percentage required for each sex; and whereas placement mandates remained unchanged, non-compliant party lists are currently rejected (Organic Law 1/2019, 29 March).

This analysis partially follows the Gender Equality Policy in Practice Project (GEPP) approach, as described by Engeli and Mazur (2018). This approach briefly addresses the adoption of the policy, and then focuses in-depth on the subsequent processes, particularly the implementation, the evaluation, and the direct impact of the policy. The main goal of this paper is therefore to systematise and discuss the implementation process of the Portuguese Parity Law, as well as its direct impact on gender balance in political representation.

For this purpose, the paper is structured as follows. The next section deals with the pre-adoption process, where the social and political context that led to the presentation of a quota law will be analysed; followed by a look into the decision-making process and a summary of the path that led to the approval 
of the law. In the fourth section, the instruments for the implementation are introduced. Here we analyse the different aspects of the institutional context that frame the implementation of the Parity Law. The fifth section is dedicated to the implementation itself, with a discussion of all the problems that concern the different actors involved. Finally, we address the direct impact of the law, specifically its influence on the descriptive representation of women in the three levels of government.

\section{The pre-adoption process}

Since the beginning of the democratic regime in Portugal (1974), there has been an ongoing concern about the political participation of women. In the first decades of democracy, that concern was mostly voiced by the most important women's policy agency - currently named the Commission for Citizenship and Gender Equality (CIG) - which was founded in 1975, and by the non-governmental organizations (NGOs) that started appearing in that period and that were supported by CIG in its NGO Section (Monteiro and Ferreira 2012). Representatives of women's departments of political parties used to have seats on the NGO Section of CIG, a factor which was probably decisive for those parties' position on women's representation. In fact, both the Portuguese Communist Party (PCP) and the Socialist Party (PS) made very brief references to the importance of defending the increasing participation of women in political and social life in their party manifestos for the 1979 election (in the case of PCP, p. 7) and for the 1980 and 1983 elections (in the case of PS, respectively p. 22 and p. 34).

However, we argue that the issue of women's political participation in decision-making did not really enter the Portuguese political agenda until the beginning of the 1990s. A more detailed analysis of the media agenda would have to be conducted, but we believe that there were two key moments in this time period. The first is the creation of a Working Group for Parity Democracy by the NGO Section of CIG in 1990. Its first initiative was to conduct an unprecedented public hearing with all political parties on 20 May 1991 - named "Political Participation and Parity Democracy' - right before the legislative election that took place on 6 October of the same year. The main goal was to gather inputs from party leaders on their willingness (or lack thereof) for a progressive achievement of parity (information kindly provided by Ana Coucello in 2017).

Another very symbolic moment took place on 31 January and 1 February 1994, when three female Portuguese MPs from different parties (Maria Belo, PS; Maria Santos, Os Verdes (The Greens); and Margarida Salema, Social Democratic Party - PSD) organized the "Parity Parliament" with Ana Coucello (Bettencourt and Silva Pereira 1995; Cabrera, Martins and Flores 2011). «For this initiative, 115 former and current female members of Parliament invited the same number of 
male partners to sit with them in a Parity Parliament gathered to debate the situation of women, citizenship, and parity democracy» (Espírito-Santo 2018, 218). The event not only had wide media coverage at the national level (Cabrera, Martins, and Flores 2011) but also received remarkable attention at the international level, patent in multiple academic references pointing to its innovative feature and striking symbolic impact (Hubert 2001; Woodward 2002; Norris and Krook 2011) and in its replication, por instance, in Ireland (Joint Committee on Justice, Equality Defence and Women's Rights 2009).

These advancements were clearly framed by the international context, namely by the Beijing Declaration and Platform for Action and the recommendations for a parity representation from the United Nations, the European Union and the Council of Europe (particularly its Recommendation No. 1269 of 1995) (Cabrera, Martins and Flores 2011; Monteiro 2011).

The issue, now clearly focused on the possibility of the adoption of a quota law, re-appeared on the political agenda at the end of the 1990s, when PS made its first attempt to introduce a gender quota law in 1998 (Baum and Espírito-Santo 2012). Notwithstanding the fact that this bill was rejected in parliament, it increased public exposure (Viegas and Faria 2001; Jimenez 2002; Meirinho Martins and Teixeira 2005; Dias 2011). Several NGOs and CIG were particularly active in 1999 and conducted many initiatives (see Espírito-Santo 2018 for some examples of those initiatives). Consequently, the percentage of women in parliament significantly increased in 1999.

It is important to add that, since 1988, PS has had internal quotas that require a minimum of $25 \%$ of each sex in both the national party organs and all multimember lists, although they were not fully implemented until 1999 (Baum and Espírito-Santo 2012). Also, in 1997, one year before PS introduced the first bill on gender quotas, the party negotiated with PSD and managed to revise the Portuguese Constitution (CPR) to guarantee that a future bill proposing a quota law would not be declared unconstitutional (Espírito-Santo 2018). Even if these two events demonstrate that PS was planning to implement a quota law at the national level for some years, the entrance of a left-wing party - the Left Bloc (BE), a party founded in 1999 that managed to get representation in parliament in the legislative election that took place in that same year (2/230 MPs) - as a strategic competitor of PS left-leaning voters (Baum and Espírito-Santo 2012; Weeks 2018) may have expedited the process. Four other bills were presented between 2000 and 2003 by both PS and BE. None of these bills was successful.

Among the political parties, only PS and BE pushed for the Parity Law in Portugal. The three remaining parties with parliamentary representation - PCP, PSD, and the right-wing conservative Christian Democrat Party (CDS-PP) opposed quotas for different reasons and have voted against all related bills. On the one hand, PCP considers social inequalities as the real problem, hence finding gender quotas a pyrrhic solution; on the other hand, PSD and CDS-PP emphasize 
merit as the means for candidate recruitment and do not recognize any gender discrimination along their parties' lines (even though some different stances can be found, especially in PSD). Within PS and BE, the roles of some key women have been considered decisive throughout the pre-adoption process (Baum and EspíritoSanto 2012; Espírito-Santo 2018) as they are often the ones who concern themselves with these issues and who attempt to resolve them.

\section{The decision-making process}

In 2006, one bill from PS - targeted at all three different types of elections (European, legislative, and local) - and three bills from BE - one on each type of election - were passed, on their general principles, in the Assembly of the Republic. These bills all proposed the adoption of a 33\% minimum representation for each sex.

Following the normal legislative process, these four bills were eventually merged into a single document and submitted to a final overall vote. With the favourable votes of PS and BE, the final text was approved and sent to the president of the Republic for enactment. The latter (Aníbal Cavaco Silva, affiliated with PSD) decided to veto the bill because he considered the sanctions - which in that first version implied the outright rejection of non-compliant party lists - excessive.

Consequently, the bill was sent back to the Assembly and amended. The former outright rejection for non-complying lists was substituted with fines on parties. The bill passed again, although this time only with the support of PS, which had the majority in Parliament. BE decided not to back the amended bill due to the less stringent sanctions.

Throughout the years, the way this matter was framed by political parties underwent some changes. During the 1990s, when the issue started entering the political agenda of PS, the chosen narrative was marked by expressions such as «positive discrimination of the least represented sex» and «equality of opportunities for citizens of either sex», signifying quotas emerged as the solution to an inequality observed in women's participation in political decision-making. Only from 2000 onwards, probably influenced by the approval of a parity law in France in 2000, did the narrative change to a parity conception of democracy. In fact, all bills that PS introduced from 2000 onwards and that BE ever proposed on this matter have the word «parity» in their titles and do not use the word «quotas» (Espírito-Santo 2018). Irrespective of this parity-focused narrative, both PS and BE have a soft conception of parity, that is, one that does not follow the more commonly used $50 / 50$ measure, using instead a quota of at least a third - or 40\%, since 2019 - for either sex. This soft operationalisation did not follow CIG's and several NGOs' preferences for true parity (50\%) (Monteiro 2011). 


\section{The instruments for implementation}

The success of public policy lies not only in its design but also in broader contextual factors that frame its implementation. Relying on the classification of instruments for policy implementation by Ingram and Schneider (1990), we will focus on the four main types of instruments to frame the implementation of the Parity Law in Portugal: the authority instruments, which impose regulatory constraints on behaviour, i.e., they authorise or ban particular behaviours; the incentive instruments, that provide encouragements, positive (rewards) or negative (sanctions), for target groups to adopt or change a particular behaviour; the capacity and learning instruments, which aim to inform and train the several actors involved; and the symbolic and hortatory instruments, which are mostly communication tools that enable exposing the positive and negative aspects and values linked to the targeted behaviour (Engeli and Mazur 2018, 115-116).

The Parity Law was enacted at a time when there were authority instruments in place in Portugal since it emerged within a favourable constitutional framework (see Espírito-Santo 2018). Since 1976, the CPR indeed contains the principle of equality (Art. 13), prohibiting formal discrimination based on «ancestry, sex, race, language, territory of origin, religion, political or ideological convictions, education, economic situation, or social condition», and since 1997 it has been included in the class of constitutions that contain affirmative action to promote the representation of women in politics (Miranda 1998). The article 109 of the CPR states that

the direct and active participation by men and women in political life is a condition and a fundamental instrument for consolidating the democratic system, and the law should promote equality in the exercise of civil and political rights and nondiscrimination on the basis of sex for access to political positions.

The Parity Law itself considers some incentive instruments that seek to achieve the law's goals by promoting encouraging behaviours. In the 2006 version of the law, for instance, if a candidate list did not comply, the respective party would be notified to correct the situation (Art. 3). Failure to do so in due time had the following consequences (Art. 4): a) the public display of the list (outside the building of the respective district court); b) its dissemination through the website of the National Electoral Commission (CNE); and c) a reduction of public funding for electoral campaigns, depending on the degree of non-compliance (see Art. 7 for details). Regarding the current 2019 version of the law, if a candidate list does not comply, the respective party is notified to correct the situation (Art. 3), but failure to rectify the candidate list in due time now results in the rejection of the whole list (Art. 4).

In what concerns the capacity and learning instruments, «the tools that provide resources, knowledge and skills to catalyse and coordinate the actions of individual policy actors» (Engeli and Mazur 2018, 115), we find some effort among the 
political parties to promote gender equality in general and gender balance in political representation in particular, which include the organization of debates, conferences, demonstrations, and exhibitions ${ }^{1}$ to discuss and make visible the importance of a more equal participation and representation. Particularly PS and, to a lesser extent, PSD have specific training courses and capacity building initiatives, such as summer and winter schools ${ }^{2}$ and workshops ${ }^{3}$, in the case of PS, particularly through the National Department of Socialist Women; and PSD's Political Training Academy for Women. Parliament has also invested in several activities aimed at improving the debate and visibility of women in politics, such as the organization and hosting of conferences, debates, book launches, etc ${ }^{4}$. Additionally, CIG has been having a role in capacity building, putting into practice one of its main goals, which is to increase consciousness of both public opinion and political agents (Monteiro and Ferreira 2012). This includes, for instance, the translation, in 2009, of the training tool «Women Can Do It!» («Na política, as mulheres são capazes!», in the Portuguese title), originally published in 1992 by the Norwegian Labour Party Women in collaboration with AOF.

Regarding symbolic and hortatory instruments, we can highlight two awarenessraising campaigns that were launched in 2009, when the Parity Law was implemented for the first time in European, legislative, and local elections. One was promoted by the Portuguese government under the motto «Women make democracy better. Difference makes equality», and was aimed at divulging the law and emphasizing the benefits of a parity democracy; the other was a campaign developed by the Portuguese Platform for Women's Rights (a platform that congregates women's rights NGOs) entitled «50/50 - Women and Men in Political Participation», which was aimed at sensitising the population to the importance of gender-balanced political representation as a requisite for democracy ${ }^{5}$.

The Parity Law has, thus, benefited from a favourable context regarding the different types of instruments for its implementation.

1 Some of these initiatives can be found in the parties' websites or other online platforms: PSD: http: / / www.psdfamalicao.pt/_a_participacao_das_mulheres_na_politica_local_em_debate_ nas_quartas_na_sede; PCP: https://www.pcp.pt/tags/mulheres; CDS-PP: https://fb.me/e/ 1vhRQEpFD; PS: https://ps.pt/orgaos-do-partido-socialista/mulheres-socialistas-igualdadedireitos; BE: https://www.bloco.org/autarquias2/item/3239-propostas-e-pol\%C3\%ADticasmunicipais-\%C3\%A0-esquerda-igualdade-de-g\%C3\%A9nero.html [Accessed 28 June 2021]. E.g., https:// ps.pt/escola-de-verao-liderancas; https:/ / ps.pt/universidade-de-verao-comecahoje; https://ps.pt/escola-de-inverno-do-dnms; https://ps.pt/mulheres-socialistas-organiza ram-escola-de-inverno-em-matosinhos [Accessed 28 June 2021].

$3 \quad$ E.g., https:/ / ps.pt/ a-mulher-e-a-intervencao-no-espaco-publico; https: / / ps.pt / formacao-autar quica-planos-para-a-igualdade-no-poder-local [Accessed 28 June 2021].

$4 \quad$ E.g., Conference Women in Politics: Gender Policies and Visibility Strategies for Female Members of Parliament, in 2012; Equality Cafe: The Role of Women in Local Government, in 2017.

5 Both the capacity and learning instruments, as well as the symbolic and hortatory instruments, here reported consist of a sample of some examples. They are not the result of a systematic analysis. 


\section{The implementation itself}

The previously described story of the Parity Law in Portugal did not end at its approval. Political parties remain the central political actors on this matter since they are the main gatekeepers of the political system (Freire 2001; Kenny and Verge 2013). They are the ones responsible for the composition of the candidate lists and for accommodating the different interests involved.

Two strategies emerge from the implementation process which reveal only a moderate commitment with the law by most Portuguese political parties. The first one, which clearly aims to circumvent the law, constitutes an effort to comply with the law during an election only to go back to the old power structures after the ballots are counted. This happens when the candidate lists are set up according to the Parity Law rules but the winners resign from their positions and are replaced by the next candidates on the lists - this mainly happens with female winners and male substitutes. This strategy was particularly noticeable in local elections when the Parity Law was implemented for the first time, where this was done overtly in some cases (Santos and Amâncio 2012). However, this trend was not found at all in national elections (Espírito-Santo, Teixeira and Santos, forthcoming). This problem was targeted by the 2018 law revision proposal presented by the government, where «in the event of substitution of an elective mandate holder, under the terms of the applicable law, the mandate is given to a candidate of the same sex from the respective list» (Draft Law 117/XIII/3). This article was not approved.

The second strategy worth mentioning entails a tendency to comply only with the minimum requirements of the law in all elections up to the most recent one (2019) (Espírito-Santo, Teixeira and Santos, forthcoming), a propensity which had been noticed before (Teixeira 2016). Furthermore, the lower we move on the lists towards ineligible positions, the more common it is to find female candidates, revealing a still slight tendency for gendered allocation of places whenever legally possible (Espírito-Santo, Teixeira and Santos, forthcoming).

Based on interviews conducted with key actors from PS and PSD, other forms of resistances were revealed (Espírito-Santo, Teixeira and Santos, forthcoming). Although compliance with the Parity Law is never questioned, resistance towards it is still explicitly expressed by some members of PSD, who find it an exaggerated measure and worry about its supposedly missing meritocracy principle. In PS, instead, that discourse still emerges at the local but not at the national level. Another example of individual resistance, which is rather common at the local level in both parties, is the belief that there are often not enough available women candidates, particularly in rural and conservative areas (Espírito-Santo, Teixeira and Santos, forthcoming).

There are two last examples of passive institutional resistance which have helped weaken the policy's reach. According to the Parity Law, the candidate lists must guarantee a minimum representation of $40 \%$ for both men and women, and 
they must also follow a sequence rule: neither sex shall occupy more than two consecutive positions, in order to prevent women from being pushed to the bottom of the lists (hence, to ineligible positions). Although complying with the law should imply that these two rules are cumulatively followed, this has not been happening. Instead, just complying with the sequence rule has been considered good enough. Therefore, many candidate lists that comply with the sequence rule but not with the minimum threshold for either sex have been considered compliant anyway.

As mentioned earlier, the Parity Law of 2006 determined an assessment of its impact on the promotion of parity between men and women five years after approval, in 2011 (the period for assessment in the new version of the law is four years). In fact, a report was produced in $2011^{6}$, but it did not echo as expected. At the time, this academic work was not made public. Since then, only a brief report was produced on this matter (see Santos, Teixeira and Espírito-Santo 2018) 7 . This scarcity is detrimental to the implementation process, by hindering the evaluation's transparency and the commitment with gender transformation.

Considering all these deterrents, which indicate some latent resistance more than open opposition, the implementation process of the Parity Law reveals a compliance with the letter of the law but does not necessarily follow the spirit of the law.

\section{Assessing the direct impact on gender transformation}

The aim of this section is to assess the implementation of the Parity Law in its direct gender transformation outcome, i.e., the direct impact of the policy on the identified problem (Mazur 2017), which is, in this case, the underrepresentation of women in the different political elective instances. To do so, we address whether the implementation was successful in achieving the goals set by the Parity Law, i.e., its required minimum proportions (in other words, the letter of the law).

For this we will analyse a set of elections that include the pre-adoption and implementation of the Parity Law (original version of 2006 and revised version of 2019) stages, from 1999 to 2019, at different levels of government, namely seven legislative elections, five local elections, and five European elections. For this analysis, only the parties with parliamentary representation in this period will be considered ${ }^{8}$.

6 «Estudo sobre a aplicação da lei da paridade do projecto promoção da cidadania e da igualdade de género: relatório final», available at https: / / bit.ly/30A83rG [Accessed 20 May 2021].

The revised version of the law (29 March 2019) is more accurate on this: it specifically states the terms of the evaluation: every four years, CIG should produce an evaluation report on the impact of the law on the promotion of parity between men and women, including recommendations for improvement.

8 BE (Left Bloc), left-wing party; CDU (Unitary Democratic Coalition), left-wing coalition between the Portuguese Communist Party and the ecologist party Os Verdes (The Greens); PS (Socialist Party), centre-left party; PSD (Social Democratic Party), centre-right party; CDS-PP 
An analysis of the three levels of political power (European, national, and local), by political party, shows a clear effect of the implementation of the 2006 version of the Parity Law. In fact, in terms of the direct impact, the data shows that the minimum proportions required by the law $(33.3 \%)$ had been achieved when considering the candidate lists - where the law applies - for the two levels of government for which we can analyse candidates, namely European and national.

In the most recent European elections, held on 26 May 2019 and already under the revised version of the law, the percentages of female candidates presented by all candidate lists were particularly high. Hence, since 1999, as shown in Figure 1, the constitution of the candidate lists of all political parties reveals a clear success of the Parity Law. Consequently, since 2009 when, as previously mentioned, the Parity Law was implemented for the first time, the percentage of women elected to the European Parliament has increased at a much higher rate than the one registered in previous elections (see Figure 4).

\section{Figure 1}

Percentage of women candidates in European elections by political party (1999-2019)

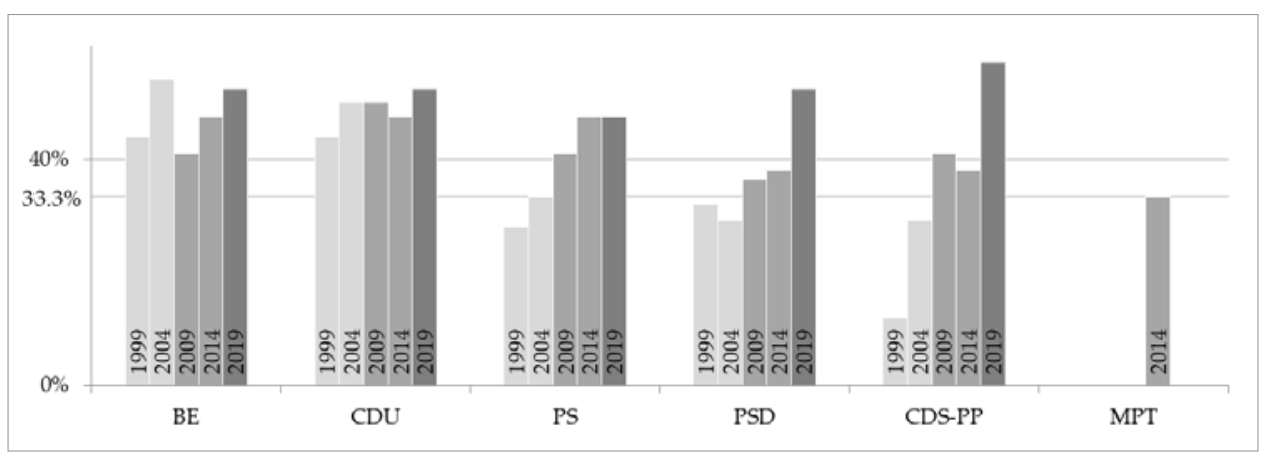

Note: In 2004 and 2014, PSD and CDS-PP ran as a coalition.

Source: SGMAI'.

With regard to national / legislative elections, the law also produced significant changes as early as 2009 (Figure 2). There was an increase in the percentage of women on all candidate lists, which was particularly visible among the political parties to the right of the political spectrum (PSD, 35.4\%, and CDS-PP, 38.0\%). In 2015, the recent People, Animals and Nature Party (PAN) stood out for the high

(People's Party), right-wing party; MPT (Earth Party), centre-right party founded in 1993; PAN (People, Animals and Nature), green party founded in 2009; LIVRE, left-wing party founded in 2014; IL (Liberal Initiative), liberal party founded in 2017; CHEGA, extreme right-wing party founded in 2019.

$9 \quad$ https:// www.sg.mai.gov.pt/AdministracaoEleitoral/EleicoesReferendos [Accessed 9 March 2021]. 
percentage of women on its lists (57.0\%); in 2019, PAN maintained its proportion of female candidates and three more parties achieved parliamentary representation: LIVRE presented a parity candidate list (50\%), Liberal Initiative (IL) presented $47.0 \%$ of female legislative candidates, and CHEGA presented $44.8 \%$ of female legislative candidates.

\section{Figure 2}

Percentage of women candidates in legislative elections by political party (1999-2019)

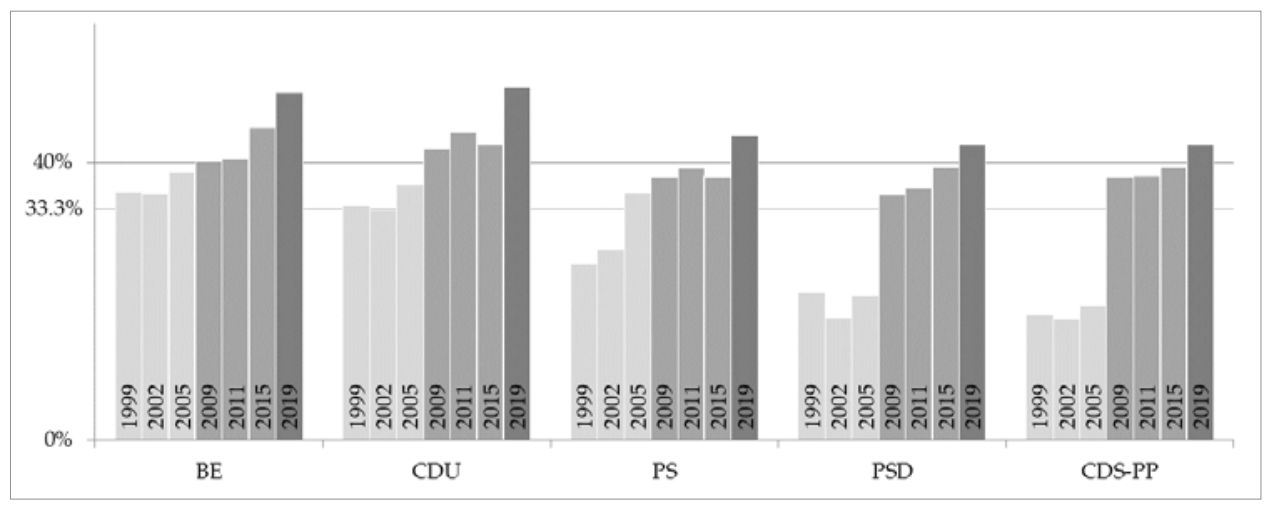

Note: In 2015, PSD and CDS-PP ran as a coalition.

Source: $\mathrm{SGMAI}^{10}$.

There is a clear increase in the percentage of women elected to Parliament as a consequence of the Parity Law (see Figure 4). Whereas in 2005 only $21.3 \%$ of women were elected to Parliament, in 2009 that percentage reached $27.8 \%$, and in 2019 it reached $38.7 \%{ }^{11}$.

Concerning local elections, we do not have data on the candidate lists, only on the elected representatives. However, we know that in every local election some candidate lists from several parties did not comply with the law, as made available by $\mathrm{CNE}$ on their website. Figure 3 presents the percentages of elected women in the four local political organs, the two deliberative organs (Municipal Assembly and Parish Assembly) and the two executive organs (City Council and Parish Council). It is clear that, in 2009, the implementation of the Parity Law boosted the proportion of elected women. However, the overall pattern remains:

https: / / www.sg.mai.gov.pt/AdministracaoEleitoral/EleicoesReferendos [Accessed 15 March 2021]. In the 2011 election, there was a small decrease $(26.5 \%)$, which might be associated with the fact that Portugal was going through an economic and political crisis. It seems that, at that time, other concerns overcame parity, indicating that the Parity Law had not changed structural gender inequalities yet. 
low proportions of female incumbents (below the desired parity threshold, except for Municipal Assembly in 2017 - 34.6\%) and a lower relative presence of women in executive bodies, displaying the persistence of the association of men to decision-making and women to decision support, shown in previous studies (Lisboa et al. 2006).

\section{Figure 3}

Percentage of women elected in local elections by organ (2001-2017)

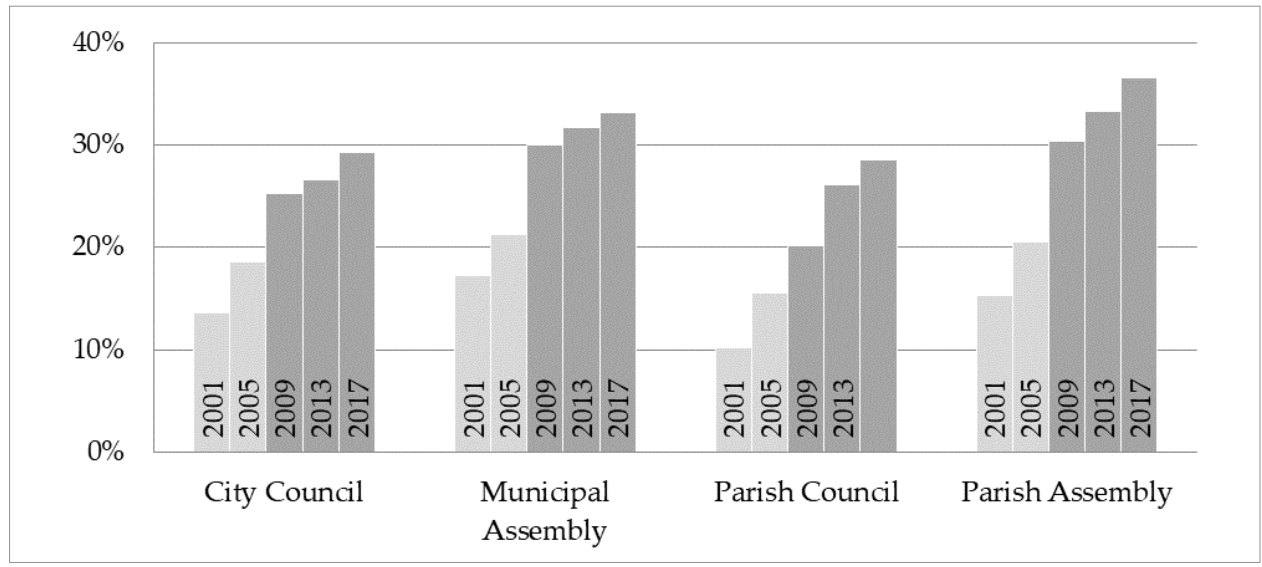

Source: SGMAI ${ }^{12}$.

Besides some cases of non-compliance with the law, namely in the local elections of 2009 to 2017, and some cases of strict compliance (for instance, the placement of women on the $3^{\text {rd }}, 6^{\text {th }}$ and $9^{\text {th }}$ positions), there is an overall compliance with the Parity Law, which resulted in a substantial increase of the proportion of elected women. Both versions of the law, in 2006 and in 2019, managed to boost previous results, as shown in Figure 4, revealing the direct gender transformation of all the elected levels of government, from a descriptive representation perspective.

However, in an analysis of the PS and PSD cases for the legislative elections (Espírito-Santo, Teixeira and Santos, forthcoming), we have found a consistently lower proportion of elected women than female candidates, hinting at a skin-deep commitment to the spirit of the law, which is to increase the share of women's political representation, while visibly complying with the letter of the law.

12 https://www.sg.mai.gov.pt/AdministracaoEleitoral/EleicoesReferendos [Accessed 15 March 2021]. Information provided by e-mail by SGMAI on 9 April 2021 regarding 2017 data. 
Figure 4

Percentage of elected women at all levels of government in Portugal, from 1999 to 2019

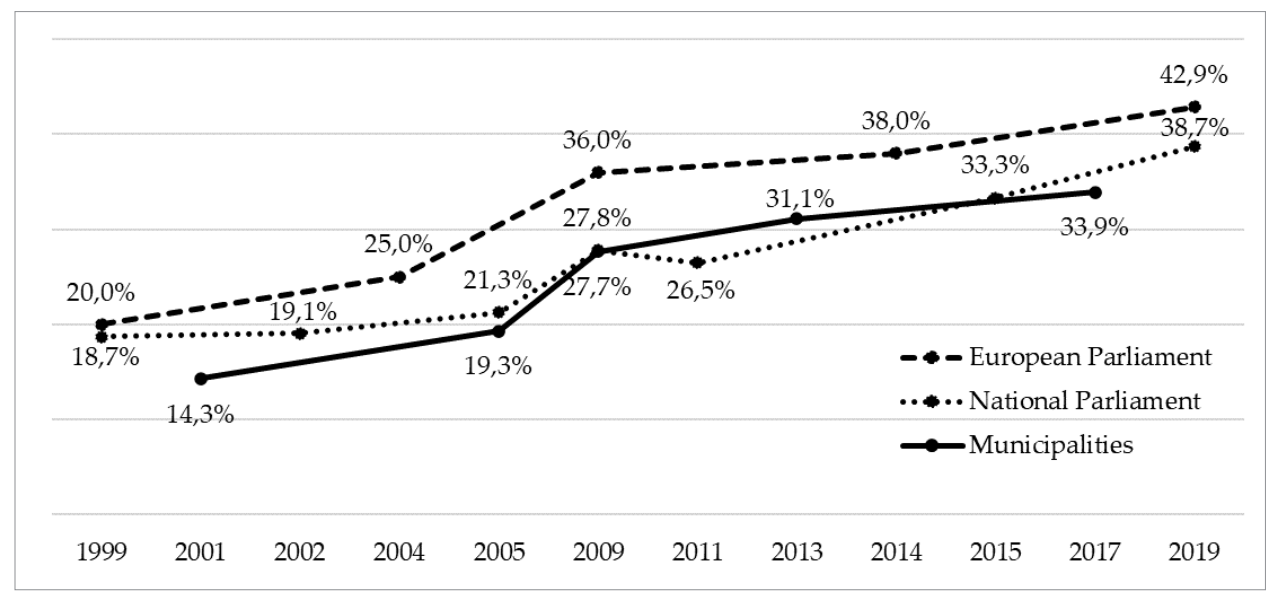

Source: SGMAI ${ }^{13}$.

\section{Conclusions}

Partially following the GEPP approach (Engeli and Mazur 2018), this paper focuses on the implementation and impact of the Parity Law adopted in Portugal in 2006 and revised in 2019. The main goal of the paper is to systematise and discuss the implementation process of the Parity Law as well as to identify to what extent this law has resulted in direct gender transformation, that is, a change in the descriptive representation of women in politics.

The Parity Law had a somewhat troubled history but found the support of both political and civil society stakeholders, although never with consensual status. At an early stage, work of internal (at Parliament level) sensitization had to be done, and the openness to this discussion surely benefited from international influences. But it was at the decision-making stage where resistance began to appear more clearly, revealing that the approved Parity Law was the attainable result of a negotiation process that ended in a script that fell short of the NGOs and the proposing parties' expectations, and resulted in a more soft approach to quota design (with a threshold of $33.3 \%$ and mild non-compliance sanctions).

Nevertheless, as we have argued, the institutional context for the implementation of the law was generally favourable in all the considered aspects (following

https: / / www.sg.mai.gov.pt/AdministracaoEleitoral/EleicoesReferendos [Accessed 9 and 15 March 2021]; regarding the 2017 local elections, information provided by e-mail by SGMAI on 9 April 2021. 
Ingram and Schneider's approach [1990]). Regarding the authority instruments, the CPR clearly states the participation by men and women in political life as a condition for consolidating the democratic system and is therefore considered to be in the class of constitutions that promote the representation of women in politics through affirmative action (Miranda 1998). Incentive instruments are also present, albeit in a negative way, in the form of non-compliance sanctions. To reinforce this feature, the 2019 revision of the Parity Law toughened sanctions. Capacity and learning instruments are also in place, with specific training and capacity-building actions being promoted by the two major political parties, along with a more broad set of activities aiming at the discussion and reflection on the importance of a gender-balanced political representation. Finally, also some symbolic actions were taken concerning sensitization to the importance of gender-balanced political representation. Consequently, the broader frame of the law's implementation can be considered positive.

It was with the implementation itself that the law faced more (covert) resistance. In fact, some practices were identified that circumvent the spirit of the law and hinder its effectiveness towards more thorough gender transformation. Despite the positive aspects of the interest shown by civil society and the action of national administrative bodies, such as CNE, some resistance was found among the main stakeholders of this process - the political parties -, revealing profound difficulties in challenging long-lasting power structures. Nevertheless, these seem to be dissipating and further studies should be conducted to analyse upcoming elections, to broaden the datasets on elections after the 2019 law revision.

In what concerns the general direct impact of the law in female political representation, the Parity Law can be considered a success, since it met its primary goal, which was to guarantee gender-balanced candidate lists. On a second level, the goal to consequently promote a balanced representation has generally been achieved, irrespective of the level of government considered: even though $40 \%$ of effective representation was only achieved among the European MPs (in 2019), the proportion of elected women has been consistently increasing and this growth has been more substantial since the Parity Law is in place.

Even though this was our goal, we have only discussed a part of the law's impact - the direct policy goals, i.e., descriptive representation. However, there are some signs that these transformations did not affect the more rooted gender asymmetries, since they did not eliminate most gender hierarchies that persist in the political world. In fact, the most powerful positions in Parliament and local governments are still overwhelmingly held by men. Furthermore, previous studies have shown a perception among female politicians that power is still in men's hands, and there is generalised consensus towards a soft approach to parity (Santos and Espírito-Santo 2017). Hence, notwithstanding great improvement, politics in Portugal still remains a gendered world. 


\section{References}

Baum, Michael, and Ana Espírito-Santo. 2012. «Portugal's 2006 Quota/Parity Law: An Analysis of its Adoption.» West European Politics 35(2): 319-342. DOI: https: / / doi.org / 10.1080/01402382.2011.648009

Bettencourt, Ana Maria, and Maria Margarida Pereira. 1995. Mulheres políticas: As suas causas. Lisboa: Quetzal Editores.

Cabrera, Ana, Carla Martins, and Teresa Mendes Flores. 2011. «Representações mediáticas das deputadas portuguesas: O "caso" do Parlamento Paritário.» Brazilian Journalism Research 7(11): 75-93. DOI: https: / / doi.org/10.25200/BJR.v7n2.2011.339

Dias, Nuno. 2011. «A paridade no Parlamento: itinerário de um paradigma.» Dinâmia Working Paper, 2011/20.

Engeli, Isabelle, and Amy Mazur. 2018. «Taking implementation seriously in assessing success: the politics of gender equality policy.» European Journal of Politics and Gender 1(12): 111-129. DOI: https: / / doi.org/10.1332/251510818X15282097548558

Espírito-Santo, Ana. 2018. «From Electoral to Corporate Board Quotas: The Case of Portugal» In Transforming Gender Citizenship. The Irresistible Rise of Gender Quotas in Europe, edited by Eléonore Lépinard and Ruth Rubio-Marín, 216-244. Cambridge: Cambridge University Press.

Espírito-Santo, Ana, Teixeira, Ana Lúcia, and Santos, Maria Helena. Forthcoming. «Implementing Gender Quotas in Portugal - A Success Story?» In Implementing Gender Quotas in Political Representation: Resisting Institutions, edited by Sabine Lang, Petra Meier, and Birgit Sauer. London: Palgrave.

Freire, André. 2001. «Sistema político, partidos e recrutamento parlamentar.» In Recrutamento parlamentar - Os deputados portugueses da Constituinte à VIII Legislatura, edited by André Freire, 23-53. Lisboa: STAPE.

Hubert, Agnès. 2001. «From Equal Pay to Parity Democracy: The Rocky Ride of Women's Policy in the European Union.» In Has Liberalism Failed Women? Assuring Equal Representation in Europe and the United States, edited by Jytte Klausen and Charles S. Maier, 143-163. New York: Palgrave.

Ingram, Helen, and Ann Schneider. 1990. «Improving Implementation by Framing Smarter Statutes.» Journal of Public Policy 10(1): 67-88. DOI: https: / / doi.org/10.1017 / S0143814 X00004682

Jiménez, Antonia María Ruiz. 2002. Mecanismos del cambio ideológico e introducción de políticas de género en partidos conservadores: el caso de AP-PP en España en perspectiva comparada. Madrid: Centro de Estudios Avanzados en Ciencias Sociales.

Joint Committee on Justice, Equality Defence and Women's Rights. 2009. Women's Participation in Politics. Second Report. Available at https://data.oireachtas.ie/ie/oireachtas/ committee/dail/32/joint_committee_on_justice_and_equality / reports / 2009/200911-05_women-s-participation-in-politics_en.pdf

Kenny, Meryl, and Tania Verge. 2013. «Decentralization, Political Parties, and Women's Representation: Evidence from Spain and Britain.» Publius: The Journal of Federalism 43(1): 109-128. DOI: https: / / doi.org/10.1093/publius/pjs023

Lisboa, Manuel, Graça Frias, Ana Roque, and Dalila Cerejo. 2006. «Participação das mulheres nas elites políticas e económicas no Portugal democrático (25 de Abril de 1974 a 2004).» Revista da Faculdade de Ciências Sociais e Humanas 18: 163-187.

Mazur, Amy. 2017. «Toward the Systematic Study of Feminist Policy in Practice: An Essential First Step.» Journal of Women, Politics E Policy 38(1): 64-83. DOI: http: / / dx.doi.org / 10.1080/1554477X.2016.1198210 
Meirinho Martins, Manuel, and Conceição Pequito Teixeira. 2005. O funcionamento dos partidos e a participação das mulheres na vida política e partidária. Lisboa: Comissão para a Igualdade e para os Direitos das Mulheres.

Miranda, Jorge. 1998. «Igualdade e participação política da mulher.» In Democracia com mais Cidadania: A questão da igualdade de participação política, edited by Vitorino Canas, Joana de Barros, Jorge Miranda, Leonor Beleza, Lúcia Amaral, Luísa Duarte, and Vital Moreira, 37-46. Lisboa: INCM.

Monteiro, Rosa. 2011. «A política de quotas em Portugal: O papel dos partidos políticos e do feminismo de Estado.» Revista Crítica de Ciências Sociais 92: 31-50. DOI: https: / doi. org $/ 10.4000 /$ rccs.3953

Monteiro, Rosa, and Virgínia Ferreira. 2012. «Metamorfoses das relações entre o Estado e os movimentos de mulheres em Portugal: Entre a institucionalização e a autonomia.» ex aequo 25: 13-27.

Norris, Pipa, and Mona Lena Krook. 2011. Gender Equality in Elected Office: A Six-Step Action Plan. Organization for Security and Co-operation in Europe. Available at https: / / www. osce.org/odihr/78432

Santos, Maria Helena, and Lígia Amâncio. 2012. «Género e política: Análise sobre as resistências nos discursos e nas práticas sociais face à Lei da Paridade.» Sociologia, Problemas e Práticas 68: 79-101. DOI: https:/ / doi.org/10.7458/SPP201268694

Santos, Maria Helena, Ana Lúcia Teixeira, and Ana Espírito-Santo. 2018. Balanço da implementação da Lei da Paridade em diferentes níveis de governo: Análise longitudinal. Lisboa: SECI /CIG. Available at https: / / www.cig.gov.pt/ 2018/03/ balanco-da-implementacaoda-lei-da-paridade-diferentes-niveis-governo-analise-longitudinal

Santos, Maria Helena, and Ana Espírito-Santo. 2017. «Para além dos números: Transformações de género associadas à Lei da Paridade.» Journal of Studies on Citizenship and Sustainability 2: 18-34.

Teixeira, Ana Lúcia. 2016. «Desigualdades de género nos cargos políticos em Portugal: Do poder central ao poder local.» $\mathrm{PhD}$ dissertation, Faculdade de Ciências Sociais e Humanas, Universidade Nova de Lisboa. Available at http:/ / hdl.handle.net/10362/ 20614.

Viegas, José Leite, and Sérgio Faria. 2001. As mulheres na política. Oeiras: Celta Editora.

Weeks, Ana Catalano. 2018. «Why Are Gender Quota Laws Adopted by Men? The Role of Inter- and Intraparty Competition.» Comparative Political Studies 51(14): 1935-1973. DOI: https: / / doi.org/10.1177/0010414018758762

Woodward, Alison. 2002. Going for Parity. Strasbourg: Council of Europe Publishing.

Ana Lúcia Teixeira. Has a PhD in Sociology and a master's degree in Data Prospecting and Analysis. She is an assistant professor at the Department of Sociology of the School of Social Sciences and Humanities, Universidade Nova de Lisboa (NOVA FCSH), and an integrated researcher at the Interdisciplinary Centre for Social Sciences (CICS.NOVA). Her research interests have focused on gender inequalities, in particular in the field of politics and violence against women, domestic violence and gender-based violence. 
Ana Espírito-Santo. Completed her $\mathrm{PhD}$ in Political and Social Sciences at the European University Institute (EUI), Florence, in 2011. Currently, she is an assistant professor at the Department of Political Science and Public Policies, ISCTE-IUL and a senior researcher at CIES-IUL (Lisbon, Portugal). Her main research interests are gender and politics, comparative politics and political representation. For more information see: http: / / www.anaespiritosanto.com/

Maria Helena Santos. Completed her PhD in Social and Organisational Psychology at the Instituto Universitário de Lisboa (ISCTE-IUL) in 2011. She is currently a researcher at CIS-IUL/ISCTE-IUL, Portugal. Her main research interests focus on gender studies and affirmative action in professional contexts that are markedly feminine and masculine, with a special emphasis on politics. She is the author and co-author of several books, chapters, and articles in national and international scientific journals.

Artigo recebido a 5 de julho e aceite para publicação em 14 de outubro de 2021. 



\title{
PARA UMA CRÍTICA PÓS-COLONIAL/DESCOLONIAL DAS RELAÇÕES SOCIAIS EM CONTEXTO ACADÉMICO: VOZES DE ESTUDANTES BRASILEIRAS
}

\author{
Rovênia Amorim Borges* \\ (D) https: / / orcid.org/0000-0001-8259-5623 \\ Almerindo Janela Afonso \\ (10) https: / / orcid.org/ 0000-0001-9879-5814
}

\section{Resumo}

As experiências de internacionalização e mobilidade estudantil têm vindo a aumentar, ainda que de forma muito assimétrica entre países. Portugal tem acolhido estudantes de diferentes procedências geográficas, sendo particularmente expressiva a presença de brasileiras/os no ensino superior. No que diz respeito às estudantes, este estudo revela que as relações sociais e académicas não são atravessadas apenas por estereótipos de género. Numa análise crítica mais ampla e profunda, conceitos teóricos pós-coloniais/descoloniais (como colonialidade de poder) e a metodologia interseccional permitem perceber condições de subalternidade na interação complexa das identidades étnico-raciais, de género e de nacionalidade.

Palavras-chave: Mobilidade estudantil, Brasil-Portugal, colonialidade de poder, interseccionalidade.

\section{Abstract \\ Towards a Postcolonial/Decolonial Critique of Social Relations in Academic Context: Voices of Brazilian female students \\ Experiences in internationalization and student mobility have been increasing, albeit in a very asymmetric way between countries. Portugal has welcomed students from different geographical origins, with the presence of Brazilians in higher education being particularly expressive. In regard to female students, this study reveals that social and academic relationships are not permeated only by gender stereotypes. In a broader and deeper critical analysis, postcolonial/decolonial theoretical concepts (such as coloniality of power) and intersectional methodology allow us to perceive subalternity conditions in the complex interaction of ethnic-racial, gender and national identities.}

Keywords: Student mobility, Brazil-Portugal, coloniality of power, intersectionality.

\footnotetext{
* Universidade do Minho (UM), Gualtar, Braga, Portugal.

Endereço postal: Universidade do Minho, 4710-057 Gualtar, Braga, Portugal.

Endereço eletrónico: roveniaa@gmail.com

** Universidade do Minho (UM), Gualtar, Braga, Portugal.

Endereço postal: Universidade do Minho, 4710-057 Gualtar, Braga, Portugal.

Endereço eletrónico: ajafonso@ie.uminho.pt
} 


\begin{abstract}
Résumé
Pour une critique postcoloniale/décoloniale des relations sociales dans un contexte académique: voix de étudiantes brésiliennes

Les expériences d'internationalisation et de mobilité des étudiants se sont multipliées, bien que de manière très asymétrique entre les pays. Le Portugal a accueilli des étudiants d'origines géographiques différentes, et la présence de brésiliens dans l'enseignement supérieur est particulièrement expressive. Notre étude montre que les relations sociales et académiques, en particulier en ce qui concerne les étudiantes, ne sont pas seulement traversées par des stéréotypes de genre. Dans une analyse critique plus large et plus approfondie, les concepts théoriques postcoloniales/décoloniales (tel que la colonialité du pouvoir) et la méthodologie intersectionnelle nous ont permis de percevoir conditions de subalternité dans l'interaction complexe des identités ethniques-raciales, de genre et de nationalité.
\end{abstract}

Mots-clés: Mobilité étudiante, Brésil-Portugal, colonialité du pouvoir, intersectionnalité.

\title{
1. Introdução
}

No contexto global de economias baseadas no conhecimento, universidades de diferentes países e continentes têm buscado alcançar e manter posições competitivas em termos de pesquisa e de ensino. Em Portugal, como efeito das políticas e estratégias de internacionalização do ensino superior, que não podem ser desligadas do espaço geopolítico lusófono-europeu e de uma «impressão neocolonial» (França, Alves e Padilha 2018, 335), verificou-se na última década, até à crise pandémica, a intensificação dos fluxos de estudantes das antigas colónias, principalmente do Brasil (DGEEC 2019). Tal como tem sido preocupação de outros estudos (Merçon 2020), interessa-nos, neste caso, perceber como é vivenciada a receção e presença de estudantes brasileiras no ensino superior português, tendo como foco essencial as interações sociais e académicas, frequentemente intersectadas por representações estereotipadas das condições e identidades étnico-raciais, de género e de nacionalidade, que, por sua vez, são passíveis de ser interpretadas por referência a estruturas de poder com ressonâncias históricas coloniais.

Trata-se de um fenómeno complexo, justificando assim a opção pela abordagem pós/(des)colonial e pela metodologia da interseccionalidade quali-quanti na análise dos dados estatísticos e de outros elementos recolhidos através de questionários e entrevistas com estudantes em mobilidade. Género, raça, nacionalidade e outras variáveis importantes não devem ser estudadas de forma isolada uma vez que há níveis sobrepostos de desigualdade que, «à primeira vista, estão invisíveis» (Lutz 2015, 39) ou costumam ser «negligenciados» (Mackinnon 2013, 1020). Mesmo que estudar no exterior do Brasil seja ainda um privilégio da (vulgarmente considerada) elite branca, estudantes negras/os ${ }^{11}$ e pobres têm sabido aproveitar as

Quando não foi possível evitar o binarismo, priorizámos o feminino (as/os). Sobre linguagem não sexista/inclusiva, ver Rezende e Silva 2018; Pessotto 2019. O termo negras/os faz referência ao somatório das pessoas que se autodeclaram pretas ou pardas. 
quotas de acesso ao ensino superior e conseguido vencer os filtros de seletividade e as barreiras de discriminação negativa que, tradicionalmente, as/os impedem de percursos mais longos de escolarização (Borges, 2018).

Este artigo tem o objetivo de ressaltar a latência, no contexto português, de um imaginário de subalternidade estereotipada em torno das estudantes brasileiras, que muitas, sobretudo as que se autodeclaram negras, descobriram ao frequentar o ensino superior. Os dados analisados (235 respostas a questionários online e oito entrevistas) referem-se à mobilidade estudantil Brasil-Portugal ocorrida entre 2012 e 2020, e fazem parte de uma investigação mais ampla e aprofundada (Borges $2020)^{2}$. Trechos de testemunhos apresentados aqui são-no apenas a título exemplificativo, com o propósito de abrir espaço a vozes que denunciam constrangimentos vividos ou presenciados, e que podem ser genericamente referenciados à colonialidade de poder que intersecciona género, raça e nacionalidade.

\section{Contextos histórico-culturais Brasil-Portugal e a colonialidade de poder}

A mobilidade de estudantes do Brasil para Portugal é um fenómeno que pode ser estudado privilegiando várias vertentes. A opção, no que diz respeito a este texto, foi a de dar centralidade ao conceito de colonialidade de poder, o qual vem sendo trabalhado por intelectuais, notadamente latino-americanos, que se inscrevem na perspetiva descolonial, descontruindo «um dos elementos constitutivos e específicos do padrão mundial de poder capitalista», e que assenta sobre a «imposição de uma classificação racial/étnica da população mundial como pedra angular do referido padrão de poder que opera em cada um dos planos, âmbitos e dimensões, materiais e subjetivas, da existência quotidiana e em escala social» (Quijano 2014, 285).

A raça (como sinalização da diferença e da desigualdade) é interpretada como invenção do imperialismo europeu ocidental para viabilizar a economia capitalista. Conforme Mignolo (2007, 13), no transitar do século XV para o XVI, «não havia índios nos continentes americanos até à chegada dos colonizadores espanhóis [e dos portugueses]; e não havia negros até ao começo do comércio massivo de escravos no Atlântico». Em outros termos, a ideia de raça serviu como «eficaz instrumento de dominação social» (Quijano 2000, 192) para «dar sentido às novas relações de poder» entre os povos originários das Américas e os conquistadores ibéricos (Quijano 2005, 18). A designação raça negra emergiu em meados do século

2 No estudo referido, a informação recolhida em Portugal resulta de 394 inquéritos online e de 12 entrevistas gravadas. Neste artigo, as categorias de análise referem-se a discriminações de género, raça e origem nacional, presenciadas ou sofridas por 235 licenciandas brasileiras que frequentavam o ensino superior em Portugal na condição de estudantes internacionais ou enquanto participantes de programas de mobilidade estudantil. 
XVI no contexto do colonialismo ibérico na América e a de raça branca bem depois, no avançar do século XVIII, na área do colonialismo britânico na América e nas Antilhas (Quijano 2005, 18).

Completava-se assim um sistema de classificação racial da população mundial que naturalizava as (ir)racionalidades de um sistema-mundo moderno/colonial para a dominação e a exploração de seres humanos. Estavam traçadas as «linhas abissais» (Santos 2010) entre o mundo dos colonizadores (homens europeus brancos) e os mundos das pessoas racializadas e colonizadas. Mas essa violência colonial não se expressava somente em termos étnico-raciais, interligando-se também a hierarquias de género (mundo masculino e patriarcal), de conhecimento (ciência europeia) e de modo de produção (capitalista). Uma sequência de colonialidades inter-relacionadas não extintas com a independência das colónias e a (re) produzir desigualdades e injustiças.

No entanto, nas interações sociais quotidianas, a colonialidade não é algo explícito ou imediatamente identificável. Pelo contrário, reconstituir a sua origem e explicar como se atualiza em novas desigualdades e racismo(s) exige uma postura crítica na investigação, nomeadamente através de uma metodologia interativa (Garcia Filice e Carnaúba 2019) e um compromisso com práticas e alternativas emancipatórias. No caso que estudámos, argumentamos que as experiências e biografias das estudantes brasileiras carregam cicatrizes produzidas historicamente pelo colonialismo (e suas consequências), as quais emergem nas relações sociais e académicas como expressão da colonialidade de poder, persistente no contexto português (do antigo colonizador), induzindo, assim, uma nova consciência crítica que pode permitir o despertar de um capital descolonial (Borges 2020). Nesse sentido, ouvir estas estudantes que experienciam a internacionalização é muito importante na construção de um diálogo crítico descolonial no espaço académico Brasil-Portugal.

Uma questão prévia importante tem a ver com as diferenças existentes nos dois países em relação ao registo das identidades étnico-raciais. No Brasil, estas informações são recolhidas de forma censitária desde o final do século XIX e, ainda que se possa e se deva questionar a inadequação das categorias elencadas, elas têm sido importantes para as lutas de reparação de injustiças sociais historicamente produzidas. Por sua vez, esses dados inexistem em Portugal, muito embora a recolha tenha sido recomendada recentemente pelo United Nations Human Rights Office $(2017)^{3}$.

Para as estudantes brasileiras que integraram este estudo, as visões e posições diferenciadas no trato das questões étnico-raciais propiciaram estranhamen-

3 Esta medida teve a aprovação de $80 \%$ da população portuguesa para que fosse incluída no Censo 2021. No entanto, o governo decidiu excluir do questionário as perguntas sobre a origem étnico-racial (Henriques 2019) sob o argumento de que a recolha desses dados contribuiria para institucionalizar a classificação das pessoas, o que suscitou um amplo e polémico debate sobre o racismo em Portugal. 
tos, comparações e reflexões críticas. Mesmo que diferentes expressões da colonialidade de poder estejam presentes e se reatualizem quotidianamente nos dois lados do Atlântico, os testemunhos recolhidos das estudantes em Portugal, brancas e negras, revelam situações de tensão e constrangimento que as surpreendem e subalternizam. Ter nascido no Portugal europeu parece suscitar uma pretensa superioridade em relação a quem vem do Brasil. Esta é a interpretação crítica de algumas entrevistadas, como relata uma paulista de 28 anos, autodeclarada branca, egressa de escola pública, de família com dificuldades financeiras e que precisou contar com a ajuda da avó para estudar por alguns meses em Portugal:

A hierarquia é uma coisa a se pensar, a origem, de onde você vem, essa questão hierárquica da colonização, da cidadania europeia, tudo isso foi constatado aqui. Não vão te achar inferior porque você tem ascendência italiana. Agora se você é afrodescendente, já é uma pessoa a se olhar torto [porque] a sua origem não é boa o bastante. Se você falar que tem origem de índio, então é como se fosse nada, como se fosse muito mais inferior [...]. (Estudante de graduação que cumpriu mobilidade em Direito na Universidade do Minho)

Este despertar descolonial não resulta apenas, ou necessariamente, das vivências decorrentes de uma situação socioeconómica precária, ou de uma condição étnico-racial indutora de experiências de uma «verdadeira subalternidade» (Spivak 2021, 128). Segundo resultados da investigação aqui referida, estudantes brancas/os e de classes com elevado capital económico também expressaram uma consciência crítica em relação à colonialidade de poder quando esta entrelaça nacionalidade, género e raça. Nesse sentido, o que estas estudantes nos lembraram é que a identidade brasileira (ou, melhor, a origem no Sul global ${ }^{4}$ ) não se encontra liberta do legado colonial, continuando a ser representada, pelo menos em alguns segmentos da sociedade portuguesa, como uma condição de subalternidade.

A existência ou inexistência de políticas de quotas para acesso ao ensino superior também parece interferir na forma como são construídas determinadas representações sociais, neste caso, relativas à identidade étnico-racial. A este propósito, aliás, convém reconhecer que Brasil e Portugal têm avançado de modo distinto em políticas de ação afirmativa e de combate ao racismo e outras formas de discriminação. $\mathrm{O}$ acesso por quotas é um exemplo com desdobramentos recentes nos dois países. Enquanto política de Estado, a reserva de vagas em instituições públicas brasileiras de ensino superior completa dez anos (Lei n. ${ }^{\circ} 12.711$ de 29 de agosto de 2012) e as discussões atuais seguem com foco na defesa e aprimoramento de ações afirmativas para a década 2022-2032 (Vieira 2021, 362). Em Portugal, o princípio da discriminação positiva, que fundamenta a criação de quotas

4 O Sul global inclui países do hemisfério sul, periféricos ou semiperiféricos no contexto capitalista mundial, e com legado colonial. 
para acesso a instituições de ensino superior e a cursos técnicos superiores profissionais, encontra acolhimento no âmbito do Plano Nacional de Combate ao Racismo e à Discriminação 2021-2025 - Portugal contra o Racismo (PNCRD - 2021-2025), aprovado em 15 de julho de 2021 (Presidência do Conselho de Ministros 2021), nomeadamente no que se refere a alunas/os das escolas TEIP (Territórios Educativos de Intervenção Prioritária). No entanto, ao privilegiar o território, este Plano não assume explicitamente o critério das desigualdades étnico-raciais, talvez por poder ser uma questão fraturante. ${ }^{5}$ Sabemos, no entanto, que a experiência brasileira dá conta de que as quotas promovem maior diversidade social nas universidades (Santana et al. 2021), o que não significa que o problema das desigualdades no ensino superior fique resolvido. A busca por justiça social no campo da educação apresenta-se como uma luta constante que impõe novos desafios a nível das políticas afirmativas e antidiscriminatórias, e demanda, nomeadamente por parte da investigação em sociologia e ciências da educação, um olhar interseccional para múltiplas e combinadas situações de (re)produção de colonialidades.

A análise interseccional empregada no já referido estudo empírico mais amplo (Borges 2020), e que nos serve de partida, revela que as políticas de fomento à internacionalização Brasil-Portugal, em ambos os países, apresentam lacunas e acionam mecanismos que contribuem e atuam para uma seletividade social e racial favorável a estudantes brancas/os, com maior domínio da língua inglesa (Borges e Afonso 2018), provenientes de escolas privadas e de famílias com elevado capital económico. Entretanto, outros resultados deste mesmo estudo mostram que estudantes pertencentes a grupos historicamente marginalizados, ainda que em número consideravelmente menor, estão a frequentar, devido também a estratégias de resistência proativa, instituições no exterior, das quais tradicionalmente estiveram excluídas/os. A este propósito, escutemos a voz de uma estudante natural do Nordeste do Brasil, proveniente de escola pública e de família pobre, que se identificou como parda. Na ausência de um programa de bolsas para internacionalização, a exemplo do extinto programa Ciência sem Fronteiras, ela precisou trabalhar enquanto estudou por alguns meses em Portugal:

Eu me custeio aqui. Eu vendi meu carro, passei um ano economizando, fiz rifas, essas coisas. Até mesmo na época em que houve o Ciência sem Fronteiras eram poucas as oportunidades, principalmente para a área de Humanas. Era [um programa] restrito às pessoas que tinham condição financeira melhor porque na hora da seleção era pedido o inglês e a gente sabe que pobre no Brasil não fala inglês. Agora como já não há bolsas, continua sendo as mesmas pessoas, com dinheiro, ou então alguém como eu que vende as coisas e vem. (Estudante que frequentou o curso de Sociologia na Universidade do Minho)

5 Ver a este propósito a posição (não coincidente) de Inocência Mata e Cristina Roldão, que integraram o Grupo de Trabalho que elaborou o relatório preliminar ao PNCRD 2021-2025 (Henriques 2021, 4). 
Este testemunho é importante em dois sentidos: porque revela a dimensão social da política de quotas no acesso ao ensino superior no Brasil e porque denuncia os reflexos das desigualdades (regionais, económicas, raciais e de género) que afetam estudantes em mobilidade internacional. Embora as políticas afirmativas implementadas no Brasil tenham contribuído para um maior acesso e presença, em instituições federais de educação superior, de estudantes das classes sociais historicamente privadas ou cerceadas nos seus direitos sociais e educacionais, esta assimetria, comparativamente com outras classes, manteve-se em relação às probabilidades de estudar fora do país. Neste sentido, os riscos de perpetuação de desigualdades também devem ser problematizados no que diz respeito a programas como o Ciência sem Fronteiras e outras ações públicas voltadas para a internacionalização dos estudos. Afinal, o ingresso nesses programas de mobilidade estudantil tem sido um mérito para quem? (Borges 2018).

Mesmo que a internacionalização esteja mais vinculada à classe social e não seja ainda uma oportunidade justa e igualitária para estudantes em função da nacionalidade, identidade étnico-racial e género, a maior diversidade brasileira nos campi universitários portugueses amplia as possibilidades de mútuas aprendizagens entre estudantes dos dois países, as quais vão além do currículo académico formal, uma vez que há mais «interconectividade de suas experiências heterogéneas» (Collins e Bilge 2021, 240). Por conseguinte, instituições de ensino superior mais plurais, democráticas e igualitárias, nomeadamente em termos epistémicos e pedagógicos, bem como étnico-raciais, de género, de classe e de nacionalidade, são necessariamente espaços de educação/formação fundamentais para desocultar criticamente como se atualizam práticas genericamente referenciáveis à colonialidade de poder (e, mais especificamente, à colonialidade dos micropoderes presentes nas relações e interações quotidianas). E, para além disso, são lugares igualmente capazes de potenciar o pensamento de alternativas e possibilitar práticas mais emancipatórias. Todavia, como veremos a seguir, há muito caminho a percorrer para alcançar estes objetivos.

\section{O despertar descolonial parcelar nas vozes das estudantes}

Apesar dos obstáculos que derivam, sobretudo, das fortes desigualdades de classe, raça e género, e que pesam fortemente na construção dos seus projetos de vida, muitas/os estudantes conseguem vir para Portugal e increver-se no ensino superior, passando a conhecer uma realidade social e educacional que as/os coloca perante novos desafios, não isentos de emoções, tensões e vivências contraditórias. Na pesquisa que realizámos, encontrámos instituições de ensino superior onde, apesar do predomínio de estudantes portuguesas/es, existe uma notória e crescente diversidade de outras nacionalidades e identidades, para a qual têm contribuído as/os estudantes brasileiras/os. 
Nesta seção apresentamos uma breve análise das respostas de 235 estudantes brasileiras a um questionário online $e^{6}$, que revelam o que podemos designar de despertar descolonial parcelar, no sentido em que as suas críticas apenas articulam ou referenciam alguns dos eixos da matriz colonial de poder (capitalismo/exploração/ /dominação, eurocentrismo, patriarcado, racismo...). O que é compreensível, considerando que eram estudantes jovens (86,5\% na faixa etária de 18 a 24 anos), e que nem todas tinham uma ampla consciência política. Importante ressaltar que os relatos, extraídos das entrevistas ou das questões abertas nos inquéritos online, foram coletados de modo a preservar a autenticidade e a evitar o que se designa de imposição de problemática.

Empregámos nas nossas análises as expressões estudante(s) branca(s) e estudante(s) negra(s), entendendo-as não como categorias singulares de classificação racial em oposição binária, mas como designações que comportam múltiplas e complexas (ou mesmo contraditórias) identidades. Por exemplo, a designação parda apresenta ambiguidades, sobretudo por poder referir-se tanto a matrizes indígenas quanto africanas. Por outro lado, alguns estudos mostram que muitas pessoas no Brasil se declaram brancas por desconhecerem a genealogia familiar ou por não terem tido acesso às memórias e histórias orais que possam conter outras informações étnico-raciais - não sendo esse facto indiferente, em muitos casos, aos apagamentos simbólicos e culturais das matrizes identitárias, por força (também) de uma certa ideologia de supremacia branca, disfarçada por discursos oficiais de democracia racial e multicultural.

$\mathrm{Na}$ abertura do seminário «Não sou pardo, sou indígena: o pardismo em debate», transmitido em 11 de abril de 2021 pela TV Tamuya no YouTube, Ailton Krenak chama a atenção para o apagamento da identidade indígena nas décadas de 1970 e 1980, quando o Movimento Negro agrupa pretas/os e pardas/os (ou mestiças/os) na categoria de negras/os. Com isso, segundo ele, ocorre o etnocídio indígena na categoria parda. A ideia, no entanto, do Movimento Negro era (re)unir as chamadas minorias étnico-raciais para reforçar a luta por direitos e pela não subalternização histórica das suas identidades. Como ressalta Rita Segato, são dois lados de uma luta com carga ideológica. Assim, o pardismo compõe o «entre-mundo da mestiçagem» tanto pelo branqueamento quanto pelo enegrecimento, ou seja, identidades forjadas ideologicamente a partir do sequestro do sangue «não branco» (negro e indígena) na «brancura», e do sangue «branco» no processo de «reconstrução do mundo indígena e afrodescendente» (Segato 2012, 115).

Em termos históricos, a ambiguidade em torno da identidade parda também pode ser explicada a partir da consagração oficial, em 1872, do sistema de classificação racial da população brasileira que, para além das categorias branca e preta, adotou também as de parda, mestiça e cabocla. Somente em 1991, «depois de 101

6 Utilizámos cruzamentos estatísticos, com suporte do software IBM SPSS Statistics 27, a partir de recorte de dados recolhidos no âmbito de um estudo de doutoramento (Borges 2020). 
anos de ausência», a categoria indígena seria reintroduzida em definitivo (Petruccelli 2013, 24). Porém, ainda que inadequadas e insuficientes, branca, preta, amarela, parda e indígena são as cinco categorias utilizadas desde 2000 na recolha censitária de dados étnico-raciais no Brasil. Essa categorização reflete, em grande medida, o mito homogeneizante das três raças formadoras do povo brasileiro (o europeu, o africano e o indígena, assim mesmo no singular), desconsiderando outros povos e outras miscigenações produzidas, por exemplo, a partir de descendências com pessoas de origem asiática (japonesa, chinesa, coreana, libanesa, síria, entre outras) e imigrantes da própria América Latina. Portanto, há também que ter em conta a ideologia racial e as funções de dominação subjacentes a essas classificações. Afinal, elas são uma das expressões da colonialidade de poder.

Neste artigo, na categoria negras estão as respostas das estudantes que se autodeclararam pretas, pardas, amarelas ou indicaram uma ascendência étnico-racial que resulta da miscigenação. Das 235 estudantes da amostra produtora de dados, 169 declararam ser brancas; 47 pardas; 9 pretas; 8 amarelas; 1 miscigenada branca com amarela, e 1 branca com parda. Nenhuma estudante se declarou indígena. Estes dados já nos informam alguma coisa sobre a desigualdade racial presente na internacionalização de estudantes do Brasil para Portugal ${ }^{7}$. Entre as estudantes brancas, $61 \%$ vinham de famílias de classe média e média alta, com renda mensal entre quatro e vinte salários mínimos; entre as estudantes negras, 68,3\% vinham de famílias com rendimento mensal inferior a quatro salários mínimos. Importante destacar que 52,7\% das estudantes que indicaram pertencer a famílias mais pobres estudavam em Portugal com bolsas concedidas pelo governo brasileiro. Na nossa perspetiva, tratando-se, em qualquer dos casos, de estudantes com percursos bem-sucedidos em termos académicos, fica bem claro que, sem políticas afirmativas, de reconhecimento, redistribuição e representação (convocando aqui Nancy Fraser 2007), os tradicionais critérios meritocráticos (ligados ao esforço e capacidades individuais), por si só, são insuficientes. Como mostram, aliás, as novas estratégias educacionais das classes médias e médias-altas, que passam pela internacionalização dos estudos das/os filhas/os, não é por acaso que os percursos de excelência escolar têm maior probabilidade de acontecer numa articulação virtuosa entre os quesitos da velha meritocracia e os recursos da parentocracia, ou seja, pela via da neomeritocracia (Afonso 2017).

A seletividade social na internacionalização opera também por género e domínio científico. $\mathrm{Na}$ altura da coleta dos dados, nas ciências exatas e engenharias,

7 No Brasil, onde a maioria da população se identifica como negra (Campos, França, e Feres Júnior 2018), o perfil étnico-racial na educação superior mostra que 51,2\% são estudantes brancas/os (INEP 2020). Este percentual só não é maior porque, como vimos, a política das quotas sociais/raciais reserva vagas em instituições mantidas pelo governo federal. Nesta rede de universidades e institutos, o percentual de estudantes brancas / os (43,6\%) é inferior à soma das demais categorias raciais. Na rede privada, onde as quotas não são obrigatórias, estudantes brancas/os são a maioria (52,5\%). 
áreas que em Portugal concentraram metade (50,3\%) das bolsas do extinto programa Ciência sem Fronteiras, somente 35,9\% beneficiaram mulheres. A maior presença feminina foi verificada nas ciências biológicas e da saúde $(60,4 \%)$. No âmbito de ingressantes pelo Exame Nacional do Ensino Médio (ENEM) e por programas privados ou institucionais de mobilidade internacional, a maior participação das estudantes registou-se nas ciências sociais e humanidades $(73,3 \%)$. Repete-se, assim, em Portugal, o que já se tinha verificado nos Estados Unidos, ou seja, uma predominância masculina em cursos de engenharias e tecnologias (Borges 2018).

A razão pela qual essas últimas assimetrias persistem passa por perceber a «segregação social e política a que as mulheres foram historicamente conduzidas» (Louro 2014, 21). Antes mesmo de ser engendrada na matriz patriarcal e racializada que se constituiu na América colonizada, a supremacia heterossexual já era reforçada pelo construto reacionário político-ideológico da «fraqueza da mente e do corpo» servindo para legitimar a própria exclusão das mulheres burguesas brancas da esfera de poder público, da produção de conhecimento e dos principais controlos sobre os meios de produção (Lugones 2007, 206). Mas é a partir da violência colonial e escravista no contexto do capitalismo na América Latina que a dominação de género embrutece e racializa. Lugones chama a isto o dark side do sistema de género. Por conseguinte, para as mulheres indígenas e africanas resta a posição mais subalternizada, inclusive em nível de inferiorização em relação aos homens negros colonizados.

Contudo, os fragmentos da violência colonial e a imagem deturpada da mulher brasileira manifestam-se em discriminações, por vezes mais veladas e subtis, nos (des)encontros entre estudantes brasileiras/os e portuguesas/es, colocando em questão o valor da diversidade na agenda política e académica de um Portugal multicultural. Na crítica de Marta Araújo, atrás do discurso de um país generoso e acolhedor de outros povos, o que se tem é um Portugal a reatualizar o «mito de uma convivialidade colonial», que guarda origem nas «teses luso-tropicais» de Gilberto Freyre (Schneider 2012). Com efeito, aos passos lentos de uma revisão descolonial da história dos (chamados) descobrimentos tem-se contraposto, a passos largos desde a década de 1990, a narrativa da interculturalidade portuguesa, com o racismo colocado como «fenómeno marginal» (Araújo 2018, 11-12).

Nesse sentido, pode perguntar-se que expressões de colonialidade podem ser percebidas nas universidades portuguesas em relação às estudantes brasileiras? Em que medida podemos associar a considerável dificuldade relatada pelas estudantes, de se sentirem integradas no contexto académico, como sendo consequência de certas representações sociais e estereótipos sexistas relacionados (ou não) a um enviesamento etnocêntrico?

A resposta transparece nas vozes de estudantes brancas:

Nunca me senti tão rejeitada e excluída, pois apesar de falar uma língua semelhante, muitos portugueses sofrem do complexo de superioridade em relação aos brasileiros. 
Sou grata pelos amigos brasileiros que fiz, pois foram os únicos que fizeram com que eu aguentasse tanto tempo. (Estudante que frequentou Ciências Sociais Aplicadas na Universidade de Coimbra)

Na minha universidade, acho que em todas do Brasil, se vem uma pessoa de qualquer lugar, a gente: “Meu Deus, como que é no seu país?" E recebe e faz isso e aquilo. E aqui não tem isso. Não senti nenhum acolhimento por parte dos portugueses. (Estudante que cumpriu mobilidade em Letras e Ciências Humanas na Universidade do Minho) Eu achei que as pessoas agiriam de uma maneira mais política, e com mais aceitação em relação ao outro. Eu não achei que numa universidade que recebe estudantes o tempo todo, eu ia ter que sofrer um bullying no primeiro dia em que eu aparecesse porque eu era uma brasileira, entende? Eu achei, sim, que eu ia chegar aqui, que é uma universidade internacional, e que eles iam saber respeitar as pessoas dentro da sala de aula. (Estudante que cumpriu mobilidade em Direito na Universidade do Minho)

Se os diálogos interculturais não estão sendo possíveis, há que perguntar o porquê. Das estudantes brasileiras que participaram da nossa pesquisa e frequentaram o ensino superior em Portugal entre 2012 e 2020 mais de metade assinalou algum tipo de discriminação. A análise dos dados revela que estas denúncias foram mais frequentes entre as negras (56,1\%), em comparação com as brancas, o que confirma a interferência da condição étnico-racial. $O$ testemunho a seguir é revelador:

Eu comentei que, por vezes, pensava na escolha de Portugal com arrependimento, esta, que foi motivada por uma questão financeira, me colocou em uma situação de vulnerabilidade social que hoje me permite compreender e lutar contra as contradições do meu país, como professora de artes nas escolas públicas, como artista. Minha saúde mental foi sendo comprometida pelos constantes assédios. A forma como fui acolhida engatilhou situações de xenofobia, racismo, misoginia; a visão portuguesa é de que somos, menos que sujeitos, objetos de exoticidade e subalternidade. (Estudante de Linguística, Letras e Artes que cumpriu mobilidade como bolsista na Universidade de Trás-os-Montes e Alto Douro)

Por outro lado, quando olhamos para as respostas dos estudantes, constatamos um percentual bem menor $(31,6 \%)$ de discriminação, ainda que consideravelmente maior entre os negros $(43,5 \%)$ em relação aos brancos $(26,4 \%)$. Considerando género e raça, a experiência dos constrangimentos revelou-se comparativamente mais acentuada entre as estudantes negras.

\section{Considerações finais}

Os resultados apresentados são, em muitos aspetos, convergentes com os de outros estudos, sobretudo daqueles que mostram que as instituições de ensino 
superior portuguesas ainda não estão preparadas para lidar com a diversidade multicultural de estudantes internacionais (Nada e Araújo 2019). No nosso caso, quisemos salientar o que muitas estudantes brasileiras sentiram devido ao efeito ampliado das desigualdades nas interações sociais em contexto académico, sobretudo quando sobrepostas as condições étnico-raciais, de género e de nacionalidade. Foi neste sentido que a análise interseccional pôde potenciar a revelação da persistência da colonialidade de poder. As denúncias destas formas de opressão, (re) atualizadas na experiência da mobilidade internacional, partiram com mais frequência das estudantes negras. $\mathrm{O}$ ecoar das suas vozes mostra a urgência de estabelecer diálogos interculturais críticos - papel que deve ser protagonizado por instituições de ensino superior, públicas e democráticas, dos dois lados do Atlântico (e não só). Mas, para isso, estas instituições não poderão deixar de fazer a crítica à hegemonia epistémica euro-norte-americana, assumindo a abertura a saberes, pedagogias, olhares e projetos alternativos que contribuam para descolonizar as práticas sociais e académicas. É, por isso, pertinente refletir e indagar que tipo de internacionalização do ensino superior poderá contribuir para nos libertar das nossas «imaturidades coloniais» (Stein e Evelyn da Silva 2020, 563).

\section{Financiamento}

Trabalho financiado pelo CIEd - Centro de Investigação em Educação, Instituto de Educação, Universidade do Minho, projetos UIDB/01661/2020 e UIDP/ /01661/2020, através de fundos nacionais da FCT/MCTES-PT.

\section{Referências bibliográficas}

Afonso, Almerindo Janela. 2017. «Neomeritocracia e novas desigualdades.» In A Excelência na Escola Pública Portuguesa, organizado por Leonor L. Torres e José A. Palhares, 253-63. V. N. de Gaia: Fundação Manuel Leão.

Araújo, Marta. 2018. «As narrativas da indústria da interculturalidade (1991-2016): Desafios para a educação e as lutas anti-racistas.» Investigar em Educação 2(7): 9-35. Disponível em http: / / pages.ie.uminho.pt/inved/index.php/ie/article/view/134/134

Borges, Rovênia Amorim. 2018. Do Brasil aos Estados Unidos: a barreira do Inglês na mobilidade de estudantes. Um estudo sobre identidades e desigualdades refletidas no Programa Ciência sem Fronteiras. Beau-Bassin: Novas Edições Acadêmicas.

Borges, Rovênia Amorim. 2020. «Estudantes brasileiros no ensino superior em Portugal: O despertar descolonial na experiência da mobilidade internacional.» $\mathrm{PhD}$ diss., Universidade do Minho. Disponível em http: / / hdl.handle.net/1822/73635

Borges, Rovênia Amorim, e Almerindo Janela Afonso. 2018. «Why subaltern language? Yes, we speak Portuguese! Para uma crítica da colonialidade da língua na mobilidade estudantil internacional.» Comunicação e Sociedade 34: 59-72. DOI: https:/ / doi.org/10.17 231/comsoc.34(2018).2935 
Campos, Luiz Augusto, Danilo França, e João Feres Júnior. 2018. Relatório das Desigualdades de Raça, Gênero e Classe - GEMAA, n. 2. Rio de Janeiro: Universidade do Estado do Rio Janeiro.

Collins, Patricia Hill, e Sirma Bilge. 2021. Interseccionalidade. Traduzido por Rane Souza. São Paulo: Boitempo.

Direção-Geral de Estatísticas da Educação e Ciência - DGEEC. 2019. Perfil do Aluno 2017/ /2018. Lisboa: DGEEC. Disponível em https:/ / www.dgeec.mec.pt/np4/ estatglobal/

França, Thais, Elisa Alves, e Beatriz Padilla. 2018. «Portuguese policies fostering international student mobility: a colonial legacy or a new strategy?» Globalisation, Societies and Education 16(3): 325-338. DOI: https:/ / doi.org/10.1080/14767724.2018.1457431

Fraser, Nancy. 2007. «Mapeando a imaginação feminista: da redistribuição ao reconhecimento e à representação.» Estudos Feministas 15(2): 291-308. DOI: https:// doi.org/ 10.1590/S0104-026X2007000200002

Garcia Filice, Renísia Cristina, e Rayssa Araújo Carnaúba. 2019. «Metodologia interativa na gestão de políticas públicas: métodos combinados numa abordagem antissexista e antirracista.» In Tecendo Redes Antirracistas: Áfricas, Brasis, Portugal, organizado por Anderson Ribeiro Oliva, Marjorie Nogueira Chaves, Renísia Cristina Garcia Filice, e wanderson flor do nascimento, 109-32. Belo Horizonte: Autêntica.

Henriques, Joana Gorjão. 2019. «INE chumba pergunta sobre origem étnico-racial no censos.» Público, junho 18, 2019.

Henriques, Joana Gorjão. 2021. «Quotas por território são eficazes para combater o racismo?» Público, Maio 2, 2021.

Instituto Nacional de Estudos e Pesquisas Educacionais Anísio Teixeira - INEP. 2020. Sinopse estatística da educação superior - 2019. Disponível em http: / / inep.gov.br/ sinopses-estatisticas-da-educacao-superior [Consultado em 29 abril de 2021].

Krenak, Ailton. 2021. «O truque colonial que produz o pardo, o mestiço e outras categorias de pobreza.» I Ciclo do Seminário «Não sou pardo, sou indígena: o pardismo em debate.» TV Tamuya, abril 11. Disponível em https:// www.youtube.com/watch?v= dvijNR9Nbgo\&list=PLu-83zx9u0a4EcnzXruYW7x9jTgwo9Hzv

Louro, Guacira Lopes. 2014. Gênero, sexualidade e educação. Petrópolis: Vozes.

Lugones, María. 2007. «Heterosexualism and the Colonial/Modern Gender System.» Hypatia 22(1): 186-209. Disponível em https: / / www.jstor.org/ stable/ 4640051

Lutz, Helma. 2015. «Intersectionality as Method.» DiGeSt Journal of Diversity and Gender Studies 2(1-2): 39-44. DOI: https:/ / doi.org/10.11116/jdivegendstud.2.1-2.0039

Mackinnon, Catharine. 2013. «Intersectionality as method: A Note.» Signs: Journal of Women in Culture and Society 38(4): 1019-30. DOI: https: / / www.journals.uchicago.edu/doi / $10.1086 / 669570$

Merçon, Aline. 2020. «Lusofonia e Identidade. Representações sociais recíprocas dos universitários brasileiros e portugueses.» PhD diss., Universidade de Aveiro \& Universidade do Minho. Disponível em http: / / hdl.handle.net/10773/28629

Mignolo, Walter D. 2007. «Epistemic disobedience: the de-colonial option and the meaning of identity in politics.» Gragoatá 12(22): 11-41. Disponível em https: / periodicos.uff.br / gragoata/article/view/33191

Nada, Cosmin I., e Helena C. Araújo. 2019. «"When you welcome students without borders, you need a mentality without borders" internationalisation of higher education: evidence from Portugal.» Studies in Higher Education 44(9): 1591-1604. DOI: https:/ / doi.org/10.1080/03075079.2018.1458219

Pessotto, Ana Lúcia. 2019. «Língua para todes: um olhar formal sobre a expressão do gênero gramatical no português e a demanda pela linguagem inclusiva.» Revista Ártemis - 
Estudos de Gênero, Feminismos e Sexualidades 28(1): 160-78. DOI: https: / / doi.org/10.22 $478 /$ ufpb.1807-8214.2019v28n1.41827

Petruccelli, José Luis. 2013. «Raça, identidade, identificação: abordagem histórica conceitual.» In Características étnico-raciais da população: Classificações e Identidades, organizado por José Luis Petruccelli e Ana Lúcia Saboia, 13-29. Rio de Janeiro: IBGE.

Presidência do Conselho de Ministros. 2021. Resolução do Conselho de Ministros n. ${ }^{\circ} 101 /$ / 2021. "Aprova o Plano nacional de combate ao racismo e à discriminação 2021-2025 - Portugal contra o Racismo.» Diário da República $1^{a}$ série, 145 (julho): 20-72. Disponível em https: / / data.dre.pt/eli/resolconsmin/101/2021/07/28/p/dre

Quijano, Aníbal. 2000. «Qué tal raza!» Revista del CESLA 1: 192-200.

Quijano, Aníbal. 2005. «Dom Quixote e os moinhos de vento na América Latina.» Estudos Avançados 19(55): 9-31.

Quijano, Aníbal. 2014. «Colonialidad del poder e clasificación social.» In Cuestiones y horizontes: de la dependencia histórico-estructural a la colonialidad/descolonialidad del poder, 285-327. Buenos Aires: CLACSO.

Rezende, Tânia Ferreira, e Daniel Marra da Silva. 2018. «Desobediência linguística: por uma epistemologia liminar que rasure a normatividade da língua portuguesa.» Revista Porto das Letras 4(1): 174-202.

Santana, Luciana Alaíde Alves, Everson Meireles, José Jorge de Carvalho, e Paulo Gabriel Soledade Nacif. 2021. «A lei de cotas nas IFES: Nenhum retrocesso, nenhum/a negro/a e indígena a menos.» Revista da Associação Brasileira de Pesquisadores/as Negros/as (ABPN) 13(36): 416-39.

Santos, Boaventura de Sousa. 2010. «Para além do pensamento abissal: das linhas globais a uma ecologia de saberes.» In Epistemologias do Sul, editado por Boaventura de Sousa Santos e Maria Paula Meneses, 31-83. São Paulo: Cortez.

Schneider, Alberto Luiz. 2012. «Iberismo e luso-tropicalismo na obra de Gilberto Freyre.» História da Historiografia: International Journal of Theory and History of Historiography 5(10): 75-93. DOI: https: / / doi.org/10.15848/hh.v0i10.438

Segato, Rita Laura. 2012. «Gênero e colonialidade: em busca de chaves de leitura e de um vocabulário estratégico descolonial.» e-cadernos CES [online] (18): 106-131. DOI: https:/ / doi.org/10.4000/ eces.1533

Stein, Sharon, e Jhuliane Evelyn da Silva. 2020. «Desafios e complexidades para decolonizar a internacionalização em tempo de crises globais.» ETD - Educação Temática Digital 22(3): 546-66. DOI: https:/ / doi.org/10.20396/ etd.v22i3.8659310

Spivak, Gayatri Chakravorty. 2021. Pode a subalterna tomar a palavra? Traduzido por António Sousa Ribeiro. Lisboa: Orfeu Negro.

United Nations Human Rights Office. 2017. CERD - International Convention on the Elimination of All Forms of Racial Discrimination - 91 Session (21 Nov 2016 - 09 Dec 2016) - CERD/C/ PRT/Q/15-17. Jurisprudence, Switzerland: The Treaty Body Database. Disponível em https: / / tbinternet.ohchr.org/_layouts / 15/treatybodyexternal/SessionDetails1. aspx?SessionID=1080\&Lang=en. [Consultado em 27 de junho de 2021].

Vieira, Cleber Santos. 2021. «Políticas de ações afirmativas: Subsídios para o debate de aprimoramento.» Revista da Associação Brasileira de Pesquisadores/as Negros/as (ABPN) 13(36): 361-364. 
Rovênia Amorim Borges. Jornalista e doutora em Ciências da Educação (Universidade do Minho), integra o Grupo de Estudo e Pesquisa em Políticas Públicas, História, Educação das Relações Raciais e de Género (GEPPHERG) da Universidade de Brasília. Endereço eletrónico: roveniaa@gmail.com

Almerindo Janela Afonso. Sociólogo, doutorado em Educação, professor aposentado da Universidade do Minho e membro colaborador do Centro de Investigação em Educação (CIEd-UM). Endereço eletrónico: ajafonso@ie.uminho.pt

Artigo recebido a 28 de junho e aceite para publicação em 5 de outubro de 2021. 



\title{
ZONAS DE LIBERDADE LGBTI+? PRÁTICAS E GRAMÁTICAS PARA UMA INTERVENÇÃO PROFISSIONAL INCLUSIVA COM CRIANÇAS E JOVENS LGBTI ${ }^{1}$
}

\author{
Mafalda Esteves* \\ (D) https: / / orcid.org/0000-0002-5224-2883 \\ Ana Cristina Santos* \\ (D) https: / / orcid.org/ 0000-0002-9597-7150 \\ Alexandra Santos \\ (D) https: / / orcid.org/0000-0001-6109-8281
}

\section{Resumo}

A partir de resultados do projeto europeu «Diversidade e Infância», cuja metodologia qualitativa e quantitativa envolveu crianças, jovens e profissionais de áreas como a educação, saúde e intervenção familiar, neste artigo são identificadas boas práticas enquanto medidas de ação afirmativa no mainstreaming LGBTI+, mas também os vazios e as resistências que afetam o quotidiano de crianças e jovens LGBTI+. Conhecer as perspetivas das diferentes partes intervenientes é um passo fundamental para ajustar a implementação, monitorização e aplicação de leis e medidas que visam garantir a igualdade e a não-discriminação em função da orientação sexual, identidade e expressão de género e características sexuais.

Palavras-chave: Lei da autodeterminação de género, diversidade sexual e de género, infância, políticas públicas, Portugal.

\footnotetext{
Abstract

LGBTI+ Freedom Zones? Practices and grammars for an inclusive professional intervention with LGBTI+ children and young people

Drawing on findings from the European research project «Diversity and Childhood», whose qualitative and quantitative methodology involved children, young people and

1 Este artigo resulta de investigação financiada pela Comissão Europeia no âmbito do programa Cidadãos, Igualdade, Direitos e Valores / Projeto de investigação europeu «Diversity and Childhood: Changing social attitudes towards gender diversity in children across Europe» [856680]. Em Portugal, o projeto teve como instituições parceiras a Comissão para a Cidadania e Igualdade de Género (CIG), o Ministério da Educação e a associação rede ex aequo.

* Centro de Estudos Sociais, Universidade de Coimbra (CES-UC), Coimbra, Portugal.

Endereço postal: CES-UC, Colégio de S. Jerónimo, 3000-995 Coimbra, Portugal.

Endereço eletrónico: mafaldaesteves@ces.uc.pt

** Centro de Estudos Sociais, Universidade de Coimbra (CES-UC), Coimbra, Portugal.

Endereço postal: CES-UC, Colégio de S. Jerónimo, 3000-995 Coimbra, Portugal.

Endereço eletrónico: cristina@ces.uc.pt

*** Centro de Estudos Sociais, Universidade de Coimbra (CES-UC), Coimbra, Portugal. Endereço postal: CES-UC, Colégio de S. Jerónimo, 3000-995 Coimbra, Portugal.

Endereço eletrónico: alexandrasantos@ces.uc.pt
} 
professionals from areas such as education, health and family intervention, in this paper the authors identify good practices as affirmative action measures in LGBTI+ mainstreaming, but also gaps and resistances that affect the daily lives of LGBTI+ children and young people. Understanding the perspectives of the different actors involved is a fundamental step to adjust the implementation, monitoring and application of laws and measures that aim to guarantee equality and non-discrimination based on sexual orientation, gender identity and expression and sexual characteristics.

Keywords: Gender self-determination law, sexual and gender diversity, childhood, public policies, Portugal.

\section{Resumen}

¿Zonas de Libertad LGBTI+? Prácticas y gramáticas para una intervención profesional inclusiva en la infancia y adolescencia LGBTI+

A partir de los resultados del proyecto europeo «Diversidad e Infancia», basado en una metodología cualitativa y cuantitativa que involucró a niños/as, jóvenes y profesionales de áreas como la educación, la salud y la intervención familiar, se identifican buenas prácticas como medidas de acción afirmativa hacia la transversalización LGBTI+, pero también brechas y resistencias que afectan la vida cotidiana en la infancia y adolescencia LGBTI+. Conocer las perspectivas de las distinctas partes involucradas es un paso fundamental para adecuar la implementación, seguimiento y aplicación de leyes y medidas que tienen como objetivo garantizar la igualdad y no discriminación por orientación sexual, identidad y expresión de género y características sexuales.

Palabras clave: Ley por la autodeterminación de género, diversidad sexual y de género, infancia, políticas públicas, Portugal.

\section{Introdução}

Em março de 2021, o Parlamento Europeu aprovou uma moção declarando a União Europeia um espaço de liberdade para pessoas lésbicas, gay, bissexuais, trans e intersexo (LGBTI+). A moção foi acompanhada da hashtag \#LGBTIQ freedomZone. A designação «espaço de liberdade» constitui uma importante medida de ação afirmativa à escala europeia em resposta ao que vinha sucedendo na Polónia desde 2019, quando algumas cidades se auto-declararam zonas livres de pessoas LGBTIQ². Este ato simbólico por parte do Parlamento Europeu dialoga com a Estratégia da União Europeia a favor de pessoas LGBTQI decidida em 2020 (UE 2020).

2 Para uma problematização das duas aceções do conceito de liberdade - nomeadamente uma conceção positiva de liberdade para fazer ou ser e uma conceção negativa de liberdade face a constrangimentos, ver Fahs 2014.

3 «Uma União de Igualdade: Estratégia em Favor da Igualdade das Pessoas LGBTIQ 2020-2025». Disponível em https:/ / ec.europa.eu/info/sites/default/files/lgbtiq_factsheet_2020-2025_pt.pdf [Consultado em 2 de agosto de 2021]. 
Também no contexto português é notório o compromisso público contra a discriminação. Este compromisso foi sendo consolidado durante o século XXI, com ênfase para 2018, quando foram dados passos como a aprovação da Estratégia Nacional para a Igualdade e a Não Discriminação 2018-2030 Portugal + Igual. Foi também em 2018 que uma nova lei reconheceu o direito à autodeterminação da identidade e expressão de género e à proteção das características sexuais de cada pessoa, permitindo a mudança de nome próprio e sexo legal a partir dos 16 anos e convertendo Portugal num dos poucos países alinhados com as recomendações das Nações Unidas no que respeita à proteção das características sexuais de bebés e crianças intersexo.

Tendo em conta a Estratégia europeia, bem como o compromisso do Estado português com a igualdade e anti-discriminação LGBTI+, importa agora conhecer as condições objetivas para operacionalizar este desígnio no quotidiano e, mais especificamente, nas diversas áreas de intervenção. Este artigo insere-se nesse esforço de observação e análise, visando informar mais e melhores políticas públicas e medidas de ação afirmativa direcionadas a crianças e jovens LGBTI+.

Começamos por mapear os avanços mais significativos na área das políticas públicas e legislação sobre anti-discriminação LGBTI+ no espaço português, oferecendo uma análise crítica acerca do potencial destas medidas. Seguidamente, após uma precisão sobre as metodologias adotadas, algumas das quais envolvendo crianças, apresentam-se resultados decorrentes do projeto europeu «Diversidade e Infância». Por fim, e à luz desses resultados, oferece-se uma discussão acerca do conceito de adultismo enquanto perspetiva que condiciona a implementação de medidas afirmativas na área da diversidade LGBTI+ na infância. A discussão deste conceito na reta final do artigo visa tão-só abrir portas para investigação futura nesta área, que, desejamos, venha a fortalecer o envolvimento de crianças e adolescentes em todas as fases de desenho, implementação e análise da pesquisa que lhes diz diretamente respeito. Por outras palavras, manter uma perspetiva crítica face ao adultismo foi uma das aprendizagens mais significativas que, enquanto investigadoras, fizemos a partir deste projeto.

\section{Políticas públicas e legislação sobre diversidade sexual e de género em Portugal}

Apesar do legado deixado pela ditadura mais longa da Europa ocidental, uma conjuntura política favorável associada a processos mais amplos de democratização e modernização permitiu, em Portugal, o desenvolvimento de uma ação coletiva LGBTI+ capaz de articular com decisores políticos e especialistas, fomentando a produção de conhecimento com base em evidência e, concomitantemente, informando medidas políticas de relevo (Almeida 2010; Santos 2013, 2018a, 2018b). Também a influência de instituições e organismos políticos europeus, sobretudo 
após a entrada de Portugal na União Europeia, tem contribuído para o progresso jurídico em matéria de igualdade LGBTI+.

Entre 2010-2020, registamos três mudanças legislativas significativas envolvendo conjugalidade, parentalidade e autodeterminação. Em 2010, a lei do casamento foi aprovada, seguindo-se um progressivo reconhecimento jurídico da homoparentalidade em 2016 (Santos, 2018a; 2018b), incluindo a adoção, coadoção, reprodução medicamente assistida e uma versão restritiva de gestação de substituição. Já em 2018, registam-se importantes mudanças em matéria de identidade e expressão de género, bem como em questões intersexo (Saleiro 2017; Hines e Santos 2018). Partindo da revisão da Lei de Identidade de Género de 2011, em 2018 a legislação estabeleceu a despatologização de pessoas trans, dispensando um relatório médico para pessoas com mais de 18 anos e adolescentes com mais de 16 anos de forma a mudar nome e sexo nos seus documentos. Esta lei também proibiu cirurgias injustificadas em bebés intersexo e estabeleceu que as escolas devem usar o nome social escolhido pela criança ou jovem trans ${ }^{4}$. Esta lei representa um reconhecimento por parte do Estado português de que a diversidade de género se manifesta ao longo da vida, pelo que é crucial reconhecer a expressão de género na infância e assegurar o respeito pela autodeterminação de crianças e jovens trans, intersexo e não binários (Diversity and Childhood 2020).

Data também de 2018 a Estratégia Nacional para a Igualdade e a Não Discriminação - Portugal+Igual, que inclui o Plano de ação para o combate à discriminação em razão da orientação sexual, identidade e expressão de género, e características sexuais (2018-2021) e que vem afirmar o compromisso do Estado português com a anti-discriminação ${ }^{5}$.

Relativamente ao contexto educativo em Portugal, pese embora o pendor cis-heteronormativo que informa historicamente a educação sexual em meio escolar (Saavedra et al. 2010; Duarte Silva et al. 2014; Matos et al. 2014), têm sido criados instrumentos e políticas públicas visando garantir proteção não somente das pessoas adultas, mas também das crianças e jovens LGBTI+. A criação do Estatuto do Aluno e Ética Escolar (Lei n. ${ }^{\circ}$ 51/2012 de 5 de Setembro) ${ }^{6}$ possibilita, a partir de 2012, a reivindicação do direito ao tratamento com respeito e correção por parte de qualquer membro da comunidade educativa, não podendo acontecer, em caso algum, discriminações em razão de sexo, orientação sexual e identidade de género.

Mais informações sobre a Lei da Identidade de Género disponíveis em https://dre.pt/pesquisa/-/ search/115933863/details/maximized

Plano de ação para o combate à discriminação em razão da orientação sexual, identidade e expressão de género, e características sexuais (2018-2021) em Estratégia Nacional para a Igualdade - Portugal + Igual (2018-2030) disponível em https://www.cig.gov.pt/wp-content/ uploads/2020/12/Resol_Cons_-Ministros_61_2018.pdf [Consultado em 5 de abril de 2021].

6 Disponível em https://dre.pt/pesquisa/-/search/174840/details/maximized [Consultado em 1 de abril de 2021]. 
Em 2019, foi aprovado o Despacho n. ${ }^{\circ} 7247 / 2019^{7}$, que estabelece medidas para a implementação da Lei n. ${ }^{\circ}$ 38/2018 em contexto escolar e que prevê o respeito pelo nome social da/o aluna/o e o direito ao uso de uniforme e casa de banho de acordo com a sua identidade de género autodeterminada. Em 2020, foi lançada a Estratégia Nacional para os Direitos da Criança (2021-2024) ${ }^{8}$, que inclui uma preocupação em garantir bem-estar, proteção, igualdade de oportunidades e acesso aos direitos fundamentais de todas as crianças e jovens, independentemente da sua orientação sexual, identidade e expressão de género e caraterísticas sexuais.

Nos contextos de prestação de cuidados de saúde, destacamos alterações na concetualização dos processos de desenvolvimento de género, incluindo a diversidade de género na infância em Portugal, parcialmente explicados por um movimento internacional de despatologização trans forte (WPATH 2010; Suess 2020). Trata-se, portanto, de alterações que colocam o bem-estar das crianças e jovens LGBTI+ no centro das preocupações. Em 2017, a Ordem dos Psicólogos Portugueses lança o primeiro Guia Orientador da Intervenção Psicológica com Pessoas Lésbicas, Gays, Bissexuais e Trans (LGBT). Posteriormente, em 2019, o Ministério da Saúde/ Direção-Geral da Saúde lança a Estratégia de saúde para as pessoas lésbicas, gays, bissexuais, trans e intersexo: Volume 1 - Promoção da saúde das pessoas trans e intersexo $0^{9}$. A criação deste importante documento contou com o envolvimento das Administrações Regionais de Saúde, Centro Hospitalar da Universidade de Coimbra - URGUS, da Comissão para a Cidadania e a Igualdade de Género - CIG, da Ordem dos Médicos, da Ordem dos Psicólogos Portugueses, da Ordem dos Enfermeiros, tendo ainda sido auscultadas associações que intervêm junto de crianças e jovens LGBTI+.

Assim, a partir do ciclo governativo iniciado em 2015, parece existir por parte do Estado um progressivo reconhecimento da relação entre a classificação da diversidade de género enquanto psicopatologia e dinâmicas de discriminação, estigmatização e violência transfóbica (Schneider 2013). Regista-se também uma mudança nas orientações da tutela visando introduzir práticas afirmativas para trabalhar com pacientes (crianças e jovens) LGBTI+, de modo a fomentar serviços de saúde inclusivos. A atual abordagem de despatologização trans informa práticas afirmativas que apoiam crianças e jovens, em consonância com estudos desenvolvidos noutros contextos (HRC 1996; Bryant 2006; Ehrensaft 2012; Green e Friedman 2013; Pyne 2014).

7 Disponível em https://dre.pt/home/-/dre/123962165/details/maximized [Consultado em 1 de abril de 2021].

8 Comissão Nacional de Promoção dos Direitos e Proteção das Crianças e Jovens. 2020. Estratégia Nacional para os Direitos da Criança (2021-2024). Disponível em https://dre.pt/application/ conteudo/ 151557423 [Consultado em 5 de abril de 2021].

9 Disponível em https://www.dgs.pt/documentos-e-publicacoes/estrategia-de-saudepara-as-pessoas-lesbicas-gays-bissexuais-trans-e-intersexo-lgbti-pdf.aspx [Consultado em 5 de abril de 2021]. 
A já mencionada Estratégia Nacional pelos Direitos da Criança (ENDC 2020-2024) reconhece a importância da proteção e promoção do bem-estar de todas as crianças, o que por sua vez se traduz num maior apoio às famílias destas crianças. Exemplos incluem o Guia para Familias de crianças com papéis e comportamentos de género diverso, produzido pela AMPLOS e Instituto de Apoio à Criança (2019), e o projeto «E se fosse outra cor ${ }^{10}$.

Apesar destes passos significativos, fruto de transformações jurídicas e socioculturais em torno do género e da sexualidade, continuam a ser encorajadas biografias íntimas normativas (Roseneil et al. 2020). A presença de uma normatividade reprodutiva (entre outras) ligada ao género e às sexualidades explica a dificuldade em mudar o contexto sociocultural, demonstrando a insuficiência de uma intervenção estritamente jurídica. A literatura sobre regimes de bem-estar e género descreve os países da Europa do Sul como familistas, repronormativos e (hetero)normativos (Torres, Mendes e Lapa 2008; Santos 2013; Mínguez e Crespi 2017). Daí que a violência e a discriminação baseada na orientação sexual, identidade e expressão de género continuem a ser reportadas (ILGA Portugal 2019; OECD 2019; rede exaequo 2019; 2020; ILGA Europe 2021) e estejamos a assistir a retrocessos em direitos sexuais e reprodutivos adquiridos, alimentados por uma onda crescente de populismo anti-género (Möser et al. 2022).

A falta de conhecimento e formação sobre temas LGBTI+ em profissionais que trabalham na área da infância e juventude reflete estas consequências da cis-heteronormatividade, acabando por impedir uma prestação de serviços inclusiva para todas as crianças. É urgente colmatar esta lacuna, já que a violência e a discriminação baseada na LGBTIfobia comporta consequências de enorme gravidade (OECD 2019; rede ex aequo, 2019; 2020).

\section{Metodologia e discussão de resultados}

\subsection{Estratégia metodológica}

Existindo em Portugal legislação e criação de instrumentos de políticas públicas que vão ao encontro do respeito e proteção da diversidade sexual e de género na infância, quisemos conhecer as perspetivas de profissionais que atuam direta ou indiretamente junto de crianças e jovens e quais os desafios e obstáculos identificados (tanto por profissionais como por crianças), no âmbito de atuação profissional da escola, intervenção familiar e saúde, que dificultam o cumprimento pleno do quadro legal nas diferentes instituições. Pretendemos assim aprofundar o modo como a estratégia de mainstreaming LGBTI+ está a ser implementada no contexto português, identificando práticas profissionais que respondam adequadamente às crianças e jovens LGBTI+.

10 Disponível em http:/ / esefosseoutracor.com / [Consultado em 5 de Abril de 2021]. 
Para tal recolhemos informação no âmbito do projeto de investigação europeu «Diversidade e Infância» (2019-2021). Tratando-se de um projeto de investigação-ação (Chevalier e Bucles 2013), seguimos uma abordagem qualitativa recorrendo à triangulação metodológica (Flick 2005) mediante diferentes métodos de recolha, análise e interpretação da informação, de modo a colmatar as limitações decorrentes de métodos únicos (Maxwell 1996). Socorremo-nos de três fontes principais: especialistas em cada uma das áreas de intervenção do projeto (educação, saúde, media, intervenção familiar e intervenção comunitária); profissionais que trabalham de forma direta ou indireta com crianças e jovens. A cada um destes grupos foi aplicado um método distinto. Assim, realizámos 10 entrevistas qualitativas semiestruturadas a especialistas com duração média de 90 minutos; aplicámos um inquérito por questionário a profissionais $\mathrm{s}^{11}$; e realizámos uma oficina com adolescentes para discutir os temas em apreço a partir da perspetiva das crianças. Os aspetos éticos foram acautelados em todas as fases.

Através de análise temática (Braun e Clarke 2006), analisámos dimensões como perspetivas individuais sobre diversidade veiculadas por profissionais e crianças, a in/existência de políticas e medidas afirmativas aplicadas pelas instituições, e práticas profissionais adotadas. Esta análise visou identificar eventuais contradições entre a Lei da Autodeterminação de Género aprovada e a sua implementação, contribuindo assim para um diagnóstico facilitador do melhor cumprimento de medidas nesta área. Segue-se uma análise dos dados recolhidos com profissionais, a partir quer do Inquérito Europeu Diversidade e Infância, quer das entrevistas qualitativas realizadas a 10 profissionais.

2.2. Perspetivas e práticas profissionais relativamente à diversidade sexual e de género na infância - discussão de resultados

Da nossa análise resulta visível uma tendência para que profissionais que trabalham com crianças e jovens nas áreas da educação, intervenção familiar e saúde considerem o género enquanto construção social e não um conjunto de caraterísticas definidas por critérios exclusivamente biomédicos. Esta tendência encontra-se alinhada com a Lei da Autodeterminação de Género.

No entanto, foram também identificados discursos que resistem a esta mesma ideia, fazendo assentar uma definição de género em pilares biomédicos, o que revela um desencontro entre o marco jurídico vigente e a atualização de conhecimentos nesta matéria.

As respostas integram o $1^{\circ}$ Inquérito Europeu Diversidade e Infância, construído pela equipa portuguesa e validado pelo Conselho Consultivo internacional do projeto. Mais informações disponíveis em https: / / www.diversityandchildhood.eu/project-reports [Consultado em 2 de abril de 2021]. 
É igualmente notória alguma dificuldade na distinção entre género e sexo, conceitos que são frequentemente tratados como sinónimos ou equivalentes. A esta justaposição está subjacente uma perspetiva de género binária que estrutura o género - e o sexo - de forma dicotómica. Consideramos que a conceção dicotómica de género ainda vigente introduz obstáculos face à estratégia do Estado português para a igualdade e anti-discriminação.

Nas áreas estudadas, a análise revela uma progressiva atenção dada a temas respeitantes à infância e juventude LGBTI+, verificando-se práticas profissionais afirmativas, tal como expresso na Estratégia Nacional Portugal + Igual. Esse crescente apoio demonstrado por profissionais põe em destaque a importância de criar respostas que tenham em conta as especificidades e necessidades das crianças e jovens LGBTI+, invisibilizadas e desprotegidas até 2018. Atentemos na seguinte citação:

Cada vez mais porque, primeiro porque preocupo-me com o bem-estar individual de cada um e acho muito importante e eu falo muito com eles desde o início sobre isso. Ninguém aprende num ambiente em que não está feliz, não está seguro, não se sente bem, não é confortável. Portanto, para isso acontecer tem que existir condições saudáveis entre eles, não é (...) quanto mais espaços de diálogo também existirem, nós sabemos que nem todos os ambientes são seguros. Tu podes criar isso aqui. (professora EB1, 40-44 anos)

Esta citação sugere que, se, por um lado, há uma consciencialização gradual das/os profissionais nas suas áreas de atuação, por outro, é urgente uma mudança no paradigma, em particular na forma como são pensadas ações ou estratégias dentro das instituições educativas ou nos serviços de prestação de cuidados de saúde. Uma mudança ao nível da mentalidade acompanha as anteriores mudanças. Note-se que a falta de informação sobre estas temáticas continua a fazer-se sentir, evidenciando a urgência de sensibilizar instituições e o conjunto alargado das/os profissionais para viabilizar práticas afirmativas que favorecem ambientes escolares inclusivos. Por exemplo, deve ser considerado um trabalho continuado junto do corpo docente e extensível ao corpo não docente:

[...] ainda há muitas pessoas, muitos profissionais na área da psicologia, com cabeças ainda, enfim... com atitudes pouco corretas deste ponto de vista. (Psicóloga, 55-59 anos)

[...] horrorosos, comentários do mais fascista, do mais agressivo possível, e vindo de professores, que é uma coisa que tu não devias aceitar. Vinte e dois anos a dar aulas e ainda continuamos a ouvir coisas. Vinte e dois anos e ainda continuas a ver nos livros escolares barbaridades e, por exemplo, esta questão do género tão mal defendida. (Professora EB1, 40-44 anos) 
A falta de informação sobre a temática da diversidade sexual e de género é identificada pela quase totalidade das/os participantes, dando conta da incerteza que estas/es profissionais sentem quando se pergunta se as normas de género influenciam o seu trabalho com crianças LGBTI+. Sendo verdade que estamos perante profissionais comprometidos/as em desenvolver um trabalho adequado junto das crianças e jovens LGBTI+, também é notório o acentuado desconhecimento e ausência de reflexão sobre o modo como as normas de género influenciam a forma como nos relacionamos com as crianças e os espaços onde a atividade profissional é desenvolvida.

Além disso, as/os profissionais consideraram que o medo da rejeição por parte de pares, famílias e outras pessoas adultas de referência, bem como o receio de poderem vir a ser vítimas de bullying, são alguns dos desafios que crianças e jovens LGBTI+ sentem no quotidiano, o que sublinha o caráter urgente de fazer cumprir uma estratégia de mainstreaming LGBTI+.

$\mathrm{Na}$ sua maioria, as/os profissionais reconhecem que existem situações de bullying por LGBTIfobia. Urge reforçar a corresponsabilização de profissionais visando alianças com crianças LGBTI+ nos diferentes espaços onde participam, tornando-os espaços seguros:

Nem sempre as pessoas sentem que é um espaço seguro, que toda a gente sente que é respeitada. [...] [A instituição] tem de mostrar ativamente que tem uma atitude de respeito e de inclusão, porque se não mostrar está implícito e o implícito é uma coisa pouco clara. [...] Sentirem que estão seguras para falar e para existirem, sentirem que aquele espaço é um espaço seguro para mostrarem. [...] O adulto que está lá não se pode esquecer que é um adulto e tem de ser o primeiro a passar uma mensagem de clara igualdade de circunstâncias de tratamento, de vida para todos. (Psicóloga, 55-59 anos).

Verificamos a existência de consenso entre profissionais sobre a importância da Lei da Autodeterminação de Género, nomeadamente ao nível do reconhecimento e proteção. A perceção dos profissionais é de que o Estado tem dado sinais de preocupação com o bem-estar destas crianças, o que é essencial para a redução do preconceito e violência. Consideram, contudo, que a legislação é insuficiente, carecendo de medidas de implementação no terreno.

Introduzir a temática do género e da diversidade sexual nas escolas e intervenção junto das famílias seria uma possível medida para garantir que a autodeterminação de género é cumprida nas áreas referidas. As/os profissionais sugerem ainda a realização de ações de formação ao nível curricular e profissional, maior articulação com famílias de crianças LGBTI+ e mais representação desta diversidade nos materiais (boletins de saúde infantis, campanhas de informação e sensibilização ou manuais escolares, por exemplo). Há também por parte destas/es profissionais a perceção de que as instituições nas várias áreas devem ter um papel 
proactivo e inequívoco no apoio a crianças LGBTI+, assumindo assim o dever de cumprimento do quadro legal vigente.

Tanto profissionais como crianças envolvidas no estudo consideram que, apesar da recetividade «formal» das instituições em desenvolver atividades visando temas LGBTI+, essa recetividade traduz-se em ações ou medidas insuficientes. A ausência de políticas específicas nas instituições ou de promoção de boas práticas LGBTI+ não permite a criação de espaços seguros de criatividade e autodeterminação que valorizem as opiniões, emoções e trajetórias de vida destas crianças e jovens.

É também apontada a ausência de implementação de forma sistemática e transversal, ficando as crianças e jovens LGBTI+ reféns da sensibilidade individual das/os profissionais. Este aspeto denuncia um desalinhamento sério face à estratégia de mainstreaming LGBTI+ que o Estado promove, devendo ser objeto de atenção.

Está muito dependente da pessoa e não do profissional, ou seja, se eu enquanto pessoa [es]tiver já de alguma forma desperta para estas questões, eu não vou deixar que isso influencie a forma como eu trato aquela criança independentemente do género que ela tem, mas eu acho que é preciso mais formação, mais informação e mais divulgação, porque acho que ainda há muitos profissionais a trabalhar com crianças, psicólogos os médicos ou o que for, que têm muito estas questões de género ainda enraizadas do Estado Novo, quase alguns será por crença própria, e por muito que as informações lhes cheguem aos olhos vão sempre fechar os olhos e virar a cara, porque se calhar não estão muito despertos. (Psicóloga social, 30-34 anos)

Os resultados do Inquérito Europeu Diversidade e Infância revelam que a falta de acesso a recursos no local de trabalho para apoiar as crianças e jovens LGBTI+ é ainda uma realidade. Para a criação de serviços mais inclusivos e sensíveis à diversidade, as/os profissionais destacam a importância do acesso a formação sobre crianças e jovens LGBTI+ e sobre população LGBTI+ no geral, a implementação de práticas e políticas LGBTI+, a construção de serviços/respostas específicas para crianças e jovens LGBTI+ e a construção de parcerias com organizações LGBTI+.

Os profissionais de saúde têm as mesmas necessidades que os docentes. Não só da tal formação, mas também de alguns materiais, normas e protocolos. Por exemplo, como falar, a questão da linguagem, que é uma coisa básica e que seria fundamental e que se devia atuar muito mais aí, e sempre do Ministério, porque tem um outro peso nas pessoas, que acabam por aderir muito mais. Portanto, acho que podia haver um trabalho próximo entre o Ministério e Associações, produzir materiais, mas que depois o Ministério lhes dava ou a Secretária de Estado [para a Igualdade], punham lá o logótipo e tal, e aquilo ficava e distribuíam eles. (Médico em pedopsiquiatria, 25-29 anos) 
O acesso a supervisão para apoiar dúvidas de casos, a divulgação de manuais para práticas profissionais inclusivas, o estabelecimento de relações com organização/coletivos LGBTI+ para prestação de apoio e assessoria são alguns exemplos identificados como práticas afirmativas em curso e que devem ser reforçadas.

\section{Impactos do adultocentrismo na regulação da diversidade sexual e de género na infância e juventude - considerações finais}

Enquanto corpo social, partilhamos a responsabilidade de combater situações de vulnerabilidade a que possam estar sujeitas crianças cujo superior interesse deve ser acautelado (Santos 2018b; 2018c). Essa responsabilidade, consagrada na Declaração dos Direitos da Criança desde $1959^{12}$, traduz-se frequentemente na reificação de um modelo cis-heteronormativo para a infância que tem como consequência prática a desproteção social e jurídica de crianças e jovens LGBTI+ ou de género diverso.

Quando olhamos para a diversidade sexual e de género na infância devemos ter presente as limitações impostas pelas normas sociais formuladas pelas pessoas adultas, que dificultam a compreensão enquanto sujeitos políticos e que influenciam a forma como incluímos as crianças nos processos democráticos ou aplicamos o quadro legal vigente (Sundhall 2017). A criança vê a sua vida determinada a partir de normas sociais formuladas pelas pessoas adultas de forma implícita e invisível, logo naturalizadas. Nesse sentido, surgem conceitos como participação da infância ou crianças-atores que pretendem destacar o reconhecimento das crianças como seres humanos completos e equivalentes aos adultos (Alanen 1988; 1992; James e Prout 1990; Qvortrup 1994; James, Jenks e Prout 1998; Hockey \& James 2003).

Outros estudos denunciam conceitos como «agência», alegando que reproduzem a norma adulta segundo a qual os direitos não são absolutos, mas devem ser alcançados (earned) (Wall 2010). Nessa linha, o conceito de childism (Pierce e Allen 1975) permite examinar de forma crítica perspetivas dominantes e desconstruir a naturalização da idade adulta.

No campo de estudos da infância, os significados e efeitos da vida adulta são pouco discutidos. A idade e as diferentes formas de regular a idade são formas comuns de criar uma ordem social (Närvänen e Näsman 2004; 2007). É por esse motivo que a idade pode ser concebida como uma ordem de poder. Figuras adultas de referência (pais, mães ou outros) poderão retirar uma vantagem injusta do poder (implícito ou explícito) que exercem sobre as crianças, e certos comporta-

12 ONU 1959. Declaração dos Direitos da Criança. Disponível em https:/ / www.dge.mec.pt/sites / default / files / ECidadania / Docs_referencia / declaracao_universal_direitos_crianca.pdf [Consultado em 2 de abril de 2021]. 
mentos adultos podem ser encorajados pela tendência dominante em ver as crianças de forma relativamente fixa e assente em relações hierárquicas, não somente com os pais ou as mães, mas com as pessoas adultas em geral.

Recordemos as reações de repúdio à Lei de Autodeterminação de Género (Lei 38/2018) a partir dos 16 anos, que dispensa intervenções cirúrgicas em pessoas intersexo menores de idade, salvaguardando situações de risco de saúde ou vida (Mariano 2020; Santos 2022). Ao respeitar a autodeterminação, Portugal colocou-se ao lado de países como a Bélgica, a Dinamarca, a Irlanda, Malta ou a Noruega, mas viu surgir movimentos de contestação que alegavam que apenas pessoas adultas poderiam tomar decisões sobre corpo, sexualidade ou género. $\mathrm{O}$ adultismo relaciona-se com esta tendência para ver as crianças e jovens como incondicionalmente subordinadas/os até atingirem a maioridade jurídica.

A diversidade sexual e de género não é exclusiva da população adulta. Daí que seja fundamental reconhecer que as experiências de crianças e jovens constituem conhecimento e que, como tal, devem informar medidas que visam garantir o superior interesse da criança. Neste ponto, importa sublinhar que o superior interesse da criança LGBTI+ tem sido sistematicamente lesado ou silenciado. Acresce que a própria noção de infância tem sido instrumentalizada ao serviço de um sistema político cis-heteronormativo (Stockton 2009; Robinson 2012; McClelland e Hunter 2013; Cardoso 2018). Preciado alerta para a construção de uma ideia de família política e uma noção de criança submetida à norma heterossexual e que se considera como tal desde o princípio, privando-a de qualquer forma de resistência e de utilizar e expressar o seu corpo de forma livre. Preciado $(2013,97)$ diz-nos que

é impossível uma criança se rebelar politicamente contra um discurso dos adultos: a criança é sempre um corpo ao qual não se reconhece o direito de governar. Quem defende então o direito das crianças que saem da norma de género e sexual? Onde está o direito à autodeterminação de género e sexualidade nas crianças e jovens?

Estando as instituições - e práticas profissionais - influenciadas por um sistema estrutural que reproduz valores cis-heteronormativos, são também elas palco de violências e fenómenos de marginalização que comprometem a igualdade no acesso à educação (Evans e Rawlings 2019; IGLYO e UNESCO 2021) e à saúde (Ceatha et al. 2020; Gato et al. 2020; Wilson e Cariola 2020). Por outras palavras, a cis-heteronormatividade regula a forma como a diversidade de género e sexual é ou não «acolhida» e garantida nos diferentes espaços institucionais, produzindo diferentes efeitos transversais, interseccionais e ao longo da vida.

Como vimos, o défice de formação e a resistência à mudança têm impactos graves para o bem-estar de crianças e jovens LGBTI+. Estes impactos são transversais, interseccionais, cumulativos e ao longo da vida. De forma a minimizar estes impactos e promover espaços seguros para todas/os, urge corresponsabilizar insti- 
tuições, envolver profissionais, apostar na formação e fomentar medidas de ação afirmativa no quotidiano, em cumprimento com o desígnio de mainstreaming LGBTI+ associado à ideia vigente de um país que se projeta internacionalmente enquanto zona de liberdade LGBTI+.

Sendo a inclusão da diversidade sexual e de género em todos os âmbitos uma forma de justiça social, constitui uma obrigação do Estado no processo de restituição de direitos (Panziera 2019). Daí a importância de olharmos para as várias áreas e espaços onde crianças e jovens participam na vida pública, fomentando perspetivas e práticas profissionais menos adultocentradas e que tenham em conta as vozes e percursos diversos de crianças e jovens.

A este respeito, importa ainda salientar que a despatologização consagrada juridicamente desde 2018 com a Lei da Autodeterminação de Género desmonta a necessidade de precaver a diversidade de género na infância, juventude e vida adulta. Consequentemente, as designadas «terapias de conversão» devem ser objeto de intervenção adequada visando a sua imediata proibição enquanto prática lesiva do bem-estar de crianças e jovens LGBTI+.

\section{Referências bibliográficas}

Alanen, Leena. 1988. «Rethinking Childhood.» Acta Sociologica 31(1): 53-67. DOI: https:/ / doi.org/10.1177/000169938803100105

Alanen, Leena. 1992. Modern childhood?: Exploring the «child question» in sociology. Jyväskä: University of Jyväskä.

Almeida, Miguel. 2010. «O contexto LGBT em Portugal.» In Estudo sobre a Discriminação em Função da Orientação Sexual e da Identidade de Género, organizado por João Oliveira e Conceição Nogueira, 45-90. Lisboa: CIG. Disponível em http:/ / bibliobase.sermais. pt:8008/BiblioNET/upload/PDF2/0892_ESTUDO_ORIENTACAOSEXUAL_IDENTID.pdf [Consultado em 15 de maio de 2021].

AMPLOS, e Instituto de Apoio à Criança. 2019. Guia para Famílias de crianças com papéis e comportamentos de género diverso. Lisboa: CIG. Disponível em https: / / www.cig.gov. pt/area-lgbti / documentacao/ publicacoes / [Consultado em 4 de maio de 2021].

Associação para o Planeamento da Família, CIG, e Fundação Vodafone. 2019. «E se fosse de outra cor.» Disponível em http: / / esefosseoutracor.com / [Consultado em 5 de abril de 2021].

Braun, Virginia, e Victoria Clarke. 2006. «Using thematic analysis in psychology.» Qualitative Research in Psychology 3(2): 77-101. DOI: http:/ / dx.doi.org/10.1191/1478088706 qp063oa

Bryant, Karl. 2006. «Making gender identity disorder of childhood: Historical lessons for contemporary debates.» Sexuality Research E Social Policy 3(3): 23-39. DOI: https:// doi.org/10.1525/srsp.2006.3.3.23

Cardoso, Daniel. 2018. «Notas sobre a Criança transviada: considerações queerfeministas sobre infâncias.» Revista Periódicus 1(9): 214-233. DOI: https: / / doi.org/10.9771/peri. v1i9.25755

Ceatha, Nerilee, Marta Bustillo, Louise Tully, Oscar James, e Des Crowley. 2020. «What is known about the protective factors that promote LGBTI+ youth wellbeing? A scoping 
review protocol.» HRB Open Research 3(11): 177. DOI: https: / doi.org/10.12688/hrbo penres.13018.2

Chevalier, Jacques, e Daniel Buckles. 2013. Handbook for Participatory Action Research, Planning and Evaluation. Ottawa: SAS2 Dialogue. Disponível em https:/ / www.betterevaluation.org/sites / default / files / Toolkit_En_March7_2013-S.pdf [Consultado em 12 de maio de 2021].

Comissão para a Cidadania e a Igualdade de Género. 2018. «Plano de ação para o combate à discriminação em razão da orientação sexual, identidade e expressão de género, e características sexuais (2018-2021).» In Estratégia Nacional para a Igualdade - Portugal + Igual (2018-2030). Disponível em https://www.cig.gov.pt/wp-content/uploads/ 2020/12/Resol_Cons_-Ministros_61_2018.pdf [Consultado em 8 de maio de 2021].

Diversity and Childhood (DaC). 2020. National Analysis on Violence against LGBTI and Gender Non-Conforming Children: Portugal. Disponível em https://www.diversityandchildhood.eu / outputs-and-publications [Consultado em 2 de abril de 2021].

Duarte Silva, Maria João, e Maria da Luz Carvalho. 2014. «Para uma Educação Sexual Corporizada: Análise situada na educação básica em Portugal.» Revista Latino-Americana de Geografia e Gênero, 5(2): 33-41. DOI: https: / / doi.org/10.5212/Rlagg.v.5.i2.0004

Ehrensaft, Diane. 2012. «From Gender Identity Disorder to Gender Identity Creativity: True Gender Self Therapy.» Journal of Homosexuality 59(3): 337-356. DOI: https: / / doi.org/1 $0.1080 / 00918369.2012 .653303$

Evans, India, e Victoria Rawlings. 2019. «"It was Just One Less Thing that I Had to Worry about": Positive Experiences of Schooling for Gender Diverse and Transgender Students.» Journal of Homosexuality 68(9): 1489-1508. DOI: https: / / doi.org/ 10.1080 / 00 918369.2019.1698918

Fahs, Breanne. 2014. "Freedom to" and "freedom from": A new vision for sex-positive politics.» Sexualities 17(3): 267-290. DOI: https: / / doi.org/10.1177/1363460713516334

Flick, Uwe. 2005. "Triangulation in Qualitative Research.» In A Companion to Qualitative Research, organizado por Uwe Flick, Ernst von Kardorff, e Ines Steinke, 178-183. London: Sage.

Gato, Jorge, Daniela Leal, Carla Moleiro, Telmo Fernandes, Diogo Nunes, Inês Marinho, Oren Pizmony-Levy, e Cody Freeman. 2020. "“The Worst Part Was Coming Back Home and Feeling Like Crying": Experiences of Lesbian, Gay, Bisexual and Trans Students in Portuguese Schools.» Frontiers in Psychology 10(2936): 1-10. DOI: https: / / doi.org/10.3389/fpsyg.2019.02936

Green, Fiona, e May Friedman, ed. 2013. Chasing Rainbows: Exploring Gender Fluid Parenting Practices. Bradford, ON, Canada: Demeter Press.

Hines, Sally, e Ana Cristina Santos. 2018. «Trans* policy, politics and research: The UK and Portugal.»Critical Social Policy 38(1): 35-56. DOI: https:// doi.org/10.1177/0261018 317732880

Hockey, Jenny, e Allison James. 2003. Social Identities Across the Life Course. Basingstoke: Palgrave Macmillan.

Human Rights Campaign (HRC). 1996. Supporting \& Caring for Transgender Children. Washington, D.C.: Human Rights Campaign. Disponível no endereço http:/ / hrc.im/ supportingtranschildren [Consultado em 3 de março de 2021].

IGLYO, e UNESCO Global Education Monitoring Report Team. 2021. «Don't look away: No place for exclusion of LGBTI students.» Policy Paper 45. Disponível no endereço https: / / en.unesco.org/gem-report/LGBTIdontlookaway [Consultado em 17 de abril de 2021]. 
ILGA Europe. 2021. Rainbow Europe Map. Disponível em https://www.ilga-europe.org/ rainboweurope/ 2021 [Consultado em 17 de abril de 2021].

ILGA Portugal. 2019. Relatório Anual: Discriminação contra pessoas LGBTI+. Disponível em https: / / ilga-portugal.pt / ficheiros / pdfs / observatorio/ILGA_Relatorio_Discrimina cao_2019.pdf [Consultado em 8 de junho de 2021].

James, Allison, e Alan Prout, ed. 1990. Constructing and Reconstructing Childhood: Contemporary Issues in the Sociological Study of Childhood. London: Falmer Press.

James, Allison, Chris Jenks, e Alan Prout. 1998. Theorizing Childhood. Cambridge: Polity Press.

Mariano, Gustavo. 2020. «Human Rights Discourses in the Production of Politics around Gender and Sexuality Education in Portugal.» Dissertação de doutoramento em curso, CES-UC.

Matos, Margarida G. de, Marta Reis, Lúcia Ramiro, José Pais Ribeiro, e Isabel Leal. 2014. «Educação sexual em Portugal: legislação e avaliação da implementação nas escolas.» Psicologia, Saúde EDoenças 15(02):335-355.DOI:https: / / doi.org/10.15309/14psd150203

Maxwell, Joseph. 1996. Qualitative Research Design: An Interactive Approach. Los Angeles: SAGE.

McClelland, Sara, e L. E. Hunter. 2013. «Bodies That Are Always Out of Line: A Closer Look at "Age Appropriate Sexuality".» In The Moral Panics of Sexuality, organizado por Breanne Fahs, Mary Dudy e Sarah Stage, 59-76. London: Palgrave Macmillan.

Mínguez, Almudena, e Isabella Crespi. 2017. «Future perspectives on work and family dynamics in Southern Europe: The importance of culture and regional contexts.» International Review of Sociology 27(3): 389-393. DOI: https: / / doi.org / 10.1080 / 0390670 1.2017.1378153

Möser, Cornelia, Jennifer Ramme, e Judit Takács, ed. 2022. Paradoxical Right-Wing Sexual Politics in Europe. Basingstoke: Palgrave Macmillan.

Närvänen, Anna-Liisa, e Elisabet Näsman. 2004. «Childhood as Generation or Life Phase?» Young 12(1): 71-91. DOI: https: / / doi.org/10.1177/1103308804039637

Närvänen, Anna-Liisa, e Elisabet Näsman. 2007. «Age order and children's agency.» In Childhood, generational order and the welfare state: Exploring children's social and economic welfare, organizado por Helmut Wintersberger, Leena Alanen, Thomas Olk, e Jens Qvortrup, 225-253. Odense: University Press of Southern Denmark.

OECD. 2019. Social Indicators: Society at a Glance 2019 - A spotlight on LGBT People. Disponível em https: / / www.oecd.org/ social/ society-at-a-glance-19991290.htm [Consultado em 14 de maio de 2021].

Ordem dos Psicólogos Portugueses. 2017. Guia Orientador da Intervenção Psicológica com Pessoas Lésbicas, Gays, Bissexuais e Trans (LGBT). Disponível em https: / / www.ordem dospsicologos.pt/ficheiros / documentos / guidelines_opp_lgbt_marco_2017.pdf [Consultado em 1 de maio de 2021].

Panziera, Andy. 2019. «Políticas públicas de acompañamiento a las infancias trans y no-binarias: Propuestas, avances y desafíos para una democracia participativa.» Revista de Educación 18: 331-338. Disponível em https://fh.mdp.edu.ar/revistas/ index.php/r_educ/article/view/3764 [Consultado em 8 de junho de 2021].

Pierce, Chester, e Gail Allen. 1975. «Childism.» Psychiatric Annals 5(7): 15-24. DOI: https: / / doi.org/10.3928/0048-5713-19750701-04

Preciado, Paul. 2013. «Quem defende a criança queer?» Traduzido por Fernanda Nogueira. Jangada 1: 96-99. Disponível em https://www.revistajangada.ufv.br/index.php/ Jangada/article/view/17 [Consultado em 1 de abril de 2021]. 
Pyne, Jake. 2014. «Gender independent kids: A paradigm shift in approaches to gender non-conforming children.» Canadian Journal of Human Sexuality 23(1): 1-8. DOI: http: / / dx.doi.org/10.3138/cjhs.23.1.CO1

Qvortrup, Jens. 1994. «Childhood matters: An introduction.» In Childhood Matters. Social Theory, Practice and Politics, organizado por Jens Qvortrup, Marjatta Bardy, Giovanni Sgritta, e Helmut Wintersberger. Aldershot: Avebury.

rede ex aequo. 2019. Relatório do Projeto de Educação 2016-2018. Disponível em https: / / www. rea.pt/relatorioprojetoeducacao / [Consultado em 18 de maio de 2021].

rede ex aequo. 2020. Relatório do Projeto de Educação 2019. Disponível em https: / / www.rea. pt / relatorioprojetoeducacao/ [Consultado em 3 de maio de 2021].

Robinson, Kerry H. 2012. "“Difficult citizenship": The precarious relationships between childhood, sexuality and access to knowledge.» Sexualities 15(3-4): 257-276. DOI: https: / / doi.org/10.1177 / 1363460712436469

Roseneil, Sasha, Isabel Crowhurst, Tone Hellesund, Ana Cristina Santos, e Mariya Stoilova, ed. 2020. The Tenacity of the Couple-Norm: Intimate citizenship regimes in a changing Europe. London: UCL Press.

Saavedra, Luisa, Conceição Nogueira, e Sara Magalhães. 2010. «Discursos de jovens adolescentes portugueses sobre sexualidade e amor: implicações para a educação sexual.» Educação \& Sociedade, 31(110): 135-156. DOI: https:// doi.org/10.1590/S0101-733020 10000100008

Saleiro, Sandra. 2017. «Diversidade de género na infância e educação: contributos para uma escola sensível ao trans(género).» ex aequo 36: 149-165. DOI: https: / / doi.org / 10.22355/ exaequo.2017.36.09

Santos, Ana Cristina. 2013. Social Movements and Intimate Citizenship in Southern Europe. Basingstoke: Palgrave.

Santos, Ana Cristina. 2018a. «Luta LGBTQ em Portugal: Duas décadas de histórias, memórias e resistências.» Revista TransVersos 14: 36-51. DOI: https://doi.org/10.12957/ transversos.2018.38654

Santos, Ana Cristina. 2018b. «Repronormativity and its Others: Queering Parental Love in Times of Culturally Compulsory Reproduction.» Analize: Journal of Gender and Feminist Studies 11: 199-215. Disponível em http://www.analize-journal.ro/library/files/ numarul_11/11_10_ana_cristina_santos_199-215.pdf [Consultado em 8 de junho de 2021].

Santos, Ana Cristina. 2018c. «Quem defende o superior interesse da criança trans?» Público, 27 de abril. Disponível em https://www.publico.pt/2018/04/27/sociedade/opiniao/ quem-defende-o-superior-interesse-da-crianca-trans-1811700 [Consultado em 8 de junho de 2021].

Santos, Ana Cristina. 2022. «Nothing from them - LGBTQI+ rights and Portuguese exceptionalism in troubled times.» In Paradoxical Right-Wing Sexual Politics in Europe, organizado por Cornelia Möser, Jennifer Ramme, e Judit Takács. Basingstoke: Palgrave Macmillan (no prelo).

Schneider, Erik. 2013. An insight into respect for the rights of trans and intersex children in Europe. Council of Europe. Disponível em https:/ / rm.coe.int/168047f2a7 [Consultado em 8 de junho de 2021].

Stockton, Kathryn B. 2009. The Queer Child, or Growing Sideways in the Twentieth Century. Durham: Duke University Press.

Suess, Amets. 2020. «Trans health care from a depathologization and human rights perspective.» Public Health Reviews 41(3). DOI: https: / / doi.org/10.1186/ s40985-020-0118-y 
Sundhall, Jeanette. 2017. «A Political Space for Children? The Age Order and Children's Right to Participation.» Social Inclusion 5(3). DOI: https:/ / doi.org/10.17645/si.v5i3.969

Torres, Anália, Rita Mendes, e Tiago Lapa. 2008. «Families in Europe.» Portuguese Journal of Social Science 7(1):49-84. DOI: https: / / doi.org/10.1386/pjss.7.1.49_1

UE. 2020. Uma União de Igualdade: Estratégia em Favor da Igualdade das Pessoas LGBTIQ 2020-2025: Construir uma União em que cada um seja livre de ser quem é. Disponível em https: / / ec.europa.eu/info/sites / default / files / lgbtiq_factsheet_2020-2025_pt.pdf [Consultado em 1 de abril de 2021].

Wall, John. 2010. Ethics in Light of Childhood. Washington, D.C.: Georgetown University Press.

Wilson, Clare, e Laura Cariola. 2020. «LGBTQI+ Youth and Mental Health: A Systematic Review of Qualitative Research.» Adolescent Research Review 5: 187-211. DOI: https: / / doi.org/10.1007/s40894-019-00118-w

WPATH - World Professional Association for Transgender Health. 2010. «Identity recognition statement.» Disponível no endereço: https:/ / epath.eu/wp-content/uploads/ 2018/11/Identity-Recognition-Statement-6-6-10-on-letterhead.pdf [Consultado em 4 de abril de 2021].

Mafalda Esteves. Investigadora júnior do CES-UC desde 2015, co-coordenando em Portugal o projeto «Diversity and Childhood» $(\mathrm{DaC})$. Mestre em Investigação e Intervenção Psicossocial pela Universitat de Barcelona com uma tese sobre a importância da organização e ação comunitária na promoção de empowerment psicológico. É atualmente doutoranda em Psicologia no CIS / ISCTE-IUL onde desenvolve uma tese sobre cidadania íntima e bem-estar psicossocial na bissexualidade.

Ana Cristina Santos. Socióloga e Doutorada em Estudos de Género pela Universidade de Leeds, é investigadora principal no CES-UC e líder de projetos de investigação nacionais e internacionais sobre género, sexualidade, corpo, LGBTQI+, movimentos sociais e cidadania. Co-coordenadora do programa doutoral Human Rights in Contemporary Societies desde 2013, entre os seus livros recentes incluem-se The SAGE Handbook of Global Sexualities (Sage, 2020) e The Tenacity of the Couple Norm (UCL, 2020).

Alexandra Santos. Investigadora júnior do Centro de Estudos Sociais da Universidade de Coimbra integrada no projeto «Diversity and Childhood» (DaC). É licenciada em Serviço Social pela Universidade Católica Portuguesa e mestre em Género, Sexualidade e Teoria Queer pela Universidade de Leeds (UK).

Artigo recebido a 30 de junho e aceite para publicação em 1 de outubro de 2021. 



\section{Estudos e Ensaios}





\title{
WHAT CAN WE SAY ABOUT GENDER STUDIES IN COLOMBIA? AN ANALYSIS FROM A SOCIO-BIBLIOMETRIC PERSPECTIVE
}

\author{
Jean Nikola Cudina* \\ (D) https:/ / orcid.org/0000-0003-4004-7615 \\ Julio César Ossa* \\ (D) http: / / orcid.org/0000-0002-3079-3318 \\ Elsa María Castrillón-Correa \\ (D) https: / / orcid.org/0000-0001-7340-2287 \\ Andrea Precht*** \\ (1) https: / / orcid.org/0000-0002-2435-5565 \\ Josiane Suelí Bería **** \\ (D) https: / / orcid.org/0000-0001-6593-6887 \\ Fernando Andrés Polanco:** \\ (D) https: / / orcid.org/0000-0003-4182-3655
}

\begin{abstract}
The aim of this study is to analyze the history of and academic production in gender studies in Colombia to understand aspects of its development and research dynamics. The empirical corpus of research is represented by the academic production in gender studies registered in the Scopus database. A total of 1328 articles were reviewed and analyzed. A socio-bibliometric analysis was carried out to determine consumption indicators,

* $\quad$ Research Department, Fundación Universitaria Católica Lumen Gentium, Cali, Colombia.

Postal address: Fundación Universitaria Católica Lumen Gentium, Cra. 122 No. 12-459 Pance, Cali, Colombia.

Electronic address: j.nikolacudina@hotmail.com

** Faculty of Psychology, Fundación Universitaria de Popayán, Popayán, Colombia.

Postal address: Fundación Universitaria de Popayán, Claustro San José Calle 5 No. 8-58, Popayán, Colombia.

*** Faculty of Education, Universidad Católica del Maule, Talca, Chile.

Postal address: Universidad Católica del Maule, Avda. San Miguel 3605, Talca, Chile.

Electronic address: elsa.castrillon@alu.ucm.cl

**** Faculty of Education, Universidad Católica del Maule, Talca, Chile.

Postal address: Universidad Católica del Maule, Avda. San Miguel 3605, Talca, Chile.

Electronic address: aprecht@ucm.cl

***** Facultad de Psicología, Universidad Nacional de San Luis/CONICET, San Luis, Argentina.

Postal address: Universidad Nacional de San Luis, Ejército de Los Andes 950, D5700HHW, San Luis, Argentina.

Electronic address: josiane.beria@gmail.com

****** Facultad de Psicología, Universidad Nacional de San Luis /CONICET, San Luis, Argentina. Postal address: Universidad Nacional de San Luis, Ejército de Los Andes 950, D5700HHW, San Luis, Argentina.

Electronic address: juceossa@gmail.com
\end{abstract}


as well as content analysis to identify the lines of research in this field. Although the academic production in gender studies appeared in the mid-1970s, in the last five years this production has increased, showing an established and consolidated field, in which the visibility of educational institutions from the official sector stands out. These institutions thus leverage the development of research in this field in the country. Despite the long history of gender processes in Colombia, the dynamics of academic production in this field are a recent development.

Keywords: Gender studies, academic production, gender, history, socio-bibliometrics.

\title{
Resumo \\ O que podemos dizer sobre os estudos de género na Colômbia? Análise de uma perspectiva sociobibliométrica
}

Este estudo tem como objetivo analisar a história e a produção académica em estudos de género na Colômbia a fim de compreender aspetos da sua dinâmica de desenvolvimento e pesquisa. O corpus empírico da pesquisa é constituído pela produção académica em estudos de género registada na base de dados Scopus. Foram revistos e analisados um total de 1328 artigos e realizada uma análise sociobibliometrica para determinar indicadores de consumo, bem como uma de análise de conteúdo para identificar as linhas de investigação neste campo. Embora a produção académica em estudos de género tenha surgido em meados da década de 1970, é nos últimos cinco anos que esta produção revela um campo consolidado, no qual se destaca a visibilidade das instituições educativas do setor oficial, as quais alavancam o desenvolvimento da pesquisa neste campo no país. Apesar da longa trajetória histórica dos processos de género na Colômbia, a dinâmica da produção académica neste campo é um acontecimento recente.

Palavras-chave: Estudos de género, produção académica, género, história, sociobibliometria.

\begin{abstract}
Resumen
¿Qué podemos decir de los estudios de género en Colombia? Un análisis desde una perspectiva socio-bibliométrica

Este estudio tiene como objeto analizar la historia y producción académica de los estudios de género en Colombia para comprender aspectos de su desarrollo y dinámicas investigativas. El corpus empírico de la investigación lo representa la producción académica de los estudios de género que se registran en la base de datos Scopus. Un total de 1328 artículos fueron revisados y analizados. Se llevó a cabo un análisis socio-bibliométrico para determinar indicadores de consumo y un análisis de contenido para identíficar las líneas de investigación que se configuran en este campo. La producción académica de los estudios de género aparece a mediados de la década de los años setenta; no obstante, es en el último quinquenio que esta producción permite mostrar un campo afianzado y consolidado, en el que se destaca la visibilidad de las instituciones educativas provenientes del sector oficial, que apalancan el desarrollo de la investigación en este campo en el país. Los hitos en los estudios de género en Colombia cuentan con una larga trayectoria histórica, pero las dinámicas de producción académica en este campo son un acontecimiento reciente.
\end{abstract}

Palabras clave: Estudios de género, producción académica, género, historia, sociobibliometria. 


\section{Introduction}

In Colombia, the object of study of gender research has involved a diversity of topics and phenomena. These issues converge in a central purpose: to transform androcentric knowledge and create a new one, which allows explaining the subordination of women and gives way to the gender perspective and the specificity of difference (León 2007). This purpose resulted in a knowledge that allows reading reality attending to the social dynamics of relations between the sexes, together with other social relations such as class, race or ethnicity (Caggiano 2012; Viveros 2013).

Gender studies in Colombia have become a specialized field of knowledge. The academic production derived from gender research has contributed to the transformation of the realities of subordination and domination (RodríguezPizarro \& Ibarra-Melo 2013). As a result, the topics and problems of knowledge within gender studies are worked upon to produce knowledge and action, which reflects a fundamental characteristic of feminist and gender epistemologies: knowledge should not be separated from action (Guzmán \& Pérez 2005; Buchely 2013; 2014). Knowledge and action constitute two dialogical and integral dimensions present in the nature of gender studies in Colombia. These two dimensions have enabled it to become a vehicle for promoting spaces for citizen participation, legitimacy and political resistance (Parola \& Linardelli 2021).

The particularities of gender studies in Colombia lead us to this article's thesis: there is a relationship between political and academic scenarios, woven from the debates opened by feminist groups and the boom in gender studies leveraged by research groups in universities. This issue has opened up the possibility of the invention of tradition (Hobsbawm \& Ranger 1983). In the particular case of gender studies in Colombia, they correspond to the legitimizing fact of the processes of indigenous vindication of women and the LGBTI population of each region in the country, in the light of human rights, citizenship and democracy (Estrada 1997; Jurado 2016; Rodríguez-Amat \& Jeffery 2017; Gil-Hernández \& Pérez-Bustos 2018).

To support this thesis, we present a historical review that provides elements to understand how the field of gender studies was forged in the country from the first social mobilizations and feminist struggles that took place in different scenarios of the national territory. Secondly, we present some conceptual resources that allow us to discuss the relationship established between knowledge and action in order to understand in greater detail the nature of gender studies in Colombia as a dynamic resource for the collective action of social groups. Thirdly, we present an analysis of academic production in gender studies in Colombia based on an empirical corpus extracted from a database with citation and bibliographic information (Scopus). 


\section{Historical elements for gender studies in Colombia}

At the beginning of $20^{\text {th }}$ century, substantial changes began to appear in the country's social structure due to the expansion of coffee production and the increase in the monetary economy of the rural sectors that led to processes of labor migration to the large cities (Salas-Díaz 2015). During this time, the construction of new patterns of intimacy, different from those of the traditional peasant family, became evident (Estrada 1997).

This shift in the intimacy patterns and roles of the traditional Colombian family precedes the Thousand Days War. In 1899, this war resulted in the death of approximately three hundred thousand Colombian citizens (Bermúdez 2014). As a result of the war, Colombia's agriculture was impoverished and widows were forced to migrate to the cities. One of the events that significantly marked the entry of women into the world of work was the 1907 decision by the Coltejer textile factory in Bogotá to hire a large number of women. However, the precarious conditions in the companies did not guarantee Colombian women a decent job, and any attempt to protest was immediately repressed (Arango 1991; Bermúdez 2007).

This period of contingency and crisis in the institutions of the country created the necessary conditions for the emergence, in the 1920s, of the first feminist groups in Colombian history. Their actions were designed to achieve the fulfilment of political and civil rights in education, health, work and moral reform (Franco-Giraldo \& Álvarez-Dardet 2008; González 2011; 2014; Bello-Urrego 2013; Huertas \& Hernández 2016). In 1919, the peasant Juana Julia Guzmán founded the Sociedad de Obreras Redención de la Mujer in the municipality of Córdoba. This movement aimed to regulate the work of women and minors, who were being exploited (Reyes \& Saavedra 2005; Velazco 2014). In the same year, the socialist party was founded following the continuous workers' protests led by 400 women against social injustices. In addition to supporting the strike in Bello (Antioquia), more than 400 women fought against injustices (Garcés 2013). These actions managed to transcend the precarious conditions and begin a struggle for the vindication of human rights within the social and institutional spheres of Colombian women at the time.

These events allowed feminism to find an important foothold for starting its political struggle in Colombia. By 1926-1927, Susana Olózaga de Cabo and Ana Restrepo founded the journal Anthena to promote the struggle for women's rights (Cohen 2001). María Rojas Tejada and Baldomero Sanín Cano actively participated in the debates on the condition of Colombian women, organizing and convening a conference on feminism in 1927 in the city of Pereira (Luna \& Villareal 1998). In the same year, the National Pedagogical Institute was created to carry out academic and professional training for women. Also in the same year, some 14,000 indigenous women signed the manifesto for the Rights of Indigenous Women in Colombia (Buitrago 2013). One of the milestones in the vindication of women's rights in Colombia was the admission of women to university in 1935 (Ramírez 2010). 
Between 1954 and 1957, under the government of General Gustavo Rojas Pinilla, the movement of «suffragettes» led by Esmeralda Arboleda and Josefina Valencia arose to fight in the National Constituent Assembly for women's right to vote without any restrictions (Ariza 2014). A foundational milestone was the election of Arboleda as the first woman in the Senate of the Republic (Luna \&Villareal 1998). The organizational process of women continued in the 1960s, when women's collectives and social movements played a definitive role in showing the inequality that women faced in accessing economic, social and cultural rights (López \& Güida 2002; Lurent 2009; Gomes-Maciazeki, Nogueira \& Filgueiras-Toneli 2016).

In the mid-1990s, the first gender research groups emerged in the country, a fact that can be linked to the establishment of the National Constituent Assembly that gave rise to Colombia's political Constitution in 1991, which declared the country to be a social, multi-ethnic and multicultural state under the rule of law. The Constitution gives priority in its articles to the defense of equality and non-discrimination on the grounds of sex, race, age, religious or philosophical beliefs (Political Constitution of Colombia, Article 13).

Thus, the academy enters the scene, and intellectual production on the subject, no longer isolated, begins to emerge and become established within the universities and research groups. Currently, 12 research groups in the field of gender studies are registered in MINCIENCIAS. ${ }^{1}$ These groups include an important number of researchers specialized in gender studies in the country.

Next, let us look at some elements that allow us to discuss the relationship established between knowledge and action in the framework of gender studies in Colombia.

\section{Knowledge and collective action in gender studies in Colombia}

Gender studies in Colombia have found a critical bridge to think about the impact of research in diverse scenarios and social collectives (Daza 2015; Buchely, Castro \& Uribe-Vásquez 2021). A close dialogic relationship is established between the dynamics of research, academic production and civil society (Ziman 2003). Specifically, Colombian gender studies, which have developed over the last two decades, converge with social, political, historical and economic processes in the country. Among these processes are: The 1991 Constitution; the peace process recently signed with the Revolutionary Armed Forces of Colombia (FARC), which gave a particular emphasis to the inclusion of the gender perspective; and impor-

The Ministry of Science, Technology and Innovation (MINCIENCIAS) is the entity in charge of formulating, guiding, directing, coordinating, executing and implementing the public policy of the Colombian State in science, technology and innovation. To see in detail the name of the research groups registered in MINCIENCIAS, please click on this link: t.ly/t0yn 
tant political and legal debates, such as equal marriage and adoption by same-sex couples, to name a few significant milestones.

The gender studies' approach in the promotion of conditions for collective action provides a framework for the complexities and social realities of the country, where this field opens up spaces for reflection, debate and political struggles. Among these, we can include the actions of women, marginalized social groups, ethnic communities, the struggle for human rights, the search for dignity and peace (Bonilla-Vélez 2007; Millán et al. 2020a). Collective actions have been used as a tool that can contribute to social change and the development of a community, fostering peace processes (Sánchez-Mora \& Rodríguez 2015). Collective action has been used as a mechanism to address various issues of interest, such as injustice, government mismanagement, knowledge of the conflict, as well as to work through activities to resolve a particular problem of a group or population (IbarraMelo 2007; 2011a).

Approaching collective actions in the framework of gender research implies carrying out a critical reading of the social, cultural, historical and political complexities to unveil how this set of conditions and circumstances is articulated (Ibarra-Melo 2015; Bonavitta 2016). Gender research focuses on recognizing the importance of the political context where collective actions take place. The relationship between knowledge and collective action creates the conditions for the formulation of demands to expand democracy and its representation in state institutions (Luna 2003).

As we have explained, in the Colombian context, collective actions have been a vehicle for mobilization, among many others, to incorporate demands for abortion rights, sexual and reproductive rights, the elimination of violence against women, and the recognition of equity and equal rights (Ibarra-Melo 2011b). This type of activism constitutes a source of knowledge within the framework of gender research in Colombia.

The academic production in gender studies in Colombia is based on its articulation with processes and dynamics of emancipatory collective action. Emancipation represents a social process carried out by forces that resist and come into tension with a system of oppressive logics (Nash 2006). Therefore, in this study, we argue that gender studies in Colombia have demarcated an important link between political and academic settings. These two settings represent two knowledge-generating dimensions within research that have led gender studies to become a specialized discipline in both socially committed and transformative terms (Rodríguez-Pizarro \& Ibarra-Melo 2013; Barranquero \& Ángel 2015). In order to delve deeper into the relationship between the country's socio-political development and the emergence and growth of gender studies, the findings of the socio-bibliometric analysis to determine consumption indicators and content analysis to identify lines of research in gender studies in the country are presented below. 


\section{Method}

An analysis of the academic production in gender studies in Colombia was carried out to provide a brief overview of this production in the country, using the socio-bibliometric method. The methodological framework focuses on articulating the analysis of academic production with historical, social and political events that have forged the field of gender studies and its multiple lines of research in Colombia. This perspective seeks to achieve a greater understanding of the data produced by academic production in light of the historical events that underlie these research dynamics (Millán, Polanco, Ossa, Beria \& Cudina 2017; Polanco, Beria \& Klappenbach 2017).

\section{Corpus}

The empirical corpus of the study consists of the academic production in gender studies recorded in the Scopus database. The Boolean term OR was used in the following descriptors: Gender, Gender studies, Gender violence, Theory of gender, and Feminism in titles, abstracts and keywords. The sample consists of 1328 articles, which were used for data extraction and analysis. The articles recorded in the database cover the period from 1976 to 2017, and are indexed in the social sciences. Only articles published by authors affiliated with Colombian national universities were considered for the study. Each paper was reviewed, taking into consideration basic information, including authors, institutions and countries.

\section{Procedure and analysis}

Once the empirical corpus was constituted, academic production and social network analysis indicators were presented (Millán et al. 2020b). The graphic representations of the conceptual network derived from the co-occurrence analysis correspond to the empirical corpus of data incorporated in the Vosviewer 1.65 program (van Eck \& Waltman 2010). The system of categories to identify and classify the thematic lines of research of the academic production in gender studies in Colombia was carried out, taking into account the historical study of Estrada (1997). This study presents 10 lines of research that have historically shaped the progress of gender studies in the country. From a co-occurrence analysis of the empirical corpus of our study, it is possible to show the emergence of other categories that translate into the appearance of three new lines of research. In total, thirteen lines of research are formed from the revision of the empirical corpus (see Figure 5 in results). 


\section{Results}

Reviewing in detail the corpus of academic production in gender studies in Colombia provides relevant data. One of them has to do with the historical line of development of research in this field, based on the academic production, as shown in Figure 1. The earliest studies were recorded in the period 1976-1977, and from then on there was a steady increase in production until 1999. During those 23 years, $1.7 \%(\mathrm{n}=23)$ of the academic production in «gender studies» recorded in the country was published.

\section{Figure 1}

Historical line of academic production in gender studies in Colombia

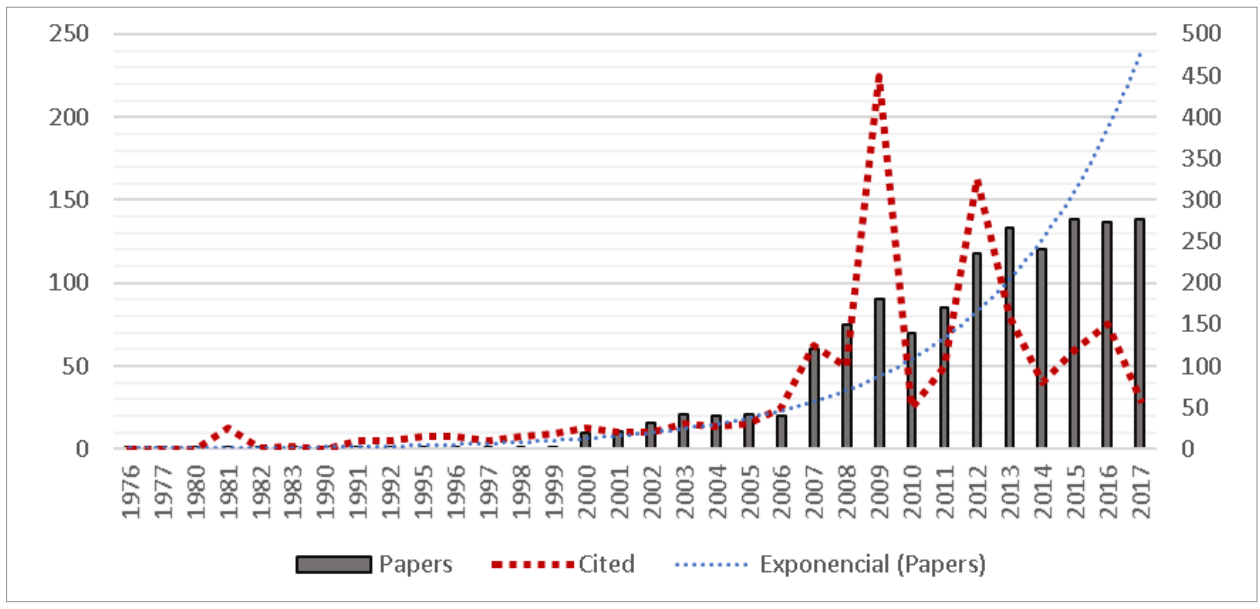

Source: Authors' compilation, based on data from Scopus (2018).

During the first decade of the years $2000,31.1 \%(n=413)$ of the academic production was recorded. However, it is from 2010 onwards that this increase shows an exponential growth. In the period 2010-2017, 67.2\% ( $n=892)$ of the academic production in gender studies in Colombia is registered.

On the other hand, the citation rate recorded in general terms shows a low indicator. A significant portion of this production $(33.0 \%$; $n=537)$ has never received a citation, while $25.8 \%(\mathrm{n}=420)$ has been cited only once. Table 1 shows the citation frequency of the academic production in gender studies according to the Scopus database. 
Table 1

Citation Frequency Gender Studies

\begin{tabular}{c|c|c}
\hline \multirow{2}{*}{ Citation Frequency } & \multicolumn{2}{|c}{ Scopus } \\
\cline { 2 - 3 } & $\mathbf{N}$ & $\%$ \\
\hline 0 & 537 & $33,0 \%$ \\
\hline 1 & 420 & $25,8 \%$ \\
\hline $2-5$ & 392 & $24,1 \%$ \\
\hline $6-10$ & 186 & $11,4 \%$ \\
\hline $11-15$ & 94 & $5,8 \%$ \\
\hline Total & 1629 & $100 \%$ \\
\hline
\end{tabular}

Source: Authors' compilation.

The citation frequency begins to have a significant behavior from 2-5 and 6-10 citations per paper. These frequencies account for $35.5 \%(n=578)$ of the citations registered within gender studies in Colombia. Concerning the authors registered, we find a total of 372 social science researchers who have been shaping the field of gender studies in Colombia. Figure 2 shows the network of authors who have contributed at least two research papers published and recorded in the database.

Figure 2

Co-authorship network in gender studies in Colombia

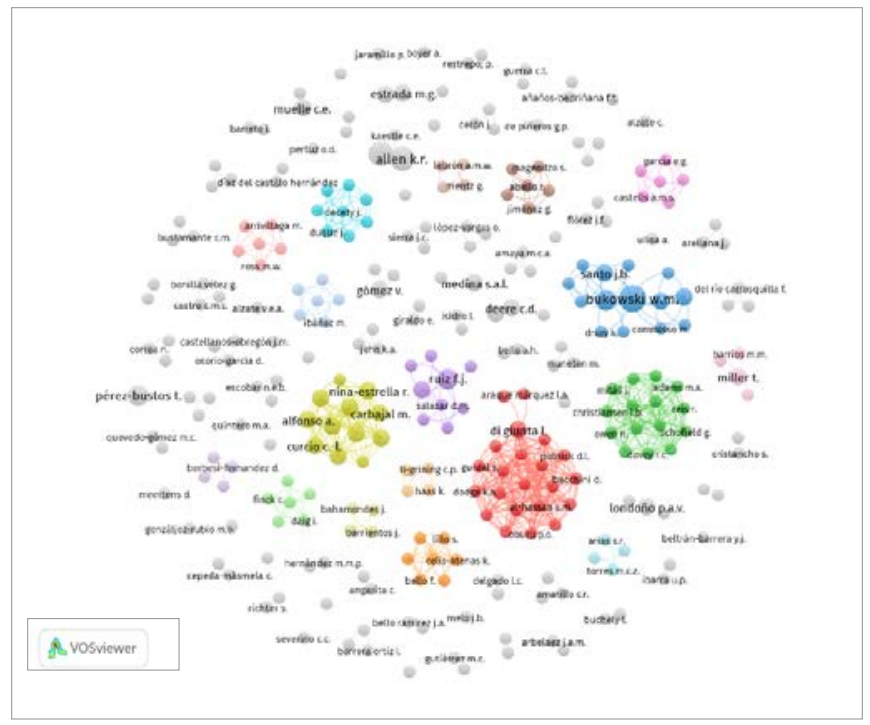

Source: Authors' compilation. 
The network reveals the communities formed from the collaborative work that is woven between national and international researchers. The map shows the formation of at least ten cooperative work niches within gender studies in Colombia (Adams, Chiang \& Starkey 2001). It is also evident that research in gender studies in Colombia is not marked by a dynamic governed by co-authorship (Cronin 2001).

The communities that can be highlighted include the works of Lina María Uribe Tirado (Red Cluster); Lina María Saldarriaga, Luz Stella López (Blue Cluster); Carmen Lucia Curcio (Yellow Cluster); Daniela Salazar, Francisco José Ruiz (Violet Cluster). It is essential to mention that the cooperation feature is marked by cross-cultural studies and the validation of instruments where gender constitutes a fundamental dimension. Work on gender theory has been carried out by authors such as María Eugenia Ibarra-Melo, Lina Fernanda Buchely, Ana L. Jaramillo-Sierra, Tania Pérez-Bustos, Laura Maria Uribe Forero, Ana Patricia Pabón Mantilla, Angela M. Estrada, Isabel Cristina Jaramillo, Helena Alviar and Julieta Lamaitre.

Figure 3 presents the co-authorship networks formed from collaborative work within gender research in Colombia.

Figure 3

Collaboration network of Colombian institutions

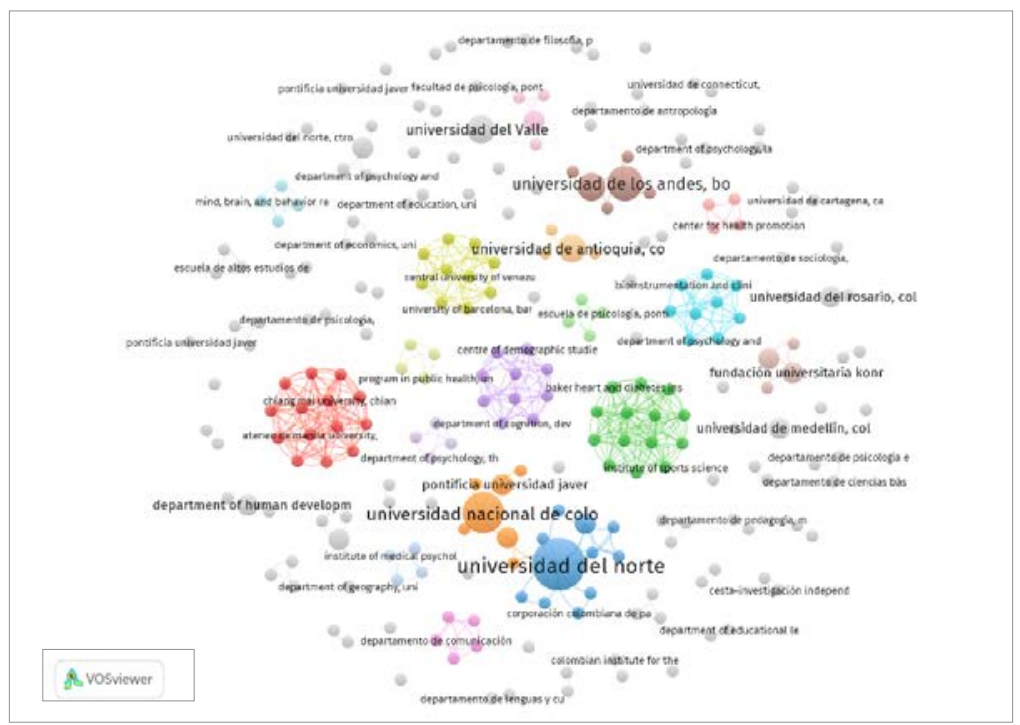

Source: Authors' compilation.

Figure 3 shows Colombian universities' meaningful participation in gender studies within the country. Partly, this is explained by the fact these institutions 
forged the first gender studies centers and research groups. Such institutions include the Universidad del Valle, the Universidad Nacional de Colombia, the Universidad de Antioquia and the Universidad de los Andes. It should also be noted that Colombian universities in the private sector have been generating a line of work in gender studies. Among these universities are Universidad del Norte, Pontificia Universidad Javeriana, Fundación Universitaria Konrad Lorenz, Universidad del Rosario and Universidad de Medellín.

\section{Semantic map of gender studies in Colombia}

In reviewing the configuration of gender studies, one can see the emergence over the last ten years of different thematic lines, as shown in Figure 4, in the cooccurrence of the most important words in gender studies research in recent years.

Figure 4

Semantic map of gender studies in Colombia

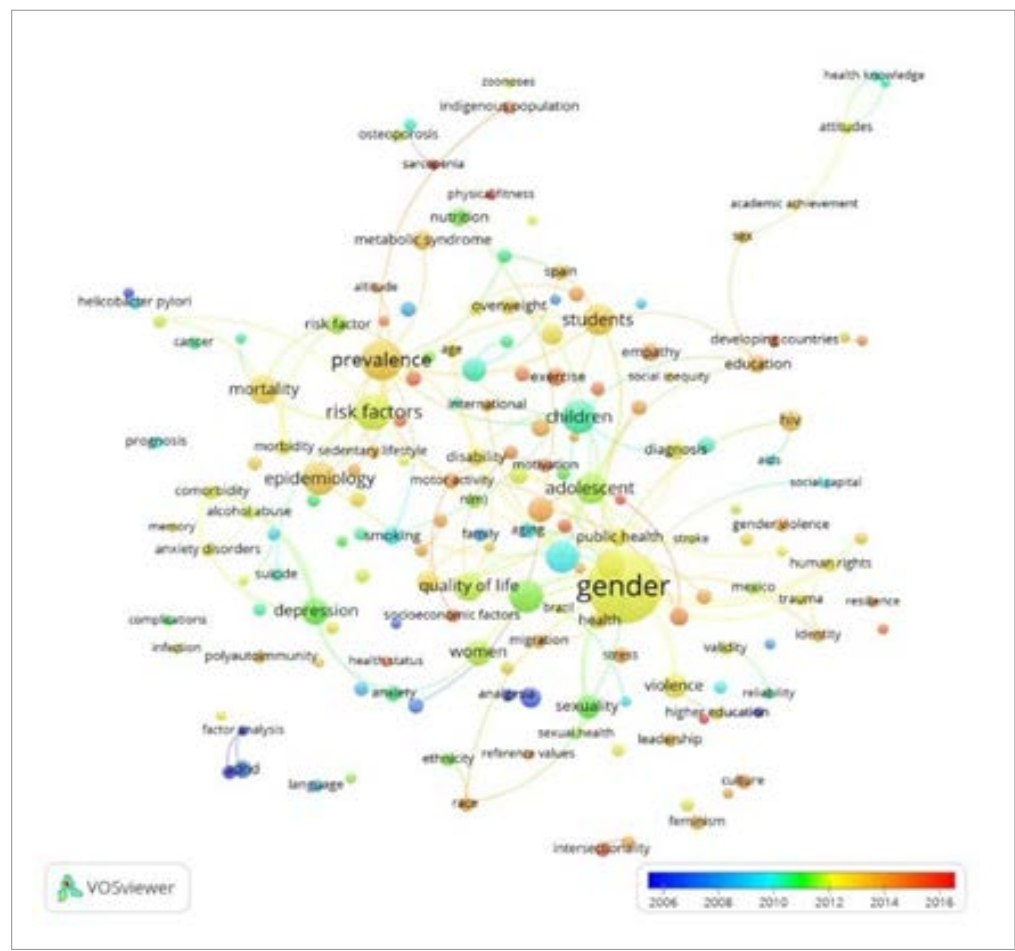

Source: Authors' compilation, based on data from Scopus (2018). 
Figure 4 shows that, from the concept of gender (the most representative cluster), concepts such as public health, quality of life, risk factors and epidemiology are juxtaposed in a more significant way. At an intermediate level, and revealing a novelty, some concepts such as identity, social inequity, socioeconomic factors and human rights show in a less significant manner an orientation towards approaching gender studies from the perspective of law and economic equity. We can understand the concept of gender as a hinge concept, that is, capable of generating much more complex understanding of relations than when only one sociological variable is used to explain a phenomenon.

The concept of gender represents a development in the research process that has permeated the academic and research scene in Colombia, enabling the emergence and consolidation of academic communities that conduct research and produce in the field of politically relevant gender studies.

\section{Thematic lines that constitute Gender Studies in Colombia}

As we have mentioned, in the last two decades there have been ten thematic lines of research that have shaped and characterized gender studies in the country (Estrada 1997). Moreover, from the dynamics of research established during this period, at least three new research lines have emerged. These lines explore gender and health, children and adolescents, with a gender rights approach, and peace and post-conflict processes. 
Figure 5

Thematic lines of gender studies in Colombia

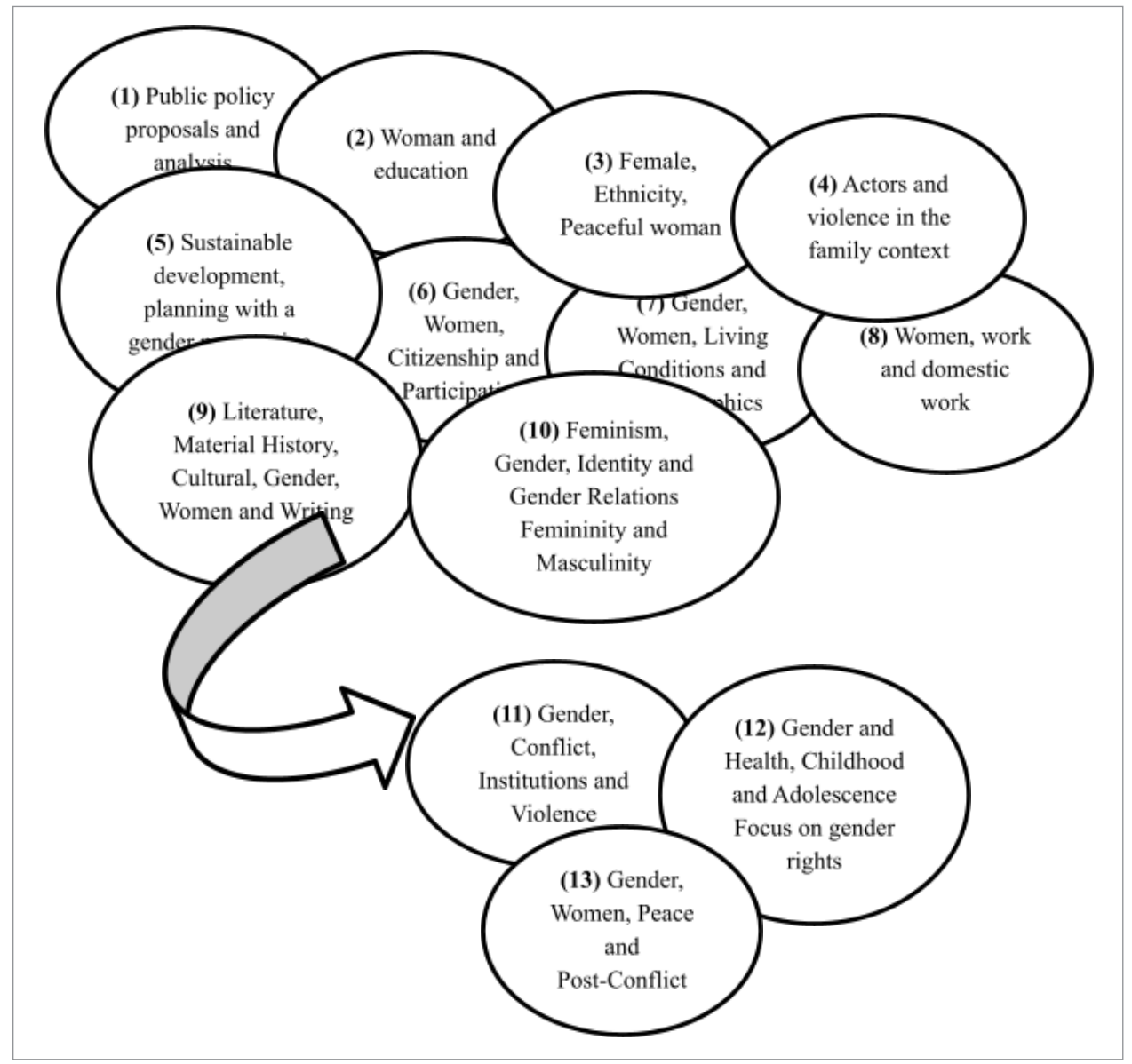

Source: Authors' compilation based on Estrada (1997).

Note: The number in parentheses indicates the thematic line presented in Table 2 below. 
Table 2 shows the frequency of articles according to the gender studies thematic lines in Colombia over the last twenty years, with a clear increase in thematic lines and proportional to the exponential growth curve.

\section{Table 2}

Frequency of articles in each thematic line

\begin{tabular}{l|c|c}
\hline Thematic line & $\begin{array}{c}\text { No. } \\
\text { Articles }\end{array}$ & $\%$ \\
\hline 1) Public policy proposals and analysis & 82 & $6,2 \%$ \\
\hline 2) Woman and education & 78 & $5,9 \%$ \\
\hline 3) Female, Ethnicity, Peaceful woman & 88 & $6,6 \%$ \\
\hline 4) Actors and violence in the family context & 85 & $6,4 \%$ \\
\hline 5) Sustainable development, planning with a gender perspective & 80 & $6,0 \%$ \\
\hline 6) Gender, Women, Citizenship and Participation & 106 & $8,0 \%$ \\
\hline 7) Gender, Women, Living Conditions and Demographics & 104 & $7,8 \%$ \\
\hline 8) Women, work and domestic work & 109 & $8,2 \%$ \\
\hline $\begin{array}{l}\text { 9) Literature, Material History, Cultural, Gender, Women and } \\
\text { Writing }\end{array}$ & 43 & $3,2 \%$ \\
\hline $\begin{array}{l}\text { 10) Feminism, Gender, Identity and Gender Relations Femininity } \\
\text { and Masculinity }\end{array}$ & 101 & $7,6 \%$ \\
\hline 11) Gender, Conflict, Institutions and Violence & 106 & $8,0 \%$ \\
\hline $\begin{array}{l}\text { 12) Gender and Health, Childhood and Adolescence Focus on } \\
\text { gender rights }\end{array}$ & 185 & $13,9 \%$ \\
\hline $\begin{array}{l}\text { 13) Gender, Women, Peace and Post-Conflict } \\
\text { Total }\end{array}$ & 161 & $12,1 \%$ \\
\hline
\end{tabular}

Source: Authors' compilation.

Regarding Table 2, it is important to note that a significant percentage of studies currently recorded are in the Gender and Health, Childhood and Adolescence, Rights-based approach thematic line, with 13.9 per cent $(n=185)$. This is followed by the thematic line of Gender, Women, Peace and Post-Conflict, with $12.1 \%$ $(n=161)$ of the academic production recorded in the last five years. There is a growing pace of academic production in gender studies, especially in the country's higher education institutions (HEIs).

Although the HEIs that stand out the most are those belonging to the official sector, in some private institutions there are also important developments in the 
field of gender studies. The most representative official sector institutions are Universidad Nacional de Colombia, Universidad del Valle, Universidad de Antioquia, Universidad de Caldas, and the private sector institutions are Universidad de los Andes, Universidad Javeriana, Universidad del Caribe and Universidad del Norte.

\section{Limitations of the study}

The analysis of the academic production in gender studies in Colombia was carried out with the information obtained from the Scopus database. It is assumed that the results presented in this study correspond to only a small sample of the scientific production in gender studies within the Colombian academic community. However, we recognize that there are other aspects, such as the diffusion and training in gender in the academic environment or publications of the so-called «grey literature», which are not included in these databases. Therefore, this study opens a door for the realization of socio-bibliometric reviews in different databases that will allow us, as in a puzzle, to put the appropriate pieces together to configure a more precise and comprehensive field of gender studies.

\section{Discussion and conclusion}

The increase in academic production in gender studies is a phenomenon that has occurred in other countries, with the conformation of clearly forged thematic lines that reveal consolidated research dynamics (Ferreira, Vieira, Silveirinha, Carvalho \& Freire 2020). However, the particularity of the gender studies thematic lines is related to central aspects of social and political conditions.

In the Colombian context, the thematic lines that are emerging in the dynamics of research within the field of gender studies are as follows: a) Gender, Conflict, Institutions and Violence; b) Gender and Health, Childhood and Adolescence, Focus on gender rights; and c) Gender, Women, Peace and Post-Conflict. These lines are representative of the volume of production in the last five years. We argue, based on the above, that gender studies in Colombia is a field driven by production dynamics within a national political context where social collectives play a preponderant role.

We hope that the current study can contribute to the development of comparative studies that allow for situating the discussions that are formed from the relationship between academic production and collective actions as two resources of analysis within gender studies in particular, and the development of sociobibliometric studies in general. This study addressed the relationship established between the dynamics of academic production and social mobilizations within 
gender studies in Colombia. From the methodological point of view, sociobibliometrics represents a novel resource that can be used to explore the progress of gender studies as a specialized field of knowledge, as well as to ask significant questions about the rationale of excessive growth in papers published by universities and institutions, which has resulted in an aimless academic production (Cadavid 2008).

This would allow us to pay attention to the approach of the thematic lines as an object of study in bibliometric research in the national and international political context. In this sense, we agree with Buchely et al. (2021), who argue that it is essential to begin to analyze the contexts of mobilization that contribute to the academic production of gender research in the country. Collective actions in the light of the socio-political events of the last five years in the country are so diverse that it is necessary to devise a working route to establish the differences and analogies of the impact of mobilization in strengthening the field of gender studies.

\section{References}

Adams, James D., Eric P. Chiang, \& Katara Starkey. 2001. «Industry-University Cooperative Research Centers.» The Journal of Technology Transfer 26: 73-86. DOI: https: / / doi.org/ 10.1023/ A:1007836328722

Arango, Luz. 1991. Mujer, religión e industria: Fabricato 1923-1982. Medellín: Universidad de Antioquia.

Ariza, María. 2014. Derecho y mujer. Ayer y hoy. Colombia: Sello Editorial Universidad de Medellín.

Barranquero, Alejandro, \& Adriana Ángel. 2015. «La producción académica sobre Comunicación, Desarrollo y Cambio Social en las revistas científicas de América Latina.» Signo y Pensamiento 34(67): 30-57. DOI: https: / / doi.org/10.11144/Javeriana.syp34-67.pacd

Bello-Urrego, Alejandra del Rocio. 2013. «Sexo/género, violencias y derechos humanos: perspectivas conceptuales para el abordaje de la violencia basada en género contra las mujeres desde el sector salud.» Revista Colombiana de Psiquiatría 42(1): 108-119. DOI: https: / / doi.org/10.1016/S0034-7450(14)60091-3

Bermúdez, Mario. 2014. Breve historia de la guerra de los mil días en Colombia. Colombia: Alcorquid.

Bermúdez, Rosa. 2007. Mujeres Obreras e identidades sociales. Cali 1930-1960. Cali: La Carreta Editores-Universidad ICESI.

Bonavitta, Paola. 2016. «Mujeres en situación de pobreza y acciones colectivas.» Revista de Ciencias Sociales 36: 35-54.

Bonilla-Vélez, Gloria. 2007. «La lucha de las mujeres en América Latina: feminismo, ciudadanía y derechos.» Palobra 8: 42-59. DOI: https: / / doi.org/10.32997/2346-2884-vol.8num.8-2007-225

Buchely, Lina, María Victoria Castro, \& Giovanna Uribe-Vásquez. 2021. «Género y derecho. Análisis bibliométrico del campo de estudio en Colombia 1991-2020.» En Perspectivas de género en la educación superior: una mirada latinoamericana, edited by Isabel Jaramillo-Sierra \& Lina F. Buchely, 303-326. Cali: Universidad ICESI. 
Buchely, Lina. 2013. «Overcoming Gender Disadvantages. Social Policy Analysis of urban middle-class women in Colombia.» Revista de Economía del Rosario 16(2): 313-340.

Buchely, Lina. 2014. «Género y constitucionalismo. Una mirada feminista al derecho constitucional colombiano.» Ciencia Política 9(18): 83-107.

Buitrago, Diego. 2013. «Mujeres indígenas: ¿protección constitucional en Colombia?» Revista CES-Derecho, 4(2): 18-31.

Cadavid, Teresa. 2008. «El papel puede con todo (Sobre aquello de "publica o perece").» Revista Iberoamericana de Educación, 45(3): 1-4. DOI: https: / / doi.org/10.35362/ rie4532118

Caggiano, Sergio. 2012. El sentido común visual: Disputas en torno a género, «raza» y clase en imágenes de circulación pública. Buenos Aires: Miño y Dávila.

Cohen, Lucy. 2001. Colombianas en la vanguardia. Medellín: Universidad de Antioquia.

Cronin, Blaise. 2001. «Hyperauthorship. A Postmodern Perversion or Evidence of a Structural Shift in Scholarly Communication Practices?» Journal of the American Society for Information Science and Technology 52(7): 558-569. DOI: https:/ / doi.org/10.1002asi.1097

Daza, Sandra. 2015. «Contando mujeres. Una reflexión sobre los indicadores de género y ciencia en Colombia.» Revista de Antropología y Sociología: Virajes 10: 29-51.

Estrada, Angela María. 1997. «Los estudios de género en Colombia: Entre los límites y las posibilidades.» Nómadas 6: 1-18.

Ferreira, Virgínia, Cristina C. Vieira, Maria João Silveirinha, Elizângela Carvalho, \& Priscila Freire. 2020. «"Estudos sobre as mulheres" em Portugal pós-declaração de Pequim estudo bibliométrico das Revistas ex aequo e Faces de Eva.» ex aequo 42: 23-56. DOI: https: / / doi.org/ 10.22355/ exaequo.2020.42.02

Franco-Giraldo, Álvaro, \& Carlos Álvarez-Dardet. 2008. «Derechos humanos, una oportunidad para las políticas públicas en salud.» Gaceta Sanitaria 22(3): 280-286.

Garcés, Juan David. 2013. «La mano de obra femenina en la industria de Medellín (1900-1925).» Pensar Historia 3: 23-34.

Gil-Hernández, Franklin, \& Tania Pérez-Bustos. 2018. Feminismos y estudios de género en Colombia. Un campo académico y político en movimiento. Bogotá: Universidad Nacional de Colombia.

Gomes-Maciazeki, Rita de Cássia, Conceição Nogueira, \& Maria Filgueiras-Toneli. 2016. «Mulheres em contextos rurais: um mapeamento sobre gênero e ruralidade.» Psicologia $\mathcal{E}$ Sociedade 28(1): 115-124.

González, Judith. 2011. «Representaciones de las mujeres en la Independencia desde la historiografía colombiana.» HISTOreLO. Revista de Historia Regional y Local 3(5): 169-190.

González, Judith. 2014. «Fe, caridad y educación: Una mirada de género sobre las mujeres de la Asociación del Sagrado Corazón de Jesús. Guadalajara de Buga 1873-1930.» Revista Historia \& Espacio 10(43): 85-118.

Guzmán, Maricela, \& Augusto Pérez. 2005. «Las Epistemologías Feministas y la Teoría de Género. Cuestionando su carga ideológica y política versus resolución de problemas concretos de la investigación científica.» Revista de Epistemología de Ciencias Sociales 22: 112-126.

Hobsbawm, Eric, \& Terence Ranger. 1983. The Invention of Tradition. Cambridge: Cambridge University Press.

Huertas, Rocío, \& María Hernández. 2016. «La importancia de llamarse juez constitucional: Reconociendo los derechos de las familias LGBTI vía judicial.» Anuario Iberoamericano de Justicia Constitucional 20: 315-333.

Ibarra-Melo, María Eugenia. 2007. «Acciones colectivas de las mujeres en contra de la guerra y por la paz en Colombia.» Revista Sociedad y Economía 13: 66-86. 
Ibarra-Melo, María Eugenia. 2011a. «Mujeres, verdad, justicia y reparación en Colombia.» Universitas Humanística 72: 247-273.

Ibarra-Melo, María Eugenia. 2011b. «Acciones colectivas de mujeres por la verdad, la justicia y la reparación.» Reflexión Política 14 (25): 136-150.

Ibarra-Melo, María Eugenia. 2015. «Aportes de las académicas latinoamericanas para comprender las acciones colectivas de las mujeres.» Revista CS 15: 173-201. DOI: https: / / doi.org/10.18046/ recs.i15.1966

Jurado, Daniel. 2016. «Extendiendo el derecho a todos los derechos: La difusión transnacional del reconocimiento legal de la identidad de género.» Colombia Internacional 87: 173-198. DOI: https: / / doi.org/10.7440/ colombiaint87.2016.07

León, Magdalena. 2007. «Tensiones presentes en los estudios de género.» En Género, mujeres y saberes en América Latina. Entre el movimiento social, la academia y el Estado, editado por Luz Gabriela Arango y Yolanda Puyana, 23-46. Bogotá: UNAL.

López, Alejandra, \& Carlos Güida. 2002. «Aportes de los Estudios de Género en la conceptualización sobre Masculinidad.» En Femenino - Masculino. Intervenciones teórico-clínicas, editado por A. Muñiz, 34-65. Montevideo: Ediciones Psicolibros.

Luna, Lola G. 2003. Los movimientos de mujeres en América Latina y la renovación de la historia. Cali: Universidad del Valle.

Luna, Lola G., \& Norma Villareal. 1998. Movimientos de mujeres y participación política en Colombia, 1930-1991. Barcelona: CICYT.

Lurent, Virginie. 2009. «Mayo del 68, cuarenta años después. Entre herencias y controversias.» Revista de Estudios Sociales 33: 29-43. DOI: https: / / doi.org/10.7440/ res33.2009.02

Millán, Juan David, Juan Fernando Aguilar, Julio César Ossa, \& Jean Nikola Cudina. 2020a. «Pensamiento político pos-fundacional y la izquierda contemporánea.» Utopía y Praxis Latinoamericana, 25(91): 203-216.

Millán, Juan David, Jean Nikola Cudina, Julio César Ossa, Maribel Vega-Arce, Hernan Scholten, \& Gonzalo Salas. 2020b. «Academic networks of critical social psychology in Brazil. An analysis of the impact and the intellectual roots.» Current Psychology. DOI: https: / / doi.org/10.1007/ s12144-020-00827-9

Millán, Juan David, Fernando Polanco, Julio César Ossa, Josiane Sueli Bería, \& Jean Nikola Cudina. 2017. «La cienciometría, su método y su filosofía: Reflexiones epistémicas de sus alcances en el siglo XXI.» Revista Guillermo de Ockham 15(2): 17-27. DOI: http:/ / dx.doi.org/10.21500/22563202.3492

Nash, Mary. 2006. «Identidades de género, mecanismos de subalternidad y procesos de emancipación femenina.» Revista CIDOB d'Afers Internacionals 73/74: 39-57.

Parola, Ruth Noemí, \& María Florencia Linardelli. 2021. «La sistematización en Trabajo Social y la epistemología feminista del punto de vista. Diálogos sobre la producción de conocimiento sustentada en experiencias.» Prospectiva 31: 71-92. DOI: https: / / doi. org / 10.25100/ prts.v0i31.10562

Polanco, Fernando, Josiane Sueli Bería, \& Hugo Klappenbach. 2017. «Cinco décadas de la Revista Interamericana de Psicología. Un estudio socio-bibliométrico.» Interamerican Journal of Psychology, 51(3): 297-319.

Ramírez, María Imelda. 2010. «La mujer en la historia de la educación superior en Colombia.» Universia. Disponible en https://www.universia.net/co/actualidad/orientacion-academica/mujer-historia-educacion-superior-colombia-258244.html

Reyes, Ana, \& Maria Saavedra. 2005. Mujeres y trabajo en Antioquia durante el siglo XX Formas de asociación y participación sindical. Medellín: Ediciones ENS. 
Rodríguez-Amat, Joan, \& Robert Jeffery. 2017. «Student Protests. Three Periods of University Governance.» TripleC. Communication, Capitalism and Critique 15(2): 526-542. DOI: https: / / doi.org/10.31269/ triplec.v15i2.771

Rodríguez-Pizarro, Alba Nubia, \& María Eugenia Ibarra-Melo. 2013. «Los estudios de género en Colombia. Una discusión preliminar.» Sociedad y Economía 24: 15-46.

Salas-Díaz, Ricardo. 2015. «La incidencia de la migración sobre las diferencias salariales de género en Colombia.» Ensayos Sobre Política Económica 33: 103-116. DOI: https: / / doi. org/10.1016/J.ESPE.2014.11.002

Sánchez-Mora, Mayra Lucia, \& Zuriñe Rodríguez-Lara. 2015. «Acciones colectivas de las organizaciones de mujeres por la paz en Colombia.» Revista de Paz y Conflictos 8(2): 149-177.

van Eck, Nees Jan, \& Ludo Waltman. 2010. «Software survey: VOSviewer, a computer program for bibliometric mapping.» Scientometrics 84(2): 523-538. DOI: https://doi. org/10.1007/s11192-009-0146-3.

Velazco, Katerine. 2014. «Mujer, sociedad y voto femenino en Cartagena 1940-1960.» Tesis de grado. Cartagena, Colombia: Universidad de Cartagena.

Viveros, Mara. 2013. «Género, raza y nación. Los réditos políticos de la masculinidad blanca en Colombia.» Maguaré 27(1): 71-104.

Ziman, John. 2003. «Ciencia y sociedad civil.»Isegoría, 28: 5-17. DOI: https://doi.org/ 10.3989/ isegoria.2003.i28.503

Jean Nikola Cudina. Psychologist. Academic at the research center of the Fundación Universitaria Católica Lumen Gentium, UNICATÓLICA. Co-founding member of the research group Bibliometrics Research Lab. Member of the History Group of the Interamerican Society of Psychology and the Iberoamerican Network of Researchers in History of Psychology.

Julio César Ossa. Ph.D. in Psychology, associate professor and researcher at the Fundación Universitaria de Popayán. Coordinator of the Iberoamerican Network of Researchers in History of Psychology and Editor of the Newsletter, Division 18, IAAP.

Elsa María Castrillón-Correa. PhD Candidate in Education at the Universidad Católica del Maule (Chile). Family Development Professional from the University of Caldas and Master in Sustainable Development and Environment from the University of Manizales (Colombia). Research interests focus on human agency and its relationship with individuals, as well as in collective contexts such as family and school.

Andrea Precht. Associate Researcher at the Center for Research in Education for Social Justice (CIEJUS) of the Universidad Católica del Maule (Chile). Doctor in Educational Sciences. Member of the academic boards of the Doctorate in Education and Doctorate in Psychology (UCM). Research interests: Families, parenting and schools; teacher training and motivational processes. 
Josiane Suelí Béria. Psychologist, Universidade Federal de Mato Grosso (UFMT), Brazil. Certificate in Political Pedagogy and Recent History, Universidad Nacional de La Plata (UNLP), Argentina. Fellow of the National Council of Science and Technology (CONICET), Argentina. Doctoral candidate at the National University of San Luis (UNSL), Argentina. Professor of Ethics at the UNSL. Coordinator of the Gender Section of the Argentine Association for the Advancement of Psychological Science (AACP).

Fernando Andrés Polanco. Psychologist, Universidade Federal de Mato Grosso (UFMT), Brazil. Certificate in Political Pedagogy and Recent History, Universidad Nacional de La Plata (UNLP), Argentina. Fellow of the National Council of Science and Technology (CONICET), Argentina. Doctoral candidate at the National University of San Luis (UNSL), Argentina. Professor of Ethics at the UNSL. Coordinator of the Gender Section of the Argentine Association for the Advancement of Psychological Science (AACP).

Received on 14 October 2020 and accepted for publication on 31 March 2021. 


\title{
CHRONICLES OF CIVIL SOCIETY IN ASSAM AND MEGHALAYA: CONVERTING GIRLS AND WOMEN FROM «BAD TO GOOD»
}

\author{
Barnali Das* \\ (D) https: / / orcid.org/0000-0001-8704-1822 \\ Rekha Pande* \\ (1) https: / / orcid.org/0000-0002-3552-5240
}

\begin{abstract}
This paper examines the standpoints and the approach of the stakeholders working towards combatting sex trafficking in Assam and Meghalaya, India, with the aim of understanding whether the selected stakeholders uphold a gender-sensitive conceptualization, understanding and approach towards sex trafficking. Such an approach is significant since it ensures that victims of sex trafficking are protected from further marginalization and exploitation. In contemplating the voices of the stakeholders, the paper shows that the implementation and execution of the anti-trafficking provisions are genderladen. It claims that, while putting the anti-trafficking provisions of prevention, rescue, rehabilitation and repatriation into action, the stakeholders do not differentiate between voluntary and forced sex work. The absence of this distinction results in the "forced rescue" of voluntary sex workers. This article therefore shows how stakeholders impose the idea of "normal womanhood" and constantly seek to control and regulate women's sexuality.
\end{abstract}

Keywords: Sex trafficking, forced rescue, rehabilitation of victims, gender-sensitive approach.

\section{Resumo}

Crónicas da sociedade civil em Assam e Meghalaya: a conversão de meninas e mulheres de «más em boas»

Neste artigo examina-se os pontos de vista e a abordagem dos/as intervenientes no combate ao tráfico sexual em Assam e Meghalaya, Índia, com o objetivo de entender se os/as intervenientes selecionados/as sustentam uma conceptualização e abordagem sensível ao género relativamente ao tráfico sexual. Tal abordagem é relevante, pois garante que

* Centre for Women's Studies, Dibrugarh University, Dibrugarh, Assam, India.

Postal address: Centre for Women's Studies, Dibrugarh University, Dibrugarh: 786004, Assam, India.

Electronic address: dasbarnali.ghy@gmail.com

** Centre for Women's Studies, University of Hyderabad, Hyderabad: 500046, Telangana, India.

Postal address: Centre for Women's Studies, University of Hyderabad, Hyderabad: 500046, Telangana, India.

Electronic address: panderekha@gmail.com 
as vítimas de tráfico sexual sejam protegidas de novas marginalizações e de exploração. Ao analisar as vozes dos/as intervenientes, o texto mostra que a implementação e a execução das disposições anti-tráfico se baseiam numa perspectiva enviesada de género. Defende-se que, embora ponham em prática as disposições anti-tráfico de prevenção, resgate, reabilitação e repatriação, os/as intervenientes não diferenciam entre trabalho sexual voluntário e forçado. A ausência desta distinção resulta no «resgate forçado» de trabalhadoras do sexo voluntárias. Assim, este artigo mostra como os/as intervenientes impõem a ideia de «feminilidade normal» e procuram constantemente controlar e regular a sexualidade das mulheres.

Palavras-chave: Tráfico sexual, resgate forçado, reabilitação de vítimas, abordagem sensível ao género.

\section{Resumen \\ Crónicas de la sociedad civil en Assam y Meghalaya: conversión de niñas y mujeres de «malas a buenas»}

En este artículo se examina los puntos de vista y el enfoque de los/las intervinientes en la lucha contra la trata sexual en Assam y Meghalaya, India, con el objetivo de comprender si los/las intervinientes seleccionados/as defienden una conceptualización, comprensión y enfoque sensibles al género hacia la trata sexual. Este enfoque es importante, ya que garantiza que las víctimas de la trata sexual estén protegidas de una mayor marginación y explotación. Al analizar las voces de los/lasintervinientes, el texto muestra que la implementación y ejecución de las disposiciones contra la trata de personas se basan en una perspectiva sesgada de género. Se defiende que, al poner en práctica las disposiciones contra la trata de prevención, rescate, rehabilitación y repatriación, los/as intervinientes no distinguen entre trabajo sexual voluntario y forzado. La ausencia de esta distinción da como resultado un «rescate forzoso» de trabajadoras sexuales voluntarias. Por lo tanto, este artículo muestra cómo los/las intervinientes imponen la idea de «feminidad normal» y intentan constantemente controlar y regular la sexualidad de las mujeres.

Palabras clave: Trata sexual, rescate forzoso, rehabilitación de víctimas, enfoque sensible al género.

\section{Introduction}

Sex trafficking is one of the serious human rights violations and a form of gender-based violence. Victims of trafficking lose their right to freedom and life, and are violated physically, sexually and psychologically. The strategies and methods to address this problem have been multifarious. The national and international responses have created a range of methods to deal with the phenomenon. However, despite the robust national and international measures, there remains considerable uncertainty and debate over the gendered implementation of these measures. To establish the argument the following gives a brief summary of the international and national measures on human trafficking.

The history of international responses to sex trafficking dates back to the $19^{\text {th }}$ and $20^{\text {th }}$ centuries. After a multitude of changes, the first international protocol for 
human trafficking was accepted in the year 2000. The history of anti-trafficking measures in India began with the surveillance of "Indian Prostitutes" in the 1870s and 1880s, with the introduction of the Contagious Diseases Acts (Tambe 2009, 52). The beginning of the anti-trafficking era in India deemed trafficking of women from other parts of the country as less important and showed more concern over the trafficking of women from Europe (Tambe 2009, 123). Sex trafficking was formally defined as a crime in 1860, when the Indian Penal Code criminalized acts that involved buying, selling or kidnapping of children for prostitution and violation of their rights (Tambe 2009, 28).

However, the formal fight against sex trafficking in India commenced in 1956 with the Suppression of Immoral Traffic in Women and Girls Act. This law adopted an abolitionist stance, and to redress sex trafficking it targeted sex workers, brothel owners, pimps and customers. Nonetheless, in 1986 The Immoral Traffic (Prevention) Act with minor changes amended the previous act. Unlike the Suppression of Immoral Traffic Prevention Act, it did not criminalise the sex workers. However, it targeted the customers of sex workers, and this provision of the act is vehemently opposed by the sex workers collectives in the country.

Moreover, apart from the Immoral Traffic (Prevention) Act of 1986, India had drafted and implemented other acts which address the problem of trafficking in persons: the Prohibition of Child Marriage Act (2006), the Bonded Labour System (Abolition) Act (1976), the Child Labour (Prohibition and Regulation) Act (1986), and the Transplantation of Human Organs Act (1994). Further, India has also designed the Ujjawala scheme to specifically address the problem of trafficking in girls and women. The components of this scheme are a) prevention, b) rescue, c) rehabilitation, $\mathrm{d}$ ) reintegration and e) repatriation of trafficked victims.

Given the above context of anti-trafficking measures, this paper argues that the measures lack a gender sensitive approach towards sex trafficking. It argues that such an approach is a necessary a priori condition to deal with the phenomenon as well as the victims of sex trafficking. Such an approach would aid in the mental and physical well being of the victims. Cunha $(2002,4)$ posits a revisit of the discourse and interventions of sex trafficking, and asserts that a gender sensitive orientation is central to the anti-trafficking strategies. Such an orientation would necessitate a multi-sectoral and a gender-sensitive approach to prevention, protection and assistance. Cunha $(2002,8)$ argues that the susceptibility of women and girls as victims of sex trafficking is grounded in their «marginalized social locations». «Measures that reproduce gender stereotypes, reinforce discrimination and control over women should be challenged» (Cunha 2002, 13). However, the implementations of the national and international interventions on human and sex trafficking lack the concerns of gender stereotypes and necessarily reinforce discrimination and control over women. The subsequent sections of this paper prove the lack of gender sensitivity amongst the stakeholders of sex trafficking. 
This context of gender sensitivity is put forth by a report developed by ASEAN $(2016,11)$, which stresses the need for a gender-sensitive anti-trafficking approach. Further, a training guide designed by the Organisation of American States $(2010,7)$ argues for a gender sensitive and strategic planning which recognises disparities and discriminations, and outlines necessary actions and activities that satisfy the "practical as well as strategic needs of women». This paper joins this debate on a gender-sensitive approach to address the phenomenon as well as the recipients of the phenomenon. A gender-analysis approach is adopted, based on the claim that, although there is a robust body of anti-trafficking measures, the implementation of these provisions are found to be gender-laden. It argues that the stakeholders implementing the anti-trafficking provisions of prevention, rescue, rehabilitation and repatriation fail to distinguish between voluntary and forced sex work. The absence of this distinction results in the "forced rescue" of voluntary sex workers.

Further, the ideological framework of the stakeholders is found to have moralistic standpoints on sex trafficking, which leads to the categorization of trafficked women as "bad" and "immoral" women. The narratives included in this paper indicate that these ideologies are guided by strong notions of permitted sexuality, which is legitimate heterosexuality, and since victims of sex trafficking are outside of this framework, we find a continuous effort to "mainstream" them into the category of "normal asexual women".

This paper argues that the rationale behind the moralistic stance on sex trafficking is based on a gendered construction of sexuality that imposes an «inferior sexual identity» on women (Chow 2003, 97). The voices cited in this paper show how the stakeholders impose the idea of "normal womanhood" and constantly seek to control and regulate women's sexuality (Chow 2003, 100). The empirical accounts included here reveal that stakeholders vehemently oppose sex work and, in the guise of addressing sex trafficking, seek to eradicate and disrupt sex markets. This attempt is understood as a necessary condition to wipe away the phenomenon of sex trafficking.

The first part of the paper presents the methodology that we adopted in the field work of the study, while the second part provides a feminist framework on sex trafficking, which explores the abolitionist and regulationist school of thought, and the third part discusses and provides gender analyses of the chronicles of the civil society.

\section{Research}

The complexities involved in the epistemology of sex trafficking demand an intensive study of sex trafficking. Owing to the sparse research on the phenomenon in Northeast India, this study is based in the regions of Assam and Meghalaya 
(India). The districts selected for Assam include Kamrup, Baksa, Sonitpur, Nalbari, Namrup, Sivasagar, Tinsukia and Dibrugarh, while those of Meghalaya include East Jaintia Hills, West Jaintia Hills, East Khasi Hills and West Khasi Hills. The states are located in the northeastern region of India and cover a total area of 78,438 sq. kilometers (Assam) and 22,429 sq. kilometers (Meghalaya) respectively. Due to their poor economic backgrounds, the states lay a fertile ground for the crime of sex trafficking.

Although women in both states are bound by different social systems, wherein Assam is a patrilineal and a patrilocal state and Meghalaya is a matrilineal and matrilocal state, the status of women in both states is inferior, subordinate, and secondary to that of their counterparts. These states function under multiple patriarchies that create disparate socio-economic and political situations of subordination for women. This therefore has its effect on the growing incidences of trafficking for commercial sexual exploitation.

To encapsulate the multiple voices within civil society, this research study collected information from a total number of 37 respondents, 19 of which were from non-governmental organizations. The study also found that in Meghalaya the Church plays a pivotal role in the socio-economic construct of the state and in spreading awareness against sex trafficking. Therefore, to situate and understand the phenomenon of sex trafficking in Meghalaya the study took responses from 10 Pastors from the Synod and Presbyterian Church. In addition to this, the researcher found that the church in Meghalaya has drop-in centres, which counsel sex workers. Further, the researcher interviewed 5 headmen of the village council (Dorbar) in order to get a nuanced perspective on sex trafficking in the state. The researcher also interviewed three politicians in Assam and Meghalaya respectively. This enabled the researcher to receive an understanding of the state's approach to sex trafficking. Considering the sensitivity of the topic, pseudo names for the respondents have been used and the names of the organizations have been kept anonymous.

In order to conduct the present study, the researcher used feminist standpoint theory. The foundation of this study was based both on primary and secondary sources. For primary data collection, the researcher made several visits to the offices of NGOs and police stations located in Assam and Meghalaya. Since the church plays an important role, the researcher visited the Synod and Presbyterian Church of Meghalaya, in order to get wider perspectives of the stakeholders involved in the drive against human and sex trafficking.

This study is based on criterion, convenience and snowball sampling method. It is built on a narrative phenomenological approach and case study approach (Adu 2016). The philosophical paradigm is based on "social constructivism" (Adu 2016). The ontology of this paradigm is based on realities that are created through individual interactions. 


\section{Feminist Debates on Sex Trafficking}

The concept of consent/non-consent has been the central parameter of the debates and arguments between two feminist schools of thought: the abolitionists and the regulationists. The former negate all forms of consent involved in sex work, while the latter demand to consider the consent of voluntary sex workers as an efficient way to address the problem of sex trafficking. In alliance with conservatives and evangelical Christians, the school of abolitionism has used the anti-trafficking movement as a means to abolish prostitution (Chuang 2006, 1658). An understanding of these two schools of thought is paramount to contemplate the ideological locations of the stakeholders of the research.

The abolitionist schools of thought make no distinction between forced and voluntary prostitution. Both forms of prostitution are considered to be coerced, since they conceive of prostitution as an institution of male dominance which is devoid of meaningful choice and consent (Chuang 2006, 1664). Abolitionists aim to remove prostitution from public sight (Tambe 2009, 101), and therefore have a reductionist approach to trafficking.

The early first and second-wave feminists were in alliance with the social purity campaigners, and as such their main concern was to protect "fallen women" from the vice of prostitution. Radical feminists and polemicists such as Kathleen Barry articulated prostitution as an inherent assault on the dignity of women and saw it as a product of men's sexual violence that had taken a vicious form in the shape of human trafficking (Weeks 2011, 139).

The Indian women's movement against sex trafficking did not depart from the abolitionist ideology, the impact of which led to the abolition of the Devadasi system or temple dancing girls (Tambe 2009, 104). It rose with the demand of the middle-class women's movement to abolish the system of Devadasis as they conceived it to be a form of prostitution. They reasoned it was based on temple dancers being engaged in offering sexual services to male patrons and prohibited from getting married (Tambe 2009, 104). Therefore, early women's associations, such as the Women's India Association (WIA) of 1917, the All India Women's Conference (AIWC) of 1926, and the National Council of Women in India (NCWI) of 1925, promoted legislation against the Devadasi system (Tambe 2009, 104). The WIA journal Stri Dharma regularly published against the Devadasi system, often associating it to prostitution (as cited in Tambe 2009, 104). The Women's Movement led legislation against the Devadasi system, which resulted in the denial of Devadasis' claims to temple property as well as inheritance rights. The first strike on the Devadasi system was due to the Devadasis resisting marriages (Tambe 2009, 105).

Therefore, the Indian women's movement and the nationalists had a paradoxical approach to prostitution. On the one hand, they pitied the prostitutes for having been robbed of their chastity and honour, and on the other hand they con- 
sidered them to the thieves of the moral purity of society. This led the early Indian women's movement to have a wider abolitionist approach (Tambe 2009, 107). The narratives included in this paper demonstrate an abolitionist stance, thereby blurring all distinction between forced and voluntary sex work.

However, the abolitionist struggle of the radical women's movement has been challenged by the postmodernist feminists, who have critiqued the modernist explanation of dominance and victimisation (Lansink 2006, 51). The defenders of sexual rights see a sharp distinction between children forced into prostitution and women who make a choice to enter the sex trade (Weeks 2011, 216). «They embrace what Sandra Harding has called "the fractured identities of modern life" and emphasise the local and the specific context of women's real life experiences (Harding in Charlesworth and Chinkin, 2000: 44)» (as cited in Lansink 2006, 51). Therefore, the postmodern, liberal and libertarian feminists have emphasised choice, agency, and freedom to choose work (Lansink 2006, 51).

The regulationist or the liberal feminist political model of sex work recognises the autonomy to engage in sexual labour. It critiques the abolitionist school of thought and states that «conflating trafficking and prostitution would divert attention from combating trafficking effectively» (Lansink 2006, 51). It counters the discourse that brings voluntary sex work into the scope of trafficking and impacts on the development of anti-trafficking measures. It argues that it negatively impacts the possibility of effective strategies, as resources would be diverted to combating prostitution rather than the very serious crime of trafficking. Within the context of trafficking, prostitution is always unacceptable, because it is done under coercive circumstances for the purposes of exploitation. But this should be separated from including all (adult) consensual recruitment or migration for sex work as trafficking (Lansink 2006, 52). Therefore, according to the regulationist school of thought, coercion is an indispensable element of sex trafficking (Doezema 2002, 20). It places women's sexual autonomy at the centre and argues that negating the dynamics of consensual sex work is anti-feminist and a threat to women's sexual autonomy (Doezema 2002, 21).

Within this framework, the Indian collectives of the National Network of Sex Workers, the Durbar Mahila Samanwaya Committee and the Veshya Anyay Mukti Parishad (VAMP) demanded to license sex work. They argue that the licensing of sex workers would not only guarantee their rights, but also enable the state to address the problem of sex trafficking. In this context, this paper critiques the gender-laden approaches of stakeholders and maintains that the effective strategy to deal with the phenomenon of sex trafficking is a gender-sensitive approach and the recognition of the distinction between forced and voluntary sex work. 


\section{Multiple Voices}

This section seeks to analyze the various aspects of sex trafficking. Delving into pre-rescue exploitations, standpoints on rescue, rehabilitation, approaches to redress sex trafficking, converting from "bad to good" girls and women and conditions of retrafficking, it examines the narratives and standpoints of the civil society. Within the framework of gender sensitivity, the subsequent section examines the said approaches.

\section{Pre Rescue: Breaking-in}

Regarding the process of breaking-in victims into the commercial sex trade, the narratives from the civil society unanimously mentioned instances of extreme physical and mental violence. Mary's experience of working with victims of sex trafficking reveals the following:

Victims of sex trafficking undergo immense mental tortures. They blackmail the victims by saying that «if you don't do as we say, we are going to harm your family». These are forms of emotional blackmail. Trafficked victims are also kept in isolation for days. (Mary, NGO worker, Meghalaya, 16 July 2016)

Placing experiences at the centre, this paper finds that emotional blackmail is one of the methods to exploit the vulnerability of trafficked victims. The realities of breaking-in experiences of violence show that traffickers exert physical and psychological tortures. Also, to silence and torture them, traffickers threaten to kill their families. These experiences of breaking-in create the epistemology of exploitation inflicted upon victims of trafficking.

\section{Rescue}

Rescue is found to be one of the primary anti-trafficking drives of the stakeholders. The foundation upon which the idea of rescue is based is to save and retrieve girls and women from situations of forced sex work and extreme exploitation of the pre-rescue phase (Sen and Nair 2005). The underlying principle of rescue is rescue from pre-rescue exploitation and "forced sex work". Nonetheless, the firsthand accounts of stakeholders have revealed a reversed understanding of this principle. We found that stakeholders have a falsified sense of the idea of rescue. An analysis of these standpoints found that stakeholders failed to distinguish between forced and voluntary sex workers, which has led to the "forced rescue" of sex workers who are willingly engaged in the business of commercial sex.

The following extract is an example of this falsified understanding of rescue, conveying the idea that rescue is a drive against the sex markets. 
Rescue operations involve stake and risk. We cross check the information we receive. We go to the place and find out how far the report is true and ask nearby shops and neighbours. Further, we observe the house about which we had received information of "bad" activities. We have our informers who report to us about the cases. (Manjula, Assam, NGO Worker, 1 March 2016)

Another narrative reveals how the parameter of "age" acts negatively for an adult woman who had voluntarily worked in the business.

One of the major challenges today is the definition of human trafficking and prostitution. There exists a thin line between both phenomena. Right to consent is not given to an individual below 18 years. Our organization adopts the age of consent as fixed by the United Nations. Thereby, while conducting rescue of trafficked victims the age at which the victim was trafficked is taken into account. A victim might state that she is fine with the work then. However, when the incident happened, it happened when she was a child. We take that age and fight against child and women trafficking. If a sex worker above the age of 18 says «I am doing it willingly», then the personal rights of the women becomes an important aspect of consideration. Although India has not legalized prostitution, it is about choice, personal rights and women's rights. However, many organizations while conducting raids pull out willful sex workers and present them as victims of trafficking. (Heena, NGO Worker, Meghalaya, 7 July 2016)

This reflects the complicated dimension of the phenomenon and the drives against it. The respondent refers to a willful sex worker who was initially trafficked but later consented to work. Therefore, the voices at the centre of this paper bring to light the gendered construction of sexuality that leads to sublimate, ignore and silence sex workers.

Based on the standpoints of the stakeholders, we argue that the trafficked victims' consent is never taken into account in the process of rescue. Due to the controlled and regulated sexuality of women, the excerpt here clearly reveals that the consent of willful sex workers is never considered. A similar standpoint of forced rescue is elucidated below:

The woman about whom I spoke was there in the red-light area and so we rescued her. Although the woman settled into the profession of sex trade, however she was originally a trafficked victim... (Rita, NGO Worker, Meghalaya, 16 July 2016)

In this narrative the respondent admits that voluntary sex workers are forcefully rescued from the business that they are settled in. Through a feminist analysis of this standpoint, we argue that forceful rescue is a displacement of women and their work, which results in depression, distress, emotional and economic turmoil. A respondent said the following: 
In one of the recent cases the victim who we have rescued also has an old shop in that particular place. They have their family. They have a shop. Everything is there and she told us that she is not into that trade anymore. We have found that many of them are not willing to be rescued. (Tiloka, NGO Worker, Assam, 7 March 2016)

The narrative throws light on the forced rescue and extraction of sex workers. Through the lenses of women's experiences of violence, this data shows the extraction and economic displacement of empowered women. Such kind of rescue pushes women to disadvantageous positions and puts them in economically distressed situations. This reveals a falsified understanding of rescue and sex trafficking. The respondent clearly shows evidence of her non-comprehension of the phenomenon, and this has led to the economic displacement of the woman.

\section{Shelter Homes}

The rescued trafficked women and girls are rehabilitated in shelter homes that are typically designed to provide protection and necessary services. However, the data collected for this study shows it to be an uncomfortable space for victims. The respondents from the civil society point out the amount of insufficient and non-nutritious food provided to the victims who are being caged in the shelter homes. Based on the experience of working in rescue homes, one of the respondents discloses the mental ostracization that rescued victims of trafficking undergo (Noor, Social Worker, Assam, 19 October 2017).

Is it important to know her entire story and insult her for the mistakes she had made in the past? Or is it important to provide solace and shelter to her? This is the reason why they have a negative mind. They [staff] would repeatedly reiterate that she was a bar dancer... (Noor, Social Worker, Assam, 19 October 2017)

Though the respondent's patriarchal mindset could be seen, yet a compassionate approach is found in Noor's articulation of the shelter home. Her views are patriarchal because she considers sex work, voluntary or forced, as the mistake of girls or women. The consequence of this "mistake" is social ostracization and the labelling of women as "bad" and "evil". These articulations of "bad" and "evil" are in line with the learned perceptions of sexuality which are imposed on social actors. Any deviation found or committed means necessarily to be outside the parameters of a normal and good woman.

Further, on account of disobedience and non-adherence to rules, there are cases wherein victims are thrown out of the shelter home. One of the respondents said the following: 
Recently a mentally unstable girl was admitted in our shelter home. However, before our arrival she was sent back to her home. I told the other staff that they had not done a wise thing. The girl was mentally unstable. (Noor, Social Worker, Assam, 19 October 2017)

The study also found that a trafficked victim was sent back to Silchar, her place of origin, without being accompanied by an NGO staff member. She was sent back because she was creating a problem in the home and was unmanageable by the staff. In one of the instances, the girl tried to undress and show herself to a passerby. Therefore, the staff decided to get rid of her.

According to the voices in this study, shelter homes are spaces wherein inmates are incarcerated. The rationale behind this incarceration is "safety" and "protection" of trafficked girls and women. However, from a feminist standpoint and epistemology, one can argue that this process of arbitrary incarceration as a mechanism of protection is based on the ideals of patriarchal control and repression of women. Referring to this phenomenon of incarceration, one of the respondents spoke about the inmates' desire for freedom. He said that «being locked in the shelter home they feel suffocated from within. The only desire they are left with is their freedom and they are desperate about it» (Kamal, Assam, 7 March 2016). During the interviews, the respondents spoke about victims being locked in the shelter homes. Referring to this, one of the respondents said:

This is because of the fact that by jailing women in the shelter homes one is trying to disempower a woman. They remain aggressive within these spaces. They run away. A number of these shelter homes sometimes focus on the numbers of victims that are been put into these homes and that they do not reintegrate them. (Josephina, NGO Worker, Meghalaya, 27 July 2016)

The conditions of the shelter homes are disclosed to be extremely inadequate, and victims reside in what can be described as regulated and surveillance sites.

In India shelter homes are in pathetic conditions. In a single room five inmates are accommodated. Victims are provided undernourished food in the shelter homes. Most shelter homes just provide dal, rice and potato. They have no lifestyle within the shelter homes. (Kamal, NGO Worker, Assam, 7 March 2016)

The desire for freedom is curtailed in the shelter or rescue homes. The responses underline that the shelter homes are spaces of discipline and control, which create a sense of suffocation and make it more of an incarcerated site. This shows a patriarchal model of rehabilitation where the disciplining of "non-docile" bodies is primary, while the victims' desires and voices are secondary and essentially subdued and ignored. 
The inmates wish to go to back to their native places. However, due to official formalities, it is deterred by the in-charge of the rescue home. Further, victims often complain of feelings of suffocation. This is because they are locked and jailed in shelter homes. Thereby, the desire that victims repeatedly express is of freedom and they are desperate about it. (Noor, Social Worker, Assam, 19 October 2017)

Mary, an NGO worker, confirms this situation:

Victims of sex trafficking are kept captive in the shelter homes, toward which they have a great deal of discontentment. This is because they feel that they are curtailing their freedom. They think that they have come to another jail. There are rules that one has to follow. (Mary, NGO Worker, Meghalaya, 16 July 2016)

The standpoint of the respondents reveals that the shelter homes are spaces to discipline and regulate women's bodies. A critical feminist analysis of these standpoints shows that these spaces constantly seek to "mainstream" trafficked women. It is found to be a site with strict rules and regulations to control the victims who have deviated from the category of "good women". The restrictive nature of these sites is revealed through the respondents' statements about the fact that victims run away from these rehabilitation spaces.

\section{Redressing Sex Trafficking}

The above attempts to redress sex trafficking show that, in Assam and Meghalaya, raids, rescue and rehabilitation are considered as important mechanisms or elements of anti-trafficking. In doing so, the data finds that curbing the sex trade is an evident attempt made by the civil society. In response to sex trafficking, a respondent said:

We feel that, when it comes to legalising prostitution, what happens is that this industry would boom rather than be curbed. Legalisation would encourage traffickers to bring in girls. Legalisation would set an easy stage for traffickers. (Bhatta, Politician, Assam, 5 October 2017)

Thereby, since sex trafficking could be articulated within the paradigm of women's sexuality, the efforts of society are towards the control, regulation and repression of women's sexuality. In this context, the above excerpt leads us to problematize the efforts of the civil society and to argue that, under the guise of curbing sex trafficking, the efforts are to curb voluntary sex work. This context is further put forth by Jameela $(2018,17-18)$ who argues that, while the Indian legal system does not per se consider sex work as an illegal activity, yet the police and the legal system persecute sex workers. 
Within this framework of restricted women's sexuality, another respondent victoriously spoke about her success in wiping away sex markets. Further, the study found that, in Meghalaya, an attempt is made to curb the entry of outsiders into the state. Concerning this a respondent said:

When our union became aware about sex trafficking, we set up a board to address the problem of sex trafficking in Meghalaya. We have awareness programmes. We don't allow the non-tribal people to come into our areas. We do so with the help of Dorbars (village council). We have this concern because we are aware that human trafficking and sex trafficking are occurring in Meghalaya and hence to avoid it, we have developed this mechanism. (Rahul, President Student's Union, Meghalaya, 11 July 2016)

This member of the civil society argues that an abolitionist stance with no distinction between forced and voluntary sex work could be an effective method to address and redress the phenomenon of sex trafficking. He also alludes to the presence of outsiders in Meghalaya, and to prevent sex trafficking in the state he urges the restricted entry of outsiders.

This study argues that the moral stance held by the abolitionists as an approach to redress sex trafficking could be critiqued and questioned (Doezema 2002; Sharma 2005; Cavalieri 2011). The method to disrupt and dismantle sex markets in order to control sex trafficking is argued to be a patriarchal and a statist approach to redress sex trafficking. It is based on the sexuality of women which has been constructed as an inferior, controlled and highly surveilled site of society, therefore any puncture on it causes increased moral and social imbalances in the social milieu.

\section{Converting Girls and Women from Bad to Good}

The efforts to redress sex trafficking by the members of the civil society reveals the necessity to bring trafficked victims into the "mainstream" society. They often mentioned that girls who become habituated to sex work are difficult to pull back to the normal course of life. The only way to deal with this problem is to provide counselling to rescued trafficked victims. Referring to this, one of the respondents said:

Their sexual needs are higher than that of normal people. To counsel them and bring them back to the mainstream is difficult. We have to have patience when dealing with them. (Jyoti, NGO Worker, Assam, 25 November 2016)

This stance of "mainstreaming" victims from "bad to good" girls and women is mirrored in the narrative of the majority of respondents. The narratives reflect the framework of the socially acceptable category of good women who are essen- 
tially chaste and sexually untouched and non-violated. The research found that the narratives were strictly restricted within this category of good versus bad women. This category of bad women is problematized by Jameela $(2018,13)$, who argues that a bad woman is one who ventures and travels at odd hours and one who does not follow the regime of the strict heterosexual order. To repress and regulate these categories of "bad women", the emphasis has increasingly been laid on combating sex trafficking as an immoral and non-ethical crime.

Nonetheless, some of the respondents also acknowledged that victims need counseling to recover from the physical and mental violence that they had undergone. Noor said:

According to me, counselling is the main treatment for rescued trafficked victims. With the help of love and care one can make a victim comfortable and secured to speak and tell their stories. This exercise helps them immensely to release their emotions and frustrations. Thereby, since counselling provides mental support, the recovery of victims becomes easier. (Noor, Social Worker, Assam, 19 October 2017)

However, most of the respondents mentioned that counselling was a technique to "mainstream" trafficked girls and women. They stated that being a trafficked victim means that they are lost, and it is imperative to bring them back to the normal life. The following narratives are about this aspect of mainstreaming trafficked victims:

See, trafficked girls are different from any other girls. When it comes to counselling them, they behave differently. Their physical need is higher than that of normal people. They are used to it. They do not trust people easily. Anyone who comes to them, they think of them as their client. So, to break that is difficult...

I believe there is another breaking-in phase. However, the process of breaking in the victims in pre and post rescue is discrete. In post-rescue there is counselling and rehabilitation. We have the work for reintegrating the victims into the society. (Mary, NGO Worker, Meghalaya, 16 July 2016)

In the discourse of sex trafficking breaking-in means physical and psychological violence used to coerce victims into the sex trade. The use of this term in the post-rescue situation reflects the respondent's approach of force and coercion to bring victims into the "normal life".

These narratives throw light upon the argument of this research study, which is that stakeholders seek to mainstream trafficked girls and women. Mary argues that the sexual need of trafficked women is higher than that of "normal women". The category of "normal women" in this context is one who is "asexual, chaste and pure". It is also implied that "normal women" do not reveal their sexual urges and 
desires. Mary's narrative shows her comparison of this internalized category of "good and normal women' vis-à-vis "bad and abnormal women". A similar standpoint is reflected in Rita's narrative: "A rescued trafficked victim after being brought to a shelter home is required to receive counselling, so that it helps the victim to recover and come to the mainstream life» (Rita, NGO Worker, Meghalaya, 16 July 2016).

\section{Re-trafficking}

Forceful rescue, confinement in rescue homes, and the gendered attempts to mainstream rescued trafficked girls and women result in creating conditions of re-trafficking. In this context, the narratives show that one of the primary causes of re-trafficking is the assurance of providing a comfortable life to the victims. In this respect, one respondent reflects that «If one is enjoying a luxurious car, then why would one wish to board an auto-rickshaw? Therefore, in the hope of comfort, luxury and money, the girls get retrafficked» (Rima, NGO Worker, Assam, 12 July 2016). Another respondent said the following:

Most of the rescued victims of trafficking that I have come across want to go back to the brothels. On the one hand, we want to rescue them from the "wrong direction". On the other hand, they wish to go back to the place. (Sarita, NGO Worker, Assam, 13 July 2016)

According to the findings of this study. the cases of re-trafficking are high. However, one has to look into this context of re-trafficking within the dimensions of choice and consent. This is because the respondents expressed their desire to return to the sex markets. Therefore, the notion of rescued trafficked women and girls as passive victims could be challenged in this context, as they constantly transgress the boundaries of victims and active agents.

As has been discussed, victims of trafficking after rescue are not freed from suppression and domination. They are subjected to innumerable forms of marginalization after rescue. As we stated before, within shelter homes victims are incarcerated, and as a consequence they choose to elope and put themselves in disadvantaged positions that make them susceptible to re-trafficking.

\section{Gender Sensitive or Gender Insensitive Approach?}

In the process of rescue and rehabilitation of trafficked victims, civil society plays a very integral role. In this regard, adopting a gender perspective in their approach is imperative. Thus, this section looks into the approach adopted by civil society organizations and other stakeholders of sex trafficking. 


\section{Gendered Treatment of Trafficked Victims}

The members of civil society subject victims to acute forms of gendered treatment. The narratives in this study show that the approach of civil society is distinct towards trafficked men and women. If a girl or a woman is rescued from bonded labour or from sexual slavery, the members of civil society incarcerate them in shelter homes. However, if a boy or a man is rescued, he is directly re-integrated into society. The reason cited by a respondent is that society is more open towards boys and men and has no problem in accepting them. However, a girl or woman is subjected to deep ostracization by the society, which judges her according to the standards of purity and impurity. In this respect, one respondent said: «Some trafficked victims become habituated to the business of prostitution and it is important for us to counsel them and bring them back to normal life» (Tiloka, NGO Worker, Assam, 7 March 2016). The following narrative is an example of the gendered treatment of trafficked victims:

In 2015, we rescued 52 boys from Bangalore. We rescued them from an agarbati (incence sticks) company. Out of the 52, two were from Arunachal Pradesh, the rest were from Assam. The traffickers said that they would give them jobs in Bangalore. After reaching Bangalore they recruited them for a factory. In the first few months of their recruitment, they sent money to their families. However, later their families stopped receiving money. On further probe, we were told by the boys that their daily wage was Rs. 10/-.

We don't keep boys in shelter homes. After rescue, when they return to Assam, we register their names and sent them back to their homes. We do so in cooperation with the Guwahati Railway Police Station (GRPS), and accordingly book their tickets for their respective homes and sent them back. Further, they go by themselves and we do not escort them. (Tiloka, NGO Worker, Assam, 7 March 2016)

The narrative refers to the gendered understanding of human trafficking and its allied protocols of rescue and rehabilitation. It is implied that, since men and boys are outside the construct of "chastity and purity", they lie outside the gendered practice of rehabilitation and protection. It essentially denotes that only girls and women are rehabilitated and restored into societies. Since in this context the victims were boys, there was no requirement of rehabilitation and protection. Also, the respondent stated that boys are easily welcomed by family and society, while girls suffer abandonment and isolation from family and society. This is disclosed in the following statement:

The boys are more eager to return back home. Their families want them to return home. In this context, the gender differences reflect because when girls stays outside 
and then return back home, they undergo opposition and questioning by their community, village and family. A number of questions arise, such as where they were. Moreover, there is stigma attached to girls. Due to which there is a question of whether the family would accept her or not. If the family is ready to accept her, they are scared of their community.

Shelter homes for boys exist, however there are no shelter homes for men. These shelter homes act like corrective homes for men wherein they are kept under observation if they commit any punishable offence such as rape, murder and so on and so forth. (Tiloka, NGO Worker, Assam, 7 March 2016)

The excerpt shows that the framework of shelter for trafficked victims is typically meant for girls and women who are victims of sex trafficking. According to the respondent, men and boys do not need shelter, but rather corrective homes in case of murder, rape or other kinds of punishable offences committed by them. It could thus be argued that the rehabilitation approach is gendered, because rehabilitation and rescue homes are essentially meant for one particular gender, i.e. women, and typically for one category of human trafficking, i.e. sex trafficking.

\section{Gendered Approach in Awareness Programme on Women and Trafficking}

The element of "prevention" involved in the discourse of anti-trafficking mandates that organizations should adopt adequate awareness programmes to prevent and deter the phenomenon of sex trafficking (UN 2000; MWCD n.d.). These programmes are held to spread awareness and consciousness about the clandestine nature of sex trafficking.

This philosophy of awareness and prevention programmes is found to be gendered and androcentric in nature, representing an attempt to restrain women's mobility and free will.

We begin the awareness programmes by speaking about women being inherently weak in education and economic spheres. Lack of education makes women unaware. They are ignorant about schemes and provisions given by the Government. (Kamal, NGO Worker, Assam, 7 March 2016)

The respondent in this narrative spells out the constructed gendered cause of sex trafficking, which in this context is the constructed and false understanding of the weak bodies of women. His awareness programme is repressive and gendered because it reiterates that women are weak and uneducated, and thereby they become easy targets for traffickers. Such kind of consciousness would deepen the subjugation and marginalization of women. 


\section{Conclusions}

The research study described in this paper confirms the gender-laden approach of the stakeholders involved in combatting sex trafficking. Such an approach fails to adequately address the concerns and needs of rescued trafficked victims. Based on the findings of this study and the experiences of working in the field, it argues that this approach further deteriorates the mental and physical conditions of trafficked girls and women. It places them in situations of self-doubt, anguish and self-loathing.

The gendered approach and fractional understanding of sex trafficking are reflected in the findings of this study. For instance, the falsified notion of rescue as upheld by the stakeholders resulted in the forced rescue of voluntary sex workers. Further, the article argues that coercive rescue places women in precarious positions and places them in economically hazardous situations. These finding suggest that stakeholders have a partial understanding of sex trafficking.

Further, rehabilitation of rescued trafficked victims is found to be based on the ideologies of patriarchy and gendered socialization. The narratives indicate that rescue homes incarcerate women and are a highly surveilled and patriarchal site for women. In addition, the findings suggest that stakeholders fail to offer a constructive rehabilitation of victims, which should provide healthy and gender-sensitive counselling to fight their trauma. The approach to counselling is found to be within the categories of "good and bad" women or based on the idea of "normal womanhood". These categories of "good and bad" women tend to further marginalize rescued trafficked victims.

Therefore, the findings presented in this paper lend support to the argument that, in the name of combatting sex trafficking, stakeholders frequently tend to curb sex work. The paper suggests that the aim of the stakeholders was not to fight against the multiple conditions of servitude involved in human trafficking, and their narratives evidently reflect a gender-biased approach and an over emphasis on sex trafficking. The rationales behind this emphasis are the polarities of morality and immorality, the normative binary of good or bad ascribed to the bodies of women. Thus, the implication is that, for stakeholders, the disruption of sex markets is held as a necessary precondition to deal and uproot the problem of sex trafficking.

\section{References}

Adu, Philip. 2016. «Writing the methodology chapter of a qualitative study.» Available at: https: / / www.youtube.com/ watch?v=KRHvxY3N708 [Accessed 24 November 2019]. ASEAN. 2016. Gender Sensitive Guideline for Handling Women Victims of Trafficking in Persons. Jakarta: ASEAN Secretariat. Available at https://asean.org/wp-content/uploads / 2012/05/FAASN_gender_8_email_REV.pdf [Accessed 15 April 2021]. 
Cavalieri, Shelley. 2011. «Between Victim and Agent: A Third-Way Feminist Account of Trafficking For Sex Work.» Indiana Law Journal 86(4): 1410-1458. Available at https:// www.repository.law.indiana.edu/ilj/vol86/iss4/5 [Accessed 14 April 2015].

Chow, Rey. 2003. «Sexuality.» In A Concise Companion to Feminist Theory, edited by Mary Eagleton, 93-110. Malden, MA: Blackwell.

Chuang, Janie. 2006. «Beyond a Snapshot: Preventing Human Trafficking in the Global Economy.» Indiana Journal of Global Legal Studies 13(1): 137-163. Available at: https:/ / www.repository.law.indiana.edu/ijgls/vol13/iss1/5 [Accessed 23 August 2012].

Cunha, Jean D. 2002. «Trafficking in Persons: A Gender and Rights Perspective.» Report prepared for the UN Expert Group Meeting on «Trafficking in Women and Girls», 18-22 November, Glen Cove, New York, USA. Available at https: / /www.un.org/womenwatch/daw / egm/trafficking2002/reports / EP-DCunha.PDF [Accessed 15 April 2021].

Doezema, Jo. 2002. «Who gets to choose? Coercion, consent, and the UN Trafficking Protocol.»GenderandDevelopment10(1):20-27.DOI:https: / / doi.org/10.1080 / 13552070215897

Jameela, Nalini. 2018. Romantic Encounters of a Sex Worker. Uttar Pradesh, India: Om Books International.

Lansink, Annette. 2006. «Human Rights Focus on Trafficked Women: An International Law and Feminist Perspective.» Agenda: Empowering Women for Gender Equity 70. Gender-Based Violence Trilogy vol. 1-2: 45-56.

MWCD. n.d. «Ujjawala Comprehensive Scheme for Prevention of Trafficking and Rescue, Rehabilitation and Re-Integration of Victims of Trafficking for Commercial Sexual Exploitation.» Ministry of Women and Child Development, Government of India, New Delhi. Available at https://wcd.nic.in/sites/default/files/Ujjawala\%20 New\%20Scheme.pdf [Accessed 6 September 2011].

Organization of American States. 2010. Training Guide. Participatory Strategic Planning with a Gender Perspective. Available at https://www.oas.org/en/CIM/docs/LabourCARICOM-Guide[EN].pdf [Accessed 15 April 2021].

Sen, Sankar, and P.M. Nair. 2005. A Report on Trafficking in Women and Children in India 20022003. New Delhi, India: Orient Longman.

Sharma, Nandita. 2005. «Anti-Trafficking Rhetoric and the Making of a Global Apartheid.» NWSA Journal, 17(3): 88-111. Available at muse.jhu.edu/article/189422 [Accessed 16 December 2017].

Tambe, Ashwini. 2009. Codes of Misconduct: Regulating Prostitution in Late Colonial Bombay. Minneapolis: University of Minnesota.

United Nations. 2000. Protocol to Prevent, Suppress and Punish Trafficking in Persons, Especially Women and Children, supplementing the United Nations Convention against Transnational Organized Crime. New York: UN. Available at https:/ / www. unodc.org/documents / treaties / Special /2000_Protocol_to_Prevent_2C_Suppress_ and_Punish_Trafficking_in_Persons.pdf [Accessed 18 August 2011].

Weeks, Jeffrey. 2011. The Languages of Sexuality. London, UK: Routledge.

Barnali Das. Assistant Professor at the Centre for Women's Studies, Dibrugarh University, Assam, India. She has written and taught in the field of gender-based violence. She has worked in a Ministry of Women and Child Development funded project in the Centre for Women's Studies, Dibrugarh University, titled «Stories Behind a Hot Cup of Assam Tea: Listening to the Voices of Women Labourers in the Tea Gardens». 
Rekha Pande is the Head of the Centre for Women's Studies and a Professor of History at the University of Hyderabad, India. She was the founding member of two Centers for Women's Studies in India. She was the Chair of the Women's World Congress in 2014. She has to her credit 20 books and 150 papers in national and international journals, proceedings and book chapters.

Received on 17 October 2020 and accepted for publication on 4 April 2021. 


\title{
ARTIVISMO FEMINISTA Y FLASHMOB: LENGUAJE CORPORAL EN EL MUNDO ORIENTAL
}

\author{
Teresa Colomina-Molina
}

Dttps: / / orcid.org/ 0000-0002-4557-7896

\section{Resumen}

Las redes sociales permiten compartir contenido diverso y mantener una interconectividad entre usuarios a nivel global. Este estudio analiza las formas de expresión y representación del fenómeno Flashmob realizado por mujeres en el continente asiático, a través de la red social Instagram. Se pretende averiguar si existe un nexo con el movimiento artivismo feminista. El análisis de los datos se hizo a partir de una metodología basada en un análisis cuantitativo y descriptivo de contenido. Teniendo en cuenta las diferentes características que se han señalado en el estudio - género, ubicación, música e indumentaria utilizada - se puede apreciar que el Flashmob favorece el empoderamiento de la mujer en la India y el sudeste asiático.

Palabras clave: Asia, artivismo, feminismo, Flashmob, Internet.

\section{Resumo}

Artivismo feminista e Flashmob: linguagem corporal no mundo oriental

As redes sociais permitem partilhar diversos conteúdos e manter a interconectividade entre utilizadores a nível mundial. Este estudo analisa as formas de expressão e representação do fenómeno Flashmob realizado por mulheres no continente asiático, através da rede social Instagram. O objectivo é descobrir se existe uma ligação com o movimento do artivismo feminista. A análise de dados foi feita a partir de uma metodologia baseada na análise quantitativa e descritiva de conteúdo. Tendo em conta as diferentes características que são apontadas no estudo - género, localização, música e vestuário utilizados -, pode ver-se que o Flashmob favorece o empoderamento das mulheres na Índia e no Sudeste Asiático.

Palavras-chave: Ásia, artivismo, feminismo, Flashmob, Internet.

Departamento de Expresión Plástica, Musical y Dinámica, Facultad de Educación, Universidad de Murcia, Murcia, España.

Dirección postal: Facultad de Educación de la Universidad de Murcia, Campus de Espinardo, 30100 Murcia, España.

Correo electrónico: colomina@um.es 


\begin{abstract}
Feminist Artivism and Flashmob: Body Language in the Eastern World

Social networks make it possible to share diverse content and maintain interconnectivity between users at a global level. This study analyses the forms of expression and representation of the Flashmob phenomenon carried out by women on the Asian continent through the social network Instagram. The aim is to find out if there is a link with the feminist artivist movement. The data analysis was made using a methodology based on a quantitative and descriptive content analysis. Taking into account the different characteristics that are pointed out in the study - gender, location, music and clothing used - it can be seen that the Flashmob favours the empowerment of women in India and Southeast Asia.
\end{abstract}

Keywords: Asia, artivism, feminism, flashmob, Internet.

\title{
Introducción
}

Desde la mitad de los años 1980 y tras el fin de la Guerra Fría, el mundo, heredero de la corriente alternativa que se conformó en Mayo del 1968, después de una serie de protestas espontáneas, comenzó a desplegar una corriente de progreso en temáticas tan dispares como los derechos humanos, el feminismo, la ecología, la libertad sexual o la búsqueda de la igualdad económica y social entre los seres humanos (Álvarez 2018). A la vez coexistían junto a un vertiginoso avance científico, tecnológico y financiero. Todos estos ítems son diferentes caras de una misma moneda llamada globalización.

Esta rápida comunicación ha quedado validada por el vasto desarrollo de la era de Internet o lo que podemos llamar el quinto poder: «La web 2.0» (Dinucci 1999). Ya que el cuarto poder, también conocido como los mass media, según Chomsky (1997), ha sucumbido a las necesidades de los políticos y no a los de la gente, ya que el fundamento en una democracia real es que los ciudadanos puedan expresar sus ideas libremente. Así mismo, Ramonet (2004) dice que los medios de comunicación - TV, radio y prensa escrita - han sido fagocitados por grupos mediáticos que les impiden realizar la función de representar a las personas si sus intereses se ven amenazados. Por esta razón, creemos que la ciudadanía ha encontrado en Internet el medio ideal para conformar el contrapoder que les preserve del abuso institucional, empresarial o gubernamental, permitiendo la inmediatez del flujo comunicativo, siendo la web el reflejo, el doble virtual de todo lo que acontece en el mundo, la herramienta explícita de las diversas expresiones artísticas que son muestra de las inquietudes de la sociedad del siglo XXI.

Por todo lo descrito, se podría llegar a pensar que la globalización es un fenómeno que se caracteriza por la interconectividad de las personas o sus bienes alrededor del planeta, favoreciendo la aparición de distintos movimientos activistas que fusionan la réplica social con medios informáticos, tecnológicos y artísticos, como el Teatro, la Danza, Performance o el Flashmob, que destaca por su fácil e instantánea 
retrasmisión. Y es que Internet ha eliminado las fronteras territoriales en el ámbito virtual generando nuevas redes comunicativas entre grupos de personas sin importar su situación geográfica. Por tanto, en este estudio se va a investigar la construcción del artivismo feminista y el Flashmob en las coordenadas geográficas de oriente.

Para entender la esencia de lo que es el artivismo, se podría usar la cita de Gordimer (1984, 7), en la que se refiere al escritor Albert Camus cuando dice que «aceptó su condición de que la mayor responsabilidad es hacia la sociedad y no al arte». Los artivistas utilizan el arte como instrumento de protesta social a través de diversas disciplinas, pero teniendo en común que se dan en la calle, que es el paroxismo del concepto de espacio público. Por tanto podemos entender que el artivismo tiene un componente agitador o propagandístico, herencia del Agitprop de la Revolución Rusa, entendiendo que «[e]l arte agitprop desempeñó un papel importante en la Revolución, en particular en las celebraciones públicas, donde se le prestó especial atención» (Korobina 2015, 86).

Esta idea de unificar propaganda política y arte se expandió rápidamente por varios continentes. En China, por ejemplo, casi una década antes del estallido de la Segunda Guerra Mundial, con el objeto de concienciar a la población para resistir ante la ofensiva japonesa, el teatro abandona los escenarios para que los campesinos tomen conciencia del problema al que su nación se enfrenta (Tang 2016). El modelo de acercar el teatro al pueblo llevándolo a la calle ocurre unas décadas después en Brasil, en los años 1960, como propuesta de Augusto Boal (1931-2009) para concienciar al pueblo y ayudarle a cambiar su situación. Esta situación de cambio nos aboca a presagiar que «la esencia del teatro es popular. Siempre ha habido teatro popular porque siempre ha habido pueblo. Por tanto, en la visión de Boal, el teatro debería ser popular y postular como fin el cambio social» (Chesney-Lawrence 2013, 34).

Según Boal $(1989,59)$ «la poética del Teatro de los oprimidos es en esencia la poética de la liberación: el espectador ya no delega poderes en los personajes ni para que piensen ni para que actúen en su lugar». Es el propio espectador el que encarna al personaje, el que emigra a la escena y se convierte en actor, en parte activa de la función. De esta manera, vive la experiencia desde dentro y le abre el camino para motivar cambiar su entorno y su realidad social.

Durante el siglo XX ha habido corrientes artísticas que han manifestado, como Beuys (1983), que todo ser humano es un artista. El teatro, por su particularidad de usar la palabra y la acción es, además de un arte, una herramienta muy poderosa de comunicación. La simpleza de sus necesidades básicas para existir lo hace permisible y alcanzable a todo el mundo. En este sentido, Brook $(1987,5)$ considera que «puede tomar cualquier espacio vacío y llamarlo un escenario desnudo. Un hombre camina por este espacio vacío mientras otro le observa, y esto es todo lo que se necesita para realizar un acto teatral». Sin embargo, en el imaginario colectivo se relaciona teatro con escenario, telones, focos, patio de butacas, en definitiva, un teatro a la italiana. Esto para Salaün (2001) es herencia del teatro burgués y de la aristocracia, que declina los cambios estéticos promulgados por Wagner 
(1813-1883), Massenet (1842-1912) o Debussy (1862-1918) y aspira a ser representado para perpetuar su preponderancia y hacer acatar al pueblo qué es y qué no es arte. Por tanto, de ahí se podría extraer la reflexión de que las élites patriarcales, desde la antigua Grecia, son las que dictan qué es arte, qué es válido y qué no a su conveniencia para preservar ese distanciamiento social y clasista que también se produce en el ámbito artístico y afecta a todos, pero en especial a las mujeres.

Todo esto da lugar a la publicación, en 1932, del primer manifiesto del Teatro de la Crueldad de Antonin Artaud (1896-1948). Ello supone una escisión con el teatro naturalista y realista de las clases dominantes. Así, Artaud (1996) promulga sustituir el teatro basado en un texto por un teatro corporal y físico que nazca del gesto y que sea capaz de expresar. En definitiva, lo que busca es acabar con el teatro aristotélico de mimesis para dar cabida a un nuevo teatro capaz de explorar nuestra naturaleza humana a través del lenguaje corporal sustentado en el movimiento y en el gesto. Tomando en consideración las propuestas de Torrents y Castañer (2009), el cuerpo es un comunicador en sí mismo, por su carácter narrativo mediante códigos simbólicos. Así, y teniendo en cuenta la comunicación a través del cuerpo, los postulados de Artaud podrían ser uno de los referentes de la performance (Pavis 2008). La danza, junto al teatro, ha contribuido en la performance, el happening y en la comunicación mediante la práctica de la expresión corporal.

En la misma línea de avance y según los antecedentes expuestos, también se podría considerar que la performance y el happening dan paso en el siglo XXI a lo que hoy día denominamos Flashmob, es decir, acción artística y comunicativa llevada a cabo mediante el avance de la tecnología y las redes sociales (Marcillas Piquer 2013). Otra cuestión a mencionar es el espacio donde se desarrollan estas acciones, ya que, como indica Lepecki (2011), toda intervención de caracter performativo descoreografia el escenario y se amplifica en el espacio común, pues la ciudad en sí misma se rige por unas coreopolíticas que los cuerpos tienen la oportunidad de apropiarse y transformar.

\section{Flashmobs}

Redes sociales como Facebook, Twitter, Instagram o YouTube han permitido generar contenidos de toda índole, entre ellos los Flashmobs, que pueden ser compartidos de forma inmediata por otros usuarios. Esta característica de la inmediatez es además una peculiaridad intrínseca de los primeros Flashmobs. Para Chauca (2015), el Flashmob comparte semejanzas con el movimiento Fluxus por su noción renovada del arte, la falta de pretensiones, la incursión del arte en lo cotidiano o con la fusión de arte y vida del situacionismo, movimiento que, según FernándezQuesada (2000), a su vez plantea el término «psicogeografía» para estudiar la interacción entre entorno e individuo. 
Para Gore (2010), los Flashmobs surgieron en el año 2003 con la denominada «Love rug», cuando un grupo de «Hipsters» (Marcillas Piquer 2013), desconocidos entre ellos, se reunió en el centro comercial de Macy's, en Nueva York, en torno a una alfombra roja de 10.000 dólares durante unos minutos y se dispersaron después ante la perplejidad del empleado. Se habían organizado mediante Internet y el uso del correo electrónico. Esta acción supuso, inconscientemente para los implicados, una especie de broma o juego que conseguía acaparar la atención del espectador y que se expandiría por vía telemática a las grandes urbes del planeta. La elección de este producto no fue realizada al azar. Este tipo de alfombra se hizo famosa en los años 1970 por su eslogan publicitario The Love Rug strokes your bodies as you make love (La alfombra del amor acaricia vuestros cuerpos mientras haces el amor). En el cuerpo del propio anuncio se explica que la alfombra «[is] almost like having another lover there with the two of you» [Es casi como tener otro amante ahí con vosotros dos], lo que supuso un guiño a la liberación sexual comenzada a finales de la década de los 1960.

En opinión de Molnár (2014), existen varios tipos bien diferenciados de Flashmob. El primero de ellos es el flashmob atomizado. Según el diccionario de Oxford, atomizar significa dividir algo en pequeñas unidades. Por tanto, entendemos que un grupo de personas que va a realizar una acción está compuesto por individuos diferenciados que no se conocen entre ellos. Y el autor explica que, para los puristas, es la forma originaria de realizar correctamente una Flashmob, donde el emplazamiento de ejecución son tiendas o espacios ubicados dentro de centros comerciales. La clave de esta catalogación es que el conjunto de personas que asisten a realizar la Flashmob no se conozcan ni interactúen entre ellos. Otro ejemplo para comprender el término ocurre cuando los integrantes acuden a bailar o escuchar una canción que puede ser la misma o diferente en sus smartphones y el baile no está coreografiado.

El segundo tipo es el flashmob interactivo, donde los integrantes interactúan entre sí. Existen unas reglas del juego que todos los participantes conocen, ya sea una pelea de almohadas o la existencia de un líder al que todos siguen e imitan. Estos Flashmob no tienen un carácter político, pero son un llamamiento para el uso y disfrute de los espacios públicos que cada vez más son arrebatados a la ciudadanía durante su tiempo de ocio con la premisa de consumir para poder disfrutar de estos espacios. Por tanto, existe un carácter legitimador en este tipo de acciones, ya sean artísticas o políticas, de reivindicar la tenencia de lugares para la comunicación y expresión, diferenciando espacios gratuitos de los de pago. Esto presenta una democratización de la participación, ya que, por otro lado, precisamente las grandes corporaciones se valen de alquilar partes del espacio común para publicitar sus productos, calando con mayor fuerza en la ciudadanía.

El tercer tipo es el flashmob performativo, en el cual se revive el espíritu de la performance artística y es concebido por una o varias personas con un objetivo artístico y unas pautas bien definidas. Podemos decir que tiene conexión con el land art, 
movimiento artístico que utiliza el entorno como material plástico (Sartoretti 2014), pero en vez de usar objetos que estimulan o se mimetizan con el entorno, son las propias personas las que se apropian del espacio y lo incentivan realizando algún tipo de acción, como cuando el puente peatonal de Brooklyn fue tomado por tres mil personas vestidas de blanco bajo la dirección de un grupo artístico llamado The Danger. Por tanto, a diferencia de las anteriores, estas tienen un marcado eje vertical o piramidal.

La cuarta tipología de los Flashmob engloba a los que tienen un alto contenido político y reivindicativo, que surgen de un movimiento llamado a su vez smart flashmob donde se realizan protestas de índole política, participando en una acción coordinada. No tienen por qué estar realizando un acto ilegal, pero sí tienen un alto contenido de demanda o queja por alguna reivindicación política que vaya en contra de los principios de los organizadores.

Finalmente, el quinto y último tipo de Flashmob es el que tiene fines publicitarios de alguna marca o entidad. Éste usa el reclamo de estas acciones para promocionar algún producto específico de forma que produzca un impacto original y atrayente entre los consumidores más jóvenes. Los consumidores, en este caso, pueden verse identificados por la marca, la música y toda la parafernalia que la acción elegida conlleva.

Por su parte, Chauca (2012) incide en que todas las categorías son conocidas por el nombre de Flashmobs sin que haya distinción real entre ellas, aunque las dividiría en dos grupos. Por un lado, están los Flashmobs de índole absurda, donde se realiza una acción por el hecho de hacer una acción con un componente lúdico (guerra de almohadas, ataque zombi y otros ejemplos similares). Por otro lado, se encuentra el llamado Smartmob, caracterizado por un tono intelectual y mucho más comprometido socialmente.

Un fenómeno y categorización espontánea que se ha observado al indagar sobre el Flashmob en la búsqueda en Internet es la forma de escribirlo. Por una parte, podemos encontrarlo escrito como «Flashmob» pero también es común encontrarlo escrito como «Flashmop». Esta particularidad, al principio, parecía deberse a una confusión por el uso del alfabeto latino por parte de personas no occidentales, pero no es así. La diferenciación se basa en que «Flashmop» es un término que deriva de «mop» en inglés («mopa, fregona») y es usado cuando existen protestas dentro del sector servicios (Prowse, Lopes \& Fells 2017). Y de este hecho también se hace eco cuando un grupo de trabajadores de los almacenes Tesco en Inglaterra entonaron canciones, mientras coreografiaban con sus utensilios de limpieza en señal de protesta por sus bajos salarios ${ }^{1}$. Por tanto, podemos dilucidar que se conoce por Flashmop cuando se realiza una protesta dentro del sector servi-

Rob Parsons, «"Flashmop" protest over Tesco cleaners' pay.» Evening Standard, 21 de junio del 2011. Disponible en https://www.standard.co.uk/news/flashmop-protest-over-tesco-cleaners-pay6413480.html [Consultado 27 de abril de 2020]. 
cios o cuando realizamos una acción que tiene que ver con prestar un servicio a la comunidad dentro de este ámbito, como puede ser limpiar, fregar, ordenar. Sin embargo, bajo esta etiqueta o hashtag se incluyen videos en las redes sociales que pertenecen a los Flashmobs.

\section{Artivismo, feminismo y expresiones del Flashmob en el mundo oriental}

Una vez aclarados los diferentes tipos de Flashmob, podemos apreciar la aparición de movimientos cómo el artivismo feminista que cada vez con más fuerza está consiguiendo logros a través del Flashmob y sus reivindicaciones.

¿Qué diferencia al artivista del activista? El artivismo difiere del activismo en cuanto que ornamenta con originalidad y dota de estética el discurso político. Lo adorna haciéndolo más cercano y más popular a la sociedad. En este sentido, Delgado (2013) nos hace ver que, en general, el artivismo lo que pretende es hacer reflexionar desde un enfoque creativo e inspirar a otros a unirse y participar de la acción; aunque el artivismo también es un movimiento que ha surgido de la clase media occidental con una premisa sobreprotectora y paternalista hacia quienes no siempre piden ser defendidos.

Aproximadamente en la década de 1960 surge el arte feminista hecho por mujeres y de temática política sobre el universo de la mujer, sus inquietudes y su participación en la sociedad. Como puntualiza Baldini (2017), es un arte realizado por y para mujeres occidentales, blancas, liberales, de clase media; un discurso hegemónico donde no se tiene en cuenta la problemática o la realidad opresiva de otras mujeres pertenecientes a esferas sociales más bajas o a otros grupos religiosos o étnicos. En cierta forma, se ha hecho patente la supremacía del feminismo occidental sobre el oriental y más tarde se ha ido tomando conciencia de cómo afecta, además, el racismo sobre las mujeres que lo padecen. Esto hizo que surgieran, por ejemplo, grupos feministas de mujeres de otras etnias, razas y religiones. Por tanto, este estudio pone en valor los Flashmobs realizados por mujeres orientales para averiguar si esta es una herramienta adecuada para el artivismo feminista.

En la actualidad, las religiones mayoritarias de la India y el sudeste asiático son el hinduismo, el islam y el budismo. En la India conviven hinduistas y musulmanes, siendo mayoría un $80 \%$ los primeros, al contrario que en Indonesia o Malasia, donde el porcentaje musulmán es mayor (Gil Pérez 2017). En Tailandia la religión preponderante es el budismo, aunque en el sur del país el islam tiene mayor número de adeptos por su proximidad fronteriza con Malasia (Sittichai \& Smith 2018).

La globalización ha hecho que el avance de la tecnología haya llegado a todos los puntos del planeta. Resulta normal ver a mujeres veladas caminando con sus smartphones por las calles, haciendo uso de las aplicaciones de la telefonía móvil no solo en occidente, sino también en cualquier país asiático. Dentro del ciberislam 
denominado por Enterría (2009), la comunidad musulmana utiliza Internet para practicar su credo y comprar artículos para seguir los preceptos de su religión. Fuera del ámbito del culto religioso, las mujeres hinduistas, musulmanas y budistas utilizan las redes sociales, las App e Internet para contactar entre ellas y darse a conocer fuera de su entorno más próximo.

Actualmente en Asia, lo cibercultural está muy presente en la sociedad y el artivismo que se lleva a cabo, cada vez con más presencia, «cobra fuerza y sirve para empoderar a la mujer artista. Performances, ilustraciones, caricaturas, instalaciones, canciones y hasta campañas de contra-publicidad conforman el artivismo feminista actual» (Maldonado 2019, 65). Precisamente fue el movimiento feminista quien se rebela contra el consumismo focalizado en la publicidad de productos para la mujer, como maquillaje, ropa, artefactos para la limpieza del hogar, no comprándolos (Douglas 1994).

La contra-publicidad o el culture jamming es una táctica contra el consumo descontrolado que fomenta el capitalismo. A través de la parodia se generan nuevos significados que buscan repensar el mensaje inicial: «El logro es valerse de los mismos códigos que conforman el discurso publicitario, hablar con el mismo lenguaje, utilizar el mismo horizonte de expectativas de la empresa para vomitar un mensaje revelador y contestatario» (González 2017, 58). Ejemplo de esto son las artistas Barbara Kruger, con la obra I shop therefore I am², o la artista Jenny Holzer y su instalación en fachadas de edificios titulada Protect me from what I want ${ }^{3}$, donde ambas reflexionan sobre el consumismo y el ámbito público (Muñoz-Muñoz y Barbaño 2014). Esta tipología artística y reivindicativa ya ha tomado su espacio en el mundo oriental. De hecho, el diario The Indian Express (2017) publicó la noticia de un grupo de chicas estudiantes de la universidad de Kerala que habían sido insultadas y trolleadas en las redes sociales por tomar parte en una flashmob que alertaba del peligro del SIDA, utilizando el hiyab ${ }^{4}$.

Por todo ello, el principal objetivo de estudio de este trabajo es analizar al Flashmob como forma de expresión corporal en las redes sociales y valorar qué repercusión puede tener dentro del movimiento artivista y del feminismo en países asiáticos. Ante la voluminosa información que existe sobre estos movimientos en occidente, se considera necesario el intentar llegar a conocer la realidad de las mujeres orientales y su implicación como internautas en relación a sus derechos y libertades establecidas en los roles de género a través de estos géneros de comunicación.

Véase https: / / www.moma.org/ collection/works / 64897

Véase https: / / www.tate.org.uk/ art/ artists/jenny-holzer-1307/5-ways-jenny-holzer-brought-art«Flash mob in Kerala protests "insult to students in hijab"», Indian Express, 10 de diciembre de 2017. Disponible en https: / / indianexpress.com/article/india/ kerala-flash-mob-protests-insultto-students-in-hijab-4975917/ 


\section{Metodología}

El objeto de estudio son videos de la red social Instagram subidos en un período de tiempo comprendido entre agosto y noviembre de 2019. Los audiovisuales propuestos como objeto de estudio han sido seleccionados por medio de palabras clave o etiquetas, utilizando el hashtag \# instaflashmob, ya que en Instagram el hashtag \#flashmob por sí mismo o acompañado de la etiqueta de una nacionalidad concreta no producía resultados de búsqueda. Puntualizar que con el hashtag \# danceflashmob también es posible encontrar resultados, aunque solo existen 5.000 publicaciones frente a los $47.2 \mathrm{k}$ publicaciones del primero.

No se ha ampliado el estudio a otras webs como YouTube por la falta de datos contenidos. Según Pérez-Rufi (2012, 50), «desde que Google adquirió YouTube dejaron de ser públicos los datos estadísticos acerca del volumen de visionados, tráfico de datos, número de usuarios», lo que impide en la actualidad conocer el cómputo global de vídeos que cumplan las características exigidas.

Dado que no existen casi estudios que reflejen la participación de la mujer asiática en el Flashmob, se ha considerado como más adecuada la metodología basada en un análisis cuantitativo y descriptivo de contenido mediante la recopilación de información a través de imágenes, permitiendo observar de modo exhaustivo las distintas variables del tipo naturaleza geográfica, vídeos en los que sólo aparecen mujeres, conjuntos integrados por hombres y mujeres, diferentes espacios donde se graban las imágenes, la tipología musical y el tipo de vestimenta, como se muestra en la Tabla 1.

\section{Datos}

Tras la búsqueda se identificaron en Instagram 26.387 publicaciones, de las cuales se han elegido cronológicamente 300 vídeos por su pertenencia exclusiva a países asiáticos.

Tabla 1

Relación numérica y de porcentajes de vídeos analizados con la temática Flashmob

\begin{tabular}{|c|c|c|c|c|c|c|c|c|c|}
\hline Países & 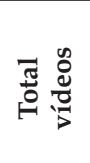 & 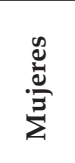 & 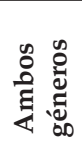 & 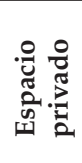 & 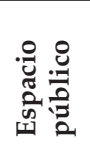 & 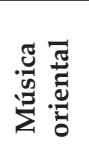 & 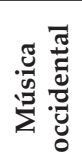 & 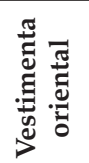 & 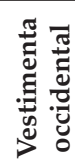 \\
\hline India & 150 & $\begin{array}{r}33 \\
22 \%\end{array}$ & $\begin{array}{l}117 \\
78 \%\end{array}$ & $\begin{array}{c}23 \\
15 \%\end{array}$ & $\begin{array}{l}127 \\
85 \%\end{array}$ & $\begin{array}{c}89 \\
59 \%\end{array}$ & $\begin{array}{c}61 \\
41 \%\end{array}$ & $\begin{array}{l}128 \\
85 \%\end{array}$ & $\begin{array}{c}22 \\
15 \%\end{array}$ \\
\hline
\end{tabular}

(continua na página seguinte) 


\begin{tabular}{|c|c|c|c|c|c|c|c|c|c|}
\hline Países & 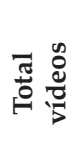 & 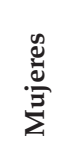 & 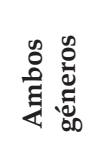 & 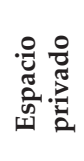 & 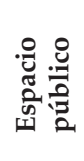 & 恚 & 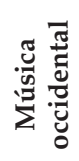 & 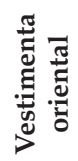 & 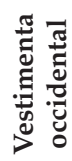 \\
\hline Indonesia & 103 & $\begin{array}{c}62 \\
60 \%\end{array}$ & $\begin{array}{c}41 \\
40 \% \%\end{array}$ & $\begin{array}{c}2 \\
2 \%\end{array}$ & $\begin{array}{l}101 \\
98 \%\end{array}$ & $\begin{array}{c}73 \\
71 \%\end{array}$ & $\begin{array}{c}30 \\
29 \%\end{array}$ & $\begin{array}{r}75 \\
72 \%\end{array}$ & $\begin{array}{c}28 \\
28 \%\end{array}$ \\
\hline Malasia & 29 & $\begin{array}{c}11 \\
38 \%\end{array}$ & $\begin{array}{c}18 \\
62 \%\end{array}$ & $\begin{array}{c}4 \\
14 \%\end{array}$ & $\begin{array}{c}25 \\
86 \%\end{array}$ & $\begin{array}{c}12 \\
41 \%\end{array}$ & $\begin{array}{c}17 \\
59 \%\end{array}$ & $\begin{array}{r}22 \\
75 \%\end{array}$ & $\begin{array}{c}7 \\
25 \%\end{array}$ \\
\hline Tailandia & 18 & $\begin{array}{r}12 \\
67 \%\end{array}$ & $\begin{array}{c}6 \\
33 \%\end{array}$ & $\begin{array}{c}0 \\
0 \%\end{array}$ & $\begin{array}{c}18 \\
100 \%\end{array}$ & $\begin{array}{c}2 \\
11 \%\end{array}$ & $\begin{array}{c}16 \\
89 \%\end{array}$ & $\begin{array}{c}3 \\
17\end{array}$ & $\begin{array}{r}15 \\
83 \%\end{array}$ \\
\hline Total & 300 & $\begin{array}{l}118 \\
39 \%\end{array}$ & $\begin{array}{l}182 \\
61 \%\end{array}$ & $\begin{array}{c}29 \\
10 \%\end{array}$ & $\begin{array}{l}271 \\
90 \%\end{array}$ & $\begin{array}{l}176 \\
59 \%\end{array}$ & $\begin{array}{l}124 \\
41 \%\end{array}$ & $\begin{array}{l}228 \\
76 \%\end{array}$ & $\begin{array}{c}72 \\
24 \%\end{array}$ \\
\hline
\end{tabular}

Fuente: Elaboración propia.

En términos globales son numerosas las propuestas en las que aparecen hombres y mujeres de forma conjunta $(61 \%)$ realizando propuestas de intervención, en contraste con las apariciones en las que solamente aparecen mujeres (39\%). Estos datos vienen a significar que la participación de las mujeres en grupos autónomos sin intervención masculina es mayoritaria en Indonesia (60\%) y Tailandia (67\%), y la participación más baja sucede en India, con tan solo un 22\% de la muestra seleccionada. Por tanto, la mujer india tiene menor autonomía que la tailandesa en cuanto a la gestión participativa en el espacio público. Únicamente un sector reducido de las mujeres indias tiene mayores privilegios que la mayoría (Gangoli 2016) debido al sistema de castas que no existe en Tailandia o en otros países asiáticos.

En lo referente a los espacios en donde tienen lugar las incursiones de los Flashmobs, se ha definido como espacios públicos calles, plazas, jardines, centros comerciales y oficinas, siendo estos los más utilizados (90\%) frente al espacio privado como el propio hogar (10\%). En otro sentido, también se ha podido observar, sobre todo en la India, que muchas de las coreografías han sido realizadas para festejar algún tipo de celebración como bodas, cumpleaños o festividades similares.

En cuanto a la utilización de la música que se escucha mientras tiene lugar el Flashmob, es notoria la presencia de música occidental (41\%) incluyendo temas de máxima actualidad a nivel internacional de intérpretes estadounidenses como Shakira o Justin Bieber, por citar a algunos. Aunque la música oriental tiene un porcentaje más alto (59\%), sobre todo en países como India e Indonesia, al contrario que en Malasia y Tailandia, donde ocupa un porcentaje relativamente más bajo. En las coreografías de India particularmente e Indonesia, está muy presente el influjo que tiene el cine de Bollywood con su particular riqueza musical que abarca desde canciones tradicionales a sonidos relacionados con la música más pop. 
Otro aspecto a tener en cuenta en las propuestas analizadas es el uso de la vestimenta. Del total de la muestra, es destacable la presencia de mujeres ataviadas con elementos característicos de su cultura. El sari, el salwar y el kurti es utilizado por el $85 \%$ de las mujeres de la India frente a un 15\% que vestía de forma occidental. Se puede precisar la existencia de mujeres bailando con velo y kebaya en países de creencias islamistas como Malasia e Indonesia, con un total del 75\% y $72 \%$ respectivamente. Solo en Tailandia el $83 \%$ no utiliza velo ni ropa tradicional típica de su cultura, sino que su vestimenta es de tipo occidental. De ahí que, en el total de las representaciones visuales en las que puede verse a mujeres bailando, un $76 \%$ se decanta por una indumentaria oriental. Sin embargo, contrasta notoriamente que, frente a los porcentajes establecidos en las mujeres, el $82 \%$ de los hombres que aparecen en los vídeos vestían con ropa occidental.

Figura 1

Cómputo total de las variables observadas

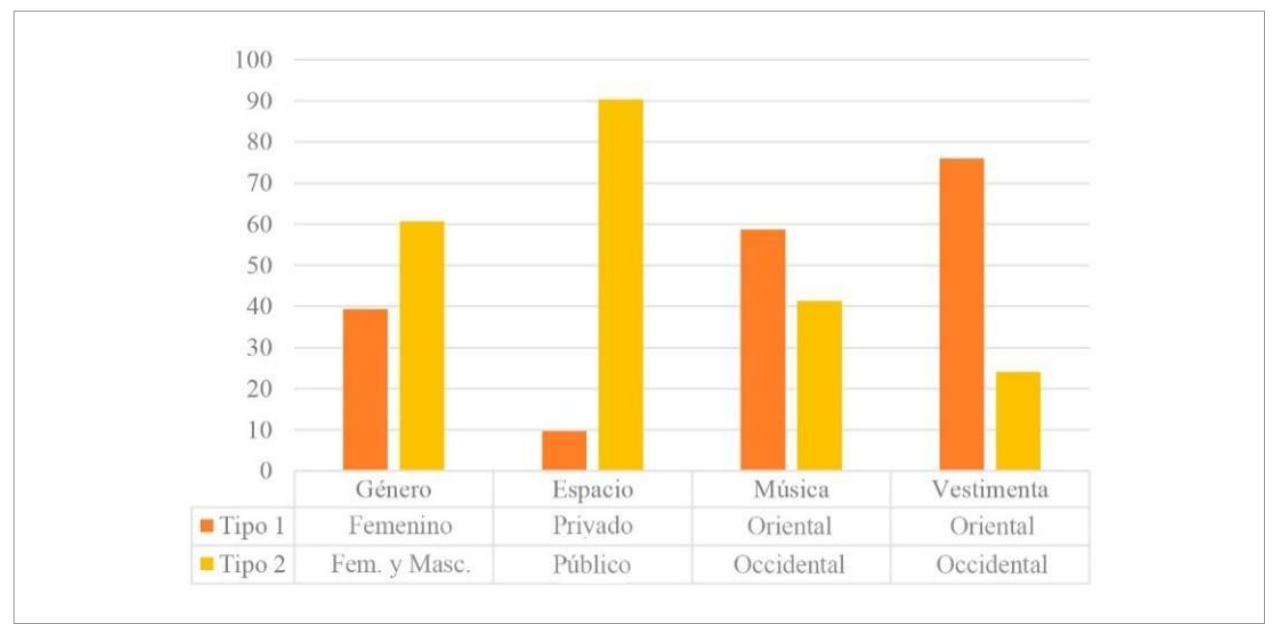

Fuente: Elaboración propia.

\section{Discusión y conclusiones}

En el presente estudio se ha detectado, al introducir el vocablo Flashmob en la red social Instagram, la existencia de numerosos vídeos subidos por mujeres hindúes, musulmanas y budistas, sobre todo de India, Indonesia, Malasia y Tailandia. Hay que tener en cuenta que países como China y otros de medio oriente tienen restringido el acceso a webs como Google, Facebook, Twitter, YouTube, Wikipedia o Instagram (Miller 2018). En ellos se observa cómo estas mujeres bailan y realizan coreografías musicales mayormente en espacios públicos como centros comercia- 
les, calles, plazas o parques, emulando las coreografías y los Flashmob que se realizan en occidente, sin que pueda apreciarse en ello signo alguno de vulnerabilidad o pudor ante la forma de hacerse presente en los espacios públicos señalados.

Para Chhachhi (1989), el surgimiento en Asia del fundamentalismo religioso junto a la falta de desarrollo industrial y de democracias reales ha ralentizado el empoderamiento de la mujer en la India y en el sudeste asiático, y las enclaustra en castas, en donde resulta casi imposible dejar que la mujer se manifieste de manera libre y realista con la situación y el momento que vive. Diversos movimientos sociales han protestado y han logrado que los gobiernos legislen para cuidar de las mujeres, pero todavía éstas son sometidas a agresiones físicas tanto en el propio hogar como en la calle, vulnerando todos los derechos que tienen como personas. Por todo esto, en los países musulmanes durante las últimas décadas ha ido creciendo entre algunos colectivos femeninos un espíritu revolucionario de lucha por garantizar los derechos de las mujeres y su acceso a disfrutar de la vida pública en igualdad con los varones (Carvalho-Pinto \& Fleschenberg 2019).

En India, por ejemplo, no existe la obligación explicita de cubrirse la cabeza con un velo, pero sí está arraigado como prenda femenina, y no está bien visto por los sectores más conservadores que una mujer acceda sola a espacios públicos si no es en compañía de un hombre (Sharma 1978). En muchos puntos de la geografía asiática, la ideología reaccionaria hace un llamamiento para que las mujeres usen el velo si salen de casa por motivos laborales o si quieren acceder a los espacios públicos en nombre de tradiciones ancestrales. La forma en la que éstas mujeres visten es un fiel reflejo que queda presente en muchos de los vídeos analizados. Sin embargo, es común observar a los hombres de estos mismos países usando ropa occidental sin que les resulte tan importante la tradición o la cultura por la que las mujeres deben de llevar dichas prendas de vestir alejándose por completo de la vestimenta occidental. Para ellos no existe la imperiosa obligación de vestir con sus prendas tradicionales. Por tanto, la mujer es víctima por el hecho de haber nacido mujer y sus derechos son mermados y dirigidos por el patriarcado imperante. Su visibilidad en los espacios públicos debe pasar lo más inadvertida posible, ya que «las mujeres no tienen valor sin sus velos; ponerse el velo es la única forma en que las mujeres pueden alcanzar valores sociales y morales» (Tami 2017, 137).

El reflejo que las redes sociales permite mostrar a través de las distintas manifestaciones del arte pone en evidencia que «el feminismo musulmán se erige sobre el espíritu igualitario del islam oponiéndose a las lecturas, interpretaciones y manipulaciones patriarcales del Libro Sagrado» (Valcárcel \& Sánchez 2014, 59), postulándose por la necesidad de querer pertenecer a una vida más igualitaria y visible ante el mundo, en donde la comunicación y el uso de los lenguajes comunicativos artísticos no puede quedar estancado y mucho menos aislado (DunbarHester 2009). Es decir, ver a las mujeres musulmanas realizando flashmobs ataviadas con velo no invalida la reivindicación feminista. 
En otro estudio, Meso Ayerdi (2004) advierte que el uso de las redes sociales e Internet para conectar individuos y para que estos realicen una actividad conjunta en los espacios públicos es una forma novedosa de fomentar la comunicación humana. Con ello, no se debe descuidar que el objetivo del artivismo ha de contener una intención, un mensaje o una propuesta clara, ya sea de índole artística, social o política. Por tanto, un Flashmob artivista ha de ser enriquecido dotándolo de concepto, para que las acciones no generen contenidos carentes de sentido y que a largo plazo sean más que eventualidades. Por tanto, al artivista occidental, el uso del Flashmob en países subdesarrollados le puede parecer, desde la óptica supremacista, bastante naíf y carente de una carga artística o ideológica sustancial porque el análisis de contenido presenta en algunas ocasiones la carencia de un propósito concreto y reivindicativo por y para las mujeres. Sin embargo, esto es una visión equivocada, ya que el Flashmob es una herramienta que fortalece el discurso corporal femenino porque la acción gestual es el medio de comunicación más vital que el ser humano conoce.

El apelativo del Flashmob en los videos visionados es utilizado con la única finalidad de subir a las redes sociales un vídeo con una coreografía. Hecho que podría catalogarse de inocente, meramente festivo o lúdico, sin el componente social o político que a simple vista parece requerir el artivismo feminista. Y es cierto, aunque en algunos casos pueda darse de forma desvirtuada sin el componente estrictamente social o político que requiere el artivismo más purista, al menos, está logrando que las mujeres tomen los espacios públicos para hacerse visibles, divertirse y, sobre todo, enviar esa información al exterior. Como destaca Díaz Gandasegui (2011), el gran logro de las redes sociales es la capacidad de generar una comunidad y traspasar las fronteras de lo físico con el fin de lanzar mensajes claros y comprensibles que surtan efecto en el receptor. Solo de esta forma puede llegar a conformarse una comunidad virtual y un intercambio de información complementaria que otorga poder a quien lo usa (Rheingold 2003).

Por otra parte, no debemos olvidar que el artivismo puede ser considerado como la ornamentación estética de una ideología, que de algún modo deja implícito un mensaje con un alto contenido reivindicativo. En Asia ya ha empezado a producirse un pequeño paso, en donde las mujeres pueden salir a la calle a bailar y grabar sus coreografías para posteriormente subirlas a la red y dejarlas en el espacio virtual como una bandera. Esta acción, que puede parecer una pequeña revolución inocente, es una gran intervención que va dejando huella y constituyendo un hito: el de que estas mujeres se sientan orgullosas de mostrar sus cuerpos bailando y contoneándose en espacios públicos, los espacios que por derecho han de pertenecer en igualdad a las personas y no únicamente a los hombres. Hacer una revolución no siempre ha de ser por la fuerza y por la línea más dura o radical, precisamente la descolonización de la India liderada por Gandhi es un claro ejemplo de lo contrario. Por ello, es necesario considerar que las mujeres asiáticas han comenzado, aunque a la sociedad occidental le pueda parecer inge- 
nuo o desvirtuado, una forma no formalmente artivista, pero sí de empoderamiento y expresión más allá de la palabra, de manifiestos y textos, basada en el gesto, la danza y el movimiento corporal. Al fin y al cabo, las acciones tienen más fuerza que las palabras.

\section{Referencias}

Álvarez, Lucía. 2018. «Uno, dos, tres... muchos 68: Hacia una memoria descentrada del mayo francés.» Nueva Sociedad 276: 172-180. Disponible en https://nuso.org/articulo/ uno-dos-tres-muchos-68 / [Consultado 16 de agosto de 2020].

Artaud, Antonin. 1996. El teatro y su doble. Barcelona: Pocket Edhasa.

Baldini, Vanessa. 2017. Articulate: Feminist Text-Art from the 1990s-Today: Four Case Studies. New York: ProQuest Dissertations Publishing.

Beuys, Joseph. 1983. «Jeder Mensch ist ein Künstler.» Praktische Theologie 18: 5-12. DOI: https: / / doi.org/10.14315/prth-1983-3-403

Boal, Augusto. 1989. Teatro del oprimido 1. Mexico: Nueva Imagen.

Brook, Peter. 1987. El espacio vacío. La Habana, Cuba: Editorial Pueblo y Educación.

Carvalho-Pinto, Vânia, y Andrea Fleschenberg. 2019. "As múltiplas inter-relações entre questões de género e a aquisição de status na arena internacional.» ex aequo 40: 9-14. DOI: https: / / doi.org/10.22355/ exaequo.2019.40.01

Chauca, Pilar. 2012. «El Flashmob: antecedentes y perspectivas como práctica escénica comprometida sociopolíticamente.» ASRI: Arte y sociedad. Revista de investigación 1. Disponible en https: / / www.eumed.net/rev/ ays / 1 / pc.html [Consultado 02 de julio de 2020].

Chauca, Pilar. 2015. «El Flashmob, respuestas artísticas hoy.» Revista de Estudios Globales y Arte Contemporáneo 3(1): 322-337. DOI: https: / / doi.org/10.1344/ regac2015.1.13

Chesney-Lawrence, Luis. 2013. «Las teorías dramáticas de Augusto Boal.» Teatro: Revista de Estudios Culturales/A Journal of Cultural Studies 26: 24-55. Disponible en https: / / digitalcommons.conncoll.edu/teatro/vol26/iss26/2/ [Consultado 19 de agosto de 2020].

Chhachhi, Amrita. 1989. «The State, Religious Fundamentalism and Women: Trends in South Asia.» Economic and Political Weekly 24: 567-578.

Chomsky, Noam. 1997. Media Control. The Spectacular Achievements of Propaganda. The Open Media Pamphlet Series. New York: Seven Stories Press.

Delgado, Manuel. 2013. «Artivismo y pospolítica. Sobre la estetización de las luchas sociales en contextos urbanos.» Quaderns-e de l'Institut Català d'Antropologia 18(2): 68-80. Disponible en https://www.raco.cat/index.php/QuadernseICA/article/view/274290 [Consultado 11 de julio de 2020].

Díaz Gandasegui, Vicente. 2011. «Mitos y realidades de las redes sociales. Información y comunicación en la Sociedad de la Información.» Prisma Social 6: 1-26. Disponible en https: / / www.isdfundacion.org / publicaciones / revista / numeros / 6 / secciones / tematica / 07-mitos-realidades-redes-sociales.html [Consultado 06 de mayo de 2020].

Dinucci, Darcy. 1999. «Fragmented Future.» PRINT Magazine. Disponible en http: / / darcyd. com/fragmented_future.pdf [Consultado 24 de agosto de 2019].

Douglas, Susan. 1994. Where the Girls Are: Growing up Female with the Mass Media. New York: Times Book.

Dunbar-Hester, Christina. 2009. «"Free the spectrum!" Activist encounters with old and new media technology.» New Media \& Society 11(1-2): 221-240. DOI: https: / / doi.org/10.11 $77 / 1461444808100160$ 
Enterría, Arturo. 2009. «El Islam en Internet: El concepto de ciberislam.» Revista de Estudios Internacionales Mediterráneos 8: 1-10. Disponible en https://revistas.uam.es/reim/ article/view / 819 [Consultado 04 de julio de 2020].

Fernández-Quesada, Blanca. 2000. «Nuevos lugares de intención: intervenciones artísticas en el espacio urbano como una de las salidas a los circuitos convencionales: Estados Unidos 1965-1995.» Tesis doctoral, Universidad Complutense de Madrid.

Gangoli, Geetanjali. 2016. Indian Feminisms: Law, Patriarchies and Violence in India. New York: Routledge.

Gil Pérez, Javier. 2017. «La India, a setenta años de la independencia.» Razón y fe 276(1427): 137-147. Disponible en https://revistas.comillas.edu/index.php/razonyfe/article/ view / 9315 [Consultado 09 de junio de 2020].

González Marí, Ximo. 2017. «Contrapublicidad en la ciudad del consumo. Subvirtiendo el sentido en la piel del asfalto.» Kult-ur 4(8): 43-72. DOI: https: / / doi.org/10.6035/Kultur.2017.4.8.1

Gordimer, Nadine. 1984. »The Essential Gesture: Writers and Responsibility.» The Tanner Lectures on Human Values, Delivered at the University of Michigan. Disponible en https:/ / tannerlectures.utah.edu/_resources/documents / a-to-z/g/gordimer85.pdf [Consultado 21 de octubre de 2019].

Gore, Georgiana. 2010. «Flash Mob Dance and the Territorialisation of Urban Movement.» Anthropological Notebooks 16(3): 125-131. Disponible en http: / / www.drustvo-antropologov.si / AN/PDF / 2010_3/Anthropological_Notebooks_XVI_3_Gore.pdf [Consultado 12 de agosto de 2020].

Korobina, Irina. 2015. «Building a New World. The Soviet Architectural Avant-Garde.» Texts 3: 83-94. Disponible en https:/ / art-texts.com/wp-content/uploads / 2019/10/2015_3_ web-1.pdf\#page=83 [Consultado 06 de mayo de 2020].

Maldonado, María Rosario. 2019. «Artivismo para combatir la injusticia social. El trinomio arte-activismo-comunicación se convierte en aliado del feminismo.» Aularia: Revista Digital de Comunicación 8: 65-72. Disponible en https://www.aularia.org/lib/pdf/ Aularia_15.pdf [Consultado 22 de mayo de 2020].

Marcillas Piquer, Isabel. 2013. «Flashmobs: la transformación de la dramaturgia a través de las redes sociales.» En Teatro e Internet en la primera década del siglo XXI, editado por José Romera Castillo, 235-249. Madrid: Editorial Verbum.

Meso Ayerdi, Koldobika. 2004. «Teléfonos móviles e Internet, nuevas tecnologías para construir un espacio público contrainformativo. El ejemplo de los flash mob en la tarde del 13M.» Revista Latina de Comunicación Social 7: 1-6. Disponible en http:/ / www.revistalatinacs.org/20041558meso.htm [Consultado 10 de junio de 2020].

Miller, María Emilia. 2018. «Acceso en Internet y libertad de expresión en línea: ¿Derechos humanos?» Revista de Derecho Público 53: 77-83. DOI: https:/ / doi.org/10.31672/53.5

Molnár, Virág. 2014. «Reframing Public Space Through Digital Mobilization: Flash Mobs and Contemporary Urban Youth Culture.» Space and Culture 17(1): 43-58. DOI: https:/ / doi.org/10.1177/1206331212452368

Muñoz - Muñoz, Ana, y María Barbaño González-Moreno. 2014. «La mujer como objeto (modelo) y sujeto (fotógrafa) en la fotografía.» Arte, Individuo y Sociedad 26(1): 39-54. DOI: https: / / doi.org/10.5209/rev_ARIS.2014.v26.n1.40581

Pavis, Patrice. 2008. «Puesta en escena, performance: ¿cuál es la diferencia?» Telondefondo: Revista de Teoría y Crítica Teatral 7: 1-37.

Pérez Rufi, José Patricio. 2012. «La actualidad en YouTube: claves de los videos más vistos durante un mes.» Global Media Journal 9(17): 44-62. Disponible en https:/ /www. redalyc.org/articulo.oa?id=68723565004 [Consultado 15 de abril de 2020]. 
Prowse, Peter, Ana Lopes, \& Ray Fells. 2017. «Community and union-led living wage campaigns.» Employee Relations 39(6): 825-839. DOI: https: / / doi.org/10.1108 / ER-03-20170053

Ramonet, Ignacio. 2004.«Información, comunicación y globalización. El quinto poder.» Chasqui. Revista Latinoamericana de Comunicación 88: 26-31.

Rheingold, Howard. 2003. «Smart mobs. Les communautés intelligentes mobiles comment reconnaître le futur quand il vous tombe dessus?» Sociétés 1(79): 75-87. DOI: https: / / doi.org/10.3917/ soc. 079.0075

Salaün, Serge. 2001. «La sociabilidad en el teatro (1890-1915).» Historia Social 41: 127-146. Disponible en http:/ / www.jstor.org/ stable/40340789

Sartoretti, Irene. 2014. «Arte e ambiente: l'esperienza della land art.» Micron 27: 24-29. Disponible en https://www.arpa.umbria.it/resources/docs/micron\%2027/micron-2724.pdf [Consultado 06 de mayo de 2020].

Sharma, Ursula. 1978. «Women and Their Affines: The Veil as a Symbol of Separation.» Man 13(2): 218-233. DOI: https: / / doi.org/10.2307/ 2800246

Sittichai, Ruthaychonnee, \& Peter K Smith. 2018. «Bullying and Cyberbullying in Thailand: Coping Strategies and Relation to Age, Gender, Religion and Victim Status.» NAER: Journal of New Approaches in Educational Research 7(1): 24-30. DOI: https://doi. org/10.7821/naer.2018.1.254

Tami, Rosmah. 2017. «The Representation of the Islamic Veil in indonesian Contemporary Art: A Feminist Poststructuralist Approach.» English and Literature Journal 1(1): 126-145. Disponible en https: / / core.ac.uk/download/pdf/234749953.pdf [Consultado 23 de abril de 2020].

Tang, Xiaobing. 2016. «Street Theater and Subject Formation in Wartime China: Toward a New Form of Public Art.» Cross-Currents: East Asian History and Culture Review 5(1): 85-114. DOI: https:/ / doi.org/10.1353/ach.2016.0004

Torrents, Carlota, y Marta Castañer. 2009. «Las consignas en la expresión corporal: una puerta abierta para la creatividad y la creación coreográfica.» Tándem. Didáctica de la Educación Física 30: 111-121. Disponible en http: / / www.observesport.com/desktop/ images / docu/xri108fq.pdf [Consultado 29 de junio de 2020].

Valcárcel, Mayra Soledad, y Nazareth Sánchez. 2014. «Católicas y musulmanas: Negociando identidades y desafiando hegemonías desde los márgenes del feminismo.» Gênero $\mathcal{E}$ Direito. Periódico do Núcleo de Estudos e Pesquisas sobre Gênero e Direito 2: 120-147. Disponible en https://periodicos.ufpb.br/index.php/ged/article/view/20495/11691 [Consultado 03 de julio de 2020].

Teresa Colomina-Molina. Profesora asociada en el Departamento de Expresión Plástica, Musical y Dinámica de la Facultad de Educación de la Universidad de Murcia (España). Formó parte del Grupo de Investigación E0A6-07 Prácticas Artísticas Activas y Ciudadanía de la Facultad de Bellas Artes de la Universidad de Murcia.

Artículo recibido el 31 de enero y acceptado para su publicación el 31 de marzo de 2021. 


\section{Recensões}



Poesia e prosa, de Judith Teixeira, organização e estudos introdutórios de Cláudia Pazos Alonso e Fabio Mario da Silva. Alfragide: Dom Quixote, 2015, $370 \mathrm{pp}$.

\author{
Manuel Abrantes \\ Dhttps: / / orcid.org/0000-0003-4411-6569 \\ SOCIUS/CSG - Investigação em Ciências Sociais e Gestão, \\ ISEG, Universidade de Lisboa, Lisboa, Portugal \\ manuelabrantes@gmail.com
}

Judith Teixeira tinha vinte anos de idade quando se iniciou o século XX. Tinha trinta anos à data da implantação da República; trinta e oito quando findou a Primeira Guerra Mundial. Foi só depois de tudo isso, tanto quanto sabemos, que começaram a surgir textos da sua autoria em jornais e revistas. O seu livro de poemas inaugural, Decadência, foi publicado em 1923 - e logo apreendido por ordem do Governo Civil de Lisboa. Continha versos que ofendiam a moral, segundo a acusação de um grupo de estudantes do ensino superior encabeçados por Pedro Teotónio Pereira, destacado reacionário que chegaria a ministro no Estado Novo. Até 1927, Judith Teixeira publicou dois outros livros de poemas, uma conferência, duas novelas; dirigiu durante alguns meses uma revista chamada Europa. Nada é conhecido sobre eventuais atividades literárias a que se tenha dedicado desde então até à sua morte em 1959.

Estamos perante um dos muitos apagamentos sob os quais se grava o ferro da ditadura. Foram múltiplas as vozes literárias do primeiro quartel do século XX português a inquietar os poderes contemporâneos e futuros - vozes que, felizmente, têm vindo a ser redescobertas e revalorizadas por um leque crescente de investigações. Pensando apenas em mulheres que se exprimiram através da palavra escrita, encontramos casos tão diversos como os de Alice Moderno, Ana de 
Castro Osório, Maria da Cunha, Olga de Morais Sarmento, Virgínia Quaresma, Irene Lisboa, Virgínia Victorino ou Fernanda de Castro. Como várias dessas autoras, Judith Teixeira suscitou nos últimos anos um novo impulso de curiosidade, traduzido no desenvolvimento de estudos sobre a sua obra e na realização de colóquios e tertúlias em sua homenagem.

Todos estes elementos justificam um olhar atento sobre o livro organizado por Cláudia Pazos Alonso e Fabio Mario da Silva. Publicado em 2015, trata-se de um contributo importante para desocultar o trabalho artístico de mulheres durante a Primeira República e a experiência de quem ousou desafiar os códigos de género impostos à expressão da sua criatividade e da sua sexualidade. A relevância deste volume evidencia-se assim em duas frentes. Por um lado, disponibiliza todos os textos de Judith Teixeira que foi possível localizar até ao momento, reunindo textos já antes publicados e outros de acesso mais difícil. Permite-nos reler os poemas que Teixeira publicou em vida, incluindo aqueles censurados em 1923 por motivos que não podem ser qualificados senão de misóginos e homofóbicos: a sua abordagem lírica ao desejo, com referências a contactos sexuais protagonizados por mulheres e entre mulheres, era afinal demasiado livre para ser respeitada - e tampouco poderia ser ignorada, pois que perigosas mensagens se propagariam através da leitura? A punição foi efetivamente firme e exemplar. O presente volume permite-nos também ler, provavelmente pela primeira vez, vários poemas inéditos e uma conferência intitulada «Da Saudade», composta a partir de cópias dactilografadas de um texto que se crê redigido entre 1922 e 1925.

Por outro lado, o livro contém estudos breves e notas introdutórias que descrevem os critérios de organização dos textos e os enquadram historicamente e literariamente. Compreendemos assim que Judith Teixeira não constitui um caso tão isolado quanto à primeira vista seríamos tentados/as a julgar. Já atrás referimos escritoras que desenvolveram trabalho pioneiro no mesmo período. São também vários os paralelismos com António Botto, que viu o seu volume Canções retirado das livrarias na mesma vaga de apreensões do Governo Civil de Lisboa em 1923 (Klobucka 2018). Nem Teixeira nem Botto estavam sozinhos, ainda que possam por vezes ter chegado a senti-lo. Um dos mecanismos da exclusão social é precisamente isolar, tornar singular, exagerar as particularidades - daí também o imperativo histórico de cruzar fontes e, sem prejuízo da originalidade de cada voz autoral, reconstruir as pontes entre elas.

Ao organizar os textos por género - poesia, ensaio e novela - e por ordem cronológica, o presente volume oferece-nos uma oportunidade de explorar o percurso e a complexidade da expressão escrita de Judith Teixeira. Na sua poesia encontramos uma estrutura métrica variável, rica e imprevisível. Nela sobressaem os temas do desejo, da paixão, da solidão, da saudade. Já na conferência «Da Saudade», a escritora rejeita de forma contundente esse «mal, espásmico e doloroso, de que a nossa raça sentimental e sonhadora adoece tantas vezes» (p. 259), contrapondo-lhe um elogio da modernidade: «Penso e afirmo-lhes desassombra- 
damente, minhas senhoras e senhores, que neste século em que a rádio telefonia nos pode trazer de países distantes a voz do amante ou do irmão, e os aviões nos levam a percorrer o mundo em poucas horas, a Saudade não deve existir na sua forma doentia e nostálgica. Ela deverá traduzir-se apenas no desejo forte de realizar novos momentos de prazer e alegria!» (p. 263). Na conferência «De Mim», defende a liberdade criativa como dever de sinceridade e esclarece que as medidas estreitas da vida convencional representam para ela uma opressão insuportável: «As minhas emoções não podem, portanto, obedecer a pautas nem a conceitos tradicionais. Nascem duma vibração misteriosa, e eu vivo-as e sinto-as e traduzo-as na maior porção de elegância que a minha arte lhes pode dar» (pp. 285-286).

A veia ensaística de Teixeira - não sabemos se as suas conferências terão sido alguma vez proferidas - funde o poético, o filosófico e o político. Com a mesma naturalidade, a escritora realça os legados inspiradores de Lenine, Isadora Duncan, Oscar Wilde ou Edgar Allan Poe, bem como a sua fé num Deus encorajador e misericordioso.

As duas novelas que encerram o volume, por sua vez, centram-se em tensas intersecções das dinâmicas de género e de classe. A protagonista da novela Satânia, Maria Margarida, confronta-se com o dilema de cumprir o dever familiar que sobre ela impende (casar com António, um homem correto e de origens sociais afluentes) ou seguir o seu desejo (consumar a atração que sente por Manuel, filho do caseiro, inegável desde a primeira ocasião em que se cruzam por casualidade no solar). A trama da novela Satânia, concluída em 1927, encontra ressonâncias iniludíveis em romances tão célebres como $O$ Amante de Lady Chatterley, de D. H. Lawrence, ou Maurice, de E. M. Forster, sendo oportuno notar que, mesmo escritos por homens em Inglaterra, o primeiro viria a ser objeto de processos judiciais e o segundo publicado só após a morte do autor.

De caráter sucinto e fragmentado, os estudos de Cláudia Pazos Alonso e Fabio Mario da Silva que acompanham os textos de Judith Teixeira não impõem significados à leitura, antes abrem portas. De facto, a escrita de Teixeira recorda-nos que podemos, na esteira do que propunha Sontag (2004), resistir à tentação da interpretação - isto é, da decifração do texto por vias intelectuais - e encarar a obra de arte não como uma caixa (uma determinada forma com o conteúdo no seu interior) mas como uma experiência na qual forma e conteúdo se entrelaçam a ponto de ser impossível autonomizá-los. Os significados exteriores à obra, sejam erigidos pela própria autora ou por quem a lê, serão então menos relevantes que o valor simples e poderoso da expressividade. Talvez estejamos com isto a reatar na literatura uma noção de «intérprete» mais próxima da que utilizamos tipicamente no âmbito da música ou da dança. O exercício de uma leitura mais sensorial que intelectual poderá até ajudar-nos a localizar com propriedade o entroncamento do modernismo e do feminismo em Judith Teixeira, o qual atinge o seu expoente numa feroz rejeição dos papéis de género e numa defesa incondicional do corpo e da liberdade. 
Como lemos no estudo introdutório, «a história da literatura portuguesa continua a estar nas suas entrelinhas assombrada por escritoras rebeldes, que ainda carecem de reavaliação à luz de assimetrias de género generalizadas» (p. 33). Embora as primeiras décadas do século XX não esgotem decerto o arco temporal a estudar, contêm uma abundância de casos notáveis (Klobucka 2013). Não resta dúvida de que temos pela frente muito trabalho.

\section{Referências}

Klobucka, Anna M. 2018. O Mundo Gay de António Botto. Lisboa: Documenta. Klobucka, Anna M. 2013. «Palmyra's Secret Garden. Iberian (Dis)Connections, Portuguese Modernism, and the Lesbian Subject.» Luso-Brazilian Review 50(2): 31-52.

Sontag, Susan. 2004 [1966]. Contra a Interpretação e Outros Ensaios. Algés: Gótica.

Gênero, neoconservadorismo e democracia: disputas e retrocessos na América Latina, de Flávia Biroli, Maria das Dores Campos Machado e Juan Marco Vaggione. São Paulo: Boitempo Editorial, 2020, 224 pp.

Monise Martinez

(D) https: / / orcid.org/ 0000-0002-2324-9752

Centro de Estudos Sociais da Universidade de Coimbra (CES/UC),

Coimbra, Portugal

martinezmonise@gmail.com

O livro Gênero, neoconservadorismo e democracia tem como uma de suas propostas fulcrais pensar o que se tem vindo a compreender como «movimentos anti-gênero» em parte da recente literatura produzida sobre movimentos sociais na América Latina e para além dela. Reflexo da convergência entre os perfis de investigação de quem o escreve, o livro oferece lentes multidisciplinares para lermos e entendermos o conservadorismo religioso na região, bem como a centralidade atribuída às agendas da igualdade de gênero e da diversidade sexual num cenário marcado pela politização e pelas disputas em torno do termo «gênero». Assim, fazendo convergir algumas das diferentes abordagens sobre essas temáticas nos campos da Ciência Política, da Sociologia e do Direito, a obra busca entender as relações entre os referidos fenômenos com os processos de desdemocratização, a qual, entre outras coisas, tem sido igualmente marcada por disputas em torno dos próprios sentidos de democracia.

Como referido pelas autoras e pelo autor na seção peritextual de apresentação do livro, um dos principais argumentos desenvolvidos ao longo das páginas que lhe 
dão corpo é o de que «a forma atual do conservadorismo latino-americano está relacionada a uma temporalidade marcada pelos avanços dos movimentos feministas e LGBTQIA+ e expressa coalizações políticas de grupos cristãos com setores não religiosos da direita» (p. 8). Fundamentado, em parte, em abordagens teóricas que respaldaram muitas das análises sobre o campo de oposição política inflamado por atores da direita religiosa no contexto estadunidense, o entendimento dos movimentos antigênero como «reações» especialmente emergidas na esteira de um ciclo de conferências sociais organizadas pela ONU na década de 1990 localiza e estende os debates sobre o fenômeno de forma atenta às especificidades da América Latina. Ao fazê-lo, as autoras e o autor não apenas situam a região no panorama transnacional dos movimentos antigênero, como delineiam perspectivas de análise para pensar as ditas «reações» a partir das conexões entre a dimensão econômica e moral, bem como de seus efeitos para a política da democracia.

Para esse efeito, na Introdução do livro a «moldura conceitual e teórica» que o embasa é apresentada a partir de dois eixos principais: o da temporalidade, lançando luz sobre o processo de determinação das bases epistemológicas das campanhas antigênero, incluindo a bem-conhecida retórica da «ideologia de gênero» ${ }^{1}$, na sua relação com atores conservadores e religiosos; e o do neoconservadorismo, conceito discutido e empregado no livro para referir «uma lógica normativa e disciplinadora interiorizada pelos sujeitos contemporâneos» e, portanto, «um modelo de governança e cidadania» (p. 26).

Norteado pelas linhas do referido enquadramento teórico, o primeiro capítulo do livro tem como foco abordar as relações entre gênero, neoconservadorismo e democracia, situando-as no campo do Direito - na perspectiva de Juan Marco Vaggione, que assina o capítulo -, uma arena e uma ferramenta estratégica crucial para compreender a materialidade democrática das tensões em torno das políticas sexuais e de gênero na América Latina. Entre as razões para isso, como elucida o capítulo, estão o fato de o neoconservadorismo operar como uma espécie de «maquinaria legal» que, regida por atores religiosos e conservadores de perfis diversos, disputa não só a própria função simbólica do direito, como também faz dele uma ferramenta para restauração da moral.

Dinamizando a construção do capítulo a partir desses dois eixos, Vaggione começa por discorrer sobre o «mito do direito secular», salientando as imbricações entre esse e a doutrina católica, o papel das políticas sexuais e de gênero na «descristianização da lei» e, enfim, a «juridificação reativa da moral» levada a cabo por uma constelação variada de atores conservadores e aliados no âmbito da sexualidade, da reprodução e do matrimônio. De seguida, as estratégias adotadas por esses diferentes perfis de atores são esmiuçadas pelo autor, lançando luz sobre as

Aqui, refiro o sintagma «ideologia de gênero» entre aspas para enfatizar o seu entendimento como parte estratégica de um projeto político concebido pela Santa Sé com vistas a deslegitimar os Estudos Feministas e de Gênero, bem como as agendas dos movimentos feministas e LGBTQIA+. 
ações de políticos cristãos, fundamentais para a criação de alianças nacionais e transnacionais em defesa de valores como a vida, a família e a liberdade religiosa, bem como advogados e juristas confessionais, cruciais na prática do uso do «litígio estratégico» para defender interpretações legais alinhadas com a doutrina religiosa. Dentre essas, Vaggione destaca ações como a «cidadanização do feto», base do chamado movimento antiaborto dito «pró-vida»; a «renaturalização da família», a qual, em resposta às «ameaças» da «ideologia de gênero», mobiliza estratégias legais como a defesa da pátria potestade; e, enfim, a «ampliação da proteção às crenças religiosas», por meio da redefinição da ideia de liberdade religiosa com vistas a reduzir a legitimidade e a legalidade dos direitos reprodutivos e sexuais.

$\mathrm{Na}$ esteira das discussões pleiteadas por Vaggione, Maria das Dores Campos Machado assina o segundo capítulo do livro focando-se em identificar os pontos de convergência entre o ativismo neoconservador protagonizado por mulheres no Brasil e na Colômbia. Atenta ao fato de que a maioria e fiéis que integram igrejas pentecostais na América Latina são do sexo feminino, e de que as inseguranças propiciadas pelos contextos de violência e desigualdade relacionados aos avanços substanciais das políticas de austeridade e neoliberais na região são úteis à compreensão do ativismo conservador acionado por mulheres pertencentes a grupos cristãos como os (neo)pentecostais e católicos carismáticos, Machado busca identificar quais são os elementos das campanhas anti-gênero que mobilizam as mulheres; o que faz com que essas mulheres reproduzam a ordem social patriarcal; e, ainda, como elas têm assumido o ativismo neoconservador nos últimos anos.

Tendo-se em conta o protagonismo que os grupos evangélicos têm tido nas ações neoconservadoras na América Latina, e a expansão desses frente à maioria católica que imperou por muitos anos na região, a primeira parte do capítulo é dedicada a apontar as principais mudanças na agenda política desses grupos evangélicos. Na esteira desse panorama, no qual o campo moral e as contraposições às agendas feministas e LGBTQIA+ ganharam protagonismo nas últimas décadas, a autora evidencia não só como a retórica da «ideologia de gênero» tornou-se uma ferramenta fundamental nas disputas no Legislativo, no Judiciário e na sociedade civil brasileira, como também como cantoras gospel, pastoras, empresárias, políticas e assessoras parlamentares têm cumprido um papel crucial na construção de alianças entre evangélicos e grupos neoconservadores e, mais recentemente, na máquina estatal brasileira gerida por Bolsonaro. De seguida, foca-se no caso colombiano e passa a delinear os pontos de convergência entre os referidos contextos. Como ressalta, em ambos os países mulheres (neo)pentecostais e ativistas dos movimentos neoconservadores têm se dedicado a confrontar agendas feministas e LGBTQIA+, engajado-se nas lutas contra a «ideologia de gênero» e reiterado os valores cristãos propagados em suas comunidades. Apresentadas por Machado como um conjunto de reações às mudanças protagonizadas pelos movimentos feministas e LGBTQIA+ nas últimas duas décadas, tais ações encontram apoio nas camadas populares por meio da mobilização do 
medo, como o discurso de ameaça à família tradicional e às crianças, bem como pelo discurso da «maioria moral» - a ideia de que existe uma suposta «maioria» ameaçada por uma minoria progressista.

O terceiro capítulo do livro, de autoria de Flávia Biroli, situa os processos analisados por Vaggione e Machado no cenário de «erosão da democracia» marcado, entre outras coisas, pela «erosão do "público" na forma da privatização e da redefinição do próprio sentido de coletivo» (p. 142) associada aos avanços do neoliberalismo na região latino-americana a partir dos anos de 1990. Compreendendo os movimentos feministas e LGBTQIA+ como partes da constelação de atores que têm produzido mudanças nas agendas dos Direitos Humanos e nos sentidos de democracia, a autora foca-se em entender como os atores neoconservadores têm produzido e promovido ideias e valores «alternativos» aos que têm sido levados a cabo por esses movimentos progressistas. Analisando protestos anti-gênero que ganharam as ruas especialmente entre 2016 e 2017, Biroli constata que a «proteção» da família que os permeiam está atrelada, por um lado, à recusa da dimensão coletiva que embasa as políticas de igualdade em seus variados níveis e, por outro, à legitimação da organização familiar heteronormativa - ambas sustentadas por uma dinâmica de autoridade restritiva, reivindicada em nome das já referidas «maiorias morais». Sem discursar contra a democracia, esses atores neoconservadores não só disputam discursivamente pelo sentido de democracia na arena pública como, nesse fazer, apresentam a produção teórica e empírica dos feminismos como «ideologia», bem como os movimentos feministas e LGBTQIA+ como inimigos.

No capítulo de conclusão, as principais ideias desenvolvidas pelas autoras e pelo autor logram sistematizar, a partir das perspectivas adotada ao longo do livro, o que há de novo e específico no campo de ações dos agentes neoconservadores na América Latina. Com badanas e quarta-capa assinadas, respectivamente, pelas investigadoras Sonia Corrêa e Maria José Rosado Nunes, o livro logra deslocar o eixo de análise sobre o tema para esse contexto do Sul global, enfatizando a produção discursiva e as relações entre religião, gênero e políticas que urgem no agora que nos cerca nas mais diversas geografias.

\section{Referências}

Biroli, Flávia, Maria das Dores Campos Machado, e Juan Marco Vaggione. 2020. Gênero, neoconservadorismo e democracia: disputas e retrocessos na América Latina, São Paulo: Boitempo Editorial. 
Feminist Media Studies, de Alison Harvey. Cambridge: Polity Press, 2020, 211 pp.

\author{
Bibiana Garcez \\ (D) https: / / orcid.org/ 0000-0002-8282-8252 \\ Doutoranda em Ciências da Comunicação, \\ Universidade de Coimbra/ICNOVA, Coimbra, Portugal \\ bibianagarcezs@gmail.com
}

Em um cenário em que se vive na mídia, sendo esta central ou transversal a diversos aspectos da vida, das nossas subjetividades e práticas (Deuze 2011), e em que as transformações são constantes e cada vez mais velozes, ter uma perspectiva feminista nos estudos midiáticos faz-se mais do que relevante - é, com efeito, imprescindível. Em Feminist Media Studies (2020), livro publicado pela Polity Press, Alison Harvey cumpre com uma importante tarefa neste sentido, a de apresentar, atualizar e problematizar concepções do amplo campo de estudos feministas da mídia, atentando-se não apenas para os avanços (aparentemente) positivos, mas também para uma continuidade histórica de profunda exclusão e marginalização das mulheres e de outros grupos oprimidos.

Inspirada no pioneiro livro de igual título de Liesbet van Zoonen (1994), produzido em uma conjuntura visivelmente distinta da atual, a autora elabora uma obra abrangente, que serve para introduzir e contextualizar novas/os pesquisadoras/es na área, ao mesmo tempo que atualiza quem já aqui pesquisa com novas e diversificadas referências. Indo além das afirmações de que, neste momento, o acesso, a participação e a visibilidade das mulheres na mídia estão democratizados de forma absoluta, muito em razão da tecnologia, Feminist Media Studies promove um olhar atento, crítico e interseccional na produção de conhecimento acadêmico em relação à mídia. Assim, ilumina caminhos possíveis na investigação e demonstra não apenas a versatilidade deste campo, mas também a sua importância.

Organizada em sete capítulos, focados em conceitos e contextos iniciais, metodologias feministas de investigação, representação, estudos transnacionais, estudos da esfera digital, do trabalho e o futuro do campo, a obra olha para a mídia de forma ampla, principalmente como indústria cultural e como plataforma, trazendo de maneira transversal a ideia de interseccionalidade, de forma a destacar a maneira insidiosa em que as diferentes opressões se podem cruzar.

É no primeiro capítulo, introdutório, que são apresentados conceitos necessários para o mergulho nos estudos feministas da mídia, demonstrando, como referido anteriormente, como a obra serve para pessoas que estão adentrando o campo. Neste sentido, esta revisão faz a leitura mais coesa, pautando, por exemplo, os conceitos de gênero e de feminismos utilizados, as linhas teóricas proeminentes e 
duas perspectivas que são centrais à obra e aos estudos da área atualmente - a atenção à interseccionalidade e ao pós-feminismo. Há uma importante clarificação deste último conceito, inicialmente trabalhado por Rosalind Gill (2007), e entendido como uma «sensibility with several interrelated themes in media and culture» (Harvey 2020, p. 26). Importa referir, entretanto, que este fenômeno é também discutido sob outros termos (ver Banet-Weiser et al. 2020).

No segundo capítulo do livro, a autora mapeia diferentes abordagens metodológicas possíveis - ainda que não as esgote - para a investigação feminista da mídia. Mostrando a abertura a diferentes formas de se olhar para os objetos e sujeitos estudados, a autora explora a crítica feminista da mídia baseada em textos, a crítica feminista da cultura midiática, assim como a pesquisa sobre a ação feminista midiática e, por fim, a ação feminista na mídia em si mesma. Uma riqueza é a forma didática como explica conceitos centrais a cada metodologia referida, assim como exemplos de aplicações realizadas nos últimos anos.

Ainda nesta mesma seção aborda-se a ética feminista na investigação acadêmica, baseada em três critérios/práticas centrais: iteração, reflexividade e localização (situatedness). Reger-se por estas práticas na realização de pesquisas acadêmicas reitera a impossibilidade de manter uma postura «neutra e objetiva»e possibilita caminhos para garantir resultados válidos, justos e éticos a partir dos nossos próprios lugares, inobliteráveis. Essas ideias voltam a ser lembradas ao longo dos demais capítulos, pensando na posição da própria autora na construção do livro.

O terceiro capítulo versa sobre as dinâmicas de representação sob uma perspectiva feminista, sendo a representação entendida não só como "presence and visibility, but also [...] the range (or lack thereof) of stories, dialogue, and lives that marginalized and oppressed groups are assigned in the media» (p. 54). Problematizando a ideia de que as mulheres estão libertas da opressão sexista por terem mais visibilidade nos conteúdos de produção midiática, o texto discorre sobre as dinâmicas de visibilidade e voz com uma perspectiva interseccional e inserida em um contexto neoliberal.

A seguir, na seção intitulada «Transnational Feminist Media Studies», enfoca-se a produção intelectual do campo no Sul global, sublinhando de maneira constante a necessidade de descolonizar a investigação acadêmica, de maneira geral, e feminista. Segundo a autora, essa descolonização «refers to the act of addressing and dismantling the effects of colonialism on our practices of knowledge production. This aim [...] is not peripheral but fundamental to feminist aims of equity and justice» (p. 75).

Entre as práticas adotadas neste processo, destacamos a reflexão acerca das citações como uma atividade também política. Isto é dizer, em suma, que as referências utilizadas também carregam uma escolha e um peso em si próprias. A busca ativa por bibliografia de localizações geográficas e/ou sociais marginalizadas pode trazer novas e emancipadoras perspectivas para a pesquisa e, com efeito, verifica- 
-se que esta é uma prática presente ao longo da obra como um todo. Muitos dos estudos mencionados descentram-se do Norte global - especialmente Europa e Estados Unidos -, o que demonstra a maneira como uma política de citação mais ampla e emancipadora, atenta a outras localidades, seus contextos e histórias pode ser colocada em prática.

O quinto capítulo foca-se nas dinâmicas digitais e nas «implications of the growth of digital media for the field, considering issues that arise based on shifts in how some parts of the world interact with media as well as in how we envision the power of these forms for resistance, action, and change» (p. 97). Neste ponto, questões centrais são a importância e o impacto da conectividade e sua popularização em relação às mulheres, mas ainda considerando que a área da tecnologia foi socialmente construída como um espaço masculino, do qual inclusive a memória de mulheres foi apagada, e que questões materiais de (falta de) acesso à Internet moldam também essa realidade, que não é universal. Dessa maneira, destaca-se, por exemplo que o ativismo nas redes sociais não pode ser a única forma de emancipação, ainda que traga ganhos, como a construção de redes, a visibilidade - que nem sempre é positiva - e relações de afeto. É, de fato, preciso pensar o online e o offline de forma conjugada, uma vez que não são, na prática, separáveis.

Em forma de considerações finais, no último capítulo a autora dialoga com o futuro do campo, apontando caminhos e pautando a construção de pesquisas a partir de uma lógica de continuidade no espectro da mídia, e não de forma a pensar cada caso, meio ou plataforma como isolada, sempre com uma perspectiva interseccional como forma de «combater opressões multifacetadas».

De maneira geral, o livro consegue promover diálogos entre os variados pontos trabalhados em cada um dos capítulos tendo essa premissa, que vem sendo amplamente trabalhada na teorização feminista e não só, como estruturante das análises necessárias. Para mais, o faz somando com insights de outras áreas de pesquisa. Com efeito, é a partir dessa trans/interdisciplinaridade que a autora argumenta que devemos avançar, buscando um

further engagement with existing and developing scholarship in critical race studies, queer theory, critical disability studies, postcolonial theory, and a range of complementary fields related to social justice. Only by engaging with the insights afforded by this interdisciplinary and international work can we address the myriad, multifaceted, and global intersectional challenges facing women today. (p. 146)

«Because we believe, with all our hearts/minds/bodies, that progressive change is necessary, that progressive change is possible, and that feminist media critics constitute a revolutionary force that transforms academia and popular culture - for real», como diz o manifesto pela crítica feminista da mídia de Mary Celeste Kearney (2012, citada por Harvey 2020, p. 148), reproduzido integralmente ao final do livro, esta obra serve para explicar, fundamentar e pavimentar cami- 
nhos necessários, através de reflexões importantes e da apresentação de ferramentas metodológicas e conceituais úteis, para futuras, mais profundas e emancipadoras explorações do campo.

\section{Referências bibiográficas}

Banet-Weiser, Sarah, Rosalind Gill, e Catherine Rottenberg. 2020. «Postfeminism, popular feminism and neoliberal feminism? Sarah Banet-Weiser, Rosalind Gill and Catherine Rottenberg in conversation.» Feminist Theory 21(1): 3-24. DOI: https:/ / doi.org/10.11 $77 / 1464700119842555$

Deuze, Mark. 2011. «Media life.» Media, Culture and Society 33(1): 137-148. DOI: https:/ / doi. org $/ 10.1177 / 0163443710386518$.

Gill, Rosalind. 2007. «Postfeminist media culture: Elements of a sensibility.» European Journal of Cultural Studies 10(2): 147-166. DOI: https: / / doi.org/10.1177/1367549407075898 van Zoonen, Liesbet. 1994. Feminist Media Studies. London: SAGE Publications. 



\section{ESTATUTO EDITORIAL}

- A ex æquo é uma publicação semestral, fundada pela Associação Portuguesa de Estudos sobre as Mulheres - APEM, com o objetivo de contribuir para o desenvolvimento, visibilização e legitimação do conhecimento produzido no âmbito dos Estudos sobre as Mulheres/Estudos Feministas/Estudos de Género. É um veículo de intercâmbio entre quem faz investigação sob a égide das perspetivas destes estudos, ao nível académico, governamental ou das organizações cívicas e culturais. Assim, destina-se a investigadores/as e a estudantes nestas áreas, procurando dirigir-se também ao público em geral no sentido da sensibilização para estes campos do saber.

- Reconhecendo que os Estudos sobre as Mulheres, do Género e Feministas se têm caracterizado pelo alargamento e entrosamento disciplinar, pela diversidade temática e pela pluralidade de perspetivas teóricas e epistemológicas, a revista assume-se interdisciplinar e multidisciplinar, aberta ao contributo das diversas disciplinas e correntes. Dado que a estrutura matricial da revista é a APEM, é objetivo da ex æquo contribuir para a alteração de práticas e representações estereotipadas e discriminatórias em função do sexo ou de outras pertenças identitárias, adotando, nomeadamente, uma linguagem não discriminatória, inclusiva e promotora da igualdade. No mesmo sentido, as investigações empíricas podem e devem sustentar artigos que incluam uma reflexão teórica e contribuam para a problematização das principais questões que afetam as relações sociais entre mulheres e homens na sociedade. A ex æquo, sem prejuízo da pluralidade e multiplicidade das perspetivas presentes nos textos que publica, reserva-se o direito de só aceitar textos que no respeito pelo princípio de defesa dos Direitos Humanos fundamentais, traduzam a valorização da diversidade da condição humana, bem como da sua integridade e dignidade.

- As áreas de interesse da revista são os Estudos sobre as Mulheres, os Estudos de Género e os Estudos Feministas.

A ex æquo publica trabalhos originais em Português, Espanhol, Francês e Inglês, provenientes de todas as áreas científicas, que se inscrevam no quadro dos Estudos sobre as Mulheres ou dos Estudos de Género ou dos Estudos Feministas. Publica, ainda, recensões sobre obras publicadas nos referidos domínios.

\section{PROCEDIMENTO DE ARBITRAGEM}

- Pareceres por duas pessoas, double blind peer review, especialistas na respetiva área em que o texto se enquadra ou referencia. Os textos são enviados sob anonimato aos/às referees, a quem é solicitado que o parecer emitido tenha em conta, de acordo com a ficha de avaliação: a adequação e enquadramento do artigo nos objetivos da revista ex æquo; a sua qualidade científica; a pertinência, originalidade, clareza e coerência de conteúdos; a adequação, atualidade e cumprimento das normas consagradas da bibliografia; a pertinência, adequação e explicitação da metodologia e da informação; a clareza da escrita e a coerência e o equilíbrio formais. Os pareceres deverão incluir uma recomendação em relação a possível publicação, entre as seguintes: aceite sem restrições; aceite com restrições (indicando quais); rejeitado. Será ainda solicitada a indicação de sugestões e sua justificação, para melhoria da qualidade científica do artigo submetido a parecer, a ser enviadas, sob anonimato, à(s) pessoa(s) autora(s).

- A revista destina-se a investigadoras/es e a estudantes nas áreas de interesse da revista, procurando também dirigir-se ao público em geral, com vista à sua sensibilização para os mesmos campos do saber. 


\section{DECLARAÇÃO DE ÉTICA E DE BOAS PRÁTICAS DA EX AEQUO}

A Revista ex æquo é uma revista com arbitragem científica, interdisciplinar e multidisciplinar, aberta ao contributo das diversas disciplinas e correntes. A ex æquo, sem prejuízo da pluralidade e multiplicidade das perspetivas presentes nos textos que publica, reserva-se o direito de só aceitar textos que respeitem os Direitos Humanos fundamentais, traduzam a valorização da diversidade da condição humana, bem como da sua integridade e dignidade.

A ex æquo é uma publicação da Associação Portuguesa de Estudos sobre as Mulheres (APEM) estando por conseguinte vinculada à sua missão de apoiar, promover e dinamizar os Estudos sobre as Mulheres / Estudos de Género / Estudos Feministas em todas as áreas do saber.

Na Revista ex æquo são defendidos os princípios da declaração de ética e de boas práticas na publicação de acordo com o Código de Conduta e Normas de Boas Práticas para Editores de Revistas do Comité sobre Ética na Publicação - COPE (disponível em http:// publicationethics.org/).

\section{RESPONSABILIDADES DA EQUIPA EDITORIAL (EDITORAS E EDITORAS DE SECÇÕES)}

Decidir quais os artigos submetidos à revista que devem ser publicados. Esta decisão é orientada pelas normas da revista (Normas para apresentação e publicação de textos da ex æquo, disponíveis em http://www.apem-estudos.org/pt/page/submissao-de-artigos) e pelos requisitos legais em matéria de difamação, violações de direitos de autoria e plágio;

Orientar a/o(s) organizador/a(s) convidada/o(s), autor/a(s) e avaliador/a(s) sobre o seu papel, bem como esclarecer sobre o processo de arbitragem científica por pares;

Informar os novos elementos do corpo editorial sobre as suas funções, práticas em vigor e projetos em lançamento;

Avaliar os artigos exclusivamente com base no seu mérito científico e intelectual, independentemente de fatores como: raça, idade, sexo, orientação sexual, deficiência, origem étnica, crença religiosa, nacionalidade, orientação política ou classe social da/o(s) autor/a(s);

Assegurar que o processo de arbitragem científica dos artigos é anónimo (double-blind peer review), justo, rigoroso e isento e que toda a informação a eles relativa permanece confidencial. Assegurar, ao mesmo tempo a proteção da identidade das autoras e dos autores e das avaliadoras e avaliadores;

Constituir e manter uma base de dados de avaliadoras/es pertinentes nas diferentes áreas disciplinares, sempre atualizada;

Garantir uma seleção adequada das avaliadoras/es em cada nova edição da revista;

Garantir que os materiais não publicados não são utilizados na investigação realizada por membros do Corpo Editorial sem consentimento expresso por escrito da(s) autora(s) ou autor(es);

Responder atempadamente a eventuais reclamações apresentadas sobre um artigo submetido ou publicado. Perante suspeita de má conduta, seguir os fluxogramas do COPE, disponíveis em http://publicationethics.org/files / Full\%20set\%20of $\%$ 20flowcharts.pdf;

Publicar correções, esclarecimentos, retratações e pedidos de desculpa sempre que necessário. 


\section{Boas práticas a observar pela equipa editorial}

Auscultar a visão de autoras/es, leitoras/es, avaliadoras/es, revisoras/es e membros do corpo editorial sobre a forma de melhorar a revista ex æquo.

Encorajar e estar consciente da investigação levada a cabo pela revisão por pares e publicar e reavaliar os processos da ex æquo à luz de novas investigações.

Apoiar iniciativas para informar e sensibilizar as/os investigadoras/es sobre as regras de ética da ex æquo.

Avaliar os efeitos das suas políticas editoriais sobre autoras e autores e avaliadoras/es, incentivando um comportamento responsável e desencorajando as más condutas.

Garantir que todos os relatórios de investigação e revisão de investigação foram revistos por avaliadoras/es com a devida qualificação (incluindo análise estatística quando apropriado), capazes de julgar os textos propostos e livres de desqualificar interesses concorrentes.

Respeitar os pedidos de autoras/es para excluir alguém de rever os textos submetidos, se estes forem bem fundamentados.

Incentivar avaliadoras/es a fazer comentários sobre a originalidade do manuscrito e estar alerta para publicações redundantes e plágio e tomar medidas para garantir um elevado nível de qualidade.

\section{RESPONSABILIDADES DO CONSELHO CIENTÍFICO} revista;

Apoiar o Conselho de Redação na interpretação e orientação da política editorial da

Assegurar a arbitragem de propostas de artigos desde que inseridos nas respetivas áreas de especialização;

Estabelecer a ligação a potenciais avaliadoras/es [referees] para o processo de arbitragem científica e em situações em que as propostas originaram pareceres antagónicos ou outro tipo de dúvidas, analisar pareceres e, com base neles, recomendar a rejeição ou publicação de originais;

Divulgar os apelos a contributos na sua rede de contactos;

Contribuir para a divulgação da revista ex æquo;

Participar em reuniões da Comissão Científica que eventualmente venham a ser convocadas.

\section{RESPONSIBILIDADES DE QUEM FAZ A AVALIAÇÃO [peer review]}

\section{Contribuição para a decisão editorial}

A revisão por pares ajuda a equipa editorial na decisão e pode também contribuir para a melhoria do manuscrito submetido.

\section{Prontidão}

Cada avaliador/a convidada/o que considere não possuir a qualificação para avaliar o manuscrito submetido ou que anteveja a impossibilidade de comunicar a sua avaliação em tempo oportuno deverá informar de imediato a equipa editorial ou a pessoa que fez o convite para que possam ser encontradas alternativas em tempo útil. 


\section{Confidencialidade}

Quaisquer trabalhos recebidos para avaliação devem ser tratados como documentos confidenciais. Não devem ser mostrados ou discutidos com outras pessoas, exceto se for autorizado pela equipa editorial.

\section{Padrões de objetividade}

Os comentários devem ser apresentados de forma objetiva. Críticas pessoais são inaceitáveis. As opiniões devem ser claras com argumentos justificativos adequados.

Conhecimento das fontes

Devem identificar obras publicadas relevantes e que não tenham sido citadas. E devem, também, chamar a atenção da equipa editorial para qualquer semelhança substancial ou sobreposição entre o manuscrito em questão e quaisquer outras informações ou publicações sobre as quais tenham conhecimento pessoal.

\section{Conflito de interesses}

Informações privilegiadas ou ideias obtidas através da avaliação por pares devem ser mantidas confidenciais e não usadas para vantagem pessoal. Quem avalia não deve aceitar participar quando existe conflitos de interesse resultantes da concorrência, colaboração, ou outros relacionamentos ou ligações com as/os autoras/es, empresas ou instituições ligadas à submissão.

\section{RESPONSABILIDADES DO/A AUTOR/A}

\section{Autoria do manuscrito}

A autoria diz respeito a quem fez contribuições significativas para o estudo. Todas as pessoas que contribuíram significativamente devem ser listadas como co-autoras. Outras que tenham participado em certos aspetos substantivos do projeto de pesquisa devem ser listadas nos agradecimentos ou contributos. Cara autora e/ou autor deve garantir que toda a co-autoria devida está incluída no manuscrito, e que viu e aprovou a versão final do documento e concordou com a sua apresentação para publicação.

\section{Padrões de apresentação}

Os resultados de pesquisas originais devem ser acompanhados da apresentação clara e precisa do trabalho realizado, bem como de uma análise objetiva do seu significado. Um documento deve conter detalhes e referências suficientes para permitir que outras pessoas possam replicar o trabalho. Declarações fraudulentas ou intencionalmente imprecisas são inaceitáveis. As regras da revista devem ser escrupulosamente observadas.

\section{Originalidade e plágio}

Cada autora e cada autor deve garantir que escreveu obras inteiramente originais, devendo o trabalho e/ou as palavras de outras autores e autores ser objeto da devida citação ou referência.

\section{Declarações e conflito de interesses}

Cada autora e cada autor deve divulgar no manuscrito qualquer contradição significativa financeira ou outra de interesse que possa ser interpretada no sentido de influenciar os resultados ou a sua interpretação no manuscrito. Todas as fontes de apoio financeiro para o projeto devem ser divulgadas. 
Publicação múltipla, redundante ou concorrente

É considerado um comportamento não ético de publicação descrever a mesma pesquisa em vários artigos e submeter o mesmo artigo a mais de uma revista.

Erros fundamentais em obras publicadas

Quando um/a autor/a descobre um erro significativo ou imprecisão no manuscrito submetido, deve notificar imediatamente a equipa editorial.

\section{Remoção}

Os artigos publicados serão removidos se avaliadoras/es, leitoras/es, bibliotecárias/ os, equipa editorial ou outras entidades detetarem erros significativos ou plágio. Antes de retirar um artigo, o conselho editorial contactará de imediato as/os respetivas/os autoras/es, estabelecendo um prazo suficiente para obter as explicações devidas. Se for decidido que o artigo deve ser retirado então ele deve sair de imediato das bases de dados em linha onde esteja, incluindo o website da APEM, e na versão impressa deve ser referida a sua retirada no número seguinte de forma visível.

\section{RESPONSABILIDADES DA EMPRESA EDITORA}

\section{Autonomia editorial}

A Empresa Editora garante a autonomia de decisões editoriais, sem influência de anunciantes ou de outros parceiros comerciais.

\section{Propriedade intelectual e direitos autorais}

A Empresa Editora protege a propriedade intelectual e direitos de autoria, o material impresso, autoras/es e parceiros de publicação promovendo e mantendo o registo de cada versão publicada. Defende a transparência de cada artigo publicado no que diz respeito a: conflitos de interesse, de publicação e de financiamento da investigação, de publicação e de ética em investigação, má conduta de publicação e investigação, confidencialidade, autoria, correções do artigo, esclarecimentos, e publicação atempada de conteúdo.

\section{Má conduta científica}

Em casos de alegada ou provada má conduta científica, publicação fraudulenta, a entidade responsável pela publicação em estreita colaboração com a equipa editorial, tomará todas as medidas adequadas para esclarecer a situação e para alterar o artigo em questão. Isso inclui a publicação rápida de um comunicado, correção ou errata ou, nos casos mais graves, a retração da obra afetada. 


\section{CONSELHO CIENTÍFICO/SCIENTIFIC BOARD}

Louise ACKERS (U. Salford, UK)

Tindara ADDABBO (U. Modena e Reggio Emilia, ITA)

Teresa ALVAREZ (U. Aberta, PRT)

Lígia AMÂNCIO (ISCTE - IUL, PRT)

Ana Luísa AMARAL (U. Porto, PRT)

Helena Costa ARAÚJO (U. Porto, PRT)

Madeleine ARNOT (U. Cambridge, UK)

Adriana BEBIANO (U. Coimbra, PRT)

Chiara BERTONE (Inst. Piemonte Orientale

"Amedeo Avogadro", ITA)

Josefina BIRULES BERTRAN (U. Autònoma

Barcelona, ESP)

Gisela BOCK (Freie Universität Berlin, DEU)

Carolyn BYERLY (Howard U., USA)

Erica BURMAN (U. Manchester, UK)

Rosa CABECINHAS (U. Minho, PRT)

Pat CARLEN (U. Leicester, UK)

Nuno CARNEIRO (U. Porto/U. Complutense Madrid, ESP)

Sara Falcão CASACA (U. Lisboa, PRT)

Fernando CASCAIS (U. Nova Lisboa, PRT)

Richard CLEMINSON (U. Leeds, UK)

Zowie DAVY (U. Lincoln, UK)

Jonathan DEAN (U. Leeds, UK)

Maria Angeles DURAN (Higher Council for

Scientific Research, ESP)

Antonia FERNANDEZ VALENCIA

(U. Complutense Madrid, ESP)

Juana GALLEGO (U. Autònoma Barcelona, ESP)

Silvana Vilodre GOELLNER (U. Federal do

Rio Grande do Sul, BRA)

Jack HALBERSTAM (U. Southern California, USA)

Jeff HEARN (U. Örebro, SWE)

Tone HELLESUND (U. Bergen, NOR)

Fernanda HENRIQUES (U. Évora, PRT)

María Jesús IZQUIERDO (U. Autònoma Barcelona, ESP)

Elisa JATO (U. Santiago Compostela, ESP)

Celia JENKINS (U. Westminster, UK)

Jane JENSON (U. Montreal, CAN)

Teresa JOAQUIM (U. Aberta, PRT)

Maria KARAMESSINI (Panteion U. Social and Political Sciences, GRC)
Maria José MAGALHÃES (U. Porto, PRT)

Barbara MERRILL (U. Warwick, UK)

Sofia NEVES (Instituto Universitário da Maia, PRT)

Áine Ní LÉIME (National U. Ireland, IRL)

Conceição NOGUEIRA (U. Porto, PRT)

Karen OFFEN (U. Stanford, USA)

João Manuel de OLIVEIRA (Inst.

Universitário de Lisboa, PRT)

Joanna OSTROUCH-KAMIŃSKA

(U. Warmińsko-Mazurski Olsztynie, POL)

Heloísa PERISTA (Centro Estudos para Intervenção Social, PRT)

Teresa PINTO (U. Aberta, PRT)

Vânia C. PINTO (Universidade de Brasília, BRA)

Adriana PISCITELLI (U. Estadual Campinas, BRA)

Lucas PLATERO (U. Rey Juan Carlos, ESP)

Sílvia PORTUGAL (U. Coimbra, PRT),

Marco Aurélio PRADO (U. Federal Minas

Gerais, BRA)

Alicia PULEO (U. Valladolid, ESP)

Rebecca ROGERS (U. Paris-Descartes, FRA)

Karen ROSS (U. Northumbria, UK),

Jill RUBERY (U. Manchester, UK)

Ana Cristina SANTOS (U. Coimbra, PRT)

Gina dos SANTOS (U. Minho, PRT)

Joan W. SCOTT (Institute for Advanced Study - Princeton, USA)

Lynne SEGAL (U. London, UK)

Paula SILVA (U. Porto, PRT)

Teresa TAVARES (U. Coimbra, PRT)

Filomena TEIXEIRA (Inst. Politécnico Coimbra, PRT)

Teresa TOLDY (U. Fernando Pessoa, PRT)

Juracy TONELI (U. Federal Santa Catarina, BRA)

Anália TORRES (U. Técnica Lisboa, PRT)

Miguel VALE DE ALMEIDA (ISCTE - IUL, PRT)

Paola VILLA (U. Trento, ITA)

Karin WALL (U. Lisboa, PRT)

Claire WALLACE (U. Aberdeen, UK)

Michelle ZANCARINI-FOURNEL (U. Lyon-1, FRA) 


\section{PROPOSTA DE ASSINATURA}

Se deseja assinar a ex æquo recorte este talão e envie-o, devidamente preenchido, para edições afrontamento,

Rua de Costa Cabral, 859 - 4200-225 Porto

$\square$ Assino a revista ex æquo

$$
\text { (n. }{ }^{\circ} 41,42 \text { ) }
$$

Continente $\quad 35 € \square$

Regiões autónomas $40 € \square$

Europa $\quad 55 € \square$

Extra-Europa $\quad 60 € \square$

[Estes preços incluem IVA à taxa de $5 \%$ e portes]

\section{Pagamento}

Junto envio o cheque . $^{\circ}$ à ordem de

Edições Afrontamento, no valor de

Número de identificação fiscal

Assinatura

Nome:

Morada:

Tel: Fax:

E-mail

Visite o sítio na internet das Edições Afrontamento em www.edicoesafrontamento.pt 
DOSSIER: DESIGUALDADES SOCIAIS E MEDIDAS DE AÇÃO AFIRMATIVA

DESIGUALDADES SOCIAIS E MEDIDAS DE AÇÃO AFIRMATIVA: ENTRE AVANÇOS, RESISTÊNCIAS, INCOMPREENSÕES E NOVOS DESAFIOS Carla Cerqueira, Maria Helena Santos e Renísia Garcia Filice

A SUB-REPRESENTAÇÃO POLÍTICA DAS MULHERES NO GOVERNO LOCAL É IRRELEVANTE? REVISÃO DO QUE SABEMOS E DO QUE FALTA SABER EM PORTUGAL. Ana Ribeiro

QUANDO O POUCO NÃO CHEGA A MUITAS: ANÁLISE INICIAL DA DISTRIBUIÇÃO DOS RECURSOS PÚBLICOS DE CAMPANHA PARA A CÂMARA DOS DEPUTADOS EM 2018 NO BRASIL. Maria Cecília Eduardo e Juliana Inez Luiz de Souza

A FAVOR, CONTRA, OU ASSIM-ASSIM? POSIÇÕES E DISCURSOS DE MEMBROS DOS ÓRGÃOS DE GESTÃO SOBRE LIMIARES DE REPRESENTAÇÃO LEGALMENTE VINCULATIVOS, MÉRITO E IGUALDADE. Sara Falcão Casaca, Maria João Guedes, Susana Ramalho Marques e Nuno Paço

AÇÕES AFIRMATIVAS NO ENSINO SUPERIOR BRASILEIRO. Elisabete Corcetti e Susane Petinelli-Souza

LADIES IN RED: UMA ANÁLISE DAS MEDIDAS LEGAIS DE COMBATE À VIOLÊNCIA POLÍTICA DE GÊNERO NO BRASIL E EM PORTUGAL. Camila Lamartine, Camila Franco Henriques

THE PARITY LAW IN PRACTICE: IMPLEMENTATION AND DIRECT OUTCOMES. Ana Lúcia Teixeira, Ana Espírito-Santo e Maria Helena Santos

PARA UMA CRÍTICA PÓS-COLONIAL/DESCOLONIAL DAS RELAÇÕES SOCIAIS EM CONTEXTO ACADÉMICO: VOZES DE ESTUDANTES BRASILEIRAS. Rovênia Amorim Borges e Almerindo Janela Afonso

ZONAS DE LIBERDADE LGBTI+? PRÁTICAS E GRAMÁTICAS PARA UMA INTERVENÇÃO PROFISSIONAL INCLUSIVA COM CRIANÇAS E JOVENS LGBTI+. Mafalda Esteves, Ana Cristina Santos e Alexandra Santos

\section{ESTUDOS E ENSAIOS}

WHAT CAN WE SAY ABOUT GENDER STUDIES IN COLOMBIA? AN ANALYSIS FROM A SOCIOBIBLIOMETRIC PERSPECTIVE. Jean Nikola Cudina, Julio César Ossa, Elsa María CastrillónCorrea, Andrea Precht, Josiane Suelí Bería e Fernando Andrés Polanco

CHRONICLES OF CIVIL SOCIETY IN ASSAM AND MEGHALAYA: CONVERTING GIRLS AND WOMEN FROM «BAD TO GOOD». Barnali Das and Rekha Pande

ARTIVISMO FEMINISTA Y FLASHMOB: LENGUAJE CORPORAL EN EL MUNDO ORIENTAL. Teresa Colomina-Molina

\section{RECENSÕES}

$15 e$ PUBLICAÇÃO SEMESTRAL

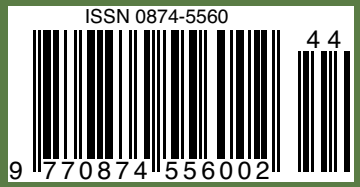

Poesia e prosa, de Judith Teixeira, organização e estudos introdutórios, de Cláudia Pazos Alonso e Fabio Mario da Silva. Alfragide: Dom Quixote, 2015, 370 pp. Manuel Abrantes

Gênero, neoconservadorismo e democracia: disputas e retrocessos na América Latina, de Flávia Biroli, Maria das Dores Campos Machado e Juan Marco Vaggione. São Paulo: Boitempo Editorial, 2020, 224 pp. Monise Martinez

Feminist Media Studies, de Alison Harvey. Cambridge: Polity Press, 2020, 211 pp. Bibiana Garcez 